Universidad Politécnica de Madrid

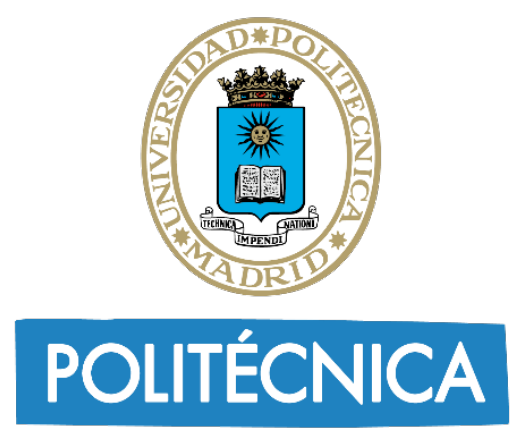

Departamento de Ingeniería de Organización, Administración de Empresas y Estadística

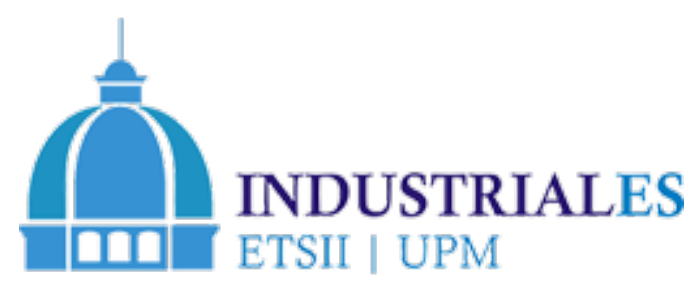

Escuela Técnica Superior de Ingenieros Industriales

\title{
UNDERSTANDING CONSUMERS' SELECTION OF LAST MILE LOGISTICS CHANNEL IN OMNICHANNEL FASHION
}

Doctoral Thesis

$\begin{array}{ll}\text { Author: } & \text { MOHAMMAD MAHDI ZAREI } \\ \text { Directors: } & \text { CHAPARRO PELAEZ, JOSE JULIAN } \\ & \text { AGUDO PEREGRINA, ANGEL FRANCISCO }\end{array}$ 



\section{TRIBUNAL TESIS DOCTORAL}

\section{Understanding consumers' selection of last mile logistics channel in Omnichannel fashion}

AUTOR: Mohammad Mahdi Zarei

DIRECTOR/ES: CHAPARRO PELAEZ, JOSE JULIAN

AGUDO PEREGRINA, ANGEL FRANCISCO

Tribunal nombrado por el Excmo. y Magfco. Sr. Rector de la Universidad Politécnica de Madrid el día de de 2020

\begin{tabular}{|l|l|}
\hline Presidente & \\
\hline Vocal & \\
\hline Vocal & \\
\hline Vocal & \\
\hline Secretario & \\
\hline Suplente & \\
\hline Suplente & \\
\hline
\end{tabular}

Realizado el acto de defensa el día de de 2020 en la Escuela Técnica Superior de Ingenieros Industriales de la Universidad Politécnica de Madrid.

Calificación obtenida:

EL PRESIDENTE

SECRETARIO 
I | P a g e 
Firstly, I would like to express my sincere gratitude to my advisors Prof. Jose Julian Chaparro Pelaez and Prof. Angel Francisco Agudo Peregrina for the continuous support of my Ph.D. study and related research, for their patience, motivation, and immense knowledge. Their guidance helped me in all the time of research and writing of this thesis. I could not have imagined having better advisors and mentors for my Ph.D. study.

Finally, I would like to express my very profound gratitude to my family for providing me with unfailing support and continuous encouragement throughout my years of study in Europe and through the process of researching and writing this thesis. This accomplishment would not have been possible without them. Thank you. 
This thesis is dedicated

to my parents for their

love, endless support

and encouragement

IV | P a g e 
V | P a g e 


\section{Abstract}

Internet began to emerge in the very late 1980s. Since then, Internet has had an extraordinary pace over the growth and spread all over the world. Due to this fact, retailers were interested to present their products through an online platform as an alternative to traditional stores. This movement brought remarkable growth in the market around the world, especially in B2C (Business-to-Consumer) companies, where sales increased more than 14.1\% compared to previous years (eMarketer, 2019) .

This was particularly significant in the Spanish market case. The Global Retail E-Commerce Index highlights that Spain, among all small countries in terms of population, has had impressive progress in e-commerce, especially in the fashion sector (Ben-Shabat et al., 2015). In fact, the fashion sector has become the fastest-growing segment in e-commerce after categories of food and beverages, with the global market size of approximately 484 billion dollars and it is expected to reach around 765 billion dollars by the year 2022 (Raes, 2019).

Within this development, retailing platforms have evolved dramatically and two contrary movements have arisen from retailers. On the one hand, physical retailers have felt the pressure to include the online channel in their retailing strategy, offering their consumers a broader selection of shopping options (Cammiss, 2015). On the other hand, pure online retailers have decided to do the opposite: opening physical stores or cooperating with other retailers to include physical channels to the offer to let consumers be able to touch and feel the products before the purchase (Mehra et al., 2013).

During the early years of offering multiple channels, retailers operated those channels separately (Bell et al., 2014). However, some multichannel retailers faced potential channel conflicts such as cannibalization sales between channels (Kollmann et al., 2012). By time passing, in order to overcome these negative "dis-synergies”, a new retailing strategy comes, which is known as the 'Omnichannel approach' (Combs, 2015). This is an evolution of the multi-channel retailing and provides a continuous background of the consumer's experience and sensations through all available purchase channels, rather than just one (Verhoef et al., 2015).

Under these rapidly changes, retailers have provided countless last-mile logistics options to deliver or return the product -i.e., regardless of buying online or offline (e.g., at home, stores, lockers, dedicated vans, or in a convenient pick-up point). Results in, almost all retailers (80\%), who have provided multiple retailing channels, offer more than one delivery option (Capper, 2014) and return option (Graham Charlton, 2014). However, as consequence, that logistics that were simple (i.e., physical stores were the end-point of transactions), has become dramatically complicated (e.g., products can be returned or picked up at home, stores, lockers, dedicated vans, or in a convenient pick-up point). 
However, offering effective and efficient last-mile logistics is not straightforward, especially in the latest retailing environment where is strongly constrained by some features, such as the volume and costs, of last-mile logistics in different channels.

Although a significant number of studies have tried to provide some guidance (Kembro et al., 2018; Weber, A. \& Badenhorst-Weiss, 2018; Buldeo Rai et al., 2019), a very little research has considered consumer's point of view in their guidance (Nguyen et al, 2019). Specifically, the dependence of consumer's behavior on contextual factors, it has been virtually unexplored.

This work proposes a framework to understand the consumers' behavior toward selecting the different types of last-mile logistics. That has been based on previous academic studies on consumer adoption of new technologies and services. The framework's core has been developed from the Theory of Planned Behavior (TPB) by Ajzen (1991). This theory is known as an adequately predictor and explainer of human behavior in specific contexts (Ajzen, 1991).

To do so, the following steps were taken:

First, elicit relevant factors in consumers' shopping behavior especially in last-mile logistics by an openended questionnaire. After collecting and analyzing the data conducted, the result shows that:

- The most relevant of Attitudinal Beliefs type, are: flexibility, saving effort, saving time, transportation cost, and risk factors,

- $\quad$ The most relevant Social-normative Beliefs type, are: family and friends,

- $\quad$ The most Relevant Perceived Behavioral Control Beliefs type, are: self-efficacy and facilitating conditions (Zarei et al., 2020).

Second, in order to fully understand consumers' behavior, the research takes situational factors into account as well. After reviewing the literature, this study finds various situational factors that affect consumer's behavior. Due to the fact, each situational factors and the combination of these situational factors can create different scenarios; hence, to reduce the complexity of the analysis, this study uses only the 3 most influential situational factors: "time availability", "channel spillover effect”, and “geographical distance” (Zarei et al., 2019).

Finally, based on previous results, the study proposes a model. In order to validate this model, a questionnaire has been developed that contains three sections.

- In the first section, the survey asks the respondents to rate their level of their opinion with a series of statements without situational scenarios context.

- In the second section, the questionnaire asks respondents to rate their level of agreement with a series of statements based on the context of eight situational scenarios.

- In the last section, the survey asks respondents to respond to demographic items. 
After distributing the survey via e-mail, 445 responses were obtained which results in the following conclusions were drawn:

- The high value of attitude shows consumers tend to complete their shopping task more efficiently (i.e., conveniently). In fact, enabling consumers to receive, and return goods most conveniently and less risky, make companies be rewarded with increased consumer loyalty, revenue growth, differentiation, and profitability. Hence, investing more in delivery and return policy not only could result in happier consumers, but also increase companies’ revenue.

- In addition, the results point out that participants have shown that in pick up points, both instore or CDPs, either for collecting or returning items, consumers feel more convenient than home delivery or return - this might come from the specific product since apparel makes consumers feel the need for assessing the products at the store and they can easily return the product - despite the fact that they can feel inconvenience - due to the extra effort for going to these points.

- An implication for managers is to use location planning for delivery and return; since access to facilities shows to be one of the obstacles for consumers while choosing different delivery and return options.

- Another implication for managers is to explicit the implicit benefits to consumers that delivery and return charges are only nominal in the shopping process. For example, retailers can show the difficulties in carrying heavy items on a rainy day and emphasize the ease of having heavy items delivered to the house.

It can be concluding that managers can use these findings to design a proper logistics strategy by targeting these factors and overcome the current challenges. For instance, managers are encouraged to emphasize the advantages of choosing different last-mile logistics options - e.g., adding more picking up points -, as well as developing strategies for assisting consumers to overcome their perceived obstacles - e.g., accessibility to facilities, cost of time and money.

Hence, retailers have to expand their horizons and be more creative in their offerings if they want to keep their consumers throughout the shopping process. In general, it is suggested that retailers need to educate Omnichannel consumers and show them how each last-mile logistics option satisfies different shopping needs. Retailers should track patronage behaviors in all the last-mile logistics options with the goal of retaining the customers, irrespective of the last-mile logistics options of their choice.

The final results produce three main contributions:

- The first is to identify the factors that are the key to last-mile logistics options preference.

- The second contribution is to assess whether situational factors affect last-mile logistics options selection and measure the relative importance of these situational factors on the last-mile logistics options selection. 
- The third contribution of this research is to measure the moderating impact of these situational factors on the main factors.

As an additional goal of the research, it can be said that it not only will strongly help retailers to have the best configuration in the last-mile logistics but, also it will contribute to explore it as a phenomenon that goes beyond the singularity of online and offline shopping behavior. 


\section{Resumen}

Desde que surgió Internet a fines de la década de 1980, ha experimentado un ritmo extraordinario de crecimiento de modo que hoy en día llega a cualquier rincón del mundo. Esto lógicamente ha provocado el interés de los agentes del mercado minorista en presentar sus productos a través de la red como una alternativa muy atractiva a la venta tradicional directamente en las tiendas. Este movimiento ha tenido un crecimiento muy remarcable en el mercado a nivel mundial, especialmente notable en las compañías de perfil B2C (Bussiness-to-Consummer), cuyas ventas se incrementaron en más del $14.1 \%$ con respecto a los años anteriores a la llegada de Internet (eMarketer, 2019).

En el caso del mercado minorista español, esto ha sido particularmente significativo, como pone de manifiesto el extraordinario crecimiento del valor del Índice Global de Comercio Electrónico Minorista en España, muy por encima a las cifras registradas en países similares en tamaño y población. Esto ha sido especialmente importante en el sector de la moda (Ben-Shabat et al., 2015). De hecho, el sector de la moda, con un tamaño de mercado global de aproximadamente 484 mil millones de dólares, y se espera que alcance alrededor de 765 mil millones de dólares para el año 2022 (Raes, 2019).

Durante este periodo de rápida evolución hacia el 'e-commerce', la plataforma de venta minorista ha sido espectacular adoptando dos tendencias contradictorias entre sí: Por un lado, los minoristas más tradicionales con distribución en tienda física, han sentido la necesidad de incluir el canal de venta “online” en su estrategia de ventas minorista, ofreciendo a sus consumidores una selección más amplia de opciones de compra (Cammiss, 2015). Por otro lado, los minoristas que utilizaban exclusivamente el modo de venta "online”, percibieron la necesidad de incluir emplazamientos físicos, almacenes o tiendas, que permitieran a los consumidores poder tocar y probar los productos antes de la compra (Mehra, Kumar and Raju, 2013), dando lugar al método mixto de oferta "multicanal”.

Durante los primeros años de aplicación del método de ofertar multicanal, los minoristas operaban cada uno de los canales, “online” y "tienda”, por separado (Bell et al., 2014). Sin embargo, al aplicar el operar ambos canales por separado, algunos minoristas sufrieron conflictos entre ambos canales, como, por ejemplo el efecto “cannibalization” (Kollmann et al., 2012). Posteriormente, para superar estas "disfunciones" y sus consecuencias negativas, se ideó y aplicó una nueva estrategia de ventas conocida como "Omnichannel" (Combs, 2015). Se trata de una evolución de la venta minorista multicanal anterior donde la estrategia se adapta continuamente en función del conocimiento de la evolución en las preferencias y sensibilidad del consumidor con la posibilidad utilizar todos los canales disponibles simultáneamente (Verhoef et al., 2015).

En este nuevo escenario, los minoristas han ofrecido una inagotable variedad de opciones en su logística de gestión de recogida-envío-devolución de productos ('last-mile logistics') (por ejemplo, en casa, tiendas, furgonetas dedicadas o en un punto de recogida conveniente). Resulta que, casi todos los 
minoristas (80\%), que han proporcionado múltiples canales minoristas, ofrecen más de una opción de entrega (Capper, 2014) y opción de devolución (Graham Charlton, 2014). Sin embargo, esa logística que era muy simple (p.e. el almacén o tienda era el único punto de destino para realizar transacciones con el producto), se ve complicado extraordinariamente (p.e. el mismo producto pueden ser recogido, enviado, devuelto, en casa, en almacenes, tiendas, furgonetas, etc.).

Sin embargo, ofrecer una logística 'last-mile’ efectiva y eficiente no es sencillo, pues, para optimizar la estrategia, es fundamental realizar correctamente la estimación del volumen y el coste para cada uno de los canales de venta, a su vez muy condicionados por las características particulares del entorno correspondiente al 'last-mile'.

Aunque se han realizado numerosos estudios para intentar proporcionar ciertas recomendaciones que sirvan de guía ello (Kembro et al., 2018; Weber, A. \& Badenhorst-Weiss, 2018; Buldeo Rai et al., 2019), en sólo uno de ellos se incluye el punto de vista del consumidor (Nguyen et al., 2019). Pero no existe prácticamente ninguno donde se haya analizado específicamente la influencia de los factores contextuales con el comportamiento del consumidor

En este trabajo se proporciona un marco que permite analizar el grado de percepción y aceptación de los consumidores para elegir entre diferentes canales para la gestión logística del entorno ‘last-mile’.

Para ello se han analizado estudios previos sobre el uso del consumidor de nuevos recursos y servicios tecnológicos. De ese modo este trabajo toma como base la Teoría del Comportamiento Planificado “Theory of Planned Behavior (TPB)” desarrollada por Ajzen (1991), que supone una herramienta muy adecuada para explicar y predecir el comportamiento humano en un contexto específico.

Para realizarlo, se siguieron los siguientes pasos:

Primero se han extraído los factores más relevantes en el comportamiento de compra de los consumidores, especialmente en la logística de 'last-mile’, mediante una encuesta. Después de procesar y analizar los datos realizados, el resultado muestra que:

- Factores de naturaleza Actitudinal del cliente: Mayor Flexibilidad; Ahorro de Esfuerzo; Ahorro de Tiempo; Coste del Transporte; Factores Riesgo,

- Factores de naturaleza Social del cliente: Familia; Amigos,

- Factores de naturaleza Conductual frente al cliente: Autonomía y Eficacia; actitud amigable y facilitadora (Zarei et al., 2020).

En segundo lugar, y para poder comprender suficientemente el comportamiento del consumidor, en este estudio se consideran adicionalmente los factores situacionales de los consumidores en el entorno logístico 'last-mile’. Del análisis de la literatura científica realizado en este trabajo se llegan a identificar varios factores situacionales que afectan al comportamiento del consumidor. Cada uno de estos factores 
y la combinación entre ellos pueden crear diferentes escenarios y complicar innecesariamente el análisis. Con el objetivo de reducir la complejidad del análisis de tal forma que se utilizaron los 3 factores situacionales más influyentes: la disponibilidad de tiempo, efecto de desbordamiento de los diversos canales de compra y la distancia física, como los tres factores de mayor influencia (Zarei et al., 2019).

Finalmente, en este trabajo se plantea un modelo de estrategia fundamentado en los resultados anteriores. Para validar dicho modelo, se ha desarrollado un nuevo cuestionario que consta de tres secciones:

- En la primera parte, las preguntas están planteadas con el propósito de evaluar el grado de acuerdo del cliente con una serie de afirmaciones sin considerar en el contexto el factor Situacional.

- En la segunda parte, las preguntas se consideran en un contexto de hasta ocho escenarios Estacionales diferentes.

- En la tercera parte, la encuesta realiza preguntas sobre aspectos demográficos.

Se procedió a la distribución de la encuesta por correo electrónico y se obtuvieron 445 respuestas de cuyo resultado se extrajeron las siguientes conclusiones:

- Los factores de naturaleza actitudinal, se muestran, con diferencia, como los más influyentes en que los consumidores tiendan a completar su tarea de compra de manera más eficientemente. De hecho, se percibe que permitir que el consumidor reciba y/o devuelva el producto de la forma más cómoda, con menor riesgo y al menor coste, repercute en grandes beneficios para la empresa, como es obtener una mayor fidelidad de los clientes, un incremento de ingresos y de la rentabilidad, a la vez que establece un factor diferencial que lo distingue respecto a la competencia. Por tanto, invertir más en políticas y procesos de entrega y devolución de productos no solo aumenta la satisfacción de los clientes, sino que recompensa sobradamente a la empresa.

- Además, la encuesta revela que el cliente prefiere recoger el producto en puntos de recogida de la empresa, ya sea, en tienda o en CDPs, que en casa, tanto para llevárselo como para, en su caso, devolverlo. Esto posiblemente sea debido a que, tratándose de prendas de vestir, el cliente prefiera probarse la prenda en tienda con el objetivo de cambiarla o devolverla fácilmente, en caso de que no sea de su agrado.

- Adicionalmente, del análisis de la encuesta, también se deprende que el modo y horario de acceso a las instalaciones del punto de recogida, se identifica como un posible obstáculo para el cliente a la hora de elegir entre las opciones. De ello se desprende la recomendación a los gestores de la empresa para que se tome en consideración la correcta y cuidada planificación 
para realizar estas acciones, así como para transmitir puntualmente la información clara y detalladamente al cliente, en todo momento.

- Otra recomendación para los gestores de empresa que también se deriva de este estudio es que se informe al cliente de los beneficios que para él representa que los gastos de envío y devolución están incluidos en el proceso de compra. Por ejemplo, las empresas pueden ofrecer al cliente que, independientemente de lo establecido de antemano, ante las dificultades para transportar artículos pesados en un día lluvioso, se puede cambiar la ubicación del punto de recogida, y, sin coste adicional, se le facilita la posibilidad de recibir dichos artículos pesados en su casa.

Los resultados de análisis bajo el marco desarrollado en este trabajo permiten a los gestores de marketing diseñar estrategias de logística adecuadas para identificar los factores clave y superar con éxito los retos actuales de servicio para el mercado minorista. Así, por ejemplo, se anima a dichos gestores a enfatizar sobre las ventajas de elegir diferentes opciones en la logística de 'last-mile’- p.e, añadiendo más puntos de recogida-, a la vez que a desarrollar estrategias de ayuda a los clientes para superar los obstáculos que puedan percibir -p.e. acceso a instalaciones, requisitos de tiempo y económicos.

Por tanto, los minoristas deben de ampliar su horizonte, demostrar más creatividad en sus ofertas si quieren mantener a su clientela haciendo cómodo y atractivo el proceso de compra. En general se sugiere a los minoristas que animen a sus clientes a utilizar métodos de Omni-chanel y demostrarles como las distintas opciones para la logística 'last-mile’ pueden satisfacer sus diferentes necesidades dependiendo del artículo de compra y sus circunstancias. Además, los agentes minoristas deben rastrear los patrones de comportamiento de sus clientes en las diferentes opciones de logística 'last-mile’ con el objetivo de fidelizarlos, independientemente de la opción logística que hayan elegido.

Finalmente, para concluir decir que de los resultados se han derivado las siguientes aportaciones:

- Primero se han identificado los factores clave para establecer preferencias en las opciones aplicables a la logística last-mile.

- En segundo lugar, se ha determinado cuando los factores situacionales intervienen en la selección de opciones para la logística 'last-mile’, y, en su caso, se ha evaluado la importancia relativa de cada uno de ellos.

- En tercer lugar, se ha evaluado el impacto relativo de los factores de situación sobre los factores principales.

Como consideración adicional de la utilidad de este trabajo decir que no sólo puede ayudar de forma importante al minorista para diseñar la configuración más adecuada de la estructura de la logística 'lastmile’ a aplicar en cada caso, sino que además, eligiendo convenientemente las variables, permite 
explorar la estrategia, como un fenómeno de comportamiento que va más allá de la particularidad de la forma de venta, sea en red o en tienda. 
$\mathbf{X V} \mid \mathbf{P}$ a g e 


\section{Contents}

$\begin{array}{lll}\text { Abstract } & \text { VI }\end{array}$

Resumen $\quad X$

Chapter 1: Introduction $\quad 2$

1.1. Introduction 3

1.2. Background 5

1.2.1. Omnichannel

1.2.2. Introducing technology acceptance models 5

$\begin{array}{ll}\text { 1.3. Formulation of research } & 7\end{array}$

$\begin{array}{ll}\text { 1.3.1. Justification of the subject } & 7\end{array}$

1.3.2. Research problem 8

1.3.3. Research contributions 8

$\begin{array}{ll}\text { 1.3.4. Objectives of the research } & 9\end{array}$

1.4. Work program, methodology, and timetable $\quad 10$

$\begin{array}{ll}\text { 1.4.1. Work program } & 10\end{array}$

1.4.2. Methodology 12

Chapter 2: Consumer's last-mile logistics behavior in the Omnichannel environment 15

2.1. The emergence of Omnichannel retailing 16

2.1.1. Traditional physical retailing 16

2.1.2. The history and growth of online retailing 18

2.1.3. Multi-channel retailing 24

2.1.4. Omnichannel retailing 30

2.2. Evolution of consumer's shopping behavior 36

2.2.1 Evolution of consumer's shopping behavior in last-mile logistics 37

2.2.2. Evolution of consumer's shopping behavior in Delivery and Return in Spain 41

2.2.3. Evolution of consumer's shopping behavior in Delivery and Return in Spain for Apparel42 Chapter 3: Model of consumer's last-mile logistics behavior in the Omnichannel environment 47

3.1. Introduction 48

3.2. The Planned Behavior Theory (TPB) 49

3. 2. 1. Main factors 50

3.2.2. Relevant factors 52

3.2.3. Situational factors 65

3.3. The model and hypothesis of research $\quad 70$

3.3.1. Hypothesis summary $\quad 71$

Chapter 4: Characteristics of the empirical work $\quad 74$

4.1. Introduction $\quad 75$

4.2. Scope of the study $\quad 75$ 
4.3. Mechanism of data collection

$\begin{array}{ll}\text { 4.3.1. Structure of the questionnaire } & 78\end{array}$

$\begin{array}{ll}\text { Chapter 5: Statistical technique used } & 87\end{array}$

5.1. Introduction $\quad 88$

5.2. Justification for using the PLS-SEM technique 88

5.3. Characteristics of the PLS-SEM model 89

5.4. Characteristics of the sample 90

5.5. Analysis of the PLS model $\quad 92$

5.5.1. Evaluation of measuring instrument (indicators or independent variables) 92

5.5.2. Evaluation of the structural model 96

5.5.3. Evaluation of the Moderator in the model 99

5.5.4. Summary of the PLS-SEM method 100

Chapter 6: Data analysis and results 103

6.1. Description of the sample 104

$\begin{array}{ll}\text { 6.1.1. Gender } & 104\end{array}$

6.1.2. Age 104

$\begin{array}{ll}\text { 6.1.3. Income } & 105\end{array}$

6.1.4. The education level 106

6.2. Analysis of the collected data 107

6.2.1. Analysis of the indicators 107

6.2.2. Analysis of the structural model 123

$\begin{array}{ll}\text { 6.2.3. Analyzing the moderating indicators } & 147\end{array}$

6.3. The final model of investigation $\quad 150$

6.3.1. Final model for Home delivery 150

6.3.2. Final model for In-store delivery 153

6.3.3. Final model for CDPs 156

6.3.4. Final model for Home return 159

6.3.5. Final model for In-store return 162

6.3.6. Final model for CRPs 165

6.4. Summary of the evaluation of the hypotheses 168

$\begin{array}{ll}\text { Chapter 7: Conclusions } & 174\end{array}$

7.1. Evaluation of compliance with the proposed objectives 175

7.2. Contribution of the investigation 176

$\begin{array}{ll}\text { 7.2.1. Theoretical contribution } & 176\end{array}$

$\begin{array}{ll}\text { 7.2.2. Methodological contribution } & 177\end{array}$

$\begin{array}{ll}\text { 7.2.3. Practical contribution } & 177\end{array}$

$\begin{array}{ll}\text { 7.3. Conclusion and discussion } & 179\end{array}$ 
7.3.1. General conclusion

$\begin{array}{ll}\text { 7.3.2. Specific conclusions } & 180\end{array}$

7.4. Study limitations and suggestions for future studies 183

7.5. Research lines for future studies 183

Chapter 8: References 185 
XIX | P a g e 


\section{List of Figures}

Figure 1 Investigation map (Source: Author) 11

Figure 2 The worldwide sales through the Internet (Source: Statista (2020a)) 19

Figure 3 Market size of electronic commerce by countries (Source: eMarketer, (2020)) 20

Figure 4 Internet user penetration (Source: eMarketer (2020)) 21

Figure 5 E-commerce volume B2C in Spain (Sources: Statista, (2019b)) 21

Figure 6 multi-channel consumer behavior (Source: BRP consulting (2019)) 26

Figure 7 European retail sales (Source: Forrester (2016)) 26

Figure 8 Number of channels used per month (Source: Forrester (2016)) 27

Figure 9 Purchasing habits in Spain (Source: Statista (2020b)) 28

Figure 10 The evolution of retailing (Source: Author) 30

Figure 11 Consumers shopping journey (Source: adopted by Kemperman et al. (2015)) 38

Figure 12 Consumers shopping journey (Source: Zebra (2019)) 42

Figure 13 Global fashion industry E-commerce (Source: Forrester (2018)) 43

Figure 14 Delivery option adoption in online channel for fashion (Source: Robinson, A. (2019)) 44

Figure 15 return option adoption in online channel for fashion (Source: Robinson, A. (2019)) 45

Figure 16 The Theory of Planned Behavior (TPB) (Source: Ajzen, $(1985,1988,1991)$ ) 50

Figure 17 The research model (Source: Author) $\quad 70$

Figure 18 Questionnaire layout (Source: Author) $\quad 77$

Figure 19 PLS-SEM model (Source: Hair et al. (2017)) 90

Figure 20 Evaluation of measuring instrument steps (Source: Hair et al. (2017)) 92

Figure 21 The steps to eliminate or keep the formative indicators (Source: Hair et al. (2017)) 93

Figure 22 The steps to eliminate or keep the formative indicators (Source: Hair et al. (2017)) 96

Figure 23 The systematic approach to evaluate the structural model (Source: Hair et al. (2017)) 97

Figure 24 Moderating effects in the model (Source: Hair et al. (2017)) 100

Figure 25 The last-mile logistics of respondents by gender (Source: Author) 104

Figure 26 The last-mile logistics of respondents by age (Source: Author) 105

Figure 27 The last-mile logistics of respondents by Income (Source: Author) 106

Figure 28 The last-mile logistics of respondents by education level (Source: Author) 106

Figure 29 The model for Home delivery (Source: Author) 151

Figure 30 The final model for Home delivery (Source: Author) 152

Figure 31 The model for In-store delivery (Source: Author) 154

Figure 32 The final model for In-store delivery (Source: Author) 155

Figure 33 The model for CDPs (Source: Author) 157

Figure 34 The final model for CDPs (Source: Author) 158

Figure 35 The model for Home return (Source: Author) 160

Figure 36 The final model for Home return (Source: Author) 161

Figure 37 The model for In-store return (Source: Author) 163

Figure 38 The final model for In-store return (Source: Author) 164

Figure 39 The model for CRPs (Source: Author) 166

Figure 40 The final model for CRPs (Source: Author) 167 


\section{List of Tables}

Table 1 The advantages and disadvantages of using traditional physical retailing 18

Table 2 The advantages and disadvantages of using online stores 24

Table 3 The advantages and disadvantages of using multi-channel retailing 30

Table 4 definitions of the multi-channel / Omnichannel strategy concept 31

Table 5 The advantages and disadvantages of using Omnichannel retailing 36

Table 6 Summary of various delivery \& return types in the last mile logistics 41

Table 7 Summary of the works which show relationship between monetary cost \& other factors 54

Table 8 Summary of the works which show relationship between convenience \& other factors 57

Table 9 Summary of the works which show relationship between perceived risk \& other factors 60

Table 10 Summary of the works which show relationship between reference groups \& other factors 61

Table 11 Summary of the works which show relationship between facilitating cond. \& other factors 63

Table 12 Summary of the works which show relationship between self-efficacy \& other factors 65

Table 13 The classification of empirical studies that use some means to measure the effects of situational factors on consumers' shopping Behavior 66

Table 14 Studies that have considered situational factors as a moderator 69

Table 15 Summary of hypotheses in delivery and return $\quad 71$

Table 16 Summary of hypotheses in moderation effect in delivery options $\quad 72$

Table 17 Spain national demographic characteristic $\quad 76$

$\begin{array}{ll}\text { Table } 18 \text { Measurement instrument } & 78\end{array}$

Table 19 Question of option selection -Intention $\quad 79$

Table 20 Question of option selection -Attitude toward the behavior $\quad 79$

Table 21 Question of option selection -Subjective norm 80

Table 22 Question of option selection - Control beliefs $\quad 80$

Table 23 Question of option selection - Convenience $\quad 80$

Table 24 Question of option selection - Monetary 81

Table 25 Question of option selection - Perceived risk 81

Table 26 Question of option selection -Normative beliefs $\quad 82$

Table 27 Question of option selection - Self-efficacy $\quad 82$

Table 28 Question of option selection - Facilitating conditions 82

Table 29 Question of option selection -attitudinal beliefs 83

Table 30 The scenarios in delivery $\quad 83$

Table 31 The scenarios in return $\quad 84$

Table 32 Differences between both methods $\quad 88$

Table 33 Minimum sample size required to detect a minimum coefficient 91

Table 34 The critical values of $t$ student last-mile logistics for 5000 samples, for one and two tails 98

Table 35 The summary of formative indicators in PLS-SEM model 100

Table 36 The summary of the structural model PLS-SEM 101

Table 37 Means and the standard deviations of the indicators for home delivery 107

Table 38 Factor loads and indicator weights for Home delivery 108

Table 39 Convergent validity indicators for home delivery 109

Table 40 Discriminant validity using the Fornell-Larcker criterion for Home delivery 109

Table 41 Means and the standard deviations of the indicators for In-store delivery 110

Table 42 Factor loads and indicator weights for In-store delivery 111

Table 43 Convergent validity indicators for home delivery 112

Table 44 Discriminant validity using the Fornell-Larcker criterion for In-store deivery 112

Table 45 Means and the standard deviations of the indicators for CDPs 113

Table 46 Factor loads and indicator weights for CDPs 113

Table 47 Convergent validity indicators for CDPs 114

Table 48 Discriminant validity using the Fornell-Larcker criterion for CDPs 115 
Table 49 Means and the standard deviations of the indicators for Home return 115

Table 50 Factor loads and indicator weights for Home return 116

Table 51 Convergent validity indicators for Home return 117

Table 52 Discriminant validity using the Fornell-Larcker criterion for Home return 117

Table 53 Means and the standard deviations of the indicators for In-store return 118

Table 54 Factor loads and indicator weights for In-store return $\quad 119$

Table 55 Convergent validity indicators for In-store return $\quad 120$

Table 56 Discriminant validity using the Fornell-Larcker criterion for In-store return $\quad 120$

Table 57 Means and the standard deviations of the indicators for CRPs 121

Table 58 Factor loads and indicator weights for CDPs 121

Table 59 Convergent validity indicators for CRPs $\quad 122$

Table 60 Discriminant validity using the Fornell-Larcker criterion for CRPs 123

Table 61 Multicollinearity evaluation using VIF for Home delivery 123

Table 62 Path coefficients for Home delivery 124

Table 63 Levels of statistical significance for Path coefficients for Home delivery 124

Table 64 The values of the variance $\left(\mathrm{R}^{2}\right)$ for Home delivery $\quad 125$

Table 65 The size of the effect $\left(\mathrm{f}^{2}\right)$ with respect to its predictor variables for Home delivery 125

Table 66 The predictive relevance index $\left(\mathrm{Q}^{2}\right)$ for Home delivery 126

Table 67 The effect size $\left(\mathrm{q}^{2}\right)$ of independent variable that predicts the construct for Home delivery 126

Table 68 Multicollinearity evaluation using VIF for In-store delivery 127

$\begin{array}{ll}\text { Table } 69 \text { Path coefficients for In-store delivery } & 128\end{array}$

Table 70 Levels of statistical significance for Path coefficients for Home delivery 128

Table 71 The values of the variance $\left(\mathrm{R}^{2}\right)$ for In-store delivery 129

Table 72 The size of the effect ( $\mathrm{f}^{2}$ ) respect to its predictor variables for In-store delivery $\quad 129$

Table 73 The predictive relevance index $\left(\mathrm{Q}^{2}\right)$ for In-store delivery 130

Table 74 The effect size $\left(\mathrm{q}^{2}\right)$ of independent variable that predict the construct for In-store delivery

Table 75 Multicollinearity evaluation using VIF for CDPs 131

Table 76 Path coefficients for CDPs 132

Table 77 Levels of statistical significance for Path coefficients for CDPs 132

Table 78 The values of the variance $\left(\mathrm{R}^{2}\right)$ for CDPs 133

Table 79 The size of the effect $\left(\mathrm{f}^{2}\right)$ with respect to its predictor variables for CDPs 133

Table 80 The predictive relevance index $\left(\mathrm{Q}^{2}\right)$ for CDPs 134

Table 81 The effect size $\left(\mathrm{q}^{2}\right)$ of independent variable that predicts the construct for CDPs $\quad 134$

Table 82 Multicollinearity evaluation using VIF for Home return $\quad 135$

Table 83 Path coefficients for Home return $\quad 135$

Table 84 Levels of statistical significance for Path coefficients for Home return 136

Table 85 The values of the variance $\left(\mathrm{R}^{2}\right)$ for Home return 137

Table 86 The size of the effect ( $\mathrm{f}^{2}$ ) with respect to its predictor variables for Home return 137

Table 87 The predictive relevance index $\left(\mathrm{Q}^{2}\right)$ for Home return 138

Table 88 The effect size $\left(\mathrm{q}^{2}\right)$ of independent variable that predicts the construct for Home return 138

Table 89 Multicollinearity evaluation using VIF for In-store return 139

Table 90 Path coefficients for In-store return $\quad 139$

Table 91 Levels of statistical significance for Path coefficients for In-store return 140

Table 92 The values of the variance $\left(R^{2}\right)$ for In-store return 141

Table 93 The size of the effect $\left(\mathrm{f}^{2}\right)$ with respect to its predictor variables for In-store return $\quad 141$

Table 94 The predictive relevance index $\left(\mathrm{Q}^{2}\right)$ for In-store return 142

Table 95 The effect size $\left(\mathrm{q}^{2}\right)$ of independent variable that predicts the construct for In-store return 142

Table 96 Multicollinearity evaluation using VIF for CRPs 143

Table 97 Path coefficients for CRPs 143

Table 98 Levels of statistical significance for Path coefficients for CRPs 144 
Table 99 The values of the variance $\left(\mathrm{R}^{2}\right)$ for CRPs

Table 100 The size of the effect $\left(\mathrm{f}^{2}\right)$ with respect to its predictor variables for CRPs

Table 101 The predictive relevance index $\left(\mathrm{Q}^{2}\right)$ for CRPs

Table 102 The effect size $\left(\mathrm{q}^{2}\right)$ of independent variable that predicts the construct for CRPs

Table 103 All scenarios apply in this study

Table 104 Comparing the path coefficients and P-value for Home delivery

Table 105 Comparing the path coefficients and P-value for In-store delivery

Table 106 Comparing the path coefficients and P-value for CDPs

Table 107 Comparing the path coefficients and P-value for Home return

Table 108 Comparing the path coefficients and P-value for In-store return

Table 110 The dummy variable regression analysis for situational factors 
1 | P a g e 
Chapter 1: Introduction 


\subsection{Introduction}

Global e-commerce sales doubled between 2015 and 2019, to almost 3.535 billion dollars, and have been predicted to rise even higher in 2022 (Statista, 2019). This increase in existing online channels has contributed to two contrary movements for retailers. On one hand, physical retailers have felt pressure to include online channels in their retailing strategy, offering their consumers a broader selection of shopping options (Cammiss, 2015). On the other hand, in order to compete with physical retailers, pure online retailers have decided to do the opposite: opening physical stores or cooperating with other retailers in include physical channels to the offer (McCormick et al., 2014).

When multiple channels were first offered, retailers operated those channels separately (Gallino \& Moreno, 2014). However, some multi-channel retailers faced potential channel conflicts, such as the cannibalization of sales between channels (Trenz, 2015). To overcome such negative 'dissynergies', some multi-channel retailers moved beyond multi-channel strategies and started integrating isolated channels into a single seamless channel known as Omni (“all”, “everything”, or “universal”). This new strategy brings a continuous retailing experience through all available shopping channels, instead of specific and separate channels (Verhoef et al., 2015). As a result of this integration, multiple-channel retailers experience a competitive advantage and channel synergies - such as sales growth or revenue increase - instead of channel cannibalization (Cao \& Li, 2015; Herhausen et al., 2015).

However, by offering various purchase channels, retailers have provided a different range of delivery and return options. Consequently, the last-mile logistics, which were previously simple (as physical stores were the end-point of transactions), have become very complicated (Fernie \& Grant, 2015; Hübner et al., 2016; Ishfaq et al., 2016). In fact, the emergence of online channels and a variety of purchase channels have meant that last-mile logistics are no longer linear (that is, products can be collected or returned or to stores, pick-up points, or consumer's homes). As a result of these changes, most retailers in worldwide (79 percent) offer more than two purchase channels (Chatterjee, 2006, 2010). Almost 80 percent of them provide more than one delivery option (Capper, 2014), and 62 percent offer return options to consumers (Graham Charlton, 2014). These options include order online and pick-up in-store or receive at home, as well as in-store return, order in-store, and receive at home.

It was expected that the apparel sector would be the slowest sector to adopt e-commerce given that consumers have traditionally considered clothes to be "experience products" (Trenz, 2015) and the difficulty of translating in-store experience into the online environment (Blázquez, 2014). Despite these challenges, apparel has been becoming the fastest-growing segment in e-commerce after food and drink and first in terms of the online market size (Raes, 2019). Therefore, more and more fashion retailers are establishing web and mobile platforms to improve their sales. Some of these fashion companies would not even exist without such platforms (Ayoade \& Eneh, 2015). In 2018, the global market size of fashion 
online retailing was approximately 484 billion dollars and it is expected to reach around $\$ 765$ billion by the year 2022 (Raes, 2019).

Not everywhere has seen the same e-commerce level and the same e-penetration. The report of Global Retail E-Commerce Index in 2015 showed that large and small market countries act differently (BenShabat et al., 2015). For instance, Spain is a country with a small market, but it had impressive progress in online selling and presented potential market matters more than its market size, even though it trails the most advanced countries in the European Union (such as the United Kingdom and Germany) in some indicators. In 2019, electronic commerce grew faster than it did in the previous three years in Spain. In absolute terms, the estimated total volume of the sector was 27.96 billion euros, $17 \%$ higher than in 2018 (Statista, 2019b). Sports equipment and clothing were the most purchased product category online (53.5 percent) (INE, 2019). Considering its relevance and promising development in the coming years, Spain's figures remain below those of the countries that are leading the adoption of electronic commerce in apparel. A report by Statista (2019a) indicated that the total number of deliveries generated by online channels in the apparel sector is expected to grow by 38 percent until 2022. Online fashion retailers have seen early challenges in the return process as a significant threat. In fact, studies showed that fashion has a very high return rate (up to 28 percent) when it is purchased online. High delivery and return rates result in secondary problems such as logistics handling, higher costs, and difficulties in planning and estimation profit margins (Hübner et al., 2016).

Nonetheless, apparel retailers are attempting to offer these lenient delivery and return policies to increase consumer satisfaction and decrease their last-mile logistics costs. Thus, the present research explores theoretical and practical information and studies Omnichannel shopping behavior as a phenomenon that goes beyond the singularity of online and offline shopping behavior.

The present study investigates the background of consumer's shopping behavior, specifically in the lastmile logistics in the Omnichannel environment. To this end, the following section provides a comprehensive review of the existing literature related to consumers' shopping journey, and consumers' shopping behavior in different environments (for example, pure-play, multi-channel, and Omnichannel), and categorizes the last-mile logistics. Section 3 introduces an appropriate theory for this investigation (for example, the Theory of Planned Behavior (TPB), and develops the model of consumer's last-mile logistics behavior in the Omnichannel environment. Section 4 characterizes the empirical work. Section 5 introduces the statistical technique used for this empirical study. Section 6 analyses the obtained data and presents the results of the empirical work. Section 7 evaluates the compliance of the results with the objectives proposed at the beginning of the investigation, presents theoretical, methodological, and practical contributions of the study and gives implications and recommendations for academic researchers and practitioners. 


\subsection{Background}

\subsubsection{Omnichannel}

The retail landscape has been changed completely by the emergence of the Internet. It has given rise to the new retailing strategy known as Omnichannel retailing. The word Omni means "all: in all ways, places, etc." and "without limits" (DHL Consumer Solutions \& Innovation, 2015). The Omnichannel can be defined as the integration of all existing channels into the market (for example, physical retailers, websites, catalogs, mobile applications, e-commerce, and social networks) used by the retailer, which seeks to generate different paths for the final consumers who initiated communication or contact with a company (Weber, A. \& Badenhorst-Weiss, 2018).

Similar to the rise of other new technologies, some changes have appeared due to the eruption of these new technologies. On one hand, these important changes have brought a continuation of remarkable growth in the markets around the world, especially in B2C, whose sales increased by more than 14.1\% percent in 2019 to almost 3.535 billion dollars (Statista, 2019b). With rapidly increasing e-shopping, companies have realized that the transformation of consumer's behavior seems inevitable, and they need to change their marketing strategy (Dange \& Kumar, 2012). On the other hand, the Omnichannel is seen as a detailed understanding of the needs and behavior of the client, delivering a homogeneous experience through all available channels, while creating a better consumer experience, which translates into greater loyalty to the brand and thus increases the purchase possibilities. It is evident that the purchase decision has been expanded with multiple options, because individuals now have more tools with which to choose, compare, and identify products and services (Lazaris \& Vrechopoulos, 2013). There is no doubt that consumers are increasingly connected, know their preferred channels of purchase, their contact information to provide offers, updates, notifications of orders and shipping device (Azhari \& Bennett, 2015). Therefore, Omnichannel consumers are well informed about their choices and are able to purchase based on their needs at the preferred time and place.

Thus, the Omnichannel approach is the next logical evolution for both consumers and retailers. It is a new and different way of managing and incentivizing business. However, it is more complex than the previous retailing approach because consumers have to experience identically in every channel and seamlessly through different channels. If a retailer knows the preferences of an in-store consumer, this information must be shared with the online channel (and vice versa). This must be done in a timely manner, ideally in real-time, as this information could affect buying decisions. Similarly, the retailer must capture each consumer's interaction in every channel and leverage these purchasing behavior insights to build the optimal Omnichannel strategy.

\subsubsection{Introducing technology acceptance models}

When individuals encounter new technology, they first gather and synthesize the information related to that the new technology through the social system framework they find. As a result, a series 
of beliefs are generated for the use of the technology, which determines whether they accept or reject it. Therefore, each of the components of the behavioral intention is determined by fundamental belief structures. In summary, it can be said that the adoption of an innovation is a process of considering a decision to use or not (Rogers, 1962). The following section briefly introduces technology acceptance models and explains them based on attitudes, since both of them are important foundations for this research.

The relationship between attitude and actual behavior has been explored by many researchers (e.g. Ajzen \& Fishbein, 1980; Schifter \& Ajzen, 1985). The interest in this relationship has led to the development of different theories that try to capture the underlying dimensions of it and to define the process through which the behavior of individuals is conditioned.

By the late 1960s, researchers had started developing theories that tried to deepen the knowledge of the relationship among attitudes, intentions, and behaviors (Fishbein, 1967). These works led to the introduction of the Theory of Reasoned Action (TRA) (Fishbein \& Ajzen, 1975). TRA is based on the assumption that human beings make rational decisions on the basis of available information. It deals with the study of attitude and its relationship with actual behavior, which can be predicted by intention, and that this intention is determined by the individual's attitude, and by the subjective norm in relation to the concrete behavior (Fishbein \& Ajzen, 1975). The attitude towards behavior describes the positive or negative feelings of an individual about the behavior, while the subjective norm defines the individual's perception that most people who are important to him/her think he/she should or should not perform the behavior in question (Ajzen, 1991).

Based on the TRA, Ajzen later introduced the Theory of Planned Behavior (TPB), by adding a third element: the Control of Perceived Behavior (PBC) (Schifter \& Ajzen, 1985; Ajzen \& Driver, 1991). This additional element tries to increase its predictive capacity in the case an individual has limited control behavior (Ajzen, 1991). Perceived behavioral control (PBC) is about the presence of factors that may facilitate or impede the performance of the behavior (Ajzen \& Driver, 1991). Ajzen (1985) incorporated the perceptions of the individuals regarding the control over their behavior as an explanatory variable of intentions and behavior, along with subjective attitudes and norms. Therefore, behavioral intention is a function of three determinants: beliefs about the individual's overall evaluation of the behavior, beliefs about the normative expectations of others, and beliefs about the presence of factors that may facilitate or impede the performance of the behavior (Schifter \& Ajzen, 1985; Ajzen, 1991).

Social Cognitive Theory (SCT) is another social psychology model that proposes the individual behavior is based on the reciprocal influence between three elements: environmental factors (such as social pressures or specific characteristics of each situation), personal factors (demographic, cognitive, personality, etc.) and the behavior of the individual (Bandura, 1977, 1982, 1986). 
By combining the theoretical approaches and the social psychology, and also based on TRA, Davis (1986) proposed a model called TAM (Technology Acceptance Model), which aims to deepen the learning processes and to develop a conceptual framework that can be applied to the use of information systems. In this model, the concept of subjective norm disappears due to the difficulty of its observation and instead, the utility and the ease of use of the system perceived by the user are considered determinants of the use of a technology (Venkatesh \& Davis, 1994). As a result, the final model is more practical and its operation is easier to perceive.

The Davis (1986) model gave rise to a proliferation of new models, taking TAM as a basic approach. Venkatesh Davis (2000) proposed the TAM2 model by adding more complementary factors to the basic TAM incorporate (such as normative factors and social influence, some of which are present in the TPB (as the subjective norm), as well as others such as experience, voluntariness, quality of the result, the relevance of the task, demonstrability of the result or the projected image). Furthermore, researchers have presented TAM3 (Bala \& Venkatesh, 2008) and C-TAM-TPB (Yayla \& Hu, 2007), in addition to other previous models.

After presenting TAM, Taylor and Todd (1995) combined TPB and TAM elements and introduced the Decomposed Theory of Planned Behavior (DTPB), in which the attitude construct is decomposed into perceived utility, ease of use, and compatibility. The subjective norm construct is decomposed into the influence of peers and the influence of superiors. Finally, the control of perceived behavior is decomposed into self-efficiency, facilitation of resources, and facilitation of technology.

\subsection{Formulation of research}

\subsubsection{Justification of the subject}

Global e-commerce sales doubled between 2015 and 2019, to almost 3.535 billion dollars, and have been predicted to rise even higher in 2022 (Statista, 2019b). However, not everywhere has the same e-commerce level and the same e-penetration. The Global Retail E-Commerce Index, 2015 report showed that big and small market countries act differently. For instance, Spain is a country with a small market, but it had impressive progress in online selling and showed that market potential matters more than size, even though Spain trails the most advanced countries in European Union (such as the UK and Germany) in some indicators. In 2019, electronic commerce grew faster than it did in the previous three years in Spain. In absolute terms, the estimated total volume of the sector was 27.96 billion dollars, 17\% higher than in 2018 (Statista, 2019b).

Apparel has become the fastest-growing segment in e-commerce after food and drink, with the biggest market size in Spain (Raes, 2019). In 2018, the global market size of fashion online retailing was approximately 484 billion dollars and it is expected to reach around 765 billion dollars by the year 2022 (Raes, 2019). Considering its relevance and promising development in the coming years, the reality is 
that the Spanish figures are interesting topics but remain below the leading countries in terms of the adoption of electronic commerce in apparel.

While the fashion retailing platform has experienced profound changes in the last decade due to ecommerce, almost 80 percent of all retailers have started to provide more than one delivery option (Capper, 2014) and 62 percent of retailers offer consumers return options (Graham Charlton, 2014). By these movements in last-mile logistics, Robinson, A. (2019) report indicated that the total number of deliveries generated by online channels in the apparel sector is expected to grow by 38 percent until 2022. Online fashion retailers have seen early challenges in the return process as a significant threat. In fact, studies showed that fashion has a very high return rate (up to 28 percent) when it is purchased online. High delivery and return rates result in secondary problems such as logistics handling, higher costs, and difficulties in planning and estimation profit margins Robinson, A. (2019).

Due to these recent and ongoing transformations in the last-mile logistics system, retail research and practice have not paid attention to these changes. This is due to the lack of a structured view of the design options for the new last-mile logistics system in the Omnichannel environment (Hübner et al., 2016), where the last-mile logistics system became more salient to multi-channel consumers (Esper et al., 2003), and the principal actor of the shopping process (Bromage, 2001).

\subsubsection{Research problem}

Last-mile logistics systems, delivery, and return are among the areas that need to be analyzed before developing and tested before implementing, to achieve a better solution that can be not only profitable but also modern and convenient for consumers. Thus, there is a need to provide a comprehensive perspective on Omni last-mile logistics based on empirical data. In recent years, some academic researchers have attempted to provide comprehensive solutions in the last-mile logistics in Omnichannel environment systems from retailers' perspectives (Kembro et al., 2018; Weber, A. and Badenhorst-Weiss, 2018), despite a lack of research from consumers' point of view (Hübner et al., 2016). As a result, retailers increasingly face the challenge of enabling seamless logistics across all channels (Hübner et al., 2016). Hence, comprehensive research is required for last-mile logistics systems within multiple retail channels. Bordering the consumer's side in delivery and return might result in a complete redesign of the operations and the augmentation of new supply chain models optimized for Omnichannel retailing.

\subsubsection{Research contributions}

The research offers a series of contributions, as described below.

From a theoretical point of view: 
- Investigating and building a conceptual framework only for the last part of the shopping journey, which has been ignored by past researchers, and using comprehensive behavioral beliefs to predict attitudes toward the behavior.

- Using environmental elements as the moderation effect on the attitude: a topic that lacks sufficient academic research despite being strongly recommended by previous researchers.

- Designing an empirical study and, reciprocally, presenting statistical techniques in order to assess the obtained data and to identify which factors are the key drivers in delivery and return option selection.

From a practical point of view:

- By knowing consumer's beliefs, retailers can encourage positive beliefs among low-active populations in different delivery and return options.

- Helping logistics planners to develop better logistics strategies in a retail setting, depending on these situational factors.

- Gearing up to create or alter particular delivery and return options based on situational factors.

- Allocating resources properly, increasing productivity, and thereby increasing consumers' satisfaction by providing more facilities.

- Enabling a personalized, consistent, and cost-effective delivery service and flexible fulfillment.

- Meeting consumers' expectations, while generating higher satisfaction and loyalty.

\subsubsection{Objectives of the research}

Given the lack of prior research on consumer's last-mile logistics behavior, the challenge is to understand why consumers select different last-mile logistics options and what factors influence consumer's option selections. The aim is to identify the factors of the intention of selecting the actual behavior of option selection in delivery and return by the Spanish final consumers in Omnichannel environments, using the case of apparel.

To achieve this main purpose, we have established the following sub-objectives:

- Establish a conceptual framework by reviewing articles to identify the factors that may affect consumer's delivery and return option selection in a multi-channel context, in order to cover the shortcomings of previous research in delivery and return in the Omnichannel environment.

- Preparation of a structural model composed of its determining factors.

- Determination of the appropriate factors in a multi-channel environment.

- Develop a model that shows the influence of previous factors (individual and situational factors) in delivery and return option selections in an Omnichannel retailer context.

- Establish an adequate methodology for analyzing the data 
- Validation of the structural model considering the moderation effects of the most influential situational factors.

- Obtain conclusions based on the results of the empirical analysis carried out

\subsection{Work program, methodology, and timetable}

This section explains, the work program, the methodology proposed to approach the research, and the calendar of activities.

\subsubsection{Work program}

Figure 1 below shows the investigation map and will serve as the basis for the work that needs to be done. Based on this approach, the research methodology and the work activities are foreseen. 


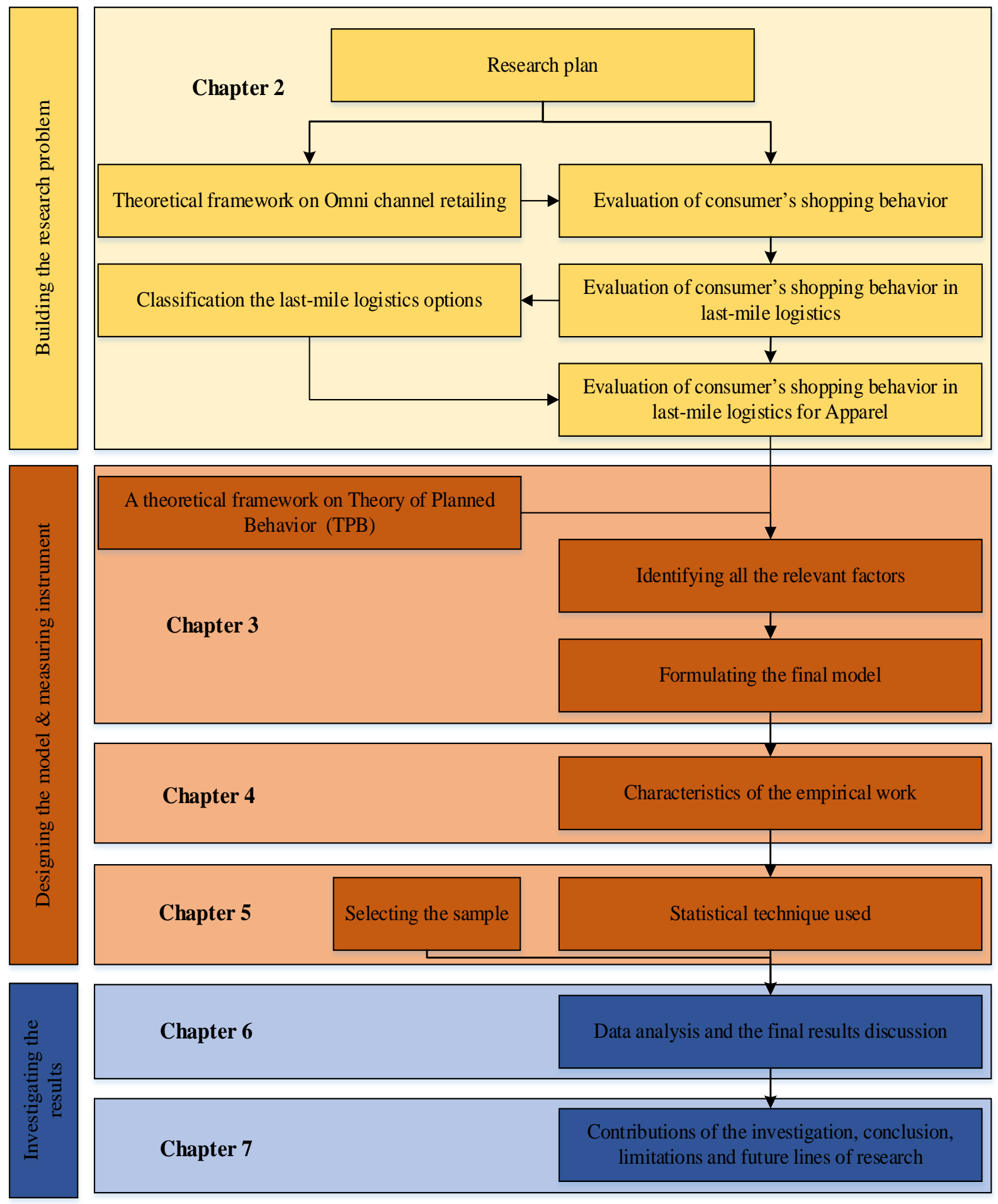

Figure 1 Investigation map (Source: Author) 


\subsubsection{Methodology}

The methodology used for proceeding with the scheme shown in the previous section is as follows:

\subsubsection{Building the research problem}

The first part of this activity consists of a research problem:

a) Consumer's last-mile logistics behavior in the Omnichannel environment

- Introducing the emergence of Omnichannel retailing.

- Introducing the evolution in consumer's shopping behavior in the Omnichannel environment.

- Identifying and then categorizing various types of last-mile logistics in the Omnichannel environment.

- Explaining consumer's last-mile logistics behavior in the Omnichannel environment.

- Explaining consumer's last-mile logistics behavior in the Omnichannel environment for apparel.

\subsubsection{Designing the model and measuring instrument}

This part addresses a structural model and introduces a measuring instrument:

a) A theoretical framework on Theory of Planned Behavior

- Introducing the Theory of Planned Behavior: concept, origin.

- Presenting their specific factors and fundamental relationships.

- Justifying the use of TPB in this research.

b) Preparing the structural of the model

- Identifying all the relevant factors.

- Identifying the analysis variables, defined as relevant constructs for the investigation.

- Identifying the different indicators that allow the measurements of the constructs.

- Identifying the relationships between the constructs that are part of the model.

- Formulating the final model.

c) Design of a measuring instrument

- Creating the questionnaire.

- Selecting the sample: 
o Presenting the scope of the study.

o Selecting and characterizing the sample.

o The methodology of data collection.

- Choosing the statistical technique.

\subsubsection{Investigating the results}

This part addresses the final development of the model, result and conclusion obtained:

a) Analyzing the data and discussing the results

- Analyzing the data based on the measuring instrument:

o Transforming data into a readable format for the selected package,

o Filtering out non-relevant or erroneous data.

o Statistical analysis.

o Validation of the proposed model.

o Contrast and validation of hypotheses.

- Discussing the results obtained based on the analysis.

b) Describing the Contributions of the investigation, conclusion, limitations and future lines of research

- Emphasizing the contributions of the work from theoretical, methodological, and practical points of view.

- Concluding the tasks and relevant findings from the research work.

- Presenting the relevant consequences of the present research for similar and/or future investigations, as well as the limitations. 


\section{Chapter 2: Consumer's last-mile logistics behavior in the Omnichannel environment}




\subsection{The emergence of Omnichannel retailing}

\subsubsection{Traditional physical retailing}

The French word 'retail' consists of the prefix "re” and the verb "tailer (cutting off)". Clearly, it refers to cutting off smaller portions of the total revenue. The trade occurs in a place where products are offered to the consumers. In other words, retailing comprises activities that involve selling directly to the end-users (known as direct-to-consumer (B2C) sales activities) (Breuer et al., 2012). Particularly, traditional physical retailers are the endpoint of all transactions and have a relationship with the endusers and the company.

Traditionally, practitioners have classified physical retailers by some criteria, namely the sales method, legal and economic organization of the company. The sales method embraces five types: physical stores (where the consumers come into a place and the seller sells a product), self-service (where the product is exposed to the consumer, who is served directly and pays to the boxes located at the exit), automatic sale (the machine sells the product directly), and sell by mail (distance selling, making the choice through a catalog, and home delivery). In traditional commerce, the store occupies at least $50 \%$ of the sales area. The seller and the counter are a barrier between the product and the consumers. In this form of buying and selling, there is an intense relationship between the seller and the consumer, so that she/he has to demand her/his need or request directly from the seller in a way that she/he is satisfied (Cox \& Dannehl, 2007).

The evolution of physical stores has had parallel changes starting in the early 1920s when the Southland Ice Company in the United States added a few products in their store (salt, tobacco products, and soap). The idea used to be quite convenient for the consumers and went from being a seasonal business to a yearly business. During the 1930s, physical stores grew slowly by adding more products, which resulted in the emergence of other types of stores such as small shops, catalog sales, and self-service markets. The decade of 1940 was a period of social changing in the retailing platform due to the Second World War. After the war, many neighborhood stores emerged to serve the prioritized needs. In the 70s, physical stores added self-service in the gasoline pumps, increasing a profit of 7 trillion dollars in only one year. Additionally, retailers moved abroad to international locations such as Canada, Mexico, Australia, Japan, France, and others. In the 90s, retailing used mail-order services in order to meet consumers' demands. Although catalog sales had been used in previous decades, this method of retailing was used in a few industries (Hoffman \& Bateson, 2010). By entering the $21^{\text {st }}$ century, the modern era of retailing was started.

\subsubsection{The tendency of traditional retailers in Spain}

In Spain, the total volume of sales is mostly made by the final consumer, that is, households and individuals, who buy $91.2 \%$ of the retail product (INE, 2019). Among this total volume of sales the percentage of consumers who visit these traditional stores, at least once a week, represents $64.7 \%$ of 
the turnover, and has grown from $40 \%$ to $48 \%$ in the last four years (Manuel Lamela Fernández, 2019). In fact, Spanish consumers are looking at the traditional stores because of the quality of the product (23.8\%), services (12.6\%) (Personalized attention and transportation of goods to the buyer's home), and above all the convenience of purchasing (31.6\%). Among all traditional stores, grocery stores are in the first place with a market share close to $63 \%$ of total Spain revenue, thanks to their presence in rural areas. After that, fashion retailers have better prospects with 35.4\% of total Spain revenue (INE, 2019).

Hence, the establishments, where aspects such as design, quality, service, and payment are visible to consumers still, are more important than the online retailing (Bell et al., 2014). Nonetheless, it should not forget the new era that underlines other commercial forms - cannot occupy the same segment of benefits. Over time, the most efficient forms will be able to dominate while the other one will be weakened or even annihilated forever. This means that other commercial forms will invade with greater success, thereby occupying other independent trade strategies, which is not adapted to new circumstances (Bell et al., 2014).

\subsubsection{The advantages of traditional physical retailing}

Obviously, there are a number of advantages in using physical retailing. Perhaps the main advantage is that a store gives consumers visibility in the geographic area, creates loyalty and provides consumers a physical entity (Ba et al., 2005).

Consumers want to see the product. There are consumers who prefer trying and seeing how things are going. This advantage will attract consumer's novelty (Holloway \& Beatty, 2003).

The interior space of a store gives shopping experience to the consumers. The mannequins, the walls, the tables, and the furniture capture the consumer's attention. This experience can be promoted by music, which is a very important element in shopping behavior and is connected with the mood of the consumers. In addition, the smell of a physical store creates vivid memories, enriching the purchase process and positively influencing consumer’s shopping experience (Pyle 1996).

\subsubsection{The disadvantages of traditional physical retailing}

The physical stores entail higher costs. Having adequate physical spaces is expensive and requires constant updating and routine maintenance to keep the interior space attractive and charming for consumers. In addition, numerous employees are required to be trained in order to serve the public, with habits and conduct appropriate to their position (Pyle 1996).

In order for the service to be efficient, care must be taken to ensure that a number of employees will be available, so that the customers do not wait a long time. The employee-consumer exchange should be cordial and friendly even in difficult cases. Face to face communication in a physical store requires 
kindness, sympathy, a good disposition, and smiles, which are not often considered by all employees (Holloway \& Beatty, 2003).

In order to be profitable, physical stores must be open in limited hours. Otherwise, their operating costs would make them unworkable (Ba et al., 2005).

For the consumers, it involves moving to the place where the store is located. They require time and a means of transport, which often becomes inconvenient. Research shows that for a buyer it is stressful to go shopping at a physical store (Holloway \& Beatty, 2003).

Table 1 The advantages and disadvantages of using traditional physical retailing

\begin{tabular}{|l|l|}
\hline \multicolumn{1}{|c|}{ Advantages } & \multicolumn{1}{c|}{ Disadvantages } \\
\hline $\begin{array}{l}\checkmark \text { Creates loyalty and provides a physical } \\
\text { entity }\end{array}$ & $x$ The physical stores entail higher costs \\
\hline$\checkmark$ Be able to see the product & $x$ A risk that the service to is not efficient \\
\hline$\checkmark$ Gives shopping experience & $x$ There is a potential risk not being profitable \\
\hline
\end{tabular}

\subsubsection{The history and growth of online retailing}

At an early stage of the emergence of the Internet, its capabilities appeared to be a complete and effective channel of communication. These capabilities included global reach, ease of access, enhanced interactivity, flexibility and speed, ability to communicate large amounts of information, cost efficiency and ease of maintenance (Pyle, 1996; Jones \& Vijayasarathy, 1998). Such capabilities were largely used in many different contexts, such as governmental agencies, defense, academic research, banking, manufacturing, healthcare and education in the 1970s and 1980s. However, it became apparent that amongst all sectors, retailers were experiencing the greatest impact from the Internet. More specifically, retailers soon discovered the Internet's potential for providing information and facilitating two-way communication with the final consumers, collecting market research data, promoting goods and services, and ultimately supporting the online ordering of merchandise, which provides an extremely rich and flexible retail channel (Doherty \& Ellis-chadwick, 2010). According to Pyle (1996), Internet is "a global connectivity, which opens up new avenues in a manner that traditional commerce channel cannot perform”.

However, e-commerce did not appear in any of the organized and substantive ways until the mid-1990s. Its entry was widely announced in several years later and triggered expectations in retailing managers and investors (Senn, 2000). Despite these expectations, online retail sales were lower than what was anticipated, a significant amount of incidents occurred when e-commerce eventually became a reality. However, companies began to use the Internet to increase their productivity and thereby resulted in the 
emergence of new formats within retailing (Burt \& Sparks, 2003). To some extent, its actual entry has still created a vested interest among academics, politicians, industrialists, bankers, executives, entrepreneurs, and especially retailers (Doherty \& Ellis-chadwick, 2010).

According to the data from Statista, in 2019 the worldwide sales through the Internet grew 14.1\%, surpassing 3.535 billion dollars for the first time in history. The forecasts for 2023 raise worldwide turnover through the Internet to almost 6.542 billion dollars, which represents almost double revenue (Statista, 2020). In the figure below, a past, present, and forecast of the evolution for these years, with the specific details is illustrated:

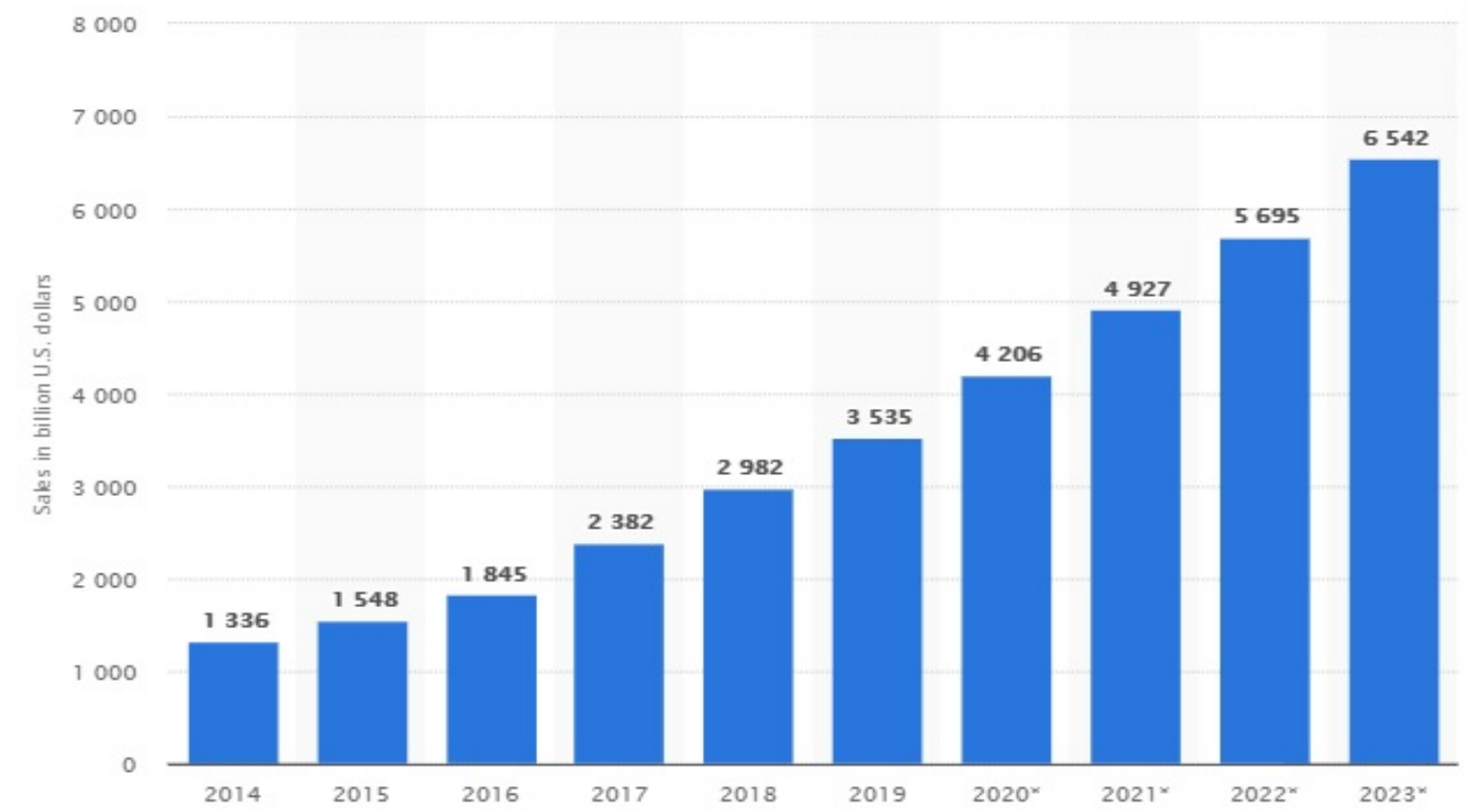

Figure 2 The worldwide sales through the Internet (Source: Statista (2020a))

Particularizing the analysis to countries, China is at the top of the market with $54.7 \%$ of the global ecommerce market, followed by the USA with $21.3 \%$. In this classification, Spain is located in eighteenth place (ATKearney, 2020). In fact, this is obvious because big market countries such as China and the United States have great e-commerce due to their market size. However, the current data shows that smaller market countries such as Spain can have impressive progress in online selling compare to their market size and can show market potential matters more than size (ATKearney, 2020). 
Top 10 Countries, Ranked by Retail Ecommerce Sales, 2018 \& 2019

billions and \% change

\begin{tabular}{lrrr}
\hline & $\mathbf{2 0 1 8}$ & $\mathbf{2 0 1 9}$ & \% change \\
\hline 1. China* & $\$ 1,520.10$ & $\$ 1,934.78$ & $27.3 \%$ \\
\hline 2. US & $\$ 514.84$ & $\$ 586.92$ & $14.0 \%$ \\
\hline 3. UK & $\$ 127.98$ & $\$ 141.93$ & $10.9 \%$ \\
\hline 4. Japan & $\$ 110.96$ & $\$ 115.40$ & $4.0 \%$ \\
\hline 5. South Korea & $\$ 87.60$ & $\$ 103.48$ & $18.1 \%$ \\
\hline 6. Germany & $\$ 75.93$ & $\$ 81.85$ & $7.8 \%$ \\
\hline 7. France & $\$ 62.27$ & $\$ 69.43$ & $11.5 \%$ \\
\hline 8. Canada & $\$ 41.12$ & $\$ 49.80$ & $21.1 \%$ \\
\hline 9. India & $\$ 34.91$ & $\$ 46.05$ & $31.9 \%$ \\
\hline 10. Russia & $\$ 22.68$ & $\$ 26.92$ & $18.7 \%$ \\
\hline Note: inclu & & &
\end{tabular}

Note: includes products or services ordered using the internet via any device, regardless of the method of payment or fulfillment; excludes travel and event tickets, payments such as bill pay, taxes or money transfers, food services and drinking place sales, gambling and other vice good sales;

*excludes Hong Kong

Figure 3 Market size of electronic commerce by countries (Source: eMarketer, (2020))

Beyond the penetrations or volumes of business, the true interest is oriented towards the study of consumers' behavior in the electronic commerce. One way to characterize this behavior is to compare the figures of access and sales through the Network.

The United States, China, Denmark, and South Korea are the most advanced countries, with a highspeed Internet connection and rising rates of online consumption. Many countries, including Spain, are in the traditional process of transforming early users into connected buyers. In fact, in Spain, an emerging situation towards the development of electronic commerce can be observed (Statista, 2020). Hence, it is logical to investigate Internet penetration and electronic commerce in Spain.

\subsubsection{The electronic commerce in Spain}

By examining the data, in just 5 years, Internet penetration in Spain has grown from $75.6 \%$ to $79.1 \%$ with the population representation of $65.5 \%$ (see Figure 4). This figure positions Spain closer to the European Union average (77.6\%), although it is still far from the leading countries such as Norway, Denmark or Netherlands with penetrations of around 89.1\%, or Internet-pioneering countries such as the United States with 93.6\% (eMarketer, 2020). 


\begin{tabular}{|c|c|c|c|c|c|c|}
\hline \multicolumn{7}{|c|}{$\begin{array}{l}\text { Internet User Penetration in Western Europe, by } \\
\text { Country, 2017-2022 } \\
\% \text { of population }\end{array}$} \\
\hline & 2017 & 2018 & 2019 & 2020 & 2021 & 2022 \\
\hline Norway & $89.1 \%$ & $89.3 \%$ & $89.5 \%$ & $89.7 \%$ & $89.8 \%$ & $89.9 \%$ \\
\hline Denmark & $88.5 \%$ & $88.9 \%$ & $89.2 \%$ & $89.4 \%$ & $89.6 \%$ & $89.7 \%$ \\
\hline Netherlands & $87.5 \%$ & $87.7 \%$ & $87.9 \%$ & $88.1 \%$ & $88.2 \%$ & $88.2 \%$ \\
\hline Finland & $85.6 \%$ & $86.4 \%$ & $87.1 \%$ & $87.7 \%$ & $88.2 \%$ & $88.5 \%$ \\
\hline Switzerland & $85.8 \%$ & $86.3 \%$ & $86.6 \%$ & $86.7 \%$ & $86.7 \%$ & $86.8 \%$ \\
\hline Sweden & $86.0 \%$ & $86.1 \%$ & $86.1 \%$ & $86.2 \%$ & $86.2 \%$ & $86.3 \%$ \\
\hline UK & $82.7 \%$ & $83.5 \%$ & $83.9 \%$ & $84.2 \%$ & $84.5 \%$ & $84.6 \%$ \\
\hline Germany & $81.3 \%$ & $82.3 \%$ & $82.8 \%$ & $83.1 \%$ & $83.2 \%$ & $83.4 \%$ \\
\hline Ireland & $79.9 \%$ & $80.8 \%$ & $81.7 \%$ & $82.4 \%$ & $82.9 \%$ & $83.1 \%$ \\
\hline Belgium & $79.3 \%$ & $80.1 \%$ & $80.7 \%$ & $81.1 \%$ & $81.4 \%$ & $81.8 \%$ \\
\hline Austria & $78.8 \%$ & $79.6 \%$ & $80.2 \%$ & $80.6 \%$ & $80.9 \%$ & $81.2 \%$ \\
\hline France & $78.8 \%$ & $79.6 \%$ & $80.2 \%$ & $80.5 \%$ & $80.9 \%$ & $81.2 \%$ \\
\hline Spain & $75.6 \%$ & $77.1 \%$ & $77.8 \%$ & $78.4 \%$ & $78.8 \%$ & $79.1 \%$ \\
\hline Portugal & $65.5 \%$ & $66.9 \%$ & $68.1 \%$ & $69.1 \%$ & $70.0 \%$ & $70.8 \%$ \\
\hline Italy & $64.0 \%$ & $64.8 \%$ & $65.7 \%$ & $66.4 \%$ & $67.0 \%$ & $67.6 \%$ \\
\hline Other & $65.4 \%$ & $66.6 \%$ & $67.5 \%$ & $68.1 \%$ & $68.5 \%$ & $68.9 \%$ \\
\hline Western Europe & $77.6 \%$ & $78.5 \%$ & $79.1 \%$ & $79.6 \%$ & $79.9 \%$ & $80.2 \%$ \\
\hline
\end{tabular}

Figure 4 Internet user penetration (Source: eMarketer (2020))

Based on the study on the B2C e-commerce of Spain, the growth of e-commerce has not stopped year after year. In 2019, electronic commerce grew faster than it did in the previous three years. In absolute terms, the estimated total volume of the sector was 27.96 billion euros, 17\% higher than in 2018 (see figure 5). For this year, a growth of about $20 \%$ is expected, which would mean ecommerce in Spain will be worth 33.56 billion euros at the end of 2020. This increase was due to a slight improvement in the socio-economic context as well as an increase in the number of Internet users and the proportion of online shoppers by 20\% (Statista, 2019b). Last year, $62 \%$ of the online population in Spain has shopped online. For this year, it's expected to increase just a little bit, with a 1 percentage point. Also, the Ecommerce Foundation estimates that the average online shopper in Spain will spend 1,304 euros online this year. That's almost two hundred euros more than one year before (IABeCommerce, 2019).

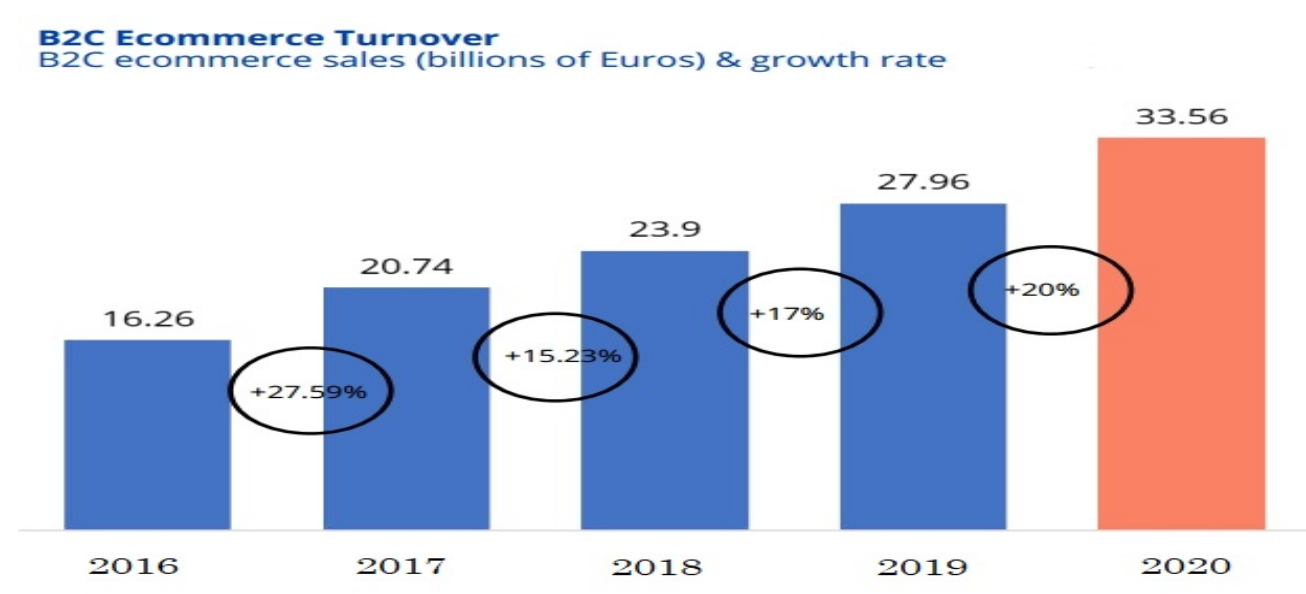

Figure 5 E-commerce volume B2C in Spain (Sources: Statista, (2019b)) 
Based on ONTSI (2019) calculation, in which the turnover is calculated by multiplying the total number of buyers through the Internet by the average cost of the online purchase, the turnover of 26.24 billion euros was obtained in 2018, which indicates $24.1 \%$ increase comparing to the previous year.

However, based on the calculation by the National Commission of the Telecommunications Market (2019), in which the turnover is quarterly calculated by the entities of means of payment, the electronic commerce in Spain exceeds 8.400 billion euros in the second quarter of 2019, 2.3\% more than the previous year. The advantage of this source is that the data are extracted from the expenses of credit card payments made in Spain, not conducted from the result of a survey.

Despite the differences in the figures due to the different methodologies used, according to the order of magnitude, it can be seen that the volume of business of electronic commerce in Spain in 2019 is approximately between 24 and 28 billion euros. However, the data shows that it is still far from the traditional trade revenue, where the turnover of companies in the commerce sector reached 243.678,1 billion euros in 2019 (INE, 2019).

\subsubsection{The advantages of online stores}

E-retailing is a new way of carrying out commercial operations and purchase process for the final consumers. The following presents a series of advantages and disadvantages of having e-retailing. The advantages of the company can be grouped into three fundamentals:

- Increasing sales and competitiveness

Expanding the market: the market is only limited by the coverage of the Network. This is a good advantage since the borders are technological and not geographical, which allows the development of a big business for distant markets (Gupta et al., 2004).

Facilitating the development of small businesses that can compete in the world market: it is difficult to understand the "size" of a company that operates on the Internet. Therefore, due to this fact, opportunities for small, medium, and large companies can be equal (Garbarino \& Strahilevitz, 2004).

Carrying out direct commercial transactions: the Internet allows selling seven days a week for twenty-four hours a day, conducting business transactions at any time (Palvia, 2013).

Rapid adjustment to the market conditions: since it is relatively easy to update the company's offer, new products, prices, etc. (Halaweh \& Fidler, 2008).

Facilitating the purchase process: for an important group of consumers, this means overcoming the obstacle of moving for the act of purchase, since through the Internet anyone can have enough information to buy a product (Palvia, 2013). 
Offering an avant-garde business image: with the Internet presence, every company reflects an image of flexibility and innovation (Cyr et al., 2007).

Facilitating building and keeping of the clientele: Internet allows offering a better pre and after-sales service. It provides a better knowledge of clients' needs and informs them of the existence of new products, accessories, etc. Through the Internet, a company can treat its consumers equally without time or space problems (Garbarino \& Strahilevitz, 2004).

Working on a global scale without establishing offices in foreign countries (Gefen, Karahanna and Straub, 2003).

- Reduction of costs

Reducing the number of intermediaries: Internet makes "disintermediation" possible by allowing the producer to contact the client directly. On the other hand, new "cyberintermediaries" have appeared that intervene directly in the commercial transaction. Nevertheless, by time passing, those intermediaries that do not add value and others who act as mediators will disappear. This will force to adopt a new strategy and sell the products without any intermediaries (Halaweh \& Fidler, 2008).

Eliminating part of the printed material, (catalogs, brochures, press releases, memos, etc.) saving costs, and reducing the budget for marketing (Cyr et al., 2007).

Reducing the costs of sales personnel: it is no longer necessary to have a large sales force, since this work can be supported or partially replaced by a Web site. Internet also facilitates the work of sales personnel by providing a more effective means of contacting current and potential consumers (Palvia, 2013).

Saving store operating's expenses (rents, supplies, personnel costs, etc.), if the products (goods and services) are commercialized through the Internet (Cyr et al., 2007).

- Improving communications

It enables millions of connected consumers to do direct marketing actions in general and communication in particular. It electronically notifies all online consumers of an offer or promotional action. In addition, the audience measurement process is simplified, through follow-up visits to the company's website (Halaweh \& Fidler, 2008).

It allows the electronic polling of the clientele and the reception of suggestions from clients on how to improve the line of goods or services (Palvia, 2013).

It provides a substantial improvement in after-sales service and online support to products on a global scale (Schneider \&Perry, 2000). 
It encourages the immediate updating of the product catalog so that potential consumers always have the latest information (Cyr et al., 2007).

\subsubsection{The disadvantages of online stores}

A number of barriers hinder the development of electronic commerce on the Internet. Perhaps the main drawbacks are the differences between the online sales and the traditional ones; for example, more information is required to decide on a purchase, or consumers may feel insecure when their personal data are needed to complete the sale.

Inadequacy of the product on the Internet: not all products have the same acceptance on the Internet. In addition, the products that best fit the majority of Internet users' profiles will have better commercial performance (McCormick et al., 2014).

Security: it is one of the aspects that greatly concern the members of the exchange activity through the Internet. Especially in advanced models that give access to the contents of the corporate applications. It is necessary to protect this information against unwanted access, especially by competitors and other external agents (Schneider \& Perry, 2000).

The logistics: this item is a challenge faced by those companies that want to carry out transactions through the Internet. Without a doubt, the delivery and return of the product are essential for the proper functioning of electronic commerce (Schneider \& Perry, 2000). The delivery and return within the agreed terms and conditions are decisive for the development of this type of commercial activity (McCormick et al., 2014).

Table 2 The advantages and disadvantages of using online stores

\begin{tabular}{|l|l|}
\hline \multicolumn{1}{|c|}{ Advantages } & \multicolumn{1}{c|}{ Disadvantages } \\
\hline$\checkmark$ Increasing sales and competitiveness & $x$ Inadequacy of the product on the Internet \\
\hline$\checkmark$ Reduction of costs & $x$ There is a potential risk of Security \\
\hline$\checkmark$ Improving communications & $\begin{array}{l}x \text { More complex logistics and greater need for } \\
\text { control }\end{array}$ \\
\hline
\end{tabular}

\subsubsection{Multi-channel retailing}

The development of the Internet has favored the retailing platform. As a result, it has become an important option for retailers to reach consumers' demands (Kollmann et al., 2012; Tsai et al., 2012). Given the e-commerce pressure, many traditional physical retailers abandoned their single-channel business models and moved to multi-channel strategies, in which it can be operated through a different channel including online, catalog (Verhoef et al., 2007), telephony (call center, telex) (Sousa \& C. Voss 
2012), and m-commerce (mobile phones, SMS). During the early years of the multi-channel strategy, most of the physical retailers separated traditional and online channel operations (Merrilees \& Fenech, 2007). However, by time passing multichannel strategy went beyond its own concept and focused on the needs of the consumer (Tsai et al., 2012). Black et al. (2002) stated that if the current trend persists, dependence on a single seamless approach will be more obvious than before for retailers. The reason, according to Black et al. (2002), is that each channel has its own strengths and weaknesses, limitations and complications, thus the use of a single seamless approach improves the market performance to what that particular channel is not capable of doing well. Supporting the implementation of multichannel strategies, the existence of multi-channels and the different characteristics of each channel provide an opportunity to offer different price-quality configurations for the different segments (Lemon \& Verhoef, 2016). Therefore, this has made the multi-channel retailing become a standard business model in retailing, a retailer with two or more channels to reach consumers, which several major companies followed to establish an online channel to supplement their existing stores (Dorman, 2013).

Given the importance of the multi-channel strategy for retailers, this definition became important among researchers. There are numerous definitions of the multichannel strategy that have been made. Schultz (2002) defines multichannel to the best combination between distribution systems and communication programs and how the company will organize these programs and alternatives in a coherent way. Nicholson et al. (2002) define it as "click and brick" in which consumers seek through the physical and electronic channels in means of purchase. For Steinfield et al. (2002) "clicks and mortar" is a strategy that buyers can move from one channel to another in the different stages that make up the purchase process. Companies that provide true channel integration can propose a variety of good offers, including movement between physical and virtual channels at the same stage of the purchasing process, for greater consumer satisfaction. Moreover, Lemon \& Verhoef (2016) that the company must be proficient in different technologies and processes, focusing on consumers and their preferences, rather than their capabilities of the company. In this sense, Payne and Frow (2004) conclude that the needs, consumer wishes and demands should be the first consideration in the design of marketing channels. For Windham and Orton (2000) the best retail distribution model will be multichannel. Consumers describe the ideal scenario as a hybrid model, in which retailers offer consumers options via "Online", catalog and/or physical store. Payne and Frow (2004) define the multichannel strategy as the use of all commercially viable channels to serve and integrate customers without trying to influence the channel the customer wants to use.

According to the data, the purchasing process through different channels is becoming something common in today's environment. Nowadays, consumers use the different channels available in order to have a better and more efficient shopping experience - approximately $50 \%$ of worldwide purchases (Beltrami et al., 2019). Based on the BRP's special report in 2019, 82\% of the purchases use some types of complementary channels of the traditional store, either at the search stage or at the purchase stage 
(BRP consulting, 2019). Additionally, 56\% of the consumers tend to check out products in-store and then make their purchase online via desktop or mobile device.

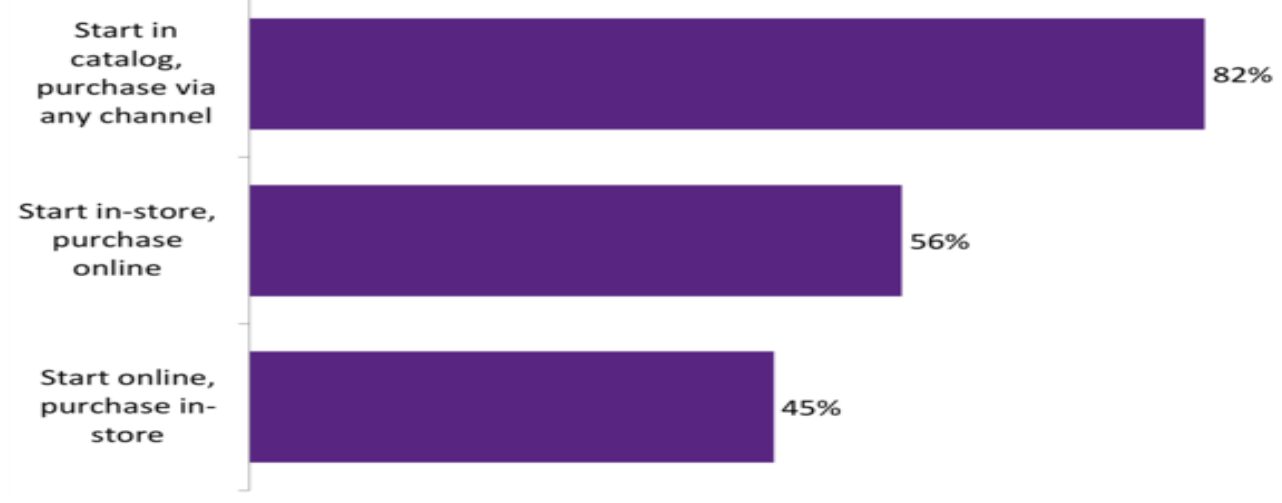

Figure 6 multi-channel consumer behavior (Source: BRP consulting (2019))

According to Deloitte (2018), the multi-channel consumers who buy their products both from traditional stores and through the Internet, catalog, or telephone, spend 82\% more money per transaction than the ones who only buy from traditional stores. Thus, the average expenditure per transaction of this type of consumer is 138 euros, compared to 76 euros of consumers who buy from traditional stores. In fact, by 2021, it is expected that the multi-channel will influence $46 \%$ of total sales. Moreover, by examining the data, European multi-channel retail sales are expected to grow at a compound annual growth rate (CAGR) of 8.5\% from 2016 to 2021 (see Figure below). Web-influenced sales will increase by 50\% over the next five years to reach $€ 748$ billion by 2021 (Forrester, 2016).

\section{European retail sales \\ ( $€$ billion)}

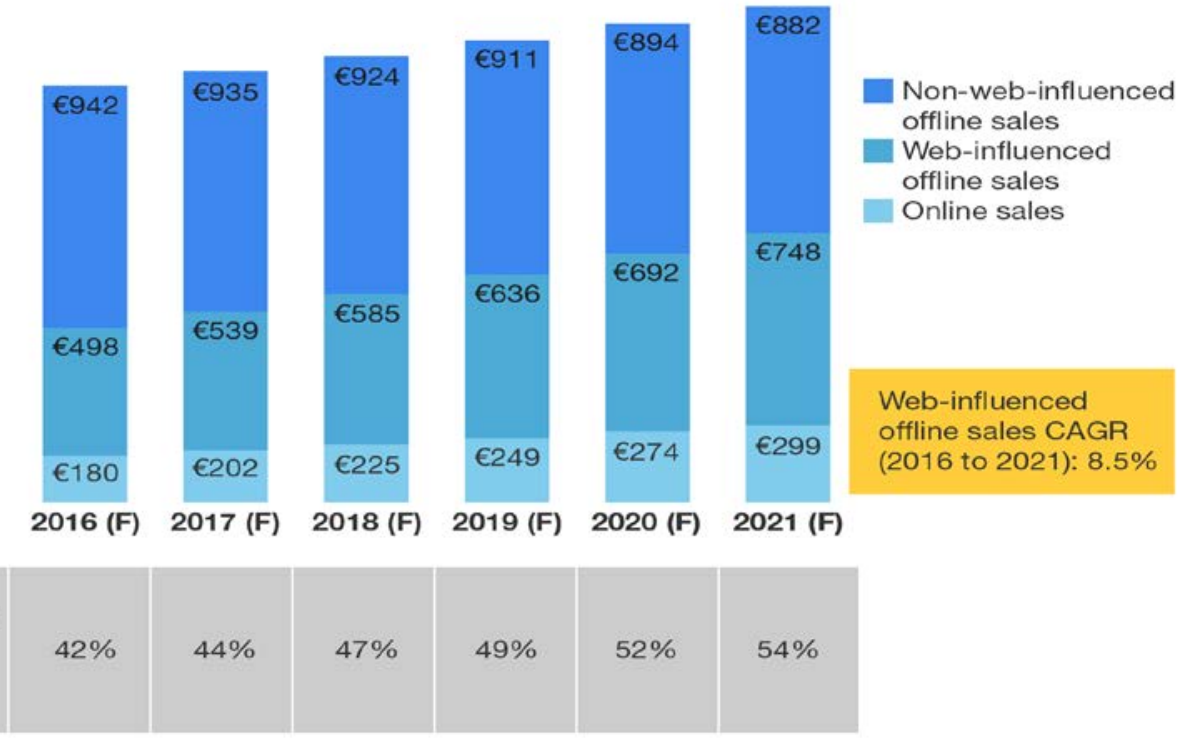

Figure 7 European retail sales (Source: Forrester (2016)) 


\subsubsection{Multi-channel retailing in Spain}

In the Spanish market, the preference of using Internet as a source of information is clear. However, Spanish consumers use social networks or other sources for searching for product information. According to Forrester (2016) almost 40\% of Spanish shoppers use the greatest number of channels per month for their shopping.

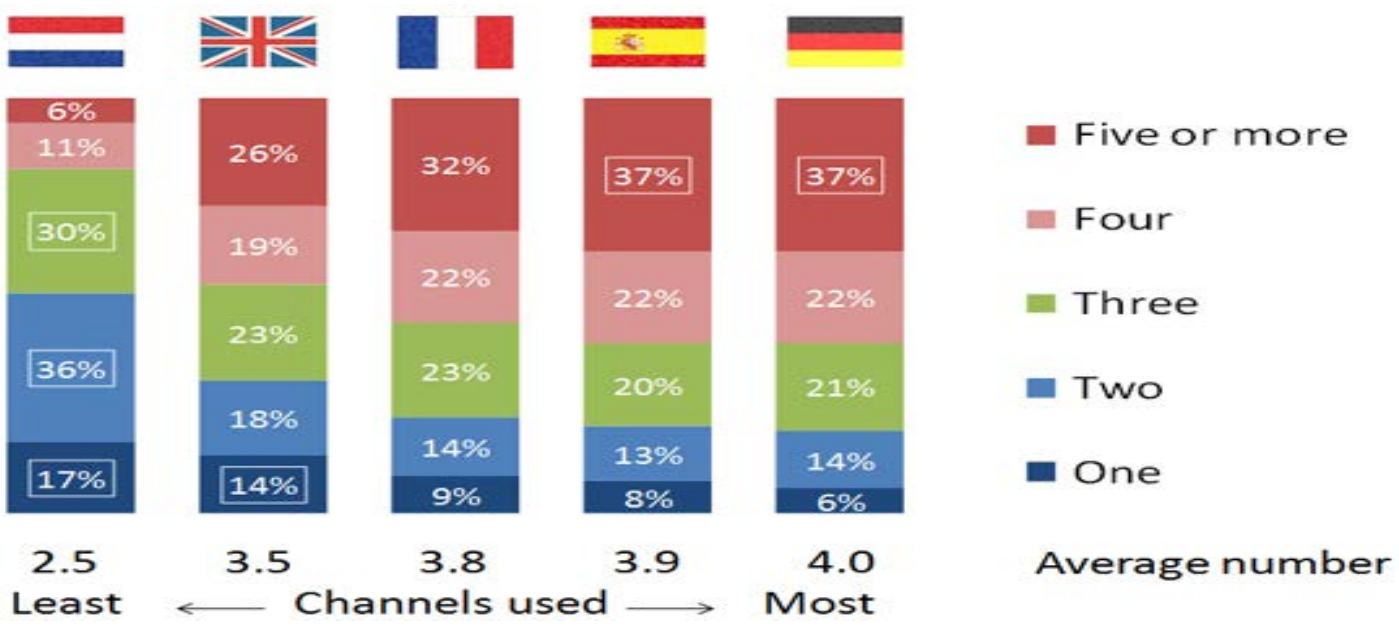

Figure 8 Number of channels used per month (Source: Forrester (2016))

The data from statistic (2020) shows the purchasing habits of Spanish Internet users who carried out searches and purchases online and offline in Spain from 2016 to 2019 with the 10\% growth in CAGRs over the next five years. During that last year, $9 \%$ of respondents who searched for offline products ended up buying online, while In the case of offline buyers who searched for information online, the percentage rose to $23 \%$. Among them the data shows that more than $70 \%$ of consumers from Spain prefer that the purchased products be sent to their preferred location (IABeCommerce, 2019). This percentage is similar to the USA, but very far from the northern countries of Europe -where only $43 \%$ of individuals wish to receive products at home - (eMarketer, 2020). A possible explanation can be alternative services given by the online retailers. Web-influenced sales will in Spain, 


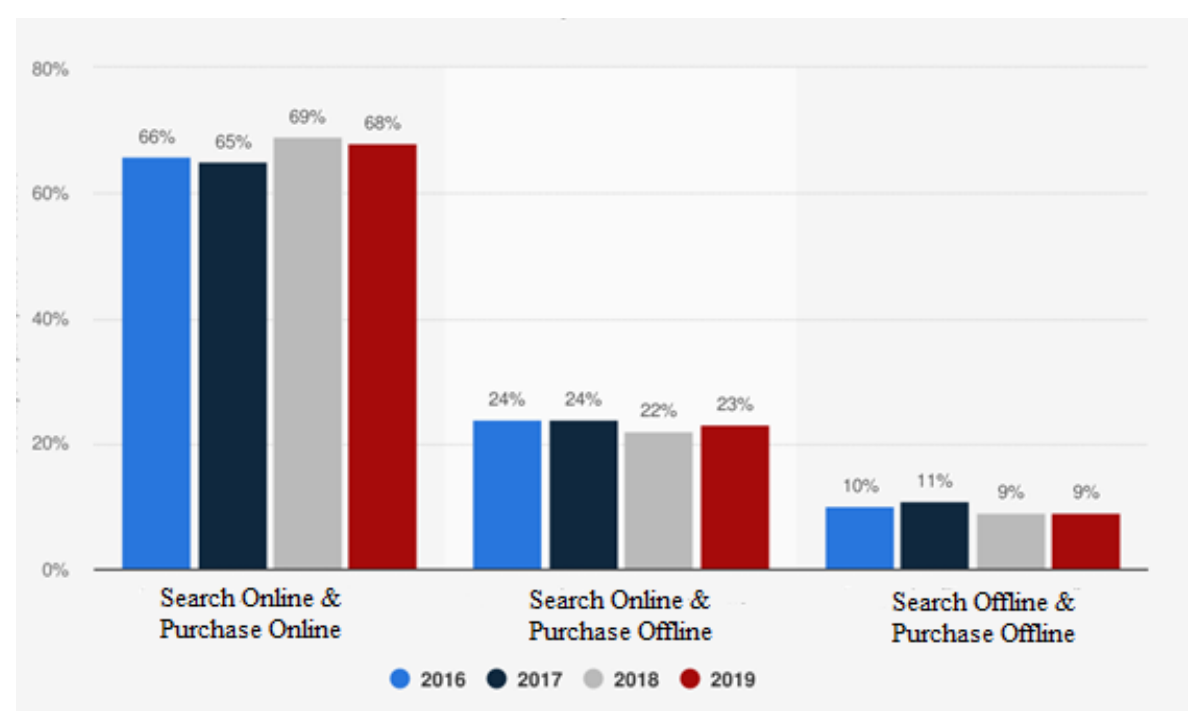

Figure 9 Purchasing habits in Spain (Source: Statista (2020b))

\subsubsection{The advantages of multichannel retailing}

Every day more companies sell their products in different channels. Combining the existence of a physical store with online sales can be a business strategy with great economic performance. As such, we have to know how to take advantage of the multichannel sale and overcome the inconvenience that it may produce.

More options for the client: consumers decide how, where, and when to buy offline or online. Hence, consumers will always appreciate offering both options (Ortis, 2010).

Bi-directional traffic feedback: having a website makes it easier for more consumers to come to physical stores and vice versa, consumers of a physical store can then finalize their online purchase (due to the lack of stock in the physical store, time to make the purchase, change of opinion, etc.) (Beamonte et al., 2007).

Reduction of the physical space required: As online sales increase, the physical space of stores can be reduced. The main advantage of the online channel is precisely the possibility of offering a catalog not linked to a limited physical exhibition in space (Merrilees \& Fenech, 2007).

Greater notoriety and brand image: Having a retailing channel on the Internet clearly increases the presence of the brand and helps better communication with the consumers. The famous "research online, purchase offline" effect is only the most noticeable consequence of this brand awareness and thereby increases the information of the product and the company available to the consumers (Gefen et al., 2003). 
Access to a greater number of potential consumers: in a worldwide where e-commerce transactions worth 323,000 billion dollars as planned for 2020, the advantages of adding an online channel to the usual offline channel should be considered (Merrilees \& Fenech, 2007).

Consumer's loyalty: multichannel marketing, characterized by its flexibility, contributes to user satisfaction and consequently, reinforces consumer loyalty. Thanks to the appearance of new channels, it is possible to reach audiences that previously, through the strategy of a single channel, could not be reached (Ye et al., 2018).

The general norm: this multifaceted approach has finally become the general strategy and even small and medium companies have succumbed to multichannel marketing in order not to be left behind by offering their range of products online in addition to their classic physical stores. Only in this way, can they avoid losing consumers to their competitors (Neslin et al., 2006).

\subsubsection{The disadvantages of multi-channel retailing}

Given the above, it might seem that all are advantages, but experience dictates that these problems can also arise:

Cannibalization: it is the biggest and most important dilemma outcome form being a multichannel retailer. Retailers can sell cheaper on the Internet than in their physical sales channels. Making this decision depends on other sectors: last-mile logistics channel, the consumers' expectations, the existing competition, the market situation, etc. (Gefen et al., 2003). However, in a multichannel strategy, each of the channels operates on its own, so that the offline channel does not benefit from a potential consumer who can subsequently sign in the website. In this case, researchers report the cannibalization effect, since the business and, therefore, the sales, move partially or totally from one channel to another (Merrilees \& Fenech, 2007). Many store owners, for example, are concerned that consumers move from the physical store to the online store. It is a fear expressed by many offline retailers that they lose profit when their regular consumers "migrate" to the online world (Ye et al., 2018).

New competitors: by using different channels, the number of competitors increases in a very significant way. In some cases, the competitors of an online channel "are already there" when retailers still do not have the online channel, but its existence is now much more evident for all, because consumers can compare retailers with the competition at a single click (Sousa \& C. Voss 2012). By not offering the client the possibility of switching from one channel to another during the same transaction (for example, in case of practical click and collect), retailers can abandon in favor of a competitor, who does offer a comprehensive shopping experience (Verhoef et al., 2007). 
Complex logistics: if communication, advertising, last-mile logistics, and sale are carried out through different channels instead of just one, a more complex logistics and a greater degree of control will be required. It can happen if different channels do not present a homogeneous corporate image. The potential consumers will be irritated and will not distinguish if the offered products and services belong to the same company (Verhoef et al., 2007).

Table 3 The advantages and disadvantages of using multi-channel retailing

\begin{tabular}{|c|c|}
\hline Advantages & Disadvantages \\
\hline $\begin{array}{l}\checkmark \text { The company is distinguished by its } \\
\text { flexibility }\end{array}$ & $\begin{array}{l}X \text { More complex logistics and greater need for } \\
\text { control }\end{array}$ \\
\hline $\begin{array}{l}\checkmark \text { Improves consumers' satisfaction and } \\
\text { thereby loyalty }\end{array}$ & $\begin{array}{l}X \text { A risk that different channels are not perceived } \\
\text { as part of the same company }\end{array}$ \\
\hline $\begin{array}{l}\checkmark \text { Better market coverage and exploitation of } \\
\text { target groups }\end{array}$ & $\begin{array}{l}\boldsymbol{X} \text { There is a potential risk of cannibalization } \\
\text { between channels }\end{array}$ \\
\hline$\checkmark$ Diversification of business risk & $\mathbf{X}$ Marketing channels are not interconnected \\
\hline$\checkmark$ Opportunity to reposition in the market & $\begin{array}{l}X \text { There is no transmission of information } \\
\text { through different channels }\end{array}$ \\
\hline
\end{tabular}

\subsubsection{Omnichannel retailing}

The evolution of modern retailing has also given rise to a new retailing strategy known as 'Omnichannel', which is similar to multi-channel but mostly united in the upper stream. Ortis (2010) defined this new retiling strategy as "an evolution of multichannel, which consumers can use all channels at the same time, not each channel in parallel". The word "Omni" comes from the Latin word "Omnis”, which means "all”, "everything”, or "universal”. By contrast, "multi” originates from "Multus", which refers to "multiple", "much”, or "many" (Combs, 2015). Hence, it can be said that Omnichannel strategy is an improvement of the multi-channel concept. In fact, Omnichannel retailing acts as multi-channel retailing, yet with a big difference, which consumers can experience a seamless integrated retailing approach (Lazaris, Vrechopoulos and Katerina, 2014).

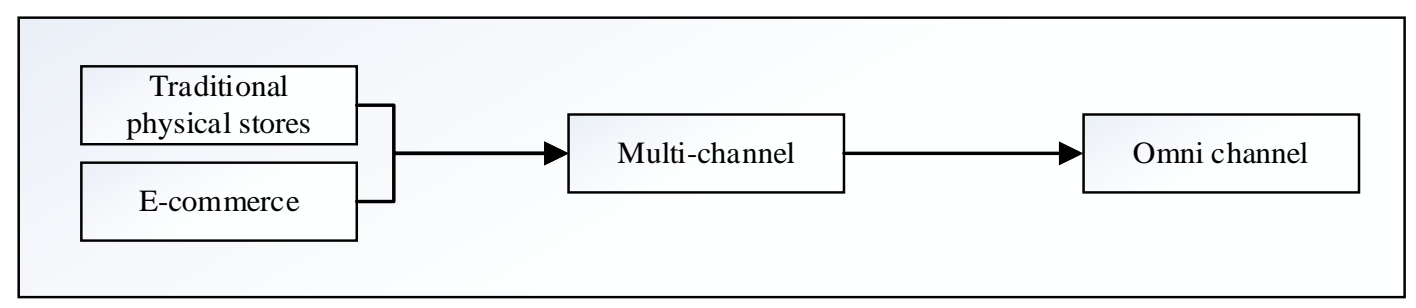

Figure 10 The evolution of retailing (Source: Author) 
Presently, many retailers are expanding the number of its shopping channels significantly (e.g. online stores) to serve their consumers better and increase their sales (Verhoef et al., 2007; Cao \& Li, 2015). During the early years of offering multiple channels, developing additional sales channels as a side of their traditional channel, retailers operated those channels separately (Bell et al., 2014). However, the lack of integration leads to these banners which are being nothing more than "mixed businesses" that provide the consumer with multiple points of uncoordinated contact (e.g. channel conflicts such as cannonballing sales between channels (Kollmann et al., 2012). Hence, multi-channel retailers feel the pressure to shift to Omnichannel retailing, which requires an integration of all channels to achieve the high levels of consumer satisfaction across all channels, as well as to allow consumers to switch easily from one channel to another (McCormick et al., 2014) (See figure 6). Adopting this new strategy as mentioned provides access through all contact points -from mobile devices to social networks in addition to in-store interactive technologies. For this reason and to move away from the mere juxtaposition of non-integrated channels, the business world currently talks about Omnichannel strategy or Omnichannel retailing (OCR).

\subsubsection{Towards a definition of Omnichannel retailing}

Although Omnichannel retailing has brought much attention to retailers, academia still does not acknowledge the term "Omnichannel ". Therefore, the debate has emerged as to whether Omnichannel is merely an industry myth or a legitimate concept that represents an important evolution in scientific research. Hence, the following part tries to recognize the term "Omnichannel retailing”. Table 4 lists different definitions of the multi-channel / Omnichannel strategy concept.

Table 4 definitions of the multi-channel / Omnichannel strategy concept

\begin{tabular}{|l|l|}
\hline \multicolumn{1}{|c|}{ Authors } & \multicolumn{1}{c|}{ Definition } \\
\hline (KATROS, 2000) & $\begin{array}{l}\text { It is the strategy in which services are provided through the most appropriate channel in } \\
\text { a synchronized manner }\end{array}$ \\
\hline $\begin{array}{l}\text { (WINDHAM \& } \\
\text { ORTON, 2000) }\end{array}$ & $\begin{array}{l}\text { A hybrid model in which merchants offer consumers the option to purchase online, by } \\
\text { catalog, and/or from a physical store }\end{array}$ \\
\hline $\begin{array}{l}\text { AL., 2002) } \\
\text { (NTCHOLSON ET }\end{array}$ & $\begin{array}{l}\text { It is the search of consumers through physical and electronic means, as well as multiple } \\
\text { ways of buying }\end{array}$ \\
\hline $\begin{array}{l}\text { In., 2002) } \\
\text { different stages that make up the purchase process. Companies that provide true channel } \\
\text { integration can propose a variety of good offers, including movement between physical } \\
\text { and virtual channels at the same stage of the purchasing process, for greater consumer } \\
\text { satisfaction }\end{array}$
\end{tabular}




\begin{tabular}{|c|c|}
\hline $\begin{array}{l}\text { (STONE ET AL., } \\
\text { 2002) }\end{array}$ & $\begin{array}{l}\text { The multichannel management of the client is the use of more than one channel or means } \\
\text { to manage clients in a way that is coherent and coordinated among all channels or media } \\
\text { used }\end{array}$ \\
\hline $\begin{array}{l}\text { (WEBB \& } \\
\text { HOGAN, 2002) }\end{array}$ & $\begin{array}{l}\text { The multichannel strategy is an agreement or collaboration of different direct and } \\
\text { indirect last-mile logistics channels to provide the products to consumers }\end{array}$ \\
\hline $\begin{array}{l}\text { (ARVIND \& } \\
\text { BRUGGEN, 2005) }\end{array}$ & $\begin{array}{l}\text { These are the commercial strategies carried out by companies to serve consumers by } \\
\text { interacting with them through several channels }\end{array}$ \\
\hline $\begin{array}{l}\text { (NESLIN ET AL., } \\
\text { 2006) }\end{array}$ & $\begin{array}{l}\text { It is the design, development, and evaluation of those channels that improve the value } \\
\text { of the client through efficient management of the acquisition, retention and development } \\
\text { of the same. }\end{array}$ \\
\hline $\begin{array}{l}\text { (BEAMONTE ET } \\
\text { AL., 2007) }\end{array}$ & $\begin{array}{l}\text { It is the alternative to reach the consumer with the offer that really interests him. The } \\
\text { company must interact and open all channels to the consumer to establish contact, but, } \\
\text { at the same time, being able to integrate them internally so that they provide the } \\
\text { appropriate information and of greater interest to the consumer. }\end{array}$ \\
\hline (ORTIS, 2010) & $\begin{array}{l}\text { The Omnichannel consumer is an evolution of the multichannel consumer, who wants } \\
\text { to use all the channels (stores, catalogs, web, call-centers and mobile) simultaneously, } \\
\text { and not independently }\end{array}$ \\
\hline (RIGBY, 2011) & $\begin{array}{l}\text { Omnichannel retailing reflects the fact that retailers interact with consumers through } \\
\text { innumerable channels (physical stores, websites, direct marketing, catalogs, call centers, } \\
\text { social networks, mobile phones and other smart devices), residing in the success in } \\
\text { providing an experience of shopping, integrating these disparate channels, and } \\
\text { combining the advantages of physical stores with the wide range of information that } \\
\text { online commerce entails }\end{array}$ \\
\hline $\begin{array}{l}\text { (KABADAYI, } \\
\text { 2011) }\end{array}$ & $\begin{array}{l}\text { It is the simultaneous use of independent and integrated channels by organizations to } \\
\text { conquer different consumer segments, sell and distribute products, minimize costs and } \\
\text { remain competitive }\end{array}$ \\
\hline $\begin{array}{l}\text { (AUBREY \& } \\
\text { JUDGE, 2012) }\end{array}$ & $\begin{array}{l}\text { The Omnichannel ecosystem is an opportunity for companies to actively promote their } \\
\text { growth, reinventing their physical stores under the consideration that electronic } \\
\text { commerce is not a threat, but an ally }\end{array}$ \\
\hline $\begin{array}{l}\text { (WANG ET AL., } \\
\text { 2012) }\end{array}$ & $\begin{array}{l}\text { The Omnichannel strategy is the last step in the multichannel evolution, merging } \\
\text { different points of contact and providing a complete and integrating experience }\end{array}$ \\
\hline (EAGLEN, 2013) & $\begin{array}{l}\text { Omnichannel is the mix of all channels through which consumers want to make the } \\
\text { purchase (the store, the web, mobile or social networks), where the retailers must } \\
\text { provide a unique message }\end{array}$ \\
\hline
\end{tabular}




\begin{tabular}{|c|c|}
\hline (DORMAN, 2013) & $\begin{array}{l}\text { Omnichannel retail is characterized by the integration of the various direct-to-consumer } \\
\text { (D2C) channels to support cross-channel consumer interaction }\end{array}$ \\
\hline $\begin{array}{l}\text { (GOLOMBEK, } \\
\text { 2013) }\end{array}$ & $\begin{array}{l}\text { Omnichannel retailing means that a company seamlessly integrates all channels of the } \\
\text { company to get the product to the consumer in the most efficient and effective way } \\
\text { possible }\end{array}$ \\
\hline (WATSON, 2013) & $\begin{array}{l}\text { A coordinated multichannel offering that provides a seamless experience when using all } \\
\text { of the retailer's shopping channels }\end{array}$ \\
\hline $\begin{array}{l}\text { (BELU \& } \\
\text { MARINOIU, 2014) }\end{array}$ & $\begin{array}{l}\text { Omnichannel is the fusion of all physical and virtual channels, aimed at providing a } \\
\text { unique and innovative experience to the client }\end{array}$ \\
\hline $\begin{array}{l}\text { (PIOTROWICZ \& } \\
\text { CUTHBERTSON, } \\
\text { 2014) }\end{array}$ & $\begin{array}{l}\text { A new approach to channel integration is emerging-the Omnichannel, which aims to } \\
\text { deliver a seamless consumer experience regardless of the channel }\end{array}$ \\
\hline (CHOPRA, 2015) & $\begin{array}{l}\text { Omnichannel retailing refers to the use of a variety of channels to interact with } \\
\text { consumers and fulfil their orders }\end{array}$ \\
\hline (ROWELL, 2015) & $\begin{array}{l}\text { In simple terms, 'Omnichannel ' retailing means we (consumers) can order goods } \\
\text { however, wherever, and whenever we want, and furthermore have those goods delivered } \\
\text { however, wherever, and whenever we want to meet our needs at the time }\end{array}$ \\
\hline $\begin{array}{l}\text { (SARMAH \& } \\
\text { PAWAR, 2015) }\end{array}$ & $\begin{array}{l}\text { Omnichannel retailing is a seamless approach of the various channels of retail and } \\
\text { concentrates on delivering a rich blend of retail sales channels }\end{array}$ \\
\hline $\begin{array}{l}\text { (VERHOEF ET } \\
A L ., \text { 2015) }\end{array}$ & $\begin{array}{l}\text { The Omnichannel strategy is defined as the coordinated management of all the channels } \\
\text { and points of contact with the consumer (touch-points), in such a way that the consumer } \\
\text { experience and the usefulness of the channels are optimal }\end{array}$ \\
\hline $\begin{array}{l}\text { (CUMMINS ET } \\
\text { AL., 2016) }\end{array}$ & $\begin{array}{l}\text { Omnichannel marketing in a sales context is the synergetic integration of consumer } \\
\text { touch-points and communication opportunities for the purpose of creating a unified } \\
\text { brand experience regardless of channel, platform, or stage in the selling process }\end{array}$ \\
\hline (Deloitte, 2017) & $\begin{array}{l}\text { Omnichannel retailing means being available at any time anywhere, making it } \\
\text { convenient for the consumer }\end{array}$ \\
\hline
\end{tabular}

Despite all the definitions, academic literature has not still come up with a specific definition for Omnichannel retailing. Therefore, McCormick et al. (2014) explain some terms of Omnichannel in place of a formal definition: 
Simultaneous channel usage: a study by Schramm-Klein et al. (2011) identifies that the majority of consumers regularly engage shopping channels simultaneously. Mobiles are a good example in which consumers can be connected simultaneously with physical stores.

Connectedness: by vanishing the boundaries of channels in Omnichannel strategy, consumers are connected simultaneously through different channels (Aubrey \& Judge, 2012). Due to this fact, this strategy is known as a highly consumer-centric and agile environment in which consumers can exploit a number of retail channels at the same time (McCormick, Cartwright and Perry, 2014).

A Single view of the consumer: as mentioned in the previous part, this strategy is consumercentric, because it contributes to consumers' satisfaction and they have a single view across channels ultimately (Berman \& Thelen, 2004). A single view of the consumer is consistent in all stages of the consumer journey rather than simply having multiple channels (McCormick, Cartwright and Perry, 2014).

Seamlessness: in the Omnichannel strategy, consumers should experience seamless and consistent shopping throughout all available channels. Seamless integration of multiple retail channels recognizes a progression within modern retailing and one that is beyond a standard multi-channel approach (McCormick, Cartwright and Perry, 2014).

Consistency: in the Omnichannel environment, retailers should offer an integrated and consistent channel in which consumers stay with the same retailer when they switch channels. From an Omnichannel perspective, the level of consistency throughout each channel should be in such a way that consumers can move flexibly between the channels (McCormick, Cartwright and Perry, 2014).

\subsubsection{Advantages of Omnichannel retailing}

Omnichannel retailing offers a large number of advantages over previous retailing strategies. It offers many opportunities for retailers not only to have an additional sales channel, but also to receive the benefits that this strategy will bring. Here are the advantages of Omnichannel:

It offers added value for consumers: consumers greatly benefit from integrating all media and facilitating contact. Consumers can select whatever, however, and whenever, from any place or device they want to buy, reserve or resolve any problem or doubt (Ortis, 2010). Consumers can recover from an interrupted communication and combine different interaction channels. Offering this service in a fluid way, without waiting, with transparency and with simple and intuitive platforms is the key to the success of Omnichannel (Dorman, 2013).

It improves loyalty: consumers are increasingly demanding, and they can be lost if they do not receive what they requested. The loyalty is strengthened with a communication without 
barriers, where the client feels attended at all times and with a quick response for all their complaints, doubts, and suggestions. If clients have all facilities in their relationship with the company, together with a good quality and satisfactory treatment, the value of the product will be raised and they will feel more comfortable and confident (Watson, 2013).

It brings more quality to all processes: the technological implementation is a fundamental challenge to compete. Implementing the Omnichannel process forces the entire company to digitize from planning to last-mile logistics (Rigby, 2011). This always provides more efficiency and control over all phases of the product to give a quick and effective response. It is an added benefit also for the people who work in the company. Motivation and commitment are greater when collaborating in a job that seeks the highest quality and participation in an active and attentive company to its public (Sarmah \& Pawar, 2015).

It generates more sales: the use of the Internet is increasingly intense. The Omnichannel offers a complete visibility to the retailer, thereby consumers can access the retailer directly from all platforms (social networks, web, or mobile applications) from any location (Dorman, 2013). This greatly drives the impact of marketing strategies - for example, in advertising, offers, promotions, etc. - to make them accessible to many potential consumers and expanding sales options (Ortis, 2010).

It provides more information: the Omnichannel retailer obtains valuable information about consumers by integrating all the information about their communications (Sarmah \& Pawar, 2015). Omnichannel allows retailers to know their consumers better, to anticipate their needs, and to offer them more than they expect. It is a great value to improve the way of communicating business strategies and even reorient the business. This leads to a complementary aid for the vital challenge of loyalty (Piotrowicz \& Cuthbertson, 2019).

\subsubsection{The disadvantages of Omnichannel retailing}

The disadvantages of using Omnichannel strategy, which could also be defined as challenges or risk factors at the time of application, are the following:

Easy to lose benefit: Since information is quickly accessible through different channels; the slow, cumbersome, or unsafe service, result in a negative impact on the clients' evaluation, which could lead to the choice of competition (Dorman, 2013).

Hard to be followed by some particular consumers: another problem of Omnichannel retailing is the paradigms that consumers can face when using, for example, digital channels (Rigby, 2011). Although it can be very easy for a 20-year-old consumer to carry out any type of digital transaction, for an older person it can be a serious challenge. However, this segment is particularly attractive for using only one channel instead of all (Watson, 2013). 
Difficulty of updating: Precision is a requirement for the effectiveness of any Omnichannel initiative. To acquire it, retailers need to identify, track, and manage the inventory accurately (Ortis, 2010). Not only is the update important, but also is the speed. To adapt to the new demands, the supply chains must be aligned with the new technological options (Piotrowicz \& Cuthbertson, 2019).

Complicated supply chain: The demands continue on the side of the supply chain, which will have to be dynamic enough to adapt its internal configuration to the detected trends. The alignment will bring the retailer closer to the consumers and the strategy used at this end of chain will have to be applied on the supply side as well, including suppliers, so that the dynamism can culminate with the generation of value and the strengthening of the end-to-end sustainable relationships (Sarmah \& Pawar, 2015).

Table 5 The advantages and disadvantages of using Omnichannel retailing

\begin{tabular}{|l|l|}
\hline \multicolumn{1}{|c|}{ Advantages } & \multicolumn{1}{c|}{ Disadvantages } \\
\hline$\checkmark$ It offers added value for consumers & $X$ Easy to lose benefit \\
\hline$\checkmark$ It improves loyalty & $\begin{array}{l}\text { X Hard to be followed by some particular } \\
\text { consumers }\end{array}$ \\
\hline$\checkmark$ It brings more quality to all processes & $X$ Difficulty of updating \\
\hline$\checkmark$ It generates more sales & $X$ Complicated supply chain \\
\hline$\checkmark$ It provides more information & \\
\hline
\end{tabular}

\subsection{Evolution of consumer's shopping behavior}

By the rise of multi-channel retailing, consumers expanded the range of choices. Consumers were offered channels in order to satisfy their needs. These channels have given rise to "consumer' power". They have made consumers shop what they want, when they want, and through the channel they prefer (Crawford, 2005). Some consumers prefer to shop through a specific channel, due to its advantages, while others might switch between different channels because of the differences among channels based on the product offering, the service quality of the channel, the cost of the channel, or the information available on that channel (Keen et al., 2004). Those consumers who regularly use multiple channels such as Internet, in-store, or catalog in different stages of shopping process are known as a multi-channel consumer (Ganesh, 2004; McCormick et al., 2014). However, Pookulangara et al. (2011a) limited this definition by the usage of three or more different channels in the shopping process, which has ignored some of the consumer's segment in the multi-channel environment. 
Channel migration is a proactive consumer-led decision whereby a consumer uses different retailing channel (Pookulangara et al., 2011a). Those consumers that show higher purchase frequency and higher spending levels, have a greater preference to use different channels (Kumar \& Venkatesan, 2005; Venkatesan et al., 2007). They are more likely to use a new channel and/or switching between channels (Kumar \& Venkatesan, 2005; Venkatesan et al., 2007) when they are not satisfied with the channel. Even more, they are more likely to change and move to competitors, rather than switching to another channel from the same retailer (Konus et al., 2008), depending on their shopping benefit (Pookulangara et al., 2011b). This behavior is known as a cross-channel free-riding (Chiu et al., 2011).

As within the channel adoption process, multi-channel consumers are often found to compare and contrast the consistency and excellence of services between organizations (e.g. competitor retailers and brands) and across the various channels within a single organization (Tate \& Johnstone, 2011). Hence, cross channel behavior fits with Omnichannel more closely than multi-channel retailing, because in the multi-channel environment, consumers cannot interact with a single organization. In addition, the relationships and transferable perceptions between channels entail studying the overall consumer's journey. Therefore, by expanding and increasing the number of retailers, it is vital to understand the consumer's shopping behavior in an environment where consumers shop anytime and anywhere. The following section aims to build a framework to understand the consumer's decision-making process.

\subsubsection{Evolution of consumer's shopping behavior in last-mile logistics}

Before studying consumer's shopping behavior in last-mile logistics, it is necessary to define the last-mile logistics stage clearly. According to Gevaers et al. (2011) the last-mile logistics can be defined as the final leg of the logistics service in a B2C whereby the consignment is delivered or returned in different ways. Within this definition, in consumer's shopping behavior process, the last-mile logistics can be located in different consumer's shopping stages. For an example, in Steinfield et al. (2002) model, the last-mile logistics can be seen in the two different stages: a purchase stage, and a postpurchase stage. Or, in Solomon (2010) model, the last-mile logistics can be located in the last stage of the consumer's decision-making shopping process: a purchase stage.

By comparing these models, in some cases there can be seen a similarity in some stages. As an example, the problem recognition phase or needs of Solomon (2010) shows similarities with the activation phase of Suominen (2005) and the need recognition of Engel et al. (1995). After carefully comparing each stage, this research presents the consumer's decision-making shopping process model or also known as "the consumers journey model” (Kemperman et al., 2015) in five stages. In fact, this presented model is more enhanced than the shopping decision model by Steinfield et al. (2002) and is comparable with the after-shopping process model such as the one by (Blackwell et al., 2006; Solomon, 2010). The model for this research consists: stimulation, search for information, purchase, delivery, and after-sale service (specifically return services) (See Figure 7). These stages are the most relevant ones for this research. 


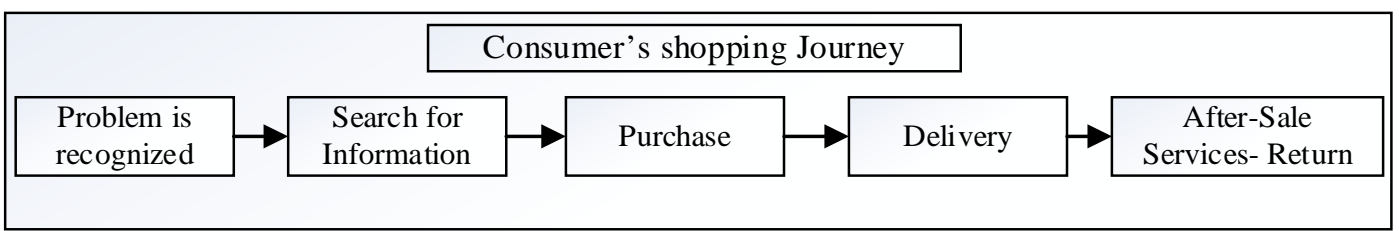

Figure 11 Consumers shopping journey (Source: adopted by Kemperman et al. (2015))

\subsubsection{Consumer's shopping behavior in Delivery}

Delivery is one of the two phases that has been explored more in this study. When a product is bought by the consumers, generally they get their purchased product immediately if they purchase it from a physical store, except for some special items such as furniture, which need home delivery service (Hsiao, 2009). By online shopping, however, consumers need to wait until the product is delivered, unless the product is downloadable (e.g. software and music), or certain kinds of services such as online banking and online consultation. Thus, depending on channel and product, it could be several alternatives that consumers receive their purchased items in their final destination. However, as retailers are moving to the new channel retailing strategy known as Omnichannel strategy, they are offering different models and designs. Consumers now have different types of last-mile logistics options, which can be easily distinguished. Gevaers (2011) defined the Omni last-mile logistics in a B2C environment as "the final leg in a business-to-consumer delivery service whereby the consignment is delivered to the recipient, either at the recipient's home, at a collection point, or at another selected location”. In order to be able to adequately analyze Omni last-mile concept, this study categorizes various types of lastmile deliveries, which are explained as follows.

\subsubsection{Delivery modes}

After careful reviewing of all delivery types, the most common last-mile logistics options in the B2C environment found in academic studies were mainly three last-mile logistics options: through consumer's location deliveries (known as Direct-to-Consumer deliveries (D2C)), or through pick-up points by its company (known as Business-to-Consumer deliveries (B2C)) or a combination of these two (known as Collection/Delivery Points (CDPs)). These delivery options may run either by outsourcing, known as CDPs, or by their company, or a combination of these two (Gevaers et al., 2011).

Consumer's location deliveries, known as direct-to-consumer deliveries, refer to sending purchased items to the consumer's doorstep or a given location (Minguela-Rata \& de Leeuw, 2013). This location can be a consumer's home, workplace, or other preferred locations. Although Madlberger (2005) distinguished home delivery and workplace delivery in his research, other studies indicated home delivery as a general location of D2C delivery (e.g., Gevaers et al., 2011). Likewise, in the majority of studies, home delivery is used as a general location of D2C deliveries. In addition, the direct-toconsumer deliveries offer two types of delivery: an attended and unattended model (e.g. Gevaers et al., 2011; Hübner et al., 2016). 
Attended Home Delivery (AHD) refers to delivering purchased items to consumer's locations while receiving consumer's signature (Wang et al., 2014). This concept provides the only place for online shoppers to contact face to face with the retailer. Nonetheless, it creates complexity for consumers to be always under the waiting time constraint of receiving items (Hübner et al., 2016).

Unattended Home Delivery (UHD) means the delivery will happen whether the consumer is in histher location or not (Hübner et al., 2016a). Usually, the orders are delivered to her/his neighbors, a secured box (e.g., letterbox), or his/her working place (Gevaers et al., 2011), where consumer can collect them later. This type of delivery from a logistical point of view can be similar to the combination of home delivery and pick-up points known as CDPs. The advantage of unattended home delivery type is eliminating the wasted waiting time and the constraints of collecting deliveries, although the main concern is that the orders should be delivered in a safe and secure way (Hübner et al., 2016).

The second main delivery option is pick-up points by its company, known as business-to-consumer deliveries (B2C). In this option, consumers need to travel to the selected location and pick up their purchased items through last-mile logistics centers or retailing stores (Minguela-Rata \& de Leeuw, 2013). Similar to D2C deliveries, Hübner et al. (2016a) added another type of delivery known as attached pick-up points. The difference between this type of delivery and in-store pick-up delivery is the location of pick-up points. Attached pick-up points are not inside the store, but they are attached to the store (Hübner et al., 2016a). However, attached pick-up points have the same pros and cons of instore pick-up points (Hübner et al., 2016b).

Lastly, regarding the main delivery options, we considered a combination of the two previous main options, which is known as Collection/Delivery Points (CDPs). Collection/delivery points refer to "convenience stores, plot properties, and other institutions, which belong to or cooperate with express companies as the place where consumers come to pick up goods" (Wang et al., 2014). These collection points are meeting points where deliveries and consumers reach together outside personal contact with the retailer (Gevaers et al., 2011). Moreover, Weltevreden (2008) has divided the CDPs into two types of delivery options: locker points (unattended) and service points (attended).

Service points or attended is based on a shop-in-shop concept, in which retailers deliver consumer's orders to the selected convenience store, post office, or petrol station where the consumer can pay, collect, and return the orders (Xu et al., 2011). In service points, the store staffs are handling the collection procedure (Weltevreden, 2008). Hübner et al. (2016) added that service points are independent and are supplied separately from warehouses.

Locker points or unattended is another type of CDP, usually known as a shared reception box (RB) set in a public area where consumers can pay, collect, and if necessary, return their orders (Weltevreden, 2008). This type of CDP uses a private shared password between the carrier and the consumer (Xu et al., 2011). Although X. Wang et al. (2014) have divided RBs from CDPs types, after careful 
consideration of their definition and their categorization, it seems that this type is a mixture of similar delivery types like unattended home delivery (UHD) and unattended CDP.

\subsubsection{Consumer's shopping behavior in Return}

Finally, the after-sale service is a significant issue, which can generate superior utility by solving consumers' problems and supporting them after the purchase process. After-sales activities include product returns, claims, and repair or maintenance services (Frasquet et al., 2015). Among all, returns play an important part of retailers not only as an opportunity to gain consumers' satisfaction and retention (Cavalieri et al., 2007; Frasquet et al., 2015), but also as a necessary part of a relationship between companies and consumers (Petersen \& Kumar, 2009). Retailers with a good retuning policy can obtain consumer loyalty (Kemperman et al., 2015). It can be a major generator of revenue, profit, and competency in modern industries (Cohen et al., 2006; Kurata \& Nam, 2010). However, the cost of having this kind of service is almost always substantially more than the price of selling goods (e.g. Cost of logistics, telephone calls, compensation, sortation, testing, reporting and reselling or disposal of the exchanged goods) (Brock, 2009).

In the Omnichannel context, researchers and practitioners have offered several options for consumers to reach the companies to do their after-sale services, similar to delivery options (offline and online). Consumers can choose whether they go back to the store/fulfillment stores, contact the store through the website/application on a mobile device, send a message through social media of the shop, call the company/store, and send an e-mail/mail to the company for their after-sale service. In the following, it categorizes return options in the last-mile logistics.

\subsubsection{Return mode}

The last logistics mode in this section and in the subsection of last-mile logistics is returns (Hübner et al., 2016). In an Omnichannel environment, last-mile logistics system consists of not only handing over the orders to their final destination (e.g., stores, consumers), but also supporting the backward last-mile logistics concepts (Hübner et al., 2016). This backward last-mile logistics of product flows from the consumer to its own retailer or to some locations in which the process of returns is managed. They are often known as "returns” or “reverse logistics” (Hübner et al., 2016). Banker and Cooke (2013) stated that consumers might have similar options to deliveries for product returns. Therefore, just like the delivery mode, we have classified return mode into three main places of returning options (in-store, postal shipments and the combination of these two). Moreover, like the channel strategy development, at the basic multi-channel strategy, consumers can only return their orders through where they bought (e.g., online purchase returned by postal shipment). But, in an advanced Omnichannel concept, consumers can return their orders through different channels available (Hübner et al., 2016). 
In the Omnichannel environment, consumers can return their orders by courier, express or return service companies, which are known as the common solution among the retailers (Hübner et al., 2016b) and can be considered the standard return option (Hübner et al., 2016a). Additionally, for Omnichannel retailers, it is mandatory to have in-store return options (Hübner et al., 2016b). On the other hand, consumers can use the combination of the in-store and postal shipment, known as CDPs, such as service points and locker points to return their orders (Weltevreden, 2008). These CDPs are managing the returns process and mostly fashion retailers with high return rates are using it (Hübner et al., 2016a).

Table 6 Summary of various delivery \& return types in the last mile logistics

\begin{tabular}{|c|c|c|c|c|}
\hline Authors & $\begin{array}{l}\text { Place of } \\
\text { delivery* }\end{array}$ & Type of delivery & Place of return & Products \\
\hline $\begin{array}{l}\text { (PUNAKIVI \& } \\
\text { SARANEN, 2001) }\end{array}$ & HD & - & - & - \\
\hline $\begin{array}{l}\text { (MADLBERGER, } \\
\text { 2005) }\end{array}$ & $\begin{array}{l}\text { HD/WD/ Pick- } \\
\text { up points }\end{array}$ & $\begin{array}{l}\text { Pick-up points: Stores, } \\
\text { railway or gas stations, } \\
\text { and deposit boxes }\end{array}$ & - & $\begin{array}{l}\text { Groceries/Books/ } \\
\text { Music/Computer } \\
\text { s and } \\
\text { accessories/Appa } \\
\text { rel/shoes }\end{array}$ \\
\hline $\begin{array}{l}\text { (WELTEVREDEN, } \\
\text { 2008) }\end{array}$ & CDPs & $\begin{array}{l}\text { Locker points } \\
\text { (unattended) and Service } \\
\text { points (attended) }\end{array}$ & CDPs & - \\
\hline $\begin{array}{l}\text { (HU \& CHANG, } \\
\text { 2009) }\end{array}$ & $\begin{array}{l}\text { Store pick-up/ } \\
\text { HD }\end{array}$ & $\begin{array}{l}\text { Store pick-up: C\&C or } \\
\text { C\&R }\end{array}$ & $\begin{array}{l}\text { In-store/ RCs/ } \\
\text { Pick-up }\end{array}$ & - \\
\hline $\begin{array}{l}\text { (GEVAERS ET } \\
\text { AL., 2011) }\end{array}$ & $\begin{array}{l}\text { Store Pick-up/ } \\
\text { Cluster/ HD }\end{array}$ & $\begin{array}{l}\text { Pick-up: DC or store/ } \\
\text { Cluster: RBs, CPs, Post } \\
\text { offices/ HD: Attended or } \\
\text { unattended }\end{array}$ & $\begin{array}{l}\text { Cluster/ Pick- } \\
\text { up/ In-store }\end{array}$ & - \\
\hline (XU ET AL., 2011) & $\begin{array}{l}\text { CDPs Pick-up } \\
\text { HD }\end{array}$ & $\begin{array}{l}\text { CDPs: Locker points } \\
\text { (unattended) or service } \\
\text { points (attended) }\end{array}$ & CDPs In-store & - \\
\hline $\begin{array}{l}\text { (MINGUELA- } \\
\text { RATA \& DE } \\
\text { LEEUW, 2013) }\end{array}$ & $\begin{array}{l}\text { CDPs Store } \\
\text { Pick-up HD }\end{array}$ & - & $\begin{array}{l}\text { In-store/ Pick- } \\
\text { up/ Return- } \\
\text { locations }\end{array}$ & - \\
\hline $\begin{array}{l}\text { (WANG ET AL., } \\
\text { 2014) }\end{array}$ & $\begin{array}{l}\text { AHD/RBs/ } \\
\text { CDPs }\end{array}$ & $\begin{array}{l}\text { RBs: Independent RBs at } \\
\text { the garage or home, } \\
\text { delivery box is equipped } \\
\text { with a docking } \\
\text { mechanism, shared RBs }\end{array}$ & RBs/ CDPs & - \\
\hline $\begin{array}{l}\text { (HÜBNER ET AL., } \\
\text { 2016A) }\end{array}$ & $\mathrm{HD} / \mathrm{C} \& \mathrm{C}$ & $\begin{array}{l}\text { HD: Attendance or } \\
\text { unattended/ C\&C: In- } \\
\text { store, attached or solitary }\end{array}$ & In-store Pick-up & Groceries \\
\hline (MURPHY, 2016) & $\begin{array}{l}\text { HD/ WD/ Drop } \\
\text { zone }\end{array}$ & $\begin{array}{l}\text { HD: Attendance or } \\
\text { unattended }\end{array}$ & - & - \\
\hline
\end{tabular}

Hints: CDPs: Collection/Delivery Points - HD: Home Delivery - WD: Work Delivery - C\&C: Click \& Collect - C\&R: Click \& Reserve - AHD: Attended Home Delivery - RBs: Reception Boxes - CP: Collection Points - RC: Return Centers

\subsubsection{Evolution of consumer's shopping behavior in Delivery and Return in Spain}

Nowadays, most retailers (79\%) offer more than two purchase channels (Chatterjee, 2010). Almost $80 \%$ of them offer more than one delivery option (Capper, 2014), and 62\% offer more than one 
return option (Graham Charlton, 2014). Hence, consumers have different options to select for their delivery and return. That's what caused $66 \%$ of consumers to choose a retailer over another due to the fact they have offered more delivery and return options (Robinson, A. 2019). In most cases, consumers prefer to be sent to their preferred location. For instance, data shows that in Spain more than 70\% prefer that the purchased products be sent to their preferred location (IABeCommerce, 2019). This percentage is similar to the USA, but very far from the northern countries of Europe -where only $43 \%$ of individuals wish to receive products at home - (eMarketer, 2020). Besides, it is predicted in Spain delivery to home option grow in 2022 by $89 \%$. (See figure 8 )

Returns of purchased items are expected to cost retailers 550 billion dollars by next year, which is 75 percent more than years prior (eMarketer, 2020). According to Robinson, A. (2019), 36\% of worldwide shoppers find in-store returns convenient and select returns from in-store. Among this portion, $45 \%$ are online shoppers Robinson, A. (2019). Spain is the second country with the most returns to store (5.43\% of the products), after Germany (6.29\% returns) and before the United Kingdom, Italy, and France Robinson, A. (2019). Also, in 2020, it is expected that in-store returns and CRPs to grow around 80\%.

A possible explanation for this can be due to many determining factors that may be influencing the percentages of returns, among which surely the climate of the countries and any psychological characteristics of their inhabitants are not found. The shipping costs and the return conditions offered by the stores are some of the factors that most affect these percentages. Free shipping and returns, for example, are a measure that some stores use to increase sales volume, while at the same time generating a higher percentage of returns.

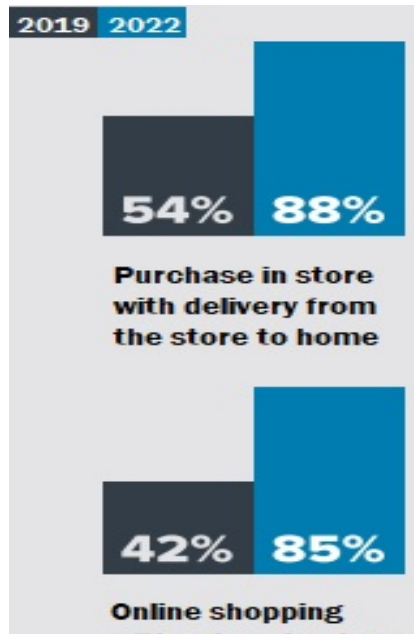

with return to store

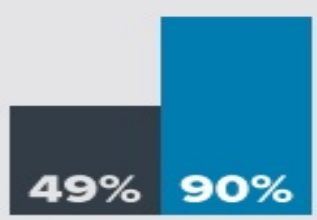

Online shopping with store pickup

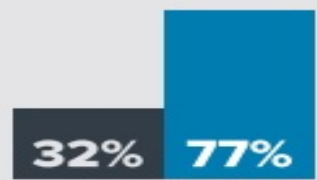

In-Store Purchase with return to post

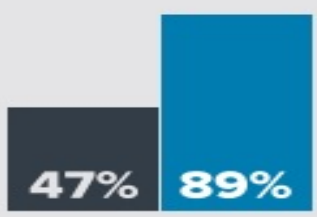

Online shopping with home delivery

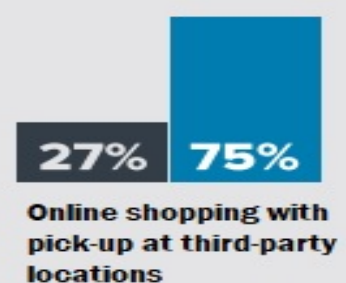

Figure 12 Consumers shopping journey (Source: Zebra (2019))

\subsubsection{Evolution of consumer's shopping behavior in Delivery and Return in Spain for Apparel}

The apparel sector is a powerful and dynamic industry that is recognized as the fastest-growing sector in e-commerce after food and drink (Deloitte, 2018; Raes, 2019). In 2018, the global market size 
of fashion online retailing was approximately 484 billion dollars and it is expected to reach around $\$ 765$ billion by the year 2022 (Raes, 2019). Thus, E-commerce has a greater impact on the fashion market, $27 \%$ of global fashion sales $-8,838$ billion dollars. Not very far from worldwide, during the last years, the sales of the Spanish online apparel sector have not stopped growing. According to Statista (2020) in Spain, in 2019 sales through the internet represented 16\% of the total fashion turnover in the country, 3,587 million dollars. Looking ahead, it is estimated that the increase in the Internet fashion sector will remain around $18 \%$ of total market turnover by 2024 . Hence, it is one of the leading sectors in terms of profitability in Spain. Thus, retailers must understand which services consumers use to receive their orders.

\section{Global Fashion Industry E-Commerce}

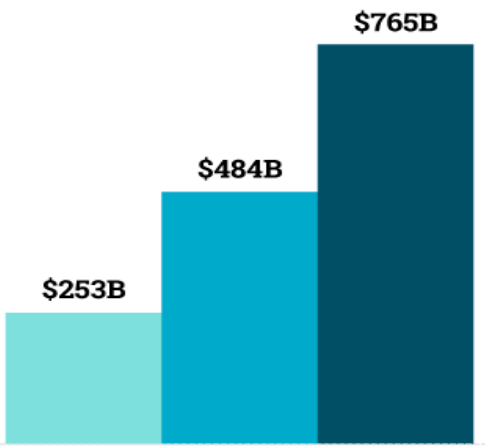

Total online fashion retail sales
2014

2018

$\square 2022$

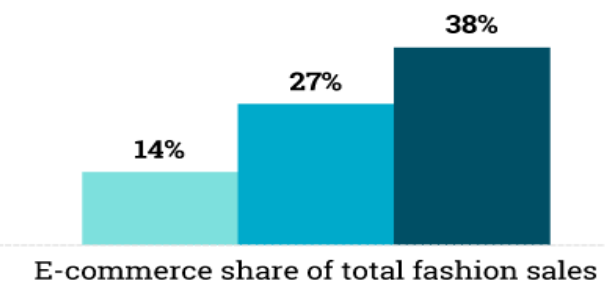

Published on MarketingCharts.com in November 2018 | Data Source: Forrester Research, Inc. (2018)

Based on Forrester Analytics: Online Fashion Retail Forcast, 2017 To 2022 (Global)

Figure 13 Global fashion industry E-commerce (Source: Forrester (2018))

In General, delivery to home and collect in-store are used more often in online shopping globally, since those are the main options offered by retailers (Capper, 2014). Hence, by increasing sales through the internet (38\%), it can be interpreted that home and collect in-store increase almost at the same level. In Spain, as mentioned before, in 2019 sales through the internet represented 16\% of the total fashion turnover in the country and it is estimated to reach around $18 \%$ of total market turnover by 2024 . Hence, it can be interpreted that home and collect in-store delivery be increased by almost $18 \%$. According to Robinson, A. (2019), in Spain, for fashion items, home delivery is the first option among consumers, followed by In-store delivery and collection points. 


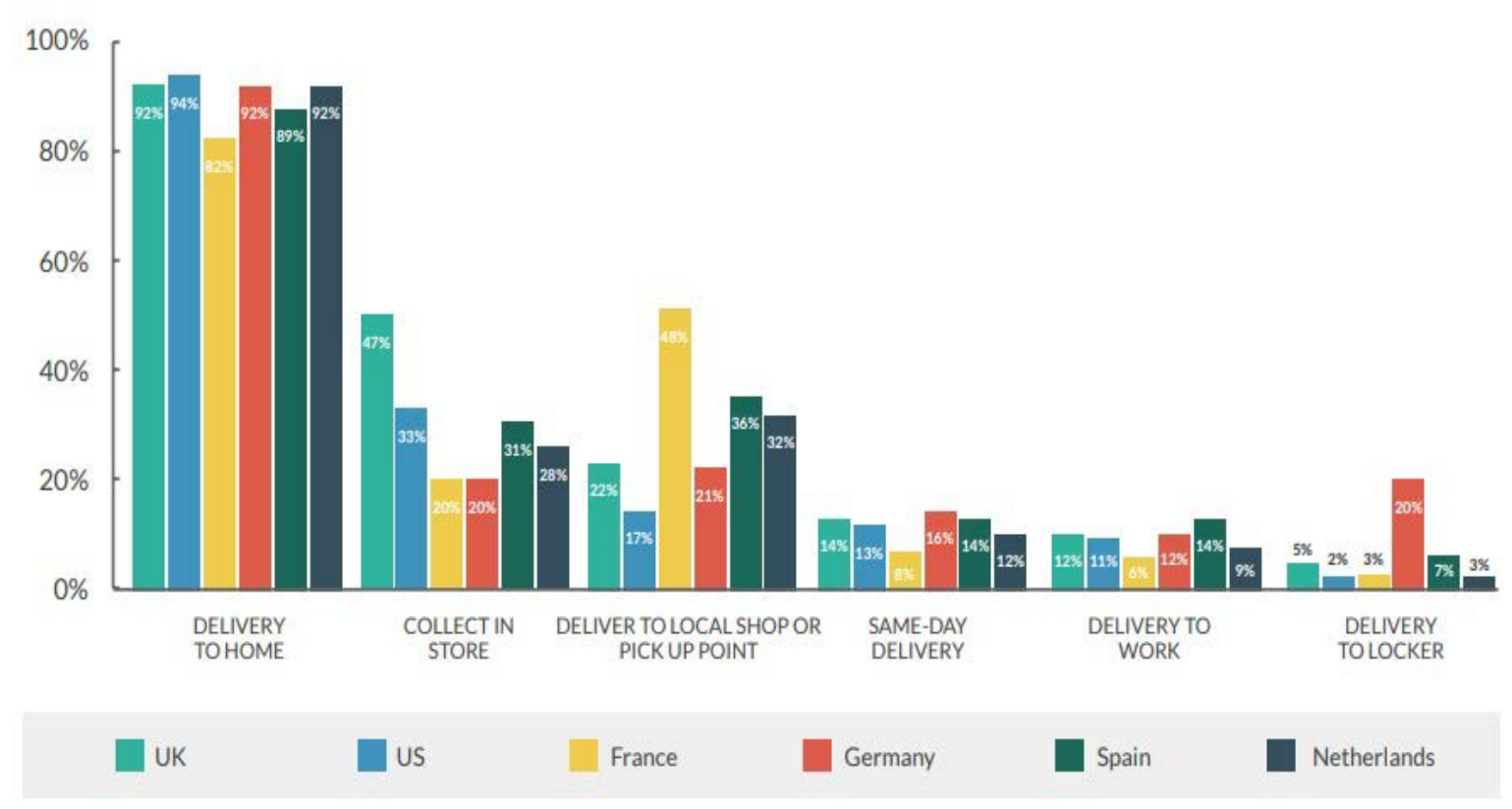

Figure 14 Delivery option adoption in online channel for fashion (Source: Robinson, A. (2019))

In fashion, about $40 \%$ of the products that have been purchased online are returned (Ma, Zhao and Ke, 2020). A possible explanation for this due to the type of products- in this case, fashion- and the circumstances involved in buying them online (i.e., more difficult for fashion retailers to translate the in-store experience to the online environment). Product returns can represent between $2 \%$ and $4 \%$ of the online store's turnover, although it depends a lot on the sector (Ma, Zhao and Ke, 2020). In the case of fashion and textiles, the third most purchased category on the internet billed 7.8 billion dollars in 2019. According to Robinson, A. (2019), in Spain, fashion items are the ones that generate the most returns with respect to their sales (22.71\%), although the percentage of electronic items is higher than the total returns (33.29\%). Moreover, it is expected product returns to reach around 28.65\% by 2022 in Spain (MarketResearch, 2018). Based on the data presented in (Zebra, 2019), from the online purchased product, home returns is the first option among consumers, followed by In-store returns and returns points (See Figure 11). 


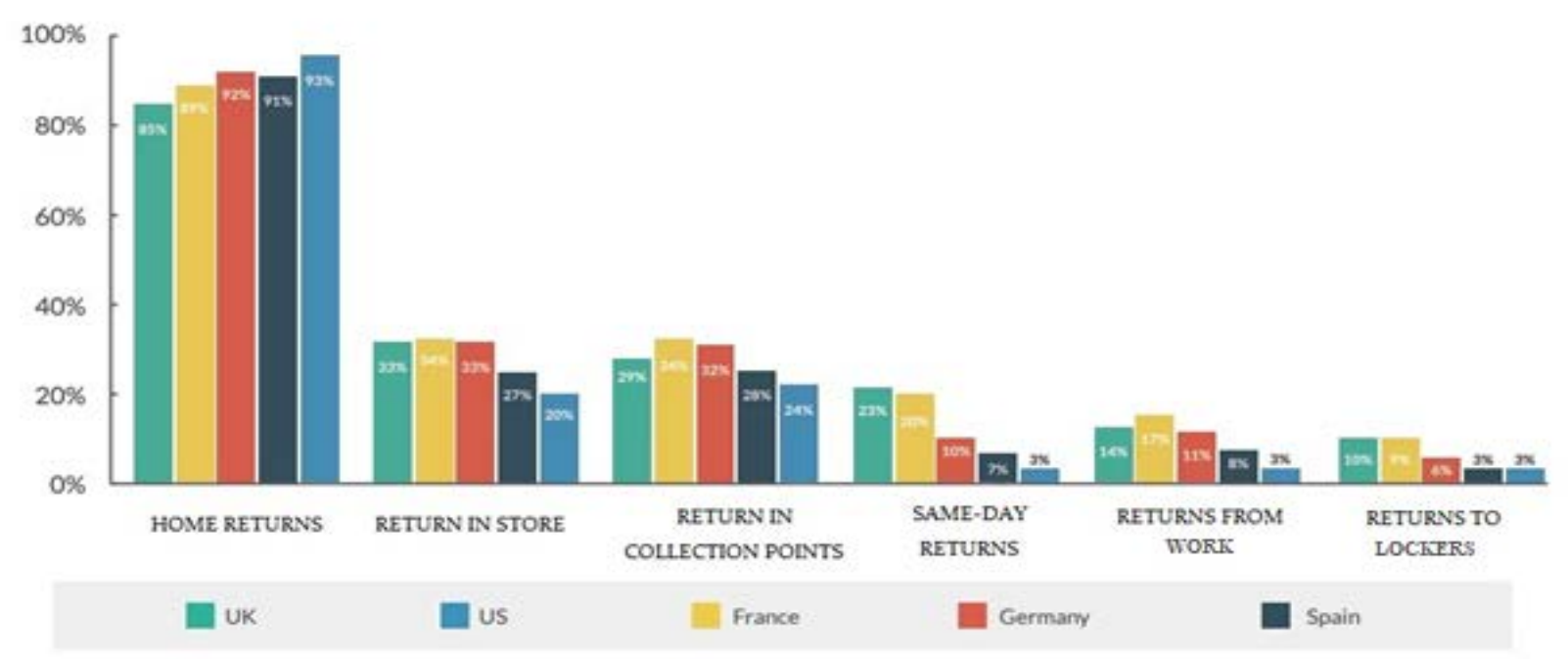

Figure 15 return option adoption in online channel for fashion (Source: Robinson, A. (2019)) 
$46 \mid \mathrm{P}$ a g e 
Chapter 3: Model of consumer's lastmile logistics behavior in the Omnichannel environment 


\subsection{Introduction}

Technology adoption models are a conceptual framework that allows determining and measuring the influence of certain factors on the consumer's behavior. This framework includes concepts from social, cognitive and behavioral psychology, sociology and information systems and its origin comes from Diffusion of Innovations by Rogers (1962). Based on this concept, researchers establish different models with different concepts (TRA, TPB, TAM, etc.) (Rogers \& Shoemaker, 1971). After reviewing previous studies in the same area, this research uses TPB model as the basis for the research. Based on these studies, there are strong supports to apply TPB to this investigation:

- It is an adequate theory for studying human's explanatory behavior and a good predictor in specific contexts (Ajzen, 1991), especially in consumer’s shopping behavior (Pookulangara et al., 2011a).

- The TPB is a simple model, and is parsimonious justification for explaining the determinants of behavior (Pookulangara et al., 2011a).

- The TPB has been used to predict and analyze a wide range of behavior (Sutton et al., 2003; Chetsumon, 2005; Zubair \& Garforth, 2006; Herath, 2010; Altawallbeh et al., 2015; Chipidza et al., 2015) due to be a complete theory in studying behaviors in a different context.

- TPB is superior, since it contemplates specific beliefs (Mathieson, 1991) and it has a compelling empirical record of predicting (Potwarka, 2015).

- Meta-analytic review of the literature shows that, on average, the constructs of the TPB explained $61 \%$ of the variance in behavioral intention and $54 \%$ of the variance in actual behavior for a wide range of shopping behaviors (Pookulangara et al., 2011a).

- $\quad$ TPB is versatile in the sense that various constructs can be added to the model to improve its predictive utility in a given behavioral context (Ajzen, 2015).

- $\quad$ TPB- based research can provide valuable information for practitioners, messages and service strategies to target the specific consequences of a particular event (Potwarka, 2015).

- The model gives a description of the attitudes and beliefs, which determine the behavior, but not other variables that influence components of the TPB (e.g., personality) (Conner \& Armitage, 1998).

However, there are some possible limitations in the TPB both in terms of conceptual and methodological aspects (Bentler \& Speckart, 1979; Sherman, 1980). The following is a summary of the limitations of this theory.

- The model does not consider other effective factors that may influence the intention of behavior such as environmental, situational, or demographic factors.

- The theory assumes a behavior to have a linear decision-making process, and the behavior does not change between the moments when the behavior is carried out. 
- The correct measurement of the underlying beliefs in the model is extremely complex.

- Generally, it only takes into account the direct effects of the factors (Montano \& Kasprzyk, 2015).

Based on the theory selected, two sections shape the structure of this chapter:

- The first section presents a review of the Theory of Planned Behavior, highlighting its origins, its main and relevant factors of the consumer's shopping behavior.

- Finally, at the end of the chapter, the study presents the final model and hypothesizes developed during previous section.

\subsection{The Planned Behavior Theory (TPB)}

The Theory of Planned Behavior (TPB) (Ajzen, 1985, 1988, 1991) appears as an evolution of TRA (Fishbein \& Ajzen, 1975; Ajzen \& Fishbein, 1980) to overcome some limitations such as predicting unconscious or voluntary behaviors (Ajzen, 1988, 1991), or not being under the individual control (Sheppard et al., 1988). Moreover, it aims to predict and explain a wide range of behaviors in terms of a limited set of constructs. In fact, the TPB was developed to incorporate social, cultural, psychological, and economic approaches into the behavioral analysis (Burton-Jones \& Hubona, 2006) and to determine a person's decision to enact a specific behavior (Conner \& Armitage, 1998).

As in TRA, the central element of TPB is the intention of the behavior, as a predictor of the individual's behavior. This intention captures the individual's motivations. However, in TPB, in addition to motivational factors, other non-motivational factors are considered such as the existence of necessary resources (Ajzen \& Driver, 1991). Considering the perceptions of these factors in the prediction of behavior is relevant and it allows to extend the applicability of the theory to capture more complex behaviors (Conner \& Armitage, 1998). Different authors have suggested a new factor that reflects "the perceived control” by the individual on the behavior. They have defined it as facilitating factors for developing the behavior (Triandis, 1977), as the existence of a "context of opportunity" to develop a certain action (Sarver, 1983), as the existence of the necessary resources to perform an action (Liska, 1984), and as a control factor over the development of the action. When the behavior is not under the conscious control of the individuals, there are many situations in which the individual needs to have certain skills, or they may have to face certain types of unforeseen events, which could ultimately interfere with the intention of the individual's behavior (Ajzen, 1985; Ajzen \& Madden, 1986). Figure below shows the TPB schematically. 


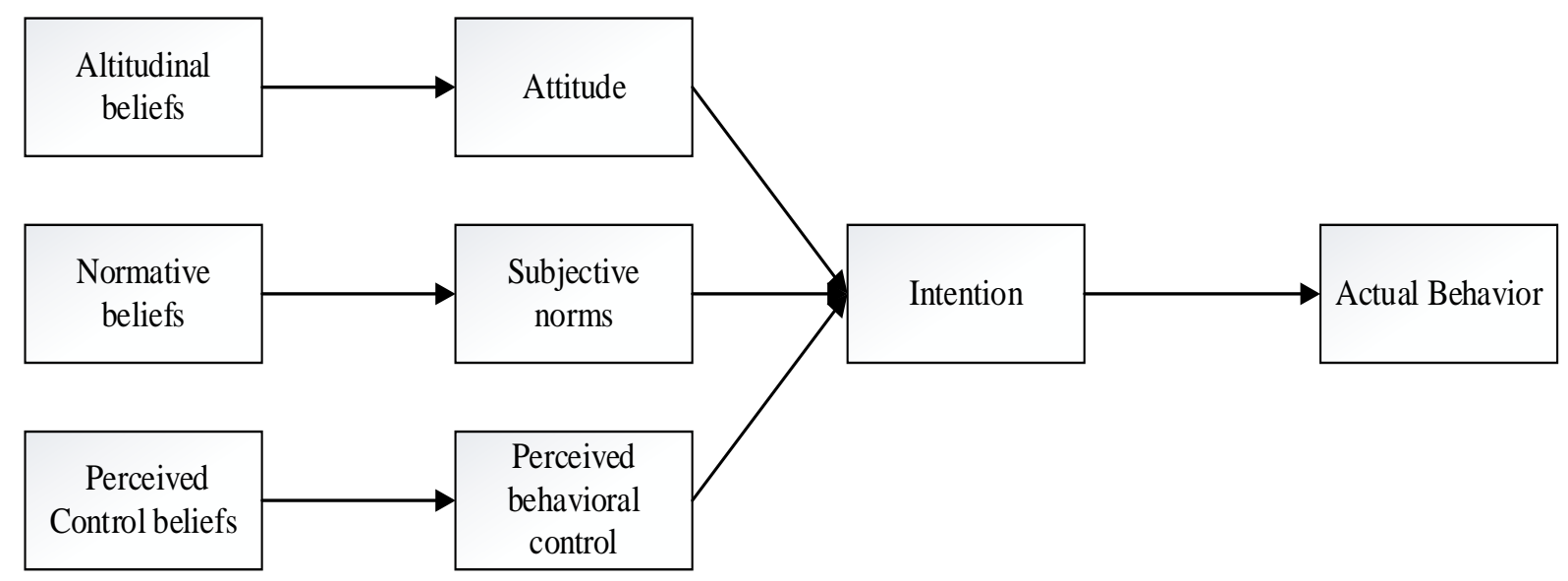

Figure 16 The Theory of Planned Behavior (TPB) (Source: Ajzen, (1985, 1988, 1991))

\section{2. 1. Main factors}

According to Ajzen (1991), the actual behavior (B) of human derives from behavioral intention (BI) - the likelihood an individual engages in the behavior of interest. This intention captures the individual's motivations. Based on the model proposed by Ajzen (1991) behavioral intention is a function of three components: attitude toward a behavior, subjective norms (SNs) and perceived behavioral control (PBC) which in the following will be explained in more detail.

Behavioral intentions refer to the subjective probability that a person will engage in a specified behavior (Fishbein \& Ajzen, 1975). Intentions contain all the motivation factors that affect the behavior and indicate how much effort a person will use in engaging in a specific behavior (Herath, 2010). Intentions and behavior are held to be strongly related when measured at the same level of specificity in relation to the action, target, context, and time frame (Fishbein \& Ajzen, 1975). The TPB predicts that the stronger the intention to perform a behavior by a person, the more likely the person will engage in that behavior (Fishbein \& Ajzen, 1975). In the context of the area of this study, the intention of selecting a last-mile logistics option can be defined as the likelihood a consumer select an option in delivery or return - Sections 2.2.1.2. and 2.2.1.4. explain the main last-mile logistics options: Home (preferred location) delivery, In-store delivery, Collection delivery points (CDPs), Home (preferred location) return, In-store return, Collection return points (CRPs). Based on this categorization, this study develops the following hypothesizes. (option ${ }_{\mathrm{a}}$ : Home delivery, option $\mathrm{b}_{\mathrm{b}}$ : In-store delivery, option ${ }_{\mathrm{c}}$ : Collection delivery points (CDPs), option ${ }_{\mathrm{d}}$ : Home return, option $\mathrm{e}_{\mathrm{e}}$ : In-store return, option ${ }_{\mathrm{f}}$ : Collection return points (CRPs)).

Attitude towards behavior (AB) refers to "disposition to respond favorably or unfavorably to an object, institution, or event” (Ajzen, 2005). Attitude is mentioned as one of the most important concepts in social psychology (Manstead et al., 1995). A person's attitude contains multiplicative beliefs related to the behavior, the person's subjective evaluation or weighted importance of the beliefs attribute (Herath, 2010). The TPB predicts that when a person perceives the behavior as favorable, there is a 
likelihood that he or she will perform the behavior. In fact, according to Fishbein and Ajzen (1975), attitude toward the behavior has long been shown to have a strong, direct, and positive influence on behavioral intentions. In the last-mile logistics, attitude toward last-mile logistics option selection is defined as the consumer's evaluation of the desirability of selecting an option in delivery or return. Using the deductive logic, a favorable attitude is likely to encourage consumer's intention to select a last-mile logistics option. Since the link between attitudes and behavioral intentions is fundamental and it is a strong, direct, and positive (Taylor \& Todd, 1995); hence, it is believed that also in last-mile logistics the link between attitudes (AB) and behavioral intentions (BI) be strong, direct, and positive.

$\mathrm{H} 1_{\mathrm{a}, \mathrm{b}, \mathrm{c}, \mathrm{d}, \mathrm{e}, \mathrm{f}}$ : Attitude has a positive influence with respect to option ${ }_{\mathrm{a}, \mathrm{b}, \mathrm{c}, \mathrm{d}, \mathrm{e}, \mathrm{f}}$ selection behavior intention.

Subjective norms (SNs) refer to "the person's perception that most people who are important to her/him think she/he should or should not perform the behavior in question” (Fishbein \& Ajzen, 1975). The SNs particularly include the tendency of an individual to engage or not to engage in a behavior as seen from persons who are important to her or him. As a result, the theory predicts that if the person perceives significantly that others would encourage such a behavior, there is a likelihood that she or he will engage in the behavior (Herath, 2010). In fact, according to Fishbein and Ajzen (1975), subjective norms are known as a direct and positive construct of behavioral intentions. In the last-mile logistics, subjective norms can be defined as the consumer's perception from others to select or not select a lastmile logistics option. Using the same deductive logic, subjective norms are likely to affect consumer's intention to select a delivery or return option. Since the link between subjective norms (SNs) and behavioral intentions (BI) is fundamental and it is direct and positive (Taylor \& Todd, 1995); hence, it is believed that also in last-mile logistics the link between subjective norms (SNs) and behavioral intentions (BI) be direct, and positive.

$\mathrm{H} 2_{\mathrm{a}, \mathrm{b}, \mathrm{c}, \mathrm{d}, \mathrm{e}, \mathrm{f}}$ : Subjective norm has a positive influence with respect to option ${ }_{\mathrm{a}, \mathrm{b}, \mathrm{c}, \mathrm{d}, \mathrm{e}, \mathrm{f}}$ selection behavior intention.

Perceived behavioral control (PBC) is an additional construct proposed by Ajzen and Driver (1991) to capture non-volitional actions. It represents perceptions of control, not actual control, and is about the presence of factors that may facilitate or impede the performance of the behavior (Pookulangara et al., 2011a). Moreover, it is defined as "the person's perceptions of the ease or difficulty in performing the behavior of interest” (Ajzen, 1991). Specifically, PBC implies that, the existence of constraints can hamper intentions to perform behavior and its actual performance (Altawallbeh et al., 2015). For instance, the greater a person perceives that she or he has control, the more likely she or he will intend to engage the behavior (Fishbein \& Ajzen, 1975). In fact, according to Fishbein and Ajzen (1975) 
perceived behavioral control has a direct and positive effect on behavioral intentions. In the context of this study, perceived behavioral control can be defined as a factor that may facilitate or impede the selection of a last-mile logistics option. Using the same deductive logic, the possibilities of selecting a delivery or return option at the end of consumers' shopping activities should increase the level of control that consumers perceive. Since the link between perceived behavioral control and behavioral intentions is fundamental and it is direct and positive (Taylor \& Todd, 1995); hence, it is believed that also in lastmile logistics the link between perceived behavioral control (PBC) and behavioral intentions (BI) be direct, and positive.

$\mathrm{H} 3_{\mathrm{a}, \mathrm{b}, \mathrm{c}, \mathrm{d}, \mathrm{e}, \mathrm{f}}$ : Perceived behavioral control has a positive influence with respect to option $\mathrm{a,b,c,d,e,f}$ selection behavior intention.

\subsubsection{Relevant factors}

Following the TPB decomposition logic, each of the behavioral intention's components is determined by fundamental belief structures. By this, attitude towards the behavior $(A B)$ is set by attitudinal (behavioral) beliefs. Subjective norm (SN) is equated with normative beliefs. And perceived behavioral control (PBC) is formed by control beliefs (Francis et al., 2004). These components are expected to allow to produce more parsimonious and a better understanding of the individual's intention about the behavior (Pookulangara et al., 2011a). Hence, the basis of the theory is based on beliefs that play a major role in predicting intentions (Herath, 2010). Thereby, identifying these beliefs, especially salient ones, it is necessary to understand consumer's shopping behavior. Therefore, to investigate consumer's last-mile logistics option behavior based on TPB, attitudinal beliefs, normative beliefs, and perceived behavioral control beliefs are explained as a starting point.

\subsubsection{Attitudinal Beliefs}

Attitudinal beliefs represent assessments to perform a specified behavior (Ajzen, 2005). This positive or negative assessment is a complex process that depends on characteristics of the beliefs (Ajzen \& Fishbein, 1980) and it is derived by consumer's motivation. Decomposing the consumer's motivation structure can assist in exploring these characteristics, which play a considerable role in determining an individual's attitude towards a behavior (Pituch \& Lee, 2006). Westbrook and Black (1985) used Tauber's (1972) studies to categorize all motivations into utilitarian and hedonic. Since then, several marketing studies have dedicated their attention to consumer's shopping behavior more holistically from both utilitarian and hedonic perspectives (Babin et al., 1994; Childers et al., 2001; Konus et al., 2008; Pookulangara et al., 2011a). However, this study excludes hedonic motivations due to the fact that marketing reports explicitly state that in the last-mile logistics, consumers are not influenced by hedonic motivations (Madlberger, 2005; Okholm et al., 2013; Zarei et al., 2020). This could be due to the fact that, in the shopping process, consumers perceive last-mile logistics as a task which it needs to be accomplished (Zarei et al., 2020). On the other hand, in the utilitarian aspect, 
numerous studies have identified utilitarian motivation factors as important factors in consumer shopping behavior (e.g., Pookulangara et al., 2011a; Mikalef et al., 2013). Hence, it is necessary to consider utilitarian motivation in this study.

Utilitarian motivation shows that the shopping process is initiated by a mission and perceiving benefit relies on whether or not this mission is completed efficiently (Doong et al., 2012). Since consumers seek to perceive maximum benefit in a mission like a shopping; they evaluate the mission by instrumental value (Doong et al., 2012). This instrumental value can be either Monetary or Nonmonetary value (e.g., Hsu \& Chiu, 2004; Balasubramanian et al., 2005; To et al., 2007; Mikalef et al., 2013).

\subsection{Monetary costs}

The monetary costs refer to the consumer's perception regarding the price of the goods or services offered by the retailers. Before, retailers establish pricing policies in different channels to encourage or discourage the use of the different channels (Keaveney, 1995; Jiang \& Rosenbloom, 2005); however, in the new era of retailing, Omnichannel strategy, products' prices are equal in every channel. Hence monetary costs are now closer to transaction costs such as transportation costs (Chintagunta et al., 2012).

According to Chatterjee (2010), transportation costs play an important role in the consumer's shopping decision. Transportation cost consists of both fixed and variable costs (Chintagunta et al., 2012). Huang and Oppewal (2006) state that fixed costs are independent and remain in the same way for any order that is placed by consumers (e.g., delivery charges or parking charges) whereas the variable costs depend on other activities (e.g., traveling cost to the physical store or petrol consumption). Since monetary costs can be varied greatly in different last-mile logistics options (e.g., going to store by a car and collect the product from a nearby store or going to nearby collection points without using car), consumers may - based on the cost sensitivity and their perception, select different last-mile logistics option.

\section{Relationship between monetary cost and other factors:}

After reviewing previous studies, since no study has investigated in our context, this study uses previous preliminary literature in channel selection. In the preliminary literature, researchers consider home/office delivery or return as the only option for online shoppers and stores for offline shoppers. Therefore, this study uses online shopping as the proxy for home/office delivery and return option and offline shopping as the store delivery and return.

Based on this proxy, a review of previous studies is conducted. The previous studies show the existence of a negative relationship between the monetary costs and the attitude or intention to channel selection (Delafrooz et al. 2009; Yu et al. 2011; Wang et al., 2016; Xu \& Jackson, 2019). 
According to Venkatesh et al. (2012), there is a positive relationship between price value and usage of a channel, this means that by increasing the price value in a certain channel, the probability that the consumer will use that channel is higher than other channels.

Despite this, in certain studies such as Balasubramanian et al. (2005) and Yu, U. J. et al. (2011), the relationship between price value and usage of a channel is showed to be negative. In this case, the higher consumers perceive price value in the preferred purchase channel the lower they tend to select that certain channel.

Moreover, Balabanis \& Reynolds (2001) and Wang et al. (2016) claim that perceive cost can influence consumers' attitude toward channel preference. This situation interprets that by the charges in shipping and returning conditions - for example, by lowering the costs, it could change the consumer's attitude toward selecting that specific last-mile logistics option.

Therefore, it is believed that:

$\mathrm{H} 4_{\mathrm{a}, \mathrm{b}, \mathrm{c}, \mathrm{d}, \mathrm{e}, \mathrm{f}}$ : Monetary costs have a negative influence with respect to attitude toward option ${ }_{\mathrm{a}, \mathrm{b}, \mathrm{c}, \mathrm{d}, \mathrm{e}, \mathrm{f}}$ selection.

$\mathrm{H} 5_{\mathrm{a}, \mathrm{b}, \mathrm{c}, \mathrm{d}, \mathrm{e}, \mathrm{f}}$ : Monetary costs have a negative influence with respect to option ${ }_{\mathrm{a}, \mathrm{b}, \mathrm{c}, \mathrm{d}, \mathrm{e}, \mathrm{f}}$ selection behavior intention.

Table 7 Summary of the works which show relationship between monetary cost \& other factors

Relationship

Outcome

Reference

\begin{tabular}{|l|c|c|}
\hline $\begin{array}{l}\text { Monetary costs } \rightarrow \text { Attitude toward selecting a } \\
\text { channel }(-)\end{array}$ & Supported & $\begin{array}{c}\text { Balabanis \& Reynolds } \\
(2001)\end{array}$ \\
\hline $\begin{array}{l}\text { Monetary costs } \rightarrow \text { Intention of selecting a channel } \\
(-)\end{array}$ & Supported & Balasubramanian et al.(2005) \\
\hline $\begin{array}{l}\text { Monetary costs } \rightarrow \text { Attitude toward using a channel } \\
(-)\end{array}$ & Supported & Delafrooz et al. (2009) \\
\hline $\begin{array}{l}\text { Monetary costs } \rightarrow \text { Intention of selecting a channel }(- \\
\text { - }\end{array}$ & Supported & Yu et al. (2011) \\
\hline Monetary costs $\rightarrow$ Intention of using a channel $(+)$ & Supported & Venkatesh et al. (2012) \\
\hline $\begin{array}{l}\text { Monetary costs } \rightarrow \text { Attitude toward selecting a } \\
\text { channel }(-)\end{array}$ & Supported & Wang et al. (2016) \\
\hline Monetary costs $\rightarrow$ Intention of selecting channel $(+)$ & Partially supported & Xu and Jackson (2019) \\
\hline
\end{tabular}

\subsection{Convenience (Non-Monetary)}

Convenience in the shopping process generally refers to non-monetary costs such as time, effort (Huang and Oppewal, 2006). Given that consumers always tend to reduce costs in every decision; hence they tend to reduce costs of effort and time involved in shopping activities. Due to this fact, many researchers have used these dimensions in several areas to capture consumers' perceived convenience in shopping such as e-commerce, multichannel, etc. (Childers et al., 2001; Hofacker, 2001; Schröder \& Zaharia, 2008; Ganesh et al., 2010). 
In the effort dimension, according to Bosnjak et al. (2007) reducing costs of effort -saving effort- can be either physical or psychological. In the physical aspect, consumers seek an alternative option to reduce physical effort while they are in the shopping process (Chatterjee, 2010). For example, for offline shoppers in addition to the necessity of putting physical effort associated with transportation, there is a physical effort linked to the body activity of handling the products in the store. This includes taking the products from the shelves, loading them onto the cart, putting them on the conveyor belt and then in bags and getting back to their location. However, online shoppers avoid any physical effort related to the handling of the products, transportation, etc. (Chintagunta et al., 2012). In terms of the psychological aspect, which refers to the whole planning process that is involved in the shopping trip, consumers tend to eliminate the pressure produced by the effort dedicated to the purchase (e.g., effort from information searching and comparing between alternatives) (Frasquet et al., 2015). Consumers prefer to have an easy evaluation of alternatives and ease of making decisions during the purchase process. Hence, most of the time consumers prefer to focus only on one option and cut off other options (Konus et al., 2008) in order to reciprocally minimize mental effort invested in buying (Schröder \& Zaharia, 2008). In the context of this study, consumers may select different delivery or return options and ignore other available last-mile logistics options due to these physical and psychological efforts in order to perceive convenience. According to Chintagunta et al. (2012), consumers perceive convenience while selecting delivery to home or return from home because they can avoid carrying heavy orders from the company. In the offline channel, consumers perceive convenience when they receive their items after the payment due to the fact that, they prefer to have an ease of making decisions during the purchase process (Konus et al., 2008).

In the time dimension, consumers seek a way to save more time and thereby perceiving more convenience in their shopping journey (Schröder \& Zaharia, 2008). A clear example can be a single visit to an online channel and purchasing via that channel. According to Morganosky and Cude (2000), the main reason that consumers buy online is time-saving. The previous literature suggests that online shopping saves the time of purchase by shorter waiting time, less travel time, less time spent on planning the purchase (Chintagunta et al., 2012), and less lead time of receiving (Modak \& Kelle, 2019). In an online channel, the time to go and return from the store is zero and the time spent on searching and selecting products (once the structure of the website is known) is lower than an offline channel, and consumers can even use automated shopping lists that allow them to purchase their needs with one click. However, in delivery and return stages, an online channel it is more time-consuming than an offline one and thereby perceiving more convenience (Hübner et al., 2016) -i.e., consumers normally receive the items immediately after payment; hence, they perceive less time-consuming than waiting to be delivered home or other options. In return, consumers may return their products to the store or nearby returning points, because it is less time-consuming than other options (Moshrefjavadi et al., 2012). 
However, in return from home, consumers have to wait until the purchased item is collected (Schröder \& Zaharia, 2008).

Besides these dimensions, Schröder and Zaharia (2008) add flexibility to the convenience dimensions where, consumers, by avoiding time and location constraints (e.g., opening hours, retailers' accessibility), perceive convenience. According to Jiang et al. (2013), consumers, by avoiding time and location constraints (e.g., opening hours, time flexibility in consumer's services, retailers' accessibility (i.e. website, physical stores)), obtain psychological benefits in the shopping process. In delivery the same thing may happen, online shoppers who are not at home seek an alternative option in order to receive their orders (e.g., collection points). However, in the offline channel, consumers do not have an alternative option (Rai et al., 2019). Hence, they receive their orders after the purchase stage. In return, either in the online channel or the offline channel, consumers who are not at home in most of the cases or cannot stay home, seek an alternative option instead of return from home to return their purchased item (Rai et al., 2019).

As a result of these dimensions, consumers consider these dimensions in order to experience less inconvenience in the delivery and return stage. For instance, compared with in-store and consumer's location delivery and return, consumer's location delivery and return offer greater convenience by providing less movement and effort in the consumer's shopping journey. However, the consumer's location delivery and return have its inconveniences due to the waiting time for a delivery that does not arrive on a specific day or time (Ferrand et al., 2008). Thus, it is believed that convenience can particularly affect the consumer's last-mile logistics options selection in the shopping journey.

\section{Relationship between convenience and other factors:}

By considering the proxy of channel selection, research is carried out regarding the relationship between convenience and last-mile logistics preference. In general, after reviewing the previous studies, the relationship between convenience with the intention of selecting the channel and attitude toward selecting in the purchasing process was positive. Examples of these studies are: Hsu et al., (2012), Wang et al. (2016) and Kim et al. (2019).

Although the majority of the studies coincide in establishing a positive relationship between the perceived convenience and the intention of using a channel, it is possible to find some exceptions (Baker et al., 2002; Pookulangara et al. 2011a). In fact, the existence of a negative relationship between these factors, it depends on the definition of the factors. For instance, the greater consumers invest in perceiving convenience, the lower the probability that consumers use that certain channel to carry out their activities (Verhoef et al., 2007; Shirdastian \& Laroch, 2017).

Regarding the relationship with other factors, no works are found between perceive convenience and other factors in channel usage preference at any stage, pre-purchase or purchase. 
It can be interpreted that convenience is one of the principal factors that influence consumers' preferences in the shopping process. Therefore, it is believed that:

$\mathrm{H6}_{\mathrm{a}, \mathrm{b}, \mathrm{c}, \mathrm{d}, \mathrm{e}, \mathrm{f}}$ : Convenience has a positive influence with respect to attitude toward option ${ }_{\mathrm{a}, \mathrm{b}, \mathrm{c}, \mathrm{d}, \mathrm{e}, \mathrm{f}}$ selection.

$\mathrm{H} 7_{\mathrm{a}, \mathrm{b}, \mathrm{c}, \mathrm{d}, \mathrm{e}, \mathrm{f}}$ : Convenience has a positive influence with respect to option ${ }_{\mathrm{a}, \mathrm{b}, \mathrm{c}, \mathrm{d}, \mathrm{e}, \mathrm{f}}$ selection behavior intention.

Table 8 Summary of the works which show relationship between convenience \& other factors

\begin{tabular}{|c|c|c|}
\hline Relationship & Outcome & Reference \\
\hline $\begin{array}{l}\text { Convenience } \rightarrow \text { Intention of selecting a channel(- } \\
\text { ) }\end{array}$ & Supported & Baker et al. (2002) \\
\hline $\begin{array}{l}\text { Convenience } \rightarrow \text { Intention of selecting channel (- } \\
\text { ) }\end{array}$ & Partially supported & Verhoef et al. (2007) \\
\hline $\begin{array}{l}\text { Convenience } \rightarrow \text { Attitude toward the channel } \\
\text { selection }(+)\end{array}$ & Supported & Pookulangara et al. (2011a) \\
\hline Convenience $\rightarrow$ Attitude toward channel use $(+)$ & Supported & Hsu et al. (2012) \\
\hline $\begin{array}{l}\text { Convenience } \rightarrow \text { Attitude toward selecting a } \\
\text { channel }(+)\end{array}$ & Partially supported & Wang et al. (2016) \\
\hline $\begin{array}{l}\text { Convenience } \rightarrow \text { Intention of channel selecting (- } \\
\text { ) }\end{array}$ & Supported & Shirdastian \& Laroch (2017) \\
\hline $\begin{array}{l}\text { Convenience } \rightarrow \text { Intention of selecting channel } \\
(+)\end{array}$ & Supported & Kim et al. (2019) \\
\hline
\end{tabular}

\subsection{Perceived risk (Non-Monetary)}

Similar to convenience, perceived risk is a part of non-monetary and such as other activities, shopping also involves some risks due to the fact that consumers cannot predict the consequences perfectly (Chiu et al., 2014). These unpredictable consequences make consumers perceive uncertainty while they are in a shopping process and since consumers do not like to perceive an uncertain and ambiguous situation, they tend to avoid such situations (Hofstede, 1980). Whereas perceiving uncertainty influences consumers' confidence in their shopping decision and thereby in the shopping behavior, it is important to understand the meaning and the dimensions of risk in our area of research. To do so, first finding a proper definition of the risk in the shopping behavior seems essential. Prior studies on consumer shopping research define the perceived risk as "the possibility of bringing about misfortune or loss while uncertainty is associated with those things that are not able to be accurately known or predicted” (Lalwani et al., 2006), which potentially inhibit consumer's action (Pavlou \& Fygenson, 2006; Gensler et al., 2012). The same as other factors, this factor is a multidimensional construct and consists of: time, performance, financial and security/privacy (Liu \& Wei, 2003; Schoenbachler \& Gordon, 2002; S. Wang et al., 2014).

According to Hoyer et al. (2012) time risk reflects "uncertainties about the length of time that must be invested in buying”. Consumers perceive the risk of time in the shopping process due to the probability 
of wasting their valuable time either before or after the purchasing stage (Wang et al., 2014). Risk of time perception before the purchasing stage normally happens when there is a probability of losing time in seeking information from a website (e.g., navigation and order submission) (Littler \& Melanthiou, 2006) or from a physical store (Bezes, 2016). Hence, consumers in order to avoid this risk of time perception, tend to change the shopping behavior by changing their shopping channel (Bezes, 2016). In the after-purchase stage, consumers tend to perceive risk of time mostly in online channels. This is due to the loss of time and inconvenience incurred because of the delays in receiving or returning the purchased items, or the difficulty of navigating the items in delivery and return (Lee, 2009) or due to the increased uncertainty in delivery and return spot time (Xu et al., 2011). This uncertain delivery includes either failing to deliver the product by online stores or to deliver with delay (Chiu et al., 2014). In fact, delivery reliability, efficiency, and punctuality are determinants of this perception (Wang et al., 2014). In an offline channel for the after-purchase stage, because consumers normally receive the items immediately after payment, they tend to perceive less time of risk than other cases. Even this perception can be narrowed to zero. Likewise, in return, consumers usually tend to return their products to the store, because their risk of time perception is less than returning via an online channel (Moshrefjavadi et al., 2012). This can be justified the same as in offline delivery where consumers are capable of returning their items immediately.

Another dimension is performance risk, also known as quality risk (Janakiraman \& Niraj, 2011) and can be defined as "the probability that a purchased product may result in a failure to function as expected" (Chiu et al., 2014). The risk of performance also can be perceived when consumers fear that online stores may abuse their credit cards or fail to deliver the desired benefits (Chou et al., 2016). Hence, consumers in order to reduce performance risk, tend to substitute online channels for offline channels (Lim et al., 2012). This risk of performance is not only perceived from the pre-purchase and purchase stage. In fact, Cunningham et al. (2005) argue that the risk of performance perception is prevalent at all stages of the consumer's shopping journey. According to Schröder and Zaharia (2008) in the after-purchase stage, consumers perceive the risk of performance due to the losses incurred by malfunctions in delivery and return. Consumers are often apprehensive about the correctness and the quality of the delivery (Schröder \& Zaharia, 2008). Thus, in order to minimize this performance risk perception, consumers tend to select the one that its risk of performance is perceived less such as instore delivery. Consumers also may experience the same risk in return due to poor service after purchase (Schröder \& Zaharia, 2008). They need to be assured that they could return the orders and get back their money if they feel that they have not received what they want. Since return policies are different in each option, consumers may select a return option that perceives less performance risk such as in-store return and thereby perceives less risk.

Financial risk arises when consumers feel "monetary loss in purchase” (Wang et al., 2014). Numerous studies show the influence of the perceived financial risk in consumer's shopping behavior, especially 
in online shopping. Considering the fact that in online shopping, particularly in clothing, the purchased items are not received after the purchase stage, there will be a potential monetary loss for the afterpurchase stage Lee (2009). In fact, Frasquet et al. (2015) explain that many consumers are afraid of losing money or feel insecure about getting their money back in the return process, which mostly occurs in the online purchases. For instance, consumers afraid that they do not receive their order if they select pick-up points (e.g., might be stolen) or carrier loses or damages their purchased item. Hence, they may select other last-mile logistics options in order to avoid this financial risk. In addition to this concept, consumers worry about "hidden costs associated with returning, maintaining products, and lack of warranty in case of faults” in the post-purchase stage (Chiu et al., 2014). Consumers fear that if they select location return or returns points, the purchased order be lost or damaged. Hence, consumers tend to change their attitude in the post-purchase stage (Lim et al., 2012).

Last but not least in risk dimensions is security/privacy risk which refers to "a potential loss due to fraud or fail to keep the personal information safe" Lee (2009). Consumers with the higher fear perception of losing their security/privacy are more likely to change their behavior and look for a way to avoid this risk than other consumers (Oomen \& Leenes, 2008). According to Bezes (2016), consumers who perceive higher security/privacy risk in one channel will more likely change their shopping channels. This high security/privacy risk is due to the fear of losing inestimable information (Wang et al., 2014) or the inability to fully follow the shopping process in one channel (Chiu et al., 2014). In the postpurchase stage, last-mile logistics, the same behavior may happen, and consumers may change their attitude. For instance, consumers in order to be anonymity while collecting or returning their orders, may select collection points. Also, consumers may select in-store due to the fact that they are afraid their personal information be used by other options, especially in collection points Huang \& Oppewal (2006).

As a result of these dimensions, consumers consider these dimensions in order to perceive less risk in last-mile logistics. As mentioned above, consumers fear that if they select a location to return or returns points, the purchased order be lost or damaged. Hence, consumers tend to change their attitude in the post-purchase stage (Lim et al., 2012). On the other hand, consumers fear if they select home delivery or return from home that they lose time because of the delays in receiving or returning (Lee, 2009) or due to the increased uncertainty in delivery and return spot time (Xu et al., 2011). Thus, it is believed that perceived risk can particularly affect the consumer's last-mile logistics options selection in the shopping journey.

\section{Relationship between perceived risk and other factors:}

By considering the proxy of channel selection, research is carried out regarding the relationship between perceived risk and last-mile logistics preference. After reviewing the previous studies, the majority state 
that there is a negative relationship between the perceived risk and the attitude toward selecting a channel (Huang \& Oppewal, 2006; Moshrefjavadi et al., 2012; Chou et al., 2016).

Unlike other factors, there are few studies that have studied perceived consumers risk related to consumer's attitudes and consumer's intentions in different delivery options. As an example, Zhou, Min, et al. (2020) study show that for selecting CDPs, perceived risk negatively affects consumer's intention or Wang et al. (2014) demonstrate that for selecting a last-mile delivery option, there is a negative influence toward consumer's attitude.

Regarding the relationship with other factors, no works are found between perceived risk and other factors in channel usage preference at any stage, pre-purchase, purchase or post-purchase.

Therefore, it is believed that:

$\mathrm{H} 8_{\mathrm{a}, \mathrm{b}, \mathrm{c}, \mathrm{d}, \mathrm{e}, \mathrm{f}}$ : Perceived risk has a negative influence with respect to attitude toward option $_{\mathrm{a}, \mathrm{b}, \mathrm{c}, \mathrm{d}, \mathrm{e}, \mathrm{f}}$ selection.

$\mathrm{H} 9_{\mathrm{a}, \mathrm{b}, \mathrm{c}, \mathrm{d}, \mathrm{e}, \mathrm{f}}$ : Perceived risk has a negative influence with respect to option ${ }_{\mathrm{a}, \mathrm{b}, \mathrm{c}, \mathrm{d}, \mathrm{e}, \mathrm{f}}$ selection behavior intention.

Table 9 Summary of the works which show relationship between perceived risk \& other factors

Relationship

\begin{tabular}{|l|c|c|}
\hline $\begin{array}{l}\text { Perceived risk } \rightarrow \text { Attitude toward using a channel } \\
(-)\end{array}$ & Supported & Hsu and Chiu (2004) \\
\hline $\begin{array}{l}\text { Perceived risk } \rightarrow \text { Intention of selecting a channel } \\
(-)\end{array}$ & Partially supported & Huang and Oppewal (2006) \\
\hline $\begin{array}{l}\text { Perceived risk } \rightarrow \text { Attitude toward using a } \\
\text { channel(-) }\end{array}$ & Supported & Lee (2009) \\
\hline $\begin{array}{l}\text { Perceived risk } \rightarrow \text { Intention of selecting a channel } \\
(-)\end{array}$ & Supported & Moshrefjavadi et al. (2012) \\
\hline Perceived risk $\rightarrow$ Intention of channel use (-) & Partially supported & Chiu et al. (2014) \\
\hline $\begin{array}{l}\text { Perceived risk } \rightarrow \text { Attitude toward the last mile } \\
\text { selection (-) }\end{array}$ & Supported & Wang et al. (2014) \\
\hline Perceived risk $\rightarrow$ Intention of selecting CDPs (-) & Supported & Zhou, Min, et al. (2020) \\
\hline
\end{tabular}

\subsubsection{Normative beliefs}

According to TPB, normative beliefs characterize subjective norms. They reflect whether specific referent groups or individuals think a person should or should not engage in a behavior, and by that person's wishes to comply with these particular references (Ajzen, 1991; Ajzen \& Fishbein, 2000). According to previous literature, subjective norm has the ability to influence the consumer's shopping behavior (Davis et al., 1989; Venkatesh \& Davis, 2000) and it happens due to the individual's motivation such as improving their personal relationship with other members of the social group (Goodwin, 1987). In a marketing context, most referents who have an impact on individuals are friends, family, word of mouth, the Internet, TV advertisements, etc. (Lim \& Dubinsky, 2005; Premkumar et 
al., 2008). These specific groups or individuals can be varied based on the context of the behavior (Lim \& Dubinsky, 2005). To be precise, in a consumer's shopping behavior context, consumers are more likely to be influenced primarily by family and friends in their shipping process (Keen et al., 2004; Priebe \& Spink, 2011). Since, last-mile logistics is a part of consumer's shopping process; thus, it is believed that friends and family would emerge as key sources of normative pressure to perform the behavior in the present behavioral context.

\section{Relationship between reference groups and other factors:}

By considering the proxy of channel usage, research is carried out regarding the relationship between reference groups (friends and family) and last-mile logistics preference. After reviewing the previous studies, the majority state that there is a positive relationship between reference groups (friends and family) and the subjective norms of using the channel (Pookulangara et al. 2011a; Lee 2009; Potwarka 2015; Davies et al., 2011; Lu et al. 2018; Madahi \& Sukati (2016)).

Regarding the relationship with other factors, no works are found between reference groups and other factors in channel usage preference at any stage, pre-purchase or purchase.

Therefore, it is believed that:

$\mathrm{H} 10_{\mathrm{a}, \mathrm{b}, \mathrm{c}, \mathrm{d}, \mathrm{e}, \mathrm{f}}$ : Reference groups (friends and family) have a positive influence with respect to subjective norms in option $\mathrm{a}, \mathrm{b}, \mathrm{c}, \mathrm{d}, \mathrm{e}, \mathrm{f}$ selection.

Table 10 Summary of the works which show relationship between reference groups \& other factors

\begin{tabular}{|c|c|c|}
\hline Relationship & Outcome & Reference \\
\hline $\begin{array}{l}\text { Normative beliefs } \rightarrow \text { Subjective norms in } \\
\text { channel use }(+)\end{array}$ & Supported & Lee (2009) \\
\hline $\begin{array}{l}\text { Normative beliefs } \rightarrow \text { Subjective norms in } \\
\text { channel selection }(+)\end{array}$ & Supported & Davies et al. (2011) \\
\hline $\begin{array}{l}\text { Normative beliefs } \rightarrow \text { Subjective norms in } \\
\text { channel selection }(+)\end{array}$ & Supported & Pookulangara et al. (2011a) \\
\hline $\begin{array}{l}\text { Normative beliefs } \rightarrow \text { Subjective norms in } \\
\text { channel selection }(+)\end{array}$ & Supported & Potwarka (2015) \\
\hline $\begin{array}{l}\text { Normative beliefs } \rightarrow \text { Subjective norms in } \\
\text { channel selection }(+)\end{array}$ & Supported & Madahi and Sukati (2016) \\
\hline $\begin{array}{l}\text { Normative beliefs } \rightarrow \text { Subjective norms } \\
\text { channel use }(+)\end{array}$ & Supported & Lu et al. (2018) \\
\hline
\end{tabular}

\subsubsection{Perceived control beliefs}

Ajzen (1991) proposed control beliefs in the TPB to represent non-volitional actions, where personal shortfalls and external barriers can obstruct performing a particular behavior (Ajzen, 2005). Control beliefs are derived from perceiving the probability of the existence of certain facilitating or constraining conditions, which the behavior may be affected, along with the perceived power over 
resources, skills, and opportunities for making performance of the behavior difficult or easy (Ajzen, 1991; Ajzen \& Fishbein, 2000). Ajzen (1991) in his study states that the fewer resources and opportunities individuals believe they have (e.g., 'I have no internet knowledge and computer skill to perform e-commerce'), and the more obstacles they anticipate (e.g., 'I do not have an IT worker to work for me), the lower they perceive control for adopting the behavior. Taylor and Todd (1995) divided control beliefs into 'facilitating conditions' and 'self-efficacy', which are explained in detail in the following.

\subsection{Facilitating conditions}

Facilitating conditions refer to "the consumers' perceptions of the resources and support available to perform a behavior" (Venkatesh et al., 2012), which later impacts on both the intention and thereby the actual behavior (Ajzen, 1991). According to the TPB model, perceived control is understood as control capacity, which reflects the perception of the individuals with respect to their ability to react favorably to unforeseen circumstances (Martocchio \& Dulebohn, 1994), while facilitating conditions refer to minimum resources that are necessary for the development of a given behavior (Viswanath et al., 2003; Zhou et al., 2010). In essence, these facilitating conditions represent passages or barriers of a consumer's behavior, meaning that the absence of any of these facilitating conditions stands for barriers to conduct the given behavior and may inhibit the formation of intention. However, the presence of facilitating conditions may not conduct the given behavior (Taylor \& Todd, 1995). In other words, facilitating conditions highlight the importance of the external resources needed, usually objective and independent of the person. For instance, in the case of electronic commerce, having an Internet connection, access to a means of electronic payment and sufficient money to make the purchase, while the perceived control emphasizes the internal and dependent capacities of the individual perceived to carry out the given behavior (Viswanath et al., 2003). In the context of this study, a consumer who has access to a favorable set of facilitating conditions in a specific last-mile logistics option is more likely to have a higher intention to select that specific delivery and return option (Piotrowicz \& Cuthbertson, 2019). For instance, consumers who live far away from the store have different conditions than those who live near the store; hence they have different levels of intention for the in-store collection or return. Or in case of the return, consumers who live nearby the store perceive different levels of control behavior. In addition to the previous statement, this study follows the general model of TPB, and it is believed that in this context, facilitating conditions are linked to the perceived behavioral control.

\section{Relationship between facilitating conditions and other factors:}

By considering the proxy of channel usage, research is carried out regarding the relationship between facilitating conditions and last-mile logistics preference. After reviewing the previous studies, there are an empirical evidence that shows facilitating conditions influences the control beliefs (Pookulangara et al., 2011a; Madahi \& Sukati, 2016). Moreover, it is shown that there is a positive relationship between facilitating conditions and perceived behavioral control (Pookulangara et al., 2011a; Yu, C. S. 2014 
Madahi \& Sukati, 2016). Also, there are studies that show here is a positive relationship between facilitating conditions and the consumer's intention (Zhou et al., 2010; Lu \& Wang, 2010). This indicates that, the higher levels of facilitating conditions they have, the higher consumers select specific delivery and return option and the higher they intent to proceed with that behavior.

Regarding the relationship with other factors, no works are found between facilitating conditions and other factors in channel usage preference at any stage, pre-purchase or purchase.

Therefore, it is believed that:

H11 $1_{\mathrm{a}, \mathrm{b}, \mathrm{c}, \mathrm{d}, \mathrm{e}, \mathrm{f}}$ : Facilitating conditions have a positive influence with respect to perceived behavioral control in option ${ }_{\mathrm{a}, \mathrm{b}, \mathrm{c}, \mathrm{d}, \mathrm{e}, \mathrm{f}}$ selection.

H12 $2_{\mathrm{a}, \mathrm{b}, \mathrm{c}, \mathrm{d}, \mathrm{e}, \mathrm{f}}$ : Facilitating conditions have a positive influence with respect to option ${ }_{\mathrm{a}, \mathrm{b}, \mathrm{c}, \mathrm{d}, \mathrm{e}, \mathrm{f}}$ selection behavior intention.

Table 11 Summary of the works which show relationship between facilitating cond. \& other factors

\section{Relationship}

Outcome

\begin{tabular}{|l|c|c|}
\hline $\begin{array}{l}\text { Facilitating cond. } \rightarrow \text { Perceived behavioral control in } \\
\text { channel use }(+)\end{array}$ & Supported & Shih and Fang (2004) \\
\hline Facilitating cond. $\rightarrow$ Intention of channel use $(+)$ & Supported & Zhou et al. (2010) \\
\hline $\begin{array}{l}\text { Facilitating cond. } \rightarrow \text { Intention of selecting a selection } \\
(+)\end{array}$ & Supported & Lu and Wang (2010) \\
\hline $\begin{array}{l}\text { Facilitating cond. } \rightarrow \text { Perceived behavioral control in } \\
\text { channel selection }(+)\end{array}$ & Supported & Pookulangara et al. (2011a) \\
\hline $\begin{array}{l}\text { Facilitating cond. } \rightarrow \text { Perceived behavioral control in } \\
\text { channel selection }(+)\end{array}$ & Supported & Yu, C. S. (2014) \\
\hline $\begin{array}{l}\text { Facilitating cond. } \rightarrow \text { Perceived behavioral control in } \\
\text { channel selection }(+)\end{array}$ & Supported & Madahi and Sukati (2016) \\
\hline Facilitating cond. $\rightarrow$ Intention of selecting a channel(+) & Supported & Juaneda-Ayensa et al. (2016) \\
\hline
\end{tabular}

\subsection{Self-efficacy}

The beliefs related to self-efficacy are an important aspect of the motivation and behavior of the individual. Bandura (1986) defines self-efficacy as "the individual's judgments about their ability to organize and execute actions required to achieve certain types of goals". It does not deal with the skills that an individual has, but rather, it involves a generative capability, which is needed to deal with prospective situations (Bandura, 1982). In a more simplified way, self-efficacy is about the individuals' beliefs on what they can achieve by using their skills in certain circumstances. Self-efficacy can also be understood as a specific version of self-esteem (Lunenburg \& Ornstein, 2011). Its basic principle is that individuals are more likely to participate in activities in which they have high self-efficacy and less likely to participate in those that do not (Shortridge-Baggett, 2002). Williams and Williams (2010) indicated that "people with high levels of self-efficacy pose difficult tasks as challenges to be achieved, 
and not as threats to be avoided”. Monsuwé et al. (2004) stated that consumers with low self-efficacy levels tend to act differently due to uncertain and uncomfortable feelings. In fact, low self-efficacy consumers show to be less likely to do complex tasks, and prefer to go through a simple procedure that requires little knowledge (Monsuwé et al., 2004). On the other hand, higher self-efficacy consumers tend to be more confidence in their ability to perform a behavior (Dabholkar \& Bagozzi, 2002), and they are more likely to engage in free-riding behavior in different stages of consumer's journey (Chiu, Hsieh and Roan, 2011). To extend this information in this context of this study, a consumer who has more confidence in her/his ability to select a specific last-mile logistics is more likely to engage in selecting that specific last-mile logistics. For instance, consumers who have more confident in selecting pickup points or stores; have different levels of perception in selecting those options than others. In addition to the previous statement, this study follows the general model of TPB and it is believed that in this context, self-efficacy is linked to the perceived behavioral control.

\section{Relationship between self-efficacy and other factors:}

By considering the proxy of channel usage, research is carried out regarding the relationship between self-efficacy and last-mile logistics preference. After reviewing the previous studies, there is empirical evidence that shows self-efficacy influences the control beliefs, either directly or indirectly (Hsu \& Chiu, 2004). Moreover, it is shown that there is a positive relationship between self-efficacy and perceived behavioral control (Pookulangara et al., 2011a; Montano \& Kasprzyk 2015; Arora et al. 2017). Also, there are studies that show there is a positive relationship between self-efficacy and the consumer's intention (Hahn \& Kim 2009; Chiu et al., 2011; Zhang \& Oh 2013). This indicates that, the higher levels of self-efficacy in a consumer perceive, the higher they intent to proceed with that behavior.

Regarding the relationship with other factors, no works are found between self-efficacy and other factors in channel usage preference at any stage, pre-purchase or purchase.

Therefore, it is believed that:

H13 $3_{a, b, c, d, e, f}$ : Self-efficacy has a positive influence with respect to perceived behavioral control in option $\mathrm{a}, \mathrm{b}, \mathrm{c}, \mathrm{d}, \mathrm{e}, \mathrm{f}$ selection.

H14 ${ }_{a, b, c, d, e, f}$ : Self-efficacy has a positive influence with respect to option ${ }_{a, b, c, d, e, f}$ selection behavior intention. 
Table 12 Summary of the works which show relationship between self-efficacy \& other factors

Relationship

\begin{tabular}{|l|c|c|}
\hline Self-efficacy $\rightarrow$ Intention of channel selection $(+)$ & Supported & Hahn and Kim (2009) \\
\hline Self-efficacy $\rightarrow$ Intention of channel selection $(+)$ & Supported & Chiu et al., (2011) \\
\hline $\begin{array}{l}\text { Self-efficacy } \rightarrow \text { Perceived behavioral control in } \\
\text { channel selection }(+)\end{array}$ & Supported & Pookulangara et al. (2011a) \\
\hline Self-efficacy $\rightarrow$ Intention of channel selection $(+)$ & Supported & Zhang and Oh (2013) \\
\hline $\begin{array}{l}\text { Self-efficacy } \rightarrow \text { Perceived behavioral control in } \\
\text { using a channel }(+)\end{array}$ & Supported & Montano and Kasprzyk (2015) \\
\hline $\begin{array}{l}\text { Self-efficacy } \rightarrow \text { Perceived behavioral control in } \\
\text { channel selection }(+)\end{array}$ & Supported & Arora et al. (2017) \\
\hline
\end{tabular}

\subsubsection{Situational factors}

TPB is criticized for ignoring the environmental influence on technology adoption models (Moon \& Kim, 2001; Wu \& Chen, 2005). Although "Attitude toward the behavior", "Subjective norms", and "Perceived behavioral control" are believed to be fundamental constructs of the TPB model (Davis, 1989, 1993), these constructs and their beliefs may not explain completely consumers' behavior in different areas. Thus, for our specific Omni last-mile logistics context, the additional explanatory factor is needed beyond the attitude toward the behavior, subjective norms, and perceived behavioral control constructs. Therefore, situational factors are incorporated in this framework, which less attention has been paid so far, in order to capture consumer's behavior in last-mile logistics.

Situational factors refer to "all those factors particular to a time and place of observation, which do not follow a knowledge of personal (intra-individual) or stimulus (choice alternative) attributes” (Belk, 1974). These situational factors are environmental factors, in which happen at a specific point of time and space in a shopping situation. In fact, these factors are apart from non-situational factors (consumers, product, and retailer characteristics) and describe the environment that consumers have while proceeding the shopping process (Gehrt \& Yan, 2004).

Despite the fact that few pieces of research have been conducted in the area of the situational factor, researchers have made an extensive effort to show the influence of situational factors on consumers' shopping decisions (see Table 13). For instance, situational factors with information searching (Gehrt \& Shim, 2002), product preferences (Belk, 1974, 1975), price sensitivity (Wakefield \& Inman, 2003), use of in-store self-service technology (Dabholkar \& Bagozzi, 2002; Wang et al., 2012), and channel preferences (Nicholson et al., 2002; Hand et al., 2009). Researchers in the previous studies have shown that either these situational factors have a direct influence on consumer's shopping decision (Nicholson et al., 2002; Gehrt \& Yan, 2004; Huang \& Oppewal, 2006; Hand et al., 2009; Chintagunta et al., 2012), or an indirect influence through consumer's value perceptions, their respective features to products, or through their compatibility with their shopping style (Gehrt \& Yan, 2004; Huang \& Oppewal, 2006). Since last-mile logistics is a part of the consumer's shopping decision, due to the above statements, it 
is believed that these factors may also directly or indirectly cause consumers to hesitate to select a particular delivery or return option in the shopping process.

Therefore, to understand how these factors influence consumer's delivery and return option selection and to answer the question of this study, the present study follows the classification suggested by Nicholson et al. (2002) for the situational factors. Based on the study by Nicholson et al. (2002), these situational factors are physical setting, social setting, temporal perspective, task definition and antecedent states. However, this study adds a new situational factor as an extra setting. This extra setting contains the influence of the previous shopping stage on the next shopping stage, known as spillover effects (Gensler et al., 2012).

Table 13 The classification of empirical studies that use some means to measure the effects of situational factors on consumers' shopping Behavior

Situational factors

\begin{tabular}{|c|l|}
\hline Physical setting & $\begin{array}{l}\text { Nicholson et al. (2002); Gehrt and Shim (2002); Zhuang et al. (2006); Hand et } \\
\text { al. (2009); Forman et al. (2009); Chintagunta et al. (2012); Chocarro et al. } \\
\text { (2013) }\end{array}$ \\
\hline Social settings & Nicholson et al. (2002); Wakefield and Inman (2003); Chocarro et al. (2013) \\
\hline Temporal perspective & $\begin{array}{l}\text { Verhoef and Langerak (2001); Nicholson et al. (2002); Gehrt and Shim (2002); } \\
\text { Dabholkar and Bagozzi (2002); Gehrt and Yan (2004); Huang and Oppewal } \\
\text { (2006); Zhuang et al. (2006); Hand et al. (2009); Wang et al. (2012); } \\
\text { Chintagunta et al. (2012); Oppewal et al. (2012); Chocarro et al. (2013) }\end{array}$ \\
\hline Antecedent states & Nicholson et al. (2002); Gehrt and Shim (2002) \\
\hline Task definition & $\begin{array}{l}\text { Nicholson et al. (2002); Gehrt and Yan (2004); Huang and Oppewal (2006); } \\
\text { Wang et al. (2012); Chintagunta et al. (2012) }\end{array}$ \\
\hline
\end{tabular}

Since each situational factor creates different scenarios and combining different situational factors produce numerous scenarios (e.g., a combination of just four situational factors would mean 16 scenarios), it is needed to use those factors that are the most important ones. After reviewing the literature, to reduce the complexity of the analysis, this study only uses the most influential ones: (a temporal setting), distance to store (a physical setting), and channel spillover effect (a spillover effect) (Zarei et al., 2019). It is worth mentioning that since there are few studies to explain well each situational factor in relation to delivery or return option decision, this study in some cases uses previous preliminary literature in channel selection. In the preliminary literature, researchers consider home/office delivery or return as the only option for online shoppers and stores for offline shoppers. For example, Zaharia (2005) connects home delivery to online and catalog shoppers or Constantinides (2004) associates product return from home/office with online stores. Therefore, this study uses online shopping as the proxy for home/office delivery and return option and offline shopping as the store delivery and return. 


\subsubsection{Geographical distance}

The geographical distance to store is one of the characteristics in physical settings, which has a significant effect on the consumer's shopping decision (Monsuwé et al., 2004; Oppewal et al., 2013). The literature on online shopping decision states that one of the main advantages of purchasing via the online channel is the easy accessibility of purchasing goods from any location (e.g., Nicholson et al., 2002; Monsuwé et al., 2004; Chocarro et al., 2013). This effectively removes the geographical distance as an obstacle in all stages of the shopping process, which are the pre-purchase, purchase, and afterpurchase stages. Therefore, consumers who have a longer distance to travel to a store, highly tend to use an online channel instead of going to store (Schröder \& Zaharia, 2008). Reciprocally, by purchasing via an online channel, consumers, in order to avoid this obstacle, tend to select nearby delivery or return as the method of receiving or returning. DHL (2015) report shows that consumers who purchase a product from distance prefer to select first delivery to home, secondly delivery to a nearby retail store, and lastly other nearby collection points. Thus, in order to minimize the geographical distance, consumers tend to select one or another delivery and return options.

\subsubsection{Time pressure}

Time pressure is one of the characteristics in a temporal perspective, which refers to "the perception of time available for an individual to perform a task” (Gehrt \& Yan, 2004). Generally, consumers who face this time pressure situation look for a convenient and fast available option to be able to accomplish the shopping process (Frasquet et al., 2015). Hence, consumers significantly change their shopping behavior when it comes to time scarcity including their choice of product, store, and channel in order to save more time (Gehrt \& Yan, 2004; Chocarro et al., 2013). Since time scarcity can influence consumer's shopping behavior across all stages of the shopping process (Frasquet et al., 2015). Predictably, time-pressed consumers tend to act differently in last-mile logistics. Time availability becomes the main driver for selecting a specific option and becomes more important than other options.

\subsubsection{Channel Spillover effects}

The last but not least situational factor belongs to extra setting. This situational factor happens due to the previous consumers' decision. Consumers encounter themselves in new environmental settings, which are created by pervious consumers' decisions and apart from the above situational factors. In channel spillover effect, consumers take into account the channel used in the previous stage of shopping journey as a new situation they are into and may continue using the same channel in the next stage of shopping journey (Verhoef et al., 2007). This effect mostly occurs when two following stages of shopping journey coincide and consumers prefer to use the same channel for both stages in order to avoid additional costs and improve efficiency (Xue \& Harker, 2002). This avoidance of cost makes the purchase channel to be the most important driver for consumers when they select a delivery and return (Bellman et al., 1999). For instance, consumers who are in the offline channel tend to receive immediately their products after the purchasing stage or prefer to return them to the same store where 
they purchased from (Hsiao, 2009). Consequently, we believe that this effect from the purchase stage probably influences consumer's intention to select a specific option.

\section{Relationship between situational factors and other factors:}

In order to see the position of the situational factors in the model, a review of previous literatures is conducted. According to Dabholkar and Bagozzi (2002), Monsuwé, et al. (2004) and Wang, et al. (2012), there is a favorable situational influence on attitudes toward an intention of behavior, and consumers are reluctant to the intention of behavior based on the situational factors. Therefore, the attitude-intention of the behavior link is somewhat weak without considering the situations, and focusing only on attitude alone does not effectively predict a consumer's actual choice (Wang et al., 2012) and may not be sufficient (Ajzen, 1991).

In order to justify the effects of situational factors as a moderator in delivery and return option selection, we follow procedures suggested by Baron and Kenny (1986), the first conceptual work in this area, to determine whether this moderator occurs in our data. Baron and Kenny (1986) suggest three conditions that need to be satisfied in order to establish moderators:

1. The independent variables need to affect the dependent variable

2. The moderators need to affect the dependent variable

3. The independent variables with the moderators need to affect the dependent variable

According to the TPB model proposed by Ajzen (1991) intention of the behavior (dependent variables) is affected by attitudinal beliefs (independent variables). This statement clearly meets the first condition. For meeting the second condition, this study shows the influence of the situational factors on the dependent variables (intention of the behavior) - sections 3.2.3.1; 3.2.3.2; 3.2.3.3. Last but not least for fulfilling the conditions, is to check the attitudinal beliefs (independent variables) with the moderators need to affect intention of the behavior (dependent variables). To do so, Ajzen (1991) stated that, attitude and intention of behavior alone may not be sufficient and the influence of attitudinal beliefs on specific actions in specific situations is greatly influenced by the presence of other, more immediate factors such as situational factors. Hence, attitudinal beliefs with the moderators - in our case situational factors - greatly influence the intention of the behavior of this study. In general, it can be said that the attitude-intention relationship is manipulated by situational factors as moderators.

Regarding the relationship with other factors, like the previous part, to reduce the complexity of the analysis, this study considers the most important relationship with situational factors in the model. According to the Theory of Planned Behavior (TPB), the intention-behavior link is expected to vary across situations (Ajzen, 1991). Moreover, Dabholkar and Bagozzi (2002) show that the situational factors can influence other factors, but the major influence happens in attitude toward the consumer's 
intention. Based on this result, Monsuwé, et al. (2004) and Wang, et al. ( 2012) also establish their model.

Therefore:

$\mathrm{H} 15_{\mathrm{a}, \mathrm{b}, \mathrm{c}, \mathrm{d}, \mathrm{e}, \mathrm{f}}$ : With greater time pressure, the positive relationship between attitudes toward the intention will be strengthened in option ${ }_{\mathrm{a}, \mathrm{b}, \mathrm{c}, \mathrm{d}, \mathrm{e}, \mathrm{f}}$ selection.

$\mathrm{H} 16_{\mathrm{a}, \mathrm{b}, \mathrm{c}, \mathrm{d}, \mathrm{e}, \mathrm{f}}$ : With greater distance to store, the positive relationship between attitudes toward the intention will be strengthened in option ${ }_{a, b, c, d, e, f}$ selection.

$\mathrm{H} 17_{\mathrm{a}, \mathrm{b}, \mathrm{c}, \mathrm{d}, \mathrm{e}, \mathrm{f}}$ : With greater spillover effect, the positive relationship between attitudes toward the intention will be strengthened in option ${ }_{\mathrm{a}, \mathrm{b}, \mathrm{c}, \mathrm{d}, \mathrm{e}, \mathrm{f}}$ selection.

Table 14 Studies that have considered situational factors as a moderator

\begin{tabular}{|l|l|}
\hline Authors & Relationship between situational variables and other factors \\
\hline Nicholson et al. (2002) & $\begin{array}{l}\text { Direct effect (exploratory study)- situational factors influences upon } \\
\text { consumer selection between the three shopping channels }\end{array}$ \\
\hline $\begin{array}{l}\text { Dabholkar and } \\
\text { Bagozzi (2002) }\end{array}$ & Moderating effect of attitude toward an intention of the behavior \\
\hline Gehrt and Yan (2004) & Moderating effect of the importance of respective channel characteristics \\
\hline Forman et al. (2009) & $\begin{array}{l}\text { Moderating effect of type-of-product within category considered and } \\
\text { price on channel choice }\end{array}$ \\
\hline Hand et al. (2009) & Direct effect on online versus physical store shopping \\
\hline Wang et al. (2012) & Moderating effect on attitude toward a behavior \\
\hline Oppewal et al. (2013) & Direct effect on consumer channel selection \\
\hline
\end{tabular}




\subsection{The model and hypothesis of research}

Finally, based on the theoretical approach detailed in the previous Chapters, and taking into account the relationships between the studied constructs, the following model is proposed for the context of this research:

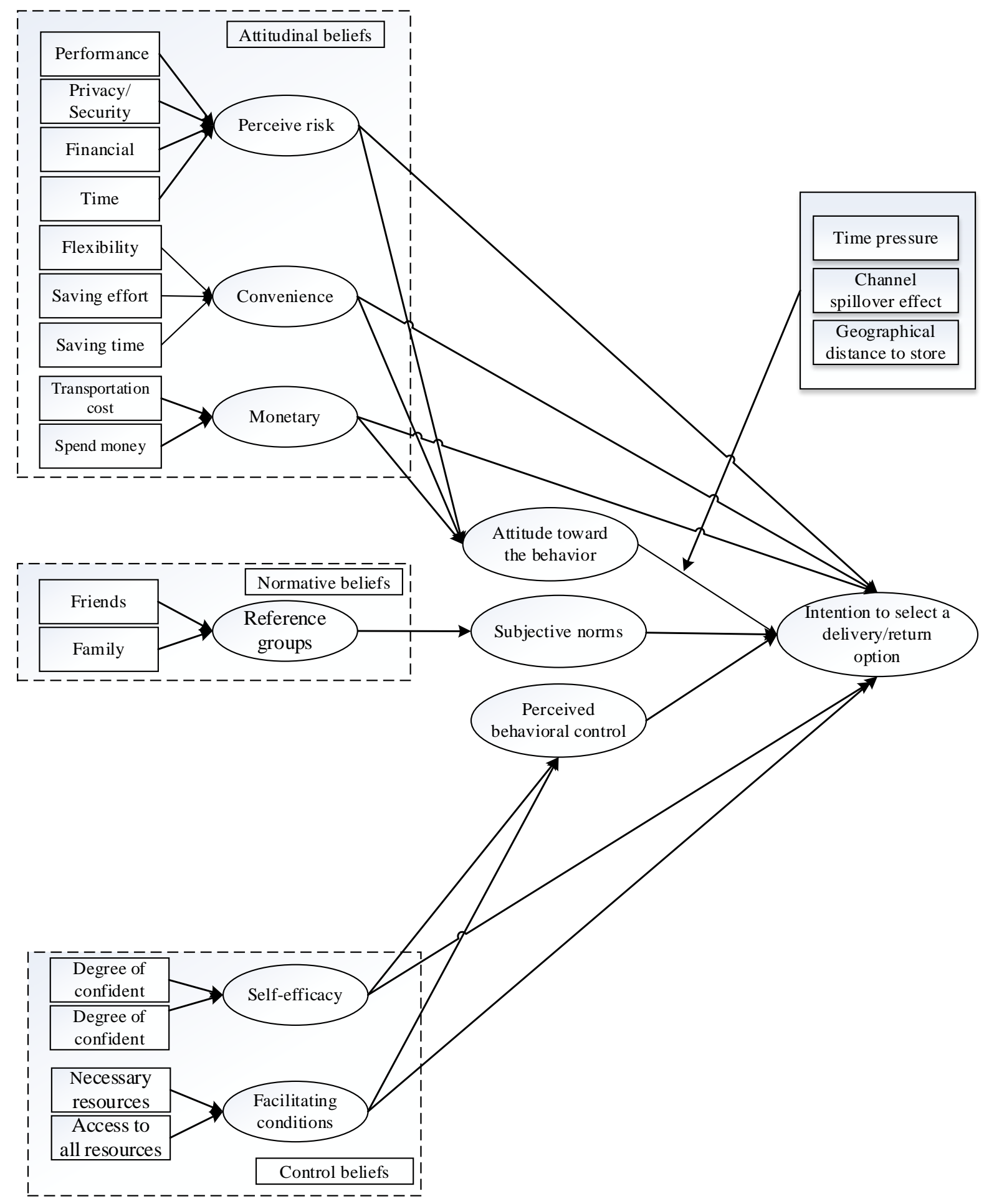

Figure 17 The research model (Source: Author) 


\subsubsection{Hypothesis summary}

Table 15 and Table 16 summarize the hypotheses based on the categorization proposed in sections 2.5.2 and 2.5.3 for the last-mile logistics options. (a: home delivery, b: store delivery, c: CDPs, d: home return, e: store return, f: CRPs)

Table 15 Summary of hypotheses in delivery and return

\begin{tabular}{|c|c|c|}
\hline$H 1_{a, b, c, d, e, f}$ & & $\begin{array}{l}\text { Attitude has a positive influence with respect to option }{ }_{a, b, c, d, e, f} \text { selection behavior } \\
\text { intention }\end{array}$ \\
\hline$H 2_{a, b, c, d, e, f}$ & 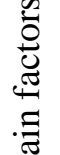 & $\begin{array}{l}\text { Subjective norm has a positive influence with respect to option }{ }_{a, b, c, d, e, f} \text { selection } \\
\text { behavior intention. }\end{array}$ \\
\hline$H 3_{a, b, c, d, e, f}$ & & $\begin{array}{l}\text { Perceived behavioral control has a positive influence with respect to option }{ }_{\mathrm{a}, \mathrm{b}, \mathrm{c}, \mathrm{d}, \mathrm{e}, \mathrm{f}} \\
\text { selection behavior intention. }\end{array}$ \\
\hline$H 4_{a, b, c, d, e, f}$ & $\begin{array}{l}\tilde{u} \\
\tilde{0}\end{array}$ & $\begin{array}{l}\text { Monetary costs have a negative influence with respect to attitude toward } \\
\text { option }{ }_{\mathrm{a}, \mathrm{b}, \mathrm{c}, \mathrm{d}, \mathrm{e}, \mathrm{f}} \text { selection. }\end{array}$ \\
\hline$H 5_{a, b, c, d, e, f}$ & 荧 & $\begin{array}{l}\text { Monetary costs have a negative influence with respect to option } a, b, c, d, e, f \text { selection } \\
\text { behavior intention. }\end{array}$ \\
\hline$H 6_{a, b, c, d, e, f}$ & 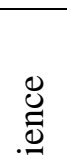 & $\begin{array}{l}\text { Convenience has a positive influence with respect to attitude toward option }{ }_{a, b, c, d, e, f} \\
\text { selection. }\end{array}$ \\
\hline$H 7_{a, b, c, d, e, f}$ & $\overbrace{0}^{\bar{\nu}}$ & $\begin{array}{l}\text { Convenience has a positive influence with respect to option }{ }_{\mathrm{a}, \mathrm{b}, \mathrm{c}, \mathrm{d}, \mathrm{e}, \mathrm{f}} \text { selection } \\
\text { behavior intention. }\end{array}$ \\
\hline$H 8_{a, b, c, d, e, f}$ & 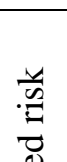 & $\begin{array}{l}\text { Perceived risk has a negative influence with respect to attitude toward option } a, b, c, d, e, f \\
\text { selection. }\end{array}$ \\
\hline$H 9_{a, b, c, d, e, f}$ & 离 & $\begin{array}{l}\text { Perceived risk has a negative influence with respect to option }{ }_{\mathrm{a}, \mathrm{b}, \mathrm{c}, \mathrm{d}, \mathrm{e}, \mathrm{f}} \text { selection } \\
\text { behavior intention. }\end{array}$ \\
\hline$H 10_{a, b, c, d, e, f}$ & $\stackrel{\oplus}{\dot{z}}$ & $\begin{array}{l}\text { Normative beliefs (friends and family) have a positive influence with respect to } \\
\text { subjective norms in option }{ }_{a, b, c, d, e, f} \text { selection. }\end{array}$ \\
\hline$H 11_{a, b, c, d, e, f}$ & $\begin{array}{l}ن \\
.0 \\
. \Xi\end{array}$ & $\begin{array}{l}\text { Facilitating conditions have a positive influence with respect to perceived behavioral } \\
\text { control in option }{ }_{\mathrm{a}, \mathrm{b}, \mathrm{c}, \mathrm{d}, \mathrm{e}, \mathrm{f}} \text { selection. }\end{array}$ \\
\hline$H 12_{a, b, c, d, e, f}$ & $\stackrel{\overparen{D}}{:}$ & $\begin{array}{l}\text { Facilitating conditions have a positive influence with respect to option }{ }_{\mathrm{a}, \mathrm{b}, \mathrm{c}, \mathrm{d}, \mathrm{e}, \mathrm{f}} \\
\text { selection behavior intention. }\end{array}$ \\
\hline
\end{tabular}




\begin{tabular}{|c|c|c|}
\hline$H 13_{a, b, c, d, e, f}$ & 己ृ & $\begin{array}{l}\text { Self-efficacy has a positive influence with respect to perceived behavioral control in } \\
\text { option }_{a, b, c, d, e, f} \text { selection. }\end{array}$ \\
\hline$H 14_{a, b, c, d, e, f}$ & 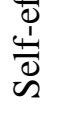 & $\begin{array}{l}\text { Self-efficacy has a positive influence with respect to option }{ }_{a, b, c, d, e, f} \text { selection } \\
\text { behavior intention. }\end{array}$ \\
\hline
\end{tabular}

Table 16 Summary of hypotheses in moderation effect in delivery options

\begin{tabular}{|c|l|}
\hline$H 15_{a, b, c, d, e, f}$ & $\begin{array}{l}\text { With greater time pressure, the positive relationship between attitudes toward the } \\
\text { intention will be strengthened in option } \\
\mathrm{a}, \mathrm{b}, \mathrm{c}, \mathrm{d}, \mathrm{e}, \mathrm{f}\end{array}$ \\
\hline$H 16_{a, b, c, d, e, f}$ selection. & $\begin{array}{l}\text { With greater distance to store, the positive relationship between attitudes toward the } \\
\text { intention will be strengthened in option } \\
\mathrm{a}, \mathrm{b}, \mathrm{c}, \mathrm{d}, \mathrm{e}, \mathrm{f}\end{array}$ \\
\hline$H 17_{a, b, c, d, e, f}$ & $\begin{array}{l}\text { With gection. } \\
\text { intention will be strengthened in option }\end{array}$ \\
\hline $\mathrm{a}, \mathrm{b}, \mathrm{c}, \mathrm{d}, \mathrm{e}, \mathrm{f}$
\end{tabular}

Hint: a: Home delivery, b: In-store delivery, c: Collection delivery points (CDPs), d: Home return, e: In-store return, f: Collection return points (CRPs) 
Chapter 4: Characteristics of the empirical work 


\subsection{Introduction}

In the present study, the objective is to investigate human behavior in the last-mile logistics of the Omnichannel environment. The study was carried out through observing the effect of a series of factors in order to explain to what extent these factors - motivational, socio-normative, control, and specific to the technology under study - can predict the consumer's actual intention of selecting each delivery and return option in the Omnichannel environment. Therefore, the research objective can be considered an attempt to obtain new information in the context of a social reality and social sciences.

According to Hair et al. (2017), there are two types of methodology for social science research: exploratory and confirmatory. Confirmatory method is used when researchers attempt to prove or confirm a specified relationship prior to performing the analysis, while exploratory method is used when researchers attempt to define possible relationships in the most general way through certain multivariate statistical techniques. Taking into account these methodologies for social science research, and given that this study proposes a new topic in search for gaining more knowledge and understanding the relationship between factors in a general way through a multivariate analysis technique, we can consider this research exploratory. On the other hand, according to Sierra (1986), and given that this research collects data from personal surveys, it can be said that the method used is empirical.

In terms of research design, empirical studies can be qualitative and quantitative (Hair et al., 2017). The quantitative approach is based on numerical data to investigate, analyze, and verify information and hypothesis through statistical techniques (Lietz \& Zayas, 2010), while the qualitative approach is based on the collection of non-standardized data and without numerical measurement (describing events, people, situations, behaviors, and interactions that are observed through a study) (Lietz \& Zayas, 2010). Based on these definitions, this research will have a quantitative design with data collected through surveys administered online. Given that the data collection is through online surveys administered to individuals under natural conditions (multichannel shoppers), we can affirm that this research is based on field studies.

Finally, the statistical techniques used to analyze the data belong to multivariate analysis techniques, and more specifically partial least squares (PLS), which will be discussed in detail in the following (see section 5).

\subsection{Scope of the study}

The main objective of this research is to understand why consumers select different last-mile logistics options and what factors influence consumer's option selections. To do so, the plan is to identify the factors of the intention of selecting the actual behavior of option selection in delivery and return by the final consumers of apparel in the Omnichannel environments in Spain. 
The empirical study was carried out in 2018. It was applied to the Spanish population who were multichannel shoppers (either from online or offline channels). Therefore, an online questionnaire was considered a good fit for the research in order to capture their shopping behavior in particular in lastmile logistics. Moreover, according to (Gehrt \& Yan, 2004), in order to have a representative data from the national population of a country, it is needed to have the demographic characteristics of that country. Due to above statement, Spain national demographic characteristic was investigated (Table 17) (INE, 2019; Pérez, 2020)

Table 17 Spain national demographic characteristic

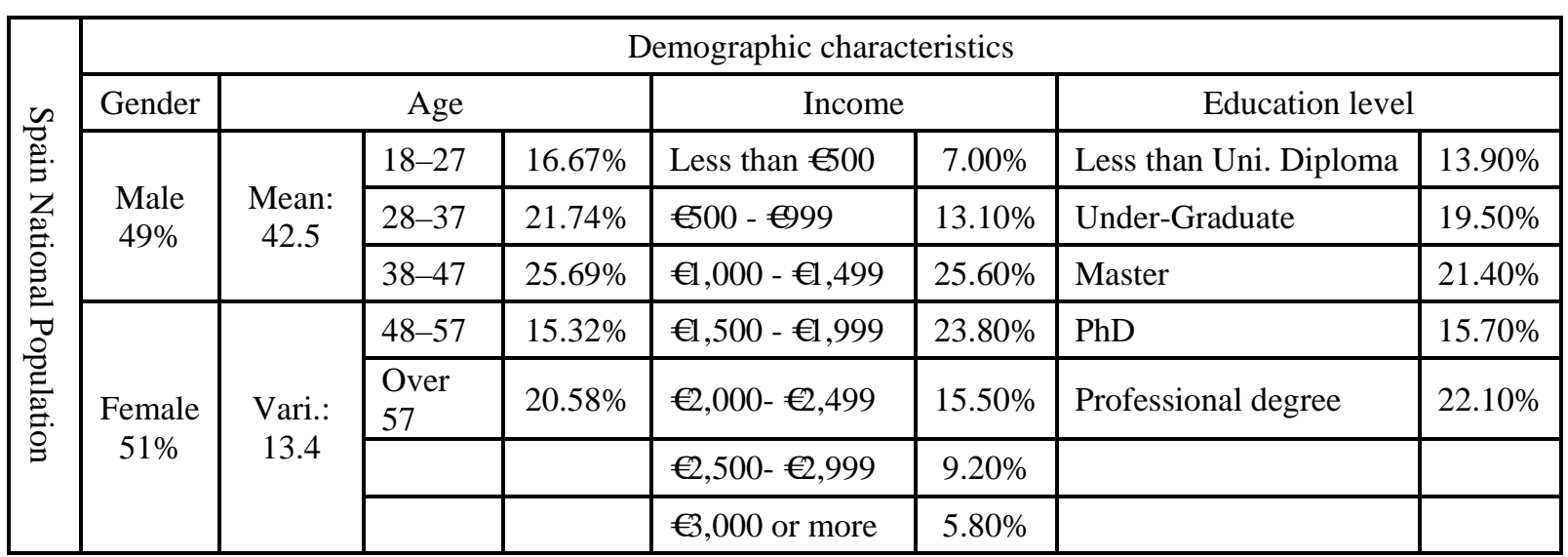

\subsection{Mechanism of data collection}

In order to capture the data needed, a two-stage survey was designed. The first one aimed to capture data from a series of statements related to the TPB's factors. The second stage aimed to analyze the moderating effects of situational factors (i.e. time availability, channel spillover effect, distance to store) in the model, based on the Monsuwé et al. (2004) and Simon \& Usunier (2007) studies, which explicitly explain that the situational factors have an impact on the relationship between attitude and consumers' intention of a behavior. The sample was taken during the months of October and November of the year 2018. The administration of the questionnaires has been carried out through the Internet using the Google forum platform. Since this study relied on the Omnichannel retailing and assumed that the participants would be multichannel shoppers, an online survey was believed to be a good fit for the research.

Before distributing the questionnaire, the questionnaire was pretested by professors and students $(n=40)$. Based on the outcome of the pre-test, the questionnaire was revised to ensure its readability and the logical flow of questions. Afterward, all respondents became aware of the situation -where they can switch easily and continuously between all channels available, and experience all channels together as one unique channel (Kemperman et al., 2015). They also needed to think about purchasing apparel through different channels-online or offline-and receiving and returning their items to each specific option-home or work delivery, retailer pick-up points and CDPs. Hence, we prepared an instruction for 
the respondents that embraced all the explanations above. Once they confirmed that they have read the instruction, they had access to the survey.

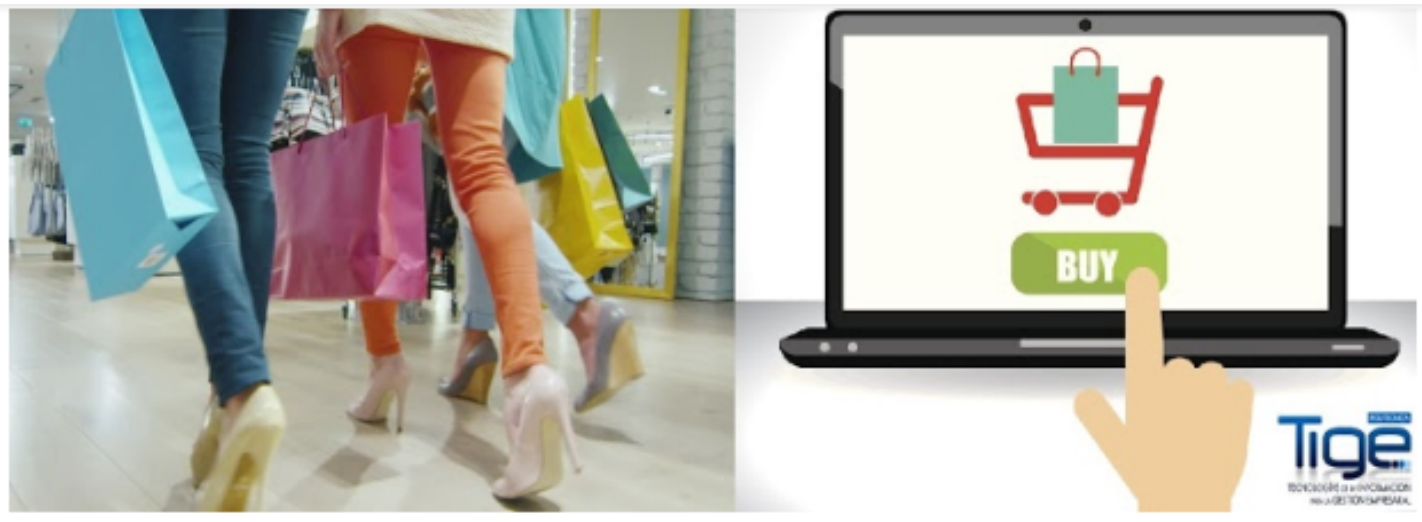

\section{Survey Instructions. IMPORTANT TO READ CAREFULLY BEFORE STARTING.}

First of all, thank you very much for participating in this survey!

WHY IS THIS SURVEY?

Companies increasingly offer alternatives when it comes to receiving or returning the items you buy, either online, through your mobile phone, or at the store itself. Nowadays it is possible to buy an item by one of these means, and receive or return it in different routes. That's why we want to know what leads the buyers to opt an option in delivery and return.

WHAT ARE THE ALTERNATIVES OF DELIVERY AND RETURNING?

Although they are called in different ways, we have summarised them in three options:

- Delivery or return to home (home, work, etc.).

- Delivery or return at the store.

- Collection points (gas stations, lockers, other stores, etc.)

WHY ONLY CLOTHING?

As buyers usually prefer to try on clothes, the way to buy clothes can be different from buying other products. That is why it is important that at all times you answer this survey considering ONLY THE PURCHASE OF CLOTHING.

\section{HOW IS THE SURVEY?}

You will find five sections with multiple choice questions (you should only choose one of the possible options).

- In the first section you will find the general questions regarding delivery and return

- In the second and third sections you will see questions related to the possible situations in which you can find yourself when buying clothes.

- In the last section there will be only basic demographic questions.

\section{WHAT DO I OBTAIN TO CHANGE ANSWER THE SURVEY?}

If you wish, you can enter the draw for 2 gift cards on Amazon for an amount of $€ 20$ each. For this you must leave your email at the end of the survey.

Thank you very much for your help!!

Figure 18 Questionnaire layout (Source: Author)

The sampling method used for this study was "non-probabilistic", which is suitable for exploratory studies. Within the non-probabilistic sampling, a mixture of two subtypes has been used: "intentional or convenience sampling" and "snowball". These methods make it easier to select the sample and to increase the number of participants in short periods of time, although it can produce bias such as not 
covering the majority of the population. However, the online developed survey was distributed via email to participants through the following channels:

- Students of different universities, sports clubs, adult and private schools (English schools, Music Schools, etc.). They were asked to distribute the survey among their contacts.

- Professors of different universities, sports clubs, and private schools (English schools, Music Schools, etc.). They were asked to distribute the survey among their students and their professional contacts.

- Distributing the questionnaire through social networks (Twitter, Facebook and LinkedIn, etc.).

\subsubsection{Structure of the questionnaire}

\subsubsection{Measurement instrument}

Empirical findings indicate that bipolar scaling $(-2$ to +2$)$ most often yields a higher correlation with the constructs (Gagne \& Godin, 2000); hence, this bipolar scaling was used. The scale developed was of the ordinal type and was characterized by using a series of statements on a scale of agreement/disagreement - likely/unlikely, Table 18. The main advantage of the use of these scales was that the participants were able to easily express their opinions and their responses could be easily processed and analyzed. These scales are not exempt from any disadvantage. Perhaps the most relevant one is associated with their ordinal character, since they are not possible to know precisely the amount of agreement/disagreement or likely/unlikely (SHEN, 2003). Nevertheless, these scales are the most widely used scale in the consumer's shopping behavior studies (Kim \& Park, 2006; Littler \& Melanthiou, 2006; Chen \& Cheng, 2012; Azhari \& Bennett, 2015).

Based on these studies, attitudinal beliefs, attitude toward a behavior scale ( -2 "Strongly disagree" to +2 "Strongly agree") was adapted from Babin et al. (1994). Regarding normative beliefs, subjective norms, self-efficacy, facilitating conditions, PBC and last-mile logistics option intentions were measured according to the scale (-2 "Very unlikely" to +2 "very likely") developed by Taylor and Todd (1995). Attitudes toward a behavior were measured using a five-point Likert-type scale (-2 "Strongly disagree" to +2 "Strongly agree") in the context of eight situational scenarios adopted from (Gehrt \& Yan, 2004). Consumer demographic characteristics were measured for a descriptive purpose and included gender, age, education level, and annual household income.

Table 18 Measurement instrument

\begin{tabular}{|c|c|c|c|c|}
\hline-2 & -1 & 0 & -1 & 2 \\
\hline Strongly disagree & Disagree & Neither agree nor disagree & Agree & Strongly agree \\
\hline Very unlikely & Unlikely & Neither unlikely nor Likely & Likely & Very likely \\
\hline
\end{tabular}




\subsubsection{Questions}

To test the hypotheses consistent with the research framework, a questionnaire was developed that contained three sections. Firstly, the survey asked the respondents to rate their level of agreement using a previous scale with a series of statements related to the TPB's factors for each following option:

1. Home delivery

2. In-store delivery

3. CDPs

4. Return from home

5. In-store return

6. CRPs

\subsection{Question of the TPB model}

For developing the measurement instrument for the elements of the TPB model in last-mile logistics option, there were several studies such as those proposed by Venkatesh et al. (2003), Shih \& Fang, (2004), Pavlou \& Fygenson (2006), Potwarka (2015). However, in the end, this study developed the following questions from "Explaining consumers' channel-switching behavior using the theory of planned behavior” by Pookulangara et al. (2011a) which was adopted from Ajzen \& Fishbein (1980) and Davis $(1986,1989)$ research and it was more related to the concept of this study than that of other available studies.

Table 19 Question of option selection -Intention

\begin{tabular}{|c|c|c|c|}
\hline & Language & Question of option selection -Intention & Source \\
\hline \multirow{2}{*}{$\begin{array}{c}\text { IQ } \\
1\end{array}$} & English & I plan to receive or return my order through ... & \multirow{4}{*}{$\begin{array}{l}\text { Pookulangara et al. } \\
\text { (2011a) }\end{array}$} \\
\hline & Spanish & $\begin{array}{l}\text { Planearía recibir o devolver mi compra } \\
\text { mediante... }\end{array}$ & \\
\hline \multirow{2}{*}{$\begin{array}{c}\text { IQ } \\
2\end{array}$} & English & I intend to receive or return my order through & \\
\hline & Spanish & $\begin{array}{l}\text { Intentaría recibir o devolver mis compras } \\
\text { mediante... }\end{array}$ & \\
\hline
\end{tabular}

The following table shows the questions for measuring attitude toward the behavior, which were adopted from the work of Pookulangara et al. (2011a).

Table 20 Question of option selection -Attitude toward the behavior

\begin{tabular}{|c|c|c|c|}
\hline & Language & $\begin{array}{c}\text { Question of option selection -Attitude toward } \\
\text { the behavior }\end{array}$ & Source \\
\hline \multirow{2}{*}{$\begin{array}{c}\mathrm{A} \\
\mathrm{Q} \\
1\end{array}$} & English & $\begin{array}{l}\text { I think that choosing the following delivery or } \\
\text { return method is a good idea }\end{array}$ & \multirow{4}{*}{$\begin{array}{l}\text { Pookulangara et al. } \\
\text { (2011a) }\end{array}$} \\
\hline & Spanish & $\begin{array}{l}\text { Creo que elegir el siguiente método de envío o } \\
\text { devolución es una buena idea }\end{array}$ & \\
\hline \multirow{2}{*}{$\begin{array}{l}\mathrm{A} \\
\mathrm{Q} \\
2\end{array}$} & English & $\begin{array}{l}\text { I like the idea of selecting the following } \\
\text { delivery or return method }\end{array}$ & \\
\hline & Spanish & $\begin{array}{l}\text { Me gusta la idea de elegir el siguiente método } \\
\text { de envío o devolución }\end{array}$ & \\
\hline
\end{tabular}


The questions necessary to measure subjective norm (Table 21) were extracted from the questions proposed by Pookulangara et al. (2011a).

Table 21 Question of option selection -Subjective norm

\begin{tabular}{|c|c|c|c|}
\hline & Language & Question of option selection -Subjective norm & Source \\
\hline $\mathrm{S}$ & English & $\begin{array}{l}\text { The people who influence my decisions } \\
\text { approve }\end{array}$ & \multirow{4}{*}{$\begin{array}{l}\text { Pookulangara et al. } \\
\qquad \text { (2011a) }\end{array}$} \\
\hline 1 & Spanish & $\begin{array}{l}\text { Las personas que influyen en mis decisiones } \\
\text { aprueban... }\end{array}$ & \\
\hline $\mathrm{S}$ & English & Most people who are important to me approve & \\
\hline $\begin{array}{l}\mathrm{N} \\
2\end{array}$ & Spanish & $\begin{array}{l}\text { La mayoría de las personas que son } \\
\text { importantes para mí aprueban ... }\end{array}$ & \\
\hline
\end{tabular}

Last but not least, the questions which form control beliefs (Table 22) were extracted from Pookulangara et al. (2011a).

Table 22 Question of option selection - Control beliefs

\begin{tabular}{|c|c|l|c|}
\hline & Language & Question of option selection - Control beliefs & \multirow{2}{*}{ Source } \\
\hline P & English & I am able to select & \multirow{2}{*}{ Pookulangara et al. } \\
\cline { 2 - 3 } C & Spanish & Soy capaz de seleccionar la opción... & \multirow{2}{*}{ (2011a) } \\
1 & & & \\
P & English & I have the resources, knowledge and ability to & \\
C & select & Tengo los recursos, el conocimiento y la & \\
2 & Spanish & habilidad para seleccionar la opción... & \\
\hline
\end{tabular}

\subsection{Attitudinal beliefs}

For measuring convenience, since it is a multidimensional factor emerging from saving time, saving effort, and flexibility of time, using these indicators provides greater coverage of the construct as well as the measure of the general convenience. The following table summarizes questions that were extracted from Jiang et al. (2013) and Srinivasan et al. (2002) studies.

Table 23 Question of option selection - Convenience

\begin{tabular}{|c|c|c|c|}
\hline & Language & Question of option selection - Convenience & Source \\
\hline \multirow[b]{2}{*}{$\begin{array}{c}\mathrm{C} \\
01\end{array}$} & English & I could receive or return anytime I wanted by & \multirow{6}{*}{$\begin{array}{c}\text { Jiang et al. (2013) } \\
\text { and Srinivasan et al } \\
\text { (2002) }\end{array}$} \\
\hline & Spanish & $\begin{array}{l}\text { Puedo recibir o devolver el producto en } \\
\text { cualquier momento si elijo recibirlo o devolver } \\
\text { usando..... }\end{array}$ & \\
\hline \multirow{2}{*}{$\begin{array}{l}\mathrm{C} \\
\mathrm{o} 2\end{array}$} & English & $\begin{array}{l}\text { I suppose that it takes effort to receive or } \\
\text { return my order by }\end{array}$ & \\
\hline & Spanish & $\begin{array}{l}\text { Supone un esfuerzo recibir o devolver mi } \\
\text { compra si elijo.... }\end{array}$ & \\
\hline \multirow{2}{*}{$\begin{array}{l}\mathrm{C} \\
\mathrm{o} 3\end{array}$} & English & $\begin{array}{l}\text { I suppose that it takes a long time to receive or } \\
\text { return by }\end{array}$ & \\
\hline & Spanish & $\begin{array}{l}\text { Supone mucho tiempo recoger o devolver mi } \\
\text { compra a través de... }\end{array}$ & \\
\hline
\end{tabular}


The questions needed to measure transportation costs were extracted from the questions proposed by Bansal et al. (2005), which are shown in the following table.

Table 24 Question of option selection - Monetary

\begin{tabular}{|c|c|l|c|}
\hline & Language & \multicolumn{1}{|c|}{ Question of option selection - Monetary } & \multirow{2}{*}{ Source } \\
\hline \multirow{2}{*}{$\begin{array}{c}\text { Tc } \\
1\end{array}$} & English & $\begin{array}{l}\text { Generally speaking, the transportation cost in } \\
\text { selecting the following delivery or return } \\
\text { method would be high }\end{array}$ & \\
\cline { 2 - 3 } & Spanish & $\begin{array}{l}\text { En general, los costes relacionados con al } \\
\text { transporte son altos si elijo la opción... }\end{array}$ & \multirow{2}{*}{ Bansal et al. (2005) } \\
\hline \multirow{2}{*}{$\begin{array}{c}\text { Tc } \\
2\end{array}$} & English & $\begin{array}{l}\text { Overall, I would spend a lot of money in } \\
\text { selecting the following delivery or return } \\
\text { method }\end{array}$ & \\
\cline { 2 - 3 } & Spanish & $\begin{array}{l}\text { Considero que me costaría mucho dinero si } \\
\text { elijo la opción... }\end{array}$ & \\
\hline
\end{tabular}

Finally, for perceived risk, since risk is a multidimensional factor emerging from time, performance, financial risk, physical risk, and security/privacy, using these indicators provides greater coverage of the construct as well as the measure of the general risk perceived. The following table summarizes questions, which were extracted from Chou et al. (2016) and Lee (2009) studies.

Table 25 Question of option selection - Perceived risk

\begin{tabular}{|c|c|c|c|}
\hline & Language & Question of option selection - Perceived risk & Source \\
\hline \multirow{2}{*}{$\begin{array}{c}\operatorname{Pr} \\
1\end{array}$} & English & $\begin{array}{l}\text { Using ....... would lead to a loss of } \\
\text { convenience of me because I would have to } \\
\text { waste a lot of time }\end{array}$ & \multirow{8}{*}{$\begin{array}{c}\text { Chou et al. (2016) } \\
\text { and Lee (2009) }\end{array}$} \\
\hline & Spanish & $\begin{array}{l}\text { Supone una pérdida de comodidad para mí } \\
\text { porque perdería mucho tiempo si elijo la } \\
\text { opción... }\end{array}$ & \\
\hline \multirow[t]{2}{*}{$\begin{array}{c}\operatorname{Pr} \\
2\end{array}$} & English & $\begin{array}{l}\text { I am afraid of losing the product due to } \\
\text { careless mistakes carried by the service } \\
\text { providers }\end{array}$ & \\
\hline & Spanish & $\begin{array}{l}\text { Tengo miedo de perder el producto debido a } \\
\text { un error si elijo la opción... }\end{array}$ & \\
\hline \multirow[b]{2}{*}{$\begin{array}{c}\operatorname{Pr} \\
3\end{array}$} & English & I am concerned about the result of & \\
\hline & Spanish & $\begin{array}{l}\text { Me preocupo por el resultado de elegir la } \\
\text { opción... }\end{array}$ & \\
\hline \multirow{2}{*}{$\begin{array}{c}\operatorname{Pr} \\
4\end{array}$} & English & $\begin{array}{l}\text { I am concerned about the risk of interception } \\
\text { of personal information when selecting }\end{array}$ & \\
\hline & Spanish & $\begin{array}{l}\text { Me preocupa el riesgo de privacidad asociado } \\
\text { a elegir... }\end{array}$ & \\
\hline
\end{tabular}

\subsection{Normative beliefs}

The construction of normative beliefs consists of family and friends elements. Hence, the questions related to the normative beliefs are formulated based on these elements, which were adopted from Pookulangara et al. (2011a). 
Table 26 Question of option selection -Normative beliefs

\begin{tabular}{|c|c|c|c|}
\hline & Language & $\begin{array}{c}\text { Question of option selection -Normative } \\
\text { beliefs }\end{array}$ & Source \\
\hline N & English & My family think that I should select & \\
\cline { 2 - 3 } q1 & Spanish & $\begin{array}{c}\text { Mi familia piensa que debo elegir el siguiente } \\
\text { método de envío o devolución }\end{array}$ & \multirow{2}{*}{$\begin{array}{c}\text { Pookulangara et al. } \\
\text { (2011a) }\end{array}$} \\
\hline N & English & My friends approve of my selection & \\
q2 & Spanish & $\begin{array}{c}\text { Mis amigos piensan que debo elegir el } \\
\text { siguiente método de envío o devolución }\end{array}$ & \\
\hline
\end{tabular}

\subsection{Control beliefs}

For developing the questions of self-efficacy, the work of Bhattacherjee (2000) has been used in which its adaptation of the concept was from the study of Taylor and Todd (1995).

Table 27 Question of option selection - Self-efficacy

\begin{tabular}{|c|c|l|c|}
\hline & Language & \multicolumn{1}{|c|}{ Question of option selection - Self-efficacy } & \multirow{2}{*}{ Source } \\
\hline \multirow{2}{*}{$\begin{array}{c}\text { Se } \\
1\end{array}$} & English & $\begin{array}{l}\text { I am able to select the following delivery or } \\
\text { return method reasonably well on my own }\end{array}$ & \multirow{2}{*}{ Bhattacherjee (2000) } \\
\cline { 2 - 3 } & Spanish & $\begin{array}{l}\text { Soy capaz de gestionar el siguiente método de } \\
\text { envío o devolución razonablemente bien por } \\
\text { mí mismo }\end{array}$ & \\
\hline \multirow{2}{*}{$\begin{array}{c}\text { Se } \\
2\end{array}$} & English & $\begin{array}{l}\text { I feel confident selecting the following } \\
\text { delivery or return method on my own }\end{array}$ \\
\cline { 2 - 3 } & Spanish & $\begin{array}{l}\text { Me siento confiado eligiendo el siguiente } \\
\text { método de envío o devolución por mí mismo }\end{array}$ & \\
\hline
\end{tabular}

General questions have been used in order to characterize facilitating conditions (Taylor and Todd, 1995; Teo and Yu, 2005). Although many studies have measured facilitating conditions by their multidimensional elements, this study in order to avoid overlapping with other factors, decided to develop general questions based on Bhattacherjee (2000) study.

Table 28 Question of option selection - Facilitating conditions

\begin{tabular}{|c|c|l|c|}
\hline & Language & \multicolumn{1}{|c|}{$\begin{array}{c}\text { Question of option selection - Facilitating } \\
\text { conditions }\end{array}$} & \multirow{2}{*}{ Source } \\
\hline Fc & English & $\begin{array}{l}\text { I consider that I have the necessary resources } \\
\text { to select the following delivery or return } \\
\text { method }\end{array}$ & \\
\cline { 2 - 3 } & Spanish & $\begin{array}{l}\text { Considero que cuento con los recursos } \\
\text { necesarios para elegir la opción... }\end{array}$ & \multirow{3}{*}{ Bhattacherjee (2000) } \\
\cline { 2 - 3 } Fc & English & $\begin{array}{l}\text { I feel that I lack having access to all resources } \\
\text { needed to select....... }\end{array}$ & \\
\cline { 2 - 3 } 2 & Spanish & $\begin{array}{l}\text { Siento que me faltan los recursos necesarios } \\
\text { para poder elegir la opción }\end{array}$ & \\
\hline
\end{tabular}




\subsection{Scenarios}

Then, in order to analyze the moderating effects of situational factors (i.e. time availability, channel spillover effect, distance to store) in the model, the survey asked respondents to rate their level of agreement using a five-point Likert scale ( -2 = strongly disagree, 2 = strongly agree) with a series of statements mentioned below (attitudinal beliefs) based on the context scenarios.

Table 29 Question of option selection -attitudinal beliefs

\begin{tabular}{|c|c|l|c|}
\hline & Language & \multicolumn{1}{|c|}{$\begin{array}{c}\text { Question of option selection -attitudinal } \\
\text { beliefs }\end{array}$} & \\
\hline A & English & $\begin{array}{l}\text { I think that choosing the following delivery or } \\
\text { return method is a good idea }\end{array}$ & \\
Q & Spanish & $\begin{array}{l}\text { Creo que elegir el siguiente método de envío o } \\
\text { devolución es una buena idea }\end{array}$ & \multirow{2}{*}{$\begin{array}{c}\text { Pookulangara et al. } \\
\text { (2011a) }\end{array}$} \\
\cline { 2 - 3 } A & English & $\begin{array}{l}\text { I like the idea of selecting the following } \\
\text { delivery or return method }\end{array}$ & \\
Q & Spanish & $\begin{array}{l}\text { Me gusta la idea de elegir el siguiente método } \\
\text { de envío o devolución }\end{array}$ & \\
\hline
\end{tabular}

To develop these scenarios, first, the levels of these selected situational factors were defined, as given by Chocarro et al. (2013): time availability (plenty of time vs. under time pressure), distance to store (far vs. nearby), and channel spillover effect (online channel vs. offline channel). Dividing each situational factor into two levels limited the number of possible scenarios and thereby reduced the complexity of the analysis and the error occurred in the results (Wang and $\mathrm{Li}, 2002$ ). All possible combinations of these factors with their two-level factors resulted in eight situational scenarios $(2 * 2 * 2)$, which were applied to the relationship between the attitude and the consumers' intention of a behavior.

Table 30 The scenarios in delivery

\begin{tabular}{|c|c|c|}
\hline & Language & Scenarios \\
\hline \multirow{2}{*}{$\begin{array}{l}\mathrm{S} \\
\mathrm{D} \\
1\end{array}$} & English & $\begin{array}{l}\text { [1] You are buying clothes via online channel. } \\
\text { [2] You want to receive your order as soon as possible. } \\
\text { [3] The collection point is far from your place (at least } 20 \text { minutes } \\
\text { driving). }\end{array}$ \\
\hline & Spanish & $\begin{array}{l}\text { [1] Estás realizando la compra de ropa a través de Internet. } \\
\text { [2] Quieres tener cuanto antes la ropa que te vas a comprar. } \\
\text { [3] El punto de recogida está lejos de tu casa (al menos a } 20 \text { minutos } \\
\text { conduciendo). }\end{array}$ \\
\hline \multirow{2}{*}{$\begin{array}{l}S \\
D \\
2\end{array}$} & English & $\begin{array}{l}\text { [1] You are buying clothes via online channel. } \\
\text { [2] You want to receive your order as soon as possible. } \\
\text { [3] The collection point is near your place. }\end{array}$ \\
\hline & Spanish & $\begin{array}{l}\text { [1] Estás realizando la compra de ropa a través de Internet. } \\
\text { [2] Quieres tener cuanto antes la ropa que te vas a comprar. } \\
\text { [3] El punto de recogida está cerca de tu casa. }\end{array}$ \\
\hline $\begin{array}{l}\text { S } \\
\text { D } \\
3\end{array}$ & English & $\begin{array}{l}\text { [1] You are buying clothes via online channel. } \\
\text { [2] You are not in a hurry to receive your order. } \\
\text { [3] The collection point is far from your place (at least } 20 \text { minutes } \\
\text { driving). }\end{array}$ \\
\hline
\end{tabular}




\begin{tabular}{|c|c|c|}
\hline & Spanish & $\begin{array}{l}\text { [1] Estás realizando la compra de ropa a través de Internet. } \\
\text { [2] No tienes prisa por tener la ropa que te estás comprando. } \\
\text { [3] El punto de recogida está lejos de tu casa (al menos a } 20 \text { minutos } \\
\text { conduciendo). }\end{array}$ \\
\hline \multirow{2}{*}{$\begin{array}{l}\text { S } \\
\text { D } \\
4\end{array}$} & English & $\begin{array}{l}\text { [1] You are buying clothes via online channel. } \\
\text { [2] You are not in a hurry to receive your order. } \\
\text { [3] The collection point is near your place. } \\
\end{array}$ \\
\hline & Spanish & $\begin{array}{l}\text { [1] Estás realizando la compra de ropa a través de Internet. } \\
\text { [2] No tienes prisa por tener la ropa que te estás comprando. } \\
\text { [3] El punto de recogida está cerca de tu casa. }\end{array}$ \\
\hline \multirow{2}{*}{$\begin{array}{l}\text { S } \\
\text { D } \\
5\end{array}$} & English & $\begin{array}{l}\text { [1] You are buying clothes via offline channel. } \\
\text { [2] You want to receive your order as soon as possible. } \\
\text { [3] The collection point is far from your place (at least } 20 \text { minutes } \\
\text { driving). }\end{array}$ \\
\hline & Spanish & $\begin{array}{l}\text { [1] Realizas la compra de la ropa directamente en la tienda. } \\
\text { [2] Quieres tener cuanto antes la ropa que te vas a comprar. } \\
\text { [3] El punto de recogida está lejos de tu casa (al menos a } 20 \text { minutos } \\
\text { conduciendo). }\end{array}$ \\
\hline \multirow{2}{*}{$\begin{array}{l}\text { S } \\
\text { D } \\
6\end{array}$} & English & $\begin{array}{l}\text { [1] You are buying clothes via offline channel. } \\
\text { [2] You want to receive your order as soon as possible. } \\
\text { [3] The collection point is near your place. }\end{array}$ \\
\hline & Spanish & $\begin{array}{l}\text { [1] Realizas la compra de la ropa directamente en la tienda. } \\
\text { [2] Quieres tener cuanto antes la ropa que te vas a comprar. } \\
\text { [3] El punto de recogida está cerca de tu casa. }\end{array}$ \\
\hline \multirow{2}{*}{$\begin{array}{l}\text { S } \\
\mathrm{D} \\
7\end{array}$} & English & $\begin{array}{l}\text { [1] You are buying clothes via offline channel. } \\
\text { [2] You are not in a hurry to receive your order. } \\
\text { [3] The collection point is far from your place (at least } 20 \text { minutes } \\
\text { driving). }\end{array}$ \\
\hline & Spanish & $\begin{array}{l}\text { [1] Realizas la compra de la ropa directamente en la tienda. } \\
\text { [2] No tienes prisa por tener la ropa que te estás comprando. } \\
\text { [3] El punto de recogida está lejos de tu casa (al menos a } 20 \text { minutos } \\
\text { conduciendo). }\end{array}$ \\
\hline \multirow{2}{*}{$\begin{array}{l}\text { S } \\
\text { D } \\
8\end{array}$} & English & $\begin{array}{l}\text { [1] You are buying clothes via offline channel. } \\
\text { [2] You are not in a hurry to receive your order. } \\
\text { [3] The collection point is near your place. }\end{array}$ \\
\hline & Spanish & $\begin{array}{l}\text { [1] Realizas la compra de la ropa directamente en la tienda. } \\
\text { [2] No tienes prisa por tener la ropa que te estás comprando. } \\
\text { [3] El punto de recogida está cerca de tu casa. }\end{array}$ \\
\hline
\end{tabular}

Table 31 The scenarios in return

\begin{tabular}{|c|c|c|}
\hline & Language & Scenarios \\
\hline \multirow{2}{*}{$\begin{array}{l}\mathrm{S} \\
\mathrm{R} \\
1\end{array}$} & English & $\begin{array}{l}\text { [1] You are going to return the clothes that you had bought via online } \\
\text { channel. } \\
\text { [2] You want to return your order as soon as possible. } \\
\text { [3] The return point is far from your place (at least } 20 \text { minutes } \\
\text { driving). }\end{array}$ \\
\hline & Spanish & $\begin{array}{l}\text { [1] Vas a devolver la ropa que habías comprado por Internet. } \\
\text { [2] Quieres devolver lo antes posible la ropa que compraste. } \\
\text { [3] El punto de devolución está lejos de tu casa (al menos a } 20 \text { minutos } \\
\text { conduciendo). }\end{array}$ \\
\hline $\begin{array}{l}\mathrm{S} \\
\mathrm{R} \\
2\end{array}$ & English & $\begin{array}{l}\text { [1] You are going to return the clothes that you had bought via online } \\
\text { channel. } \\
\text { [2] You want to return your order as soon as possible. }\end{array}$ \\
\hline
\end{tabular}




\begin{tabular}{|c|c|c|}
\hline & & [3] The return point is near your place. \\
\hline & Spanish & $\begin{array}{l}\text { [1] Vas a devolver la ropa que habías comprado por Internet. } \\
\text { [2] Quieres devolver lo antes posible la ropa que compraste. } \\
\text { [3] El punto de devolución está cerca de tu casa. }\end{array}$ \\
\hline \multirow{2}{*}{$\begin{array}{l}\mathrm{S} \\
\mathrm{R} \\
3\end{array}$} & English & $\begin{array}{l}\text { [1] You are going to return the clothes that you had bought via online } \\
\text { channel. } \\
\text { [2] You are not in a hurry to return your order. } \\
\text { [3] The return point is far from your place (at least } 20 \text { minutes } \\
\text { driving). }\end{array}$ \\
\hline & Spanish & $\begin{array}{l}\text { [1] Vas a devolver la ropa que habías comprado por Internet. } \\
\text { [2] No tienes prisa en devolver la ropa que habías comprado. } \\
\text { [3] El punto de devolución está lejos de tu casa (al menos a } 20 \text { minutos } \\
\text { conduciendo). }\end{array}$ \\
\hline \multirow{2}{*}{$\begin{array}{l}\mathrm{S} \\
\mathrm{R} \\
4\end{array}$} & English & $\begin{array}{l}\text { [1] You are going to return the clothes that you had bought via online } \\
\text { channel. } \\
\text { [2] You are not in a hurry to return your order. } \\
\text { [3] The return point is near your place. }\end{array}$ \\
\hline & Spanish & $\begin{array}{l}\text { [1] You are going to return the clothes that you had bought via offline } \\
\text { channel. } \\
\text { [2] You want to return your order as soon as possible. } \\
\text { [3] The return point is far from your place (at least } 20 \text { minutes } \\
\text { driving). }\end{array}$ \\
\hline \multirow{2}{*}{$\begin{array}{l}S \\
R \\
5\end{array}$} & English & $\begin{array}{l}\text { [1] You are buying clothes via offline channel. } \\
\text { [2] You want to receive your order as soon as possible. } \\
\text { [3] The collection point is far from your place (at least } 20 \text { minutes } \\
\text { driving). }\end{array}$ \\
\hline & Spanish & $\begin{array}{l}\text { [1] Vas a devolver la ropa que habías comprado en la tienda. } \\
\text { [2] Quieres devolver lo antes posible la ropa que compraste. } \\
\text { [3] El punto de devolución está lejos de tu casa (al menos a } 20 \text { minutos } \\
\text { conduciendo). }\end{array}$ \\
\hline \multirow{2}{*}{$\begin{array}{l}\text { S } \\
\mathrm{R} \\
6\end{array}$} & English & $\begin{array}{l}\text { [1] You are going to return the clothes that you had bought via offline } \\
\text { channel. } \\
\text { [2] You want to return your order as soon as possible. } \\
\text { [3] The return point is near your place. }\end{array}$ \\
\hline & Spanish & $\begin{array}{l}\text { [1] Vas a devolver la ropa que habías comprado en la tienda. } \\
\text { [2] Quieres devolver lo antes posible la ropa que compraste. } \\
\text { [3] El punto de devolución está cerca de tu casa. }\end{array}$ \\
\hline \multirow{2}{*}{$\begin{array}{l}\mathrm{S} \\
\mathrm{R} \\
7\end{array}$} & English & $\begin{array}{l}\text { [1] You are going to return the clothes that you had bought via offline } \\
\text { channel. } \\
\text { [2] You are not in a hurry to return your order. } \\
\text { [3] The return point is far from your place (at least } 20 \text { minutes } \\
\text { driving). }\end{array}$ \\
\hline & Spanish & $\begin{array}{l}\text { [1] Vas a devolver la ropa que habías comprado en la tienda. } \\
\text { [2] No tienes prisa en devolver la ropa que habías comprado. } \\
\text { [3] El punto de devolución está lejos de tu casa (al menos a } 20 \text { minutos } \\
\text { conduciendo). }\end{array}$ \\
\hline \multirow{2}{*}{$\begin{array}{l}\mathrm{S} \\
\mathrm{R} \\
8\end{array}$} & English & $\begin{array}{l}\text { [1] You are going to return the clothes that you had bought via offline } \\
\text { channel. } \\
\text { [2] You are not in a hurry to return your order. } \\
\text { [3] The return point is near your place. }\end{array}$ \\
\hline & Spanish & $\begin{array}{l}\text { [[1] Vas a devolver la ropa que habías comprado en la tienda. } \\
\text { [2] No tienes prisa en devolver la ropa que habías comprado. } \\
\text { [3] El punto de devolución está cerca de tu casa. }\end{array}$ \\
\hline
\end{tabular}


$86 \mid$ P a g e 
Chapter 5: Statistical technique used 


\subsection{Introduction}

The statistical technique used for this empirical study is Partial Least Squares, also known as PLS. PLS is a multivariate analysis technique, which contains principal component analysis, factorial analysis, discriminant analysis or multiple regression, and its objective is to measure models (Wold, 1980). However, like other techniques, this technique is not exempt from some limitations (e.g., measuring simple models with only one dependent variable and several independent ones). To overcome these limitations, the second-generation techniques are presented, incorporated with the firstgeneration technique, in which a set of interrelated dependency relationships can be estimated simultaneously- known as Models of Structural Equations (PLS-SEM). This technique is adequate when a theory is being developed and the theoretical knowledge is scarce (Wold, 1985). Therefore, PLS shows great potential for exploratory analyses, while the results from other analyses such as confirmatory analyses are less satisfactory due to its low capacity to filter some variables (Tobias, 1995).

\subsection{Justification for using the PLS-SEM technique}

To analyze parameters of structural equation models, two approaches can be carried out: covariance-based is known as SEM (CB-SEM) and variance-based known as PLS-SEM (Hair et al., 2017). PLS-SEM and SEM (CB-SEM) share the same characteristics regarding the measurement and structural models. However, the difference between both lies in their objective. Firstly, PLS-SEM focuses on prediction through estimators and their variances, and therefore, it is recommended for exploratory investigations. In contrast, the SEM (CB-SEM) is recommended for confirmatory studies, because it focuses on parameter estimation through the analysis of the covariance between the multiple variables (Hair et al., 2017). Secondly, PLS-SEM estimates model parameters via ordinary least squares regression (OLS), while CB-SEM is applied to the maximum likelihood method. The PLS-SEM technique estimates the relationships between the endogenous variables of the model with the objective of minimizing the residual variance of all the variables dependent on the model (Chin, 1998). Finally, PLS-SEM emerged as a study method for research related to behavior and social sciences in which, generally, there is no extensive theoretical basis and a reduced level of information is used. The main differences between both methods are summarized in the following table.

Table 32 Differences between both methods

\begin{tabular}{|l|l|l|}
\hline \multicolumn{1}{|c|}{ Criteria } & \multicolumn{1}{|c|}{ PLS-SEM } & \multicolumn{1}{c|}{ CB-SEM } \\
\hline Objective & Prediction & Estimation of parameters \\
\hline Approach & Based on variance & Based on covariance \\
\hline Assumptions & & $\begin{array}{l}\text { Usually multivariate normal last- } \\
\text { mile logistics and independent }\end{array}$ \\
\hline & Specification of the predictor & observations \\
\hline
\end{tabular}




\begin{tabular}{|c|c|c|}
\hline Estimation of parameters & $\begin{array}{l}\text { Consistent as the number of } \\
\text { indicators and sample size } \\
\text { increases }\end{array}$ & Consistent \\
\hline Score of latent variables & Explicitly estimated Indeterminate & Indeterminate \\
\hline $\begin{array}{l}\text { Epistemic relationships between } \\
\text { latent variables and their } \\
\text { measurements }\end{array}$ & $\begin{array}{l}\text { They can be modeled in both } \\
\text { reflective and formative forms }\end{array}$ & $\begin{array}{l}\text { Usually only with reflective } \\
\text { indicators }\end{array}$ \\
\hline Implications & Optimal for prediction accuracy & $\begin{array}{l}\text { Optimal for complexity accuracy } \\
\text { of models }\end{array}$ \\
\hline Complexity of the models & Great complexity & Small to moderate complexity \\
\hline Sample size & $\begin{array}{l}\text { Power analysis based on the } \\
\text { model portion with the largest } \\
\text { number of predictors }\end{array}$ & $\begin{array}{l}\text { Ideally based on the power of } \\
\text { analysis of a specific model }\end{array}$ \\
\hline
\end{tabular}

Therefore, it could be said that PLS-SEM is a better and more appropriate technique to be used since it is suitable for exploratory analyses, such as the one carried out in this research, while (CB-SEM) are more suited to the analyses aimed at confirming an existing theory.

\subsection{Characteristics of the PLS-SEM model}

PLS-SEM model evaluates the relationships between the variables and also the variables themselves. In fact, based on these evaluations, the hypotheses of the investigation will be examined. The evaluation also includes the measuring indicators themselves in order to examine the validity of each indicator. The PLS-SEM technique is composed of three fundamental elements:

- Construct (latent or non-observable variable): These variables are known as not being able to be measured experimentally. However, these variables are represented by a set of observable variables. These variables can be of two types, endogenous or dependent and exogenous or independent, which act as predictor variables of the endogenous variables.

- Indicators (observable variables): These variables are known as being able to be measured directly via observation. These variables can also be categorized into two types of indicators (MacKenzie et al., 2005):

o Reflective indicators (effects): These indicators express unobservable constructs. Since these indicators are manifesting the constructs, it is necessary to have a strong correlation between them and other indicators. This means that any changes in the constructs will produce changes in the indicators - indicators have a linear functional relationship with construct, plus an error term. Therefore, these indicators can be considered interchangeable. 
o Formative indicators (causal): These indicators are considered as causes or determinants of the construct (MacCallum \& Browne, 1993), and do not need to be correlated with each other. In fact, these indicators are recognized as a weight of the variables and jointly plus an error influence a construct. In other words, if an indicator is omitted, a part of the meaning of the construct will be deleted and will be considered a part of measurement error. Therefore, these indicators are not interchangeable.

- Relationships between variables: Represent the predictive or causal relationships of two variables. These relationships can be either between constructs or between constructs and indicators.

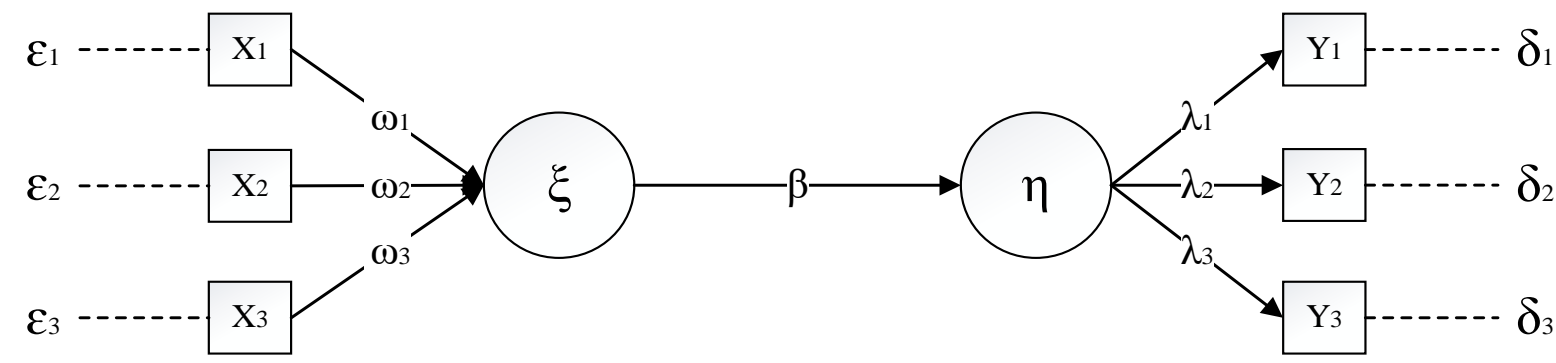

Figure 19 PLS-SEM model (Source: Hair et al. (2017))

Once the topology of the PLS-SEM model has been specified, it is necessary to estimate the parameters. The parameters mentioned are estimated through simple and multiple regression, and least-squares ordinary. The process in detail is explained in the following (Barclay et al., 1995):

The first step of PLS-SEM is to estimate the value of the endogenous construct, which is obtained simply by measuring the value of variables.

The second step is to estimate the weights $(\omega)$ of the endogenous construct by regression between dependent variables and independent variables. The estimated weights will give an initial value for the exogenous construct.

The factor loads for the reflective indicators are estimated through a series of simple regressions of the reflective indicators on the exogenous construct. The estimated weights will give an initial value for the endogenous construct.

The procedure continues until the difference between consecutive iterations is extremely small. Finally, the regression coefficient between the exogenous construct and endogenous construct is calculated.

\subsection{Characteristics of the sample}

In this section, the characteristics of the sample needed in the investigation, such as the size of the sample, the normality of the sample, a statistical technique for analyzing the data and interpretation of the model as criteria of PLS-SEM will be discussed. 
In order to obtain correct conclusions, it is important to find the minimum size of the sample population that is needed to analyze and validate the research model built with PLS-SEM. According to Reinartz et al. (2009), PLS-SEM is an appropriate statistical technique, which allows working with small samples. Moreover, it guarantees the statistical validity in the complex models with small samples, compared with the method of the structural equation, which is based on covariance and needs a huge number of samples. To determine the number of the samples needed, the following general rules need to be considered:

- The sample size must be at least ten times greater than the number of indicators of the complex model.

- In the case of having constructs with reflective indicators, the sample size must be at least ten times greater than the number of constructs that are routed to a particular dependent construct in the structural model.

Due to this technique, the complexity of the model has little influence on the minimum size of the sample needed, since it does not calculate the existing relations in the model simultaneously. Hence, it is recommended to take into account other rules such as those proposed by J. E. Cohen (1988). In this method, the minimum sample size is detected by the variability of the statistical response, the level of statistical significance used - usually $5 \%(\alpha=0.05)$. Table 33 shows the minimum sample size required to detect a minimum coefficient with $R^{2}$ of: $0.10,0.25,0.50$ and 0.75 in any endogenous number in the model for statistical significance levels of $1 \%, 5 \%$ and $10 \%$.

Table 33 Minimum sample size required to detect a minimum coefficient

\begin{tabular}{|c|c|c|c|c|c|c|c|c|c|c|c|c|}
\hline \multirow{4}{*}{$\begin{array}{l}\text { Maximum number } \\
\text { of arrows pointing } \\
\text { at a construct }\end{array}$} & \multicolumn{12}{|c|}{ Significance level } \\
\hline & \multicolumn{4}{|c|}{$1 \%$} & \multicolumn{4}{|c|}{$5 \%$} & \multicolumn{4}{|c|}{$10 \%$} \\
\hline & \multicolumn{4}{|c|}{ Minimum $R^{2}$} & \multicolumn{4}{|c|}{ Minimum $R^{2}$} & \multicolumn{4}{|c|}{ Minimum $R^{2}$} \\
\hline & 0.10 & 0.25 & 0.50 & 0.75 & 0.10 & 0.25 & 0.50 & 0.75 & 0.10 & 0.25 & 0.50 & 0.75 \\
\hline 2 & 158 & 75 & 47 & 38 & 110 & 52 & 33 & 26 & 88 & 41 & 26 & 21 \\
\hline 3 & 176 & 84 & 53 & 42 & 124 & 59 & 38 & 30 & 100 & 48 & 30 & 25 \\
\hline 4 & 191 & 91 & 58 & 46 & 137 & 65 & 42 & 33 & 111 & 53 & 34 & 27 \\
\hline 5 & 205 & 98 & 62 & 50 & 147 & 70 & 45 & 36 & 120 & 58 & 37 & 30 \\
\hline 6 & 217 & 103 & 66 & 53 & 157 & 75 & 48 & 39 & 128 & 62 & 40 & 32 \\
\hline 7 & 228 & 109 & 69 & 56 & 166 & 80 & 51 & 41 & 136 & 66 & 42 & 35 \\
\hline 8 & 238 & 114 & 73 & 59 & 174 & 84 & 54 & 44 & 143 & 69 & 45 & 37 \\
\hline 9 & 247 & 119 & 76 & 62 & 181 & 88 & 57 & 46 & 150 & 73 & 47 & 39 \\
\hline 10 & 256 & 123 & 79 & 64 & 189 & 91 & 59 & 48 & 156 & 76 & 49 & 41 \\
\hline
\end{tabular}


By considering this information, for this research, in order to validate and analyze the model, the minimum sample size needed is 174 samples with the level of statistical significance of $5 \%(\alpha=0.05)$.

\subsection{Analysis of the PLS model}

Once the PLS-SEM model has been developed based on the research hypotheses and the sample size needed to verify the model, it is time to introduce the statistical tool for this action. These measurements focus on the relationships between the observable variables (indicators or independent variables) and the endogenous variables (constructs or dependent variables) as well as the relationships between the endogenous variables. The analysis of the PLS-SEM model is carried out by Smart PLS 3 software in the following two phases, which will be discussed in the following parts.

\subsubsection{Evaluation of measuring instrument (indicators or independent variables)}

In this stage, the reliability and validity of the independent variables that have been considered to obtain the data corresponding to the endogenous variables are evaluated - verifying those ones that wish to measure. This analysis guarantees the validity of the study design and the reliability and consistency of the data obtained. However, when evaluating the measuring instrument, it is essential to distinguish between reflective and formative indicators, because they should be treated differently.

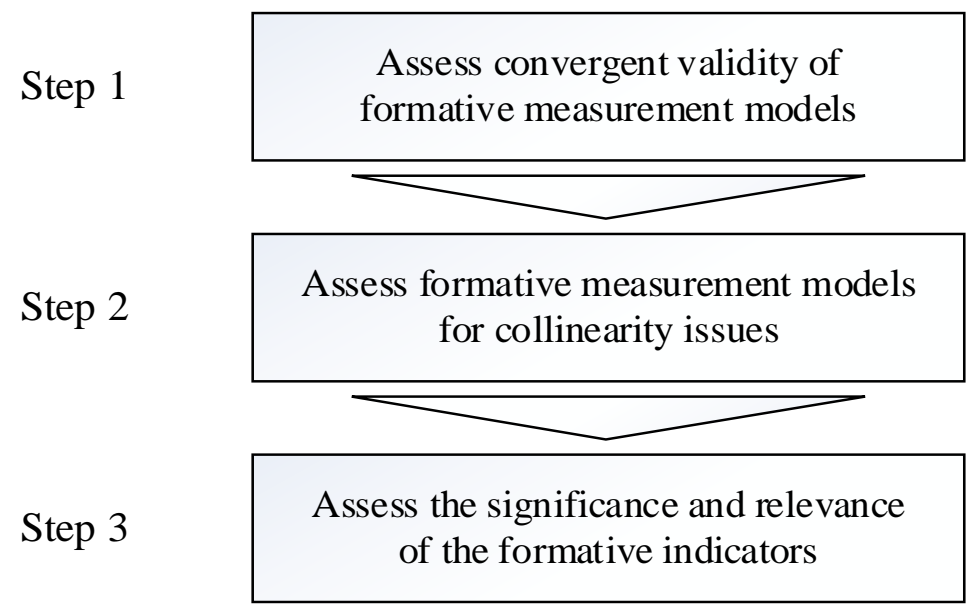

Figure 20 Evaluation of measuring instrument steps (Source: Hair et al. (2017))

\subsubsection{Reflective Indicators}

The first step is to analyze the reliability of the indicators by factorial loads $\left(\lambda_{i}\right)$ or simple correlations of each indicator with their respective construct. The most accepted rule for accepting an indicator as valid to measure a construct, is that the factor load reaches at least a minimum of 0.707. The underlying reason for setting is related to the concept of indicator commonality, which is defined as the square of the standardized load $\left(\lambda_{i}^{2}\right)$. Communality represents how much variance of the indicator is shared with the construct. Generally, it is accepted that a latent variable must explain at least $50 \%$ of the variance of the indicator; this implies that the shared variance is greater than the error variance. Therefore, the minimum load must be 0.707 since $0.707^{2}>0.5$, although in most cases a standardized load level greater than 0.7 is accepted ) (Hair et al., 2017) (Step 1). 
Moreover, indicators that show a load between 0.4 and 0.7 should evaluate their elimination by analyzing the reliability constructs or Average Variance Extracted (AVE) (Hair et al., 2017). On the other hand, those indicators that do not reach a standardized factor load of 0.4 should be removed from the measurement model (Hair et al., 2017). Figure below schematically shows the steps of whether or not to remove an indicator from the measurement model.

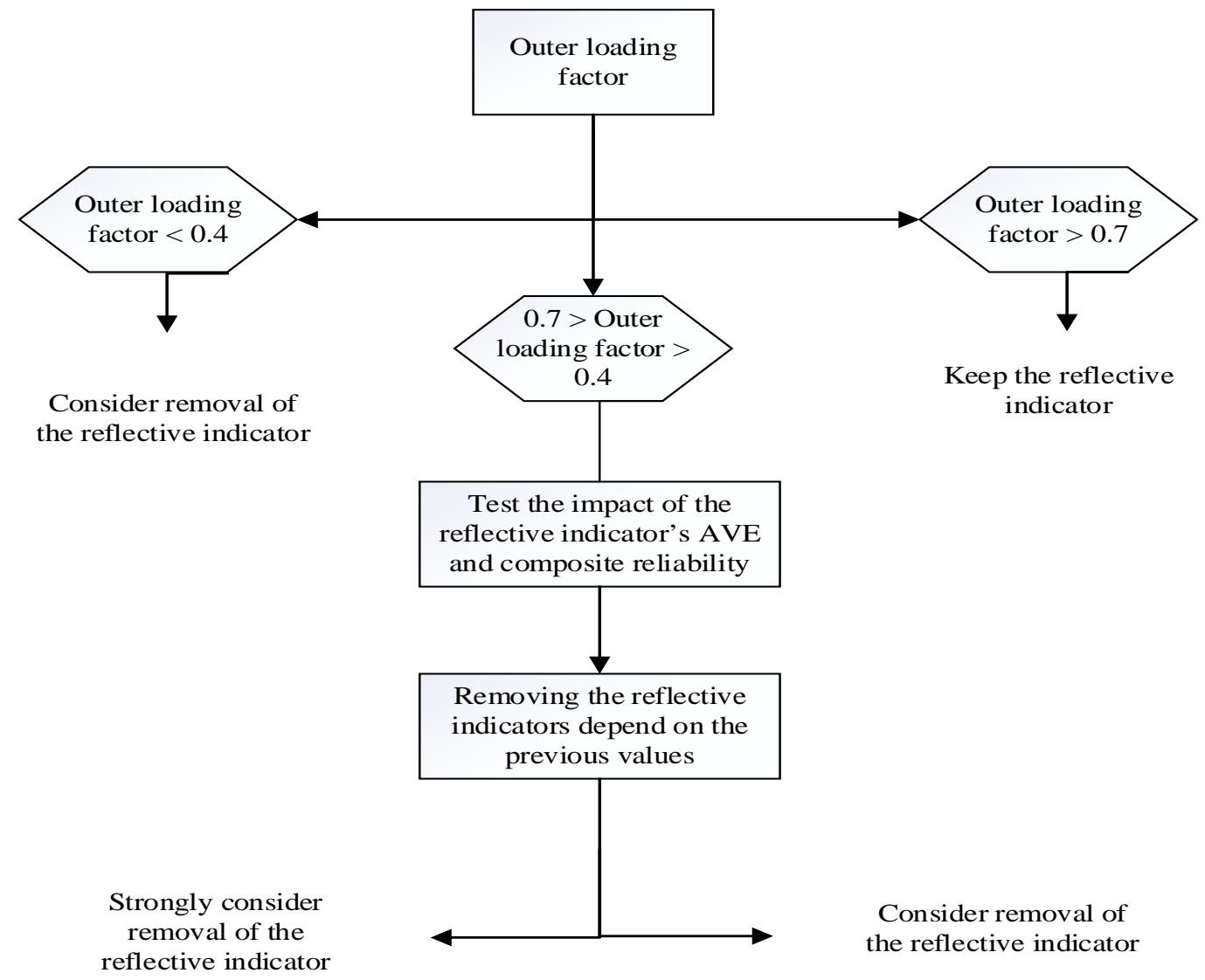

Figure 21 The steps to eliminate or keep the formative indicators (Source: Hair et al. (2017))

Based on the previous paragraph, it is necessary to measure the reliability of the indicators. The classic criterion used to assess the reliability of the constructs by Cronbach's alpha. This index is based on the correlations between the observable variables of the latent variable. Another alternative to evaluate the measuring instrument is the composite reliability index $(\rho c)$ (Werts et al., 1974). This index may be more appropriate than Cronbach's alpha according to Fornell and Larcker (1981), since it prioritizes the indicators according to their reliability, while Cronbach's alpha considers that the reliability of all the indicators is the same and equal to the unit (Barclay et al., 1995). The composite reliability varies between 0 and 1 . As the value approaches 1 , the internal consistency of the construct will be greater. Its interpretation should be made in the same sense as Cronbach's alpha: values between 0.6 and 0.7 can be considered acceptable in exploratory studies, while in the case of confirmation of theories, values between 0.7 and 0.9 will be necessary (Nunally \& Bernstein, 1994 ). Values above 0.9 and especially above 0.95 may indicate that the items on the measurement are extremely similar and do not really 
cover all the features of the construct that is intended to be measured (Hayduk \& Littvay, 2012) (Step 2).

Like the previous section in order to check the internal consistency of all the indicators that measure a construct, it is necessary to evaluate the observable variables of a certain construct by convergent validity. In convergent validity, the observable variables must be strongly correlated with each other. To do so, convergent validation is verified in practice by observing the Average Variance Extracted (AVE) of the constructs. The AVE provides us with a measure of the amount of variance that a construct obtains from its indicators in relation to the amount of variance due to the measurement error (Fornell \& Larcker, 1981); in other words, the explained variance (Gefen \& Straub, 2005). According to Fornell and Larcker (1981), the AVE must reach a minimum value of 0.5 to be able to affirm that there is convergent validation. This fact means that more than half of the variance explained by the latent variable, is due to its observable variables (Step 3).

Last but not least step in assessing the reflective indicators is to analyze the discriminant validity. This measurement is verified through a certain construct that is measuring a certain concept different from that of the other constructs present in the model. In practice, for discriminant validity to exist, there must be weak correlations between one construct and the other constructs in the model (Cepeda Carrión \& Salgueiro 2004). The evaluation consists of verifying that the square root of AVE ( $\sqrt{ } A V E(Y i))$ of each construct. Fornell and Larcker (1981) recommend that the AVE should be greater than 0.5. The reason behind this criterion is that a construct shares more variance with its indicators than with any construct in the model (Hair et al., 2017) (Step 4).

\subsubsection{Formative indicators}

The first step is evaluating the convergent validity of formative indicators by correlating the formative factor of the measured construct with a reflective factor of the same construct (Step 1). However, to do so, it is necessary to add indicators. Executing this approach also needs to define new reflective indicators in the research design and to obtain a new sample size collection for the research. Including sets of reflective constructs for each formative construct, thereby defining reflective indicators, will not be desirable and will increase the survey length. Having a long survey will more likely result in respondents' fatigue, low response rates, an increase in missing values, and thereby data bias. Furthermore, establishing reflective indicators may not be a suitable method, and constructing a new scale is difficult and time-consuming. An alternative is to use global variables, which summarize the essence of the construct (Sarstedt et al., 2014).

Despite the fact that the importance of the first step was not highlighted by previous studies, the next two steps were bold. In fact, researchers should use these two steps critically and examine whether a particular indicator should be included or not. The second step is to examine collinearity among formative indicators. This examination is for checking that the indicator's information is redundant in 
case of having high correlations with other indicators of the same construct. Under high correlations, PLS-SEM cannot estimate the coefficients of the relationships. In practice, having collinearity has two main effects. The first is that it increases the standard error, and therefore, makes it impossible to show that the weights are different than zero. The second effect has to do with the correct estimation of the weights, as well as the inversion of the sign of the same. To estimate collinearity, tolerance (TOL) or inflation factor of variance (VIF) are calculated. If tolerance is less than 0.20 or if the variance inflation factor (VIF) exceeds 5, it will be acceptable to maintain the indicator in the model (Kleinbaum et al., 1988). Otherwise, it is necessary to omit the formative indicator (Step 2).

The second step is to check that a formative indicator may or may not significantly contribute to the construct. This aspect examines the (statistical) significance and relevance of the formative indicators (Step 3). In order to do that, it is necessary to use a multiple regression between the constructs and their formative indicators (Hair et al., 2017). The comparison allows knowing the relative contribution of each indicator to the dependent variable. To confirm that an indicator contributes to the dependent variable with a value considerably greater than zero, it is necessary to use the bootstrapping procedure. Through this procedure, we will obtain the t-values that will allow us to know if the indicator is statistically significant or not.

If an indicator is not significant as a result of the analysis, it should not be automatically eliminated from the model. In fact, according to Hair et al. (2017), in this case, the loading of this indicator should be measured. If the loading is greater than 0.5 , the indicator should be retained in the model. When the loading is less than 0.5 , it will be up to the researcher to maintain the indicator in the model or not. However, researchers strongly recommend removing this indicator form the model, due to the potential overlap in terms of content with other indicators.

Figure below shows schematically the steps needed to decide whether to eliminate the indicators or not in the case of measuring indicators. 


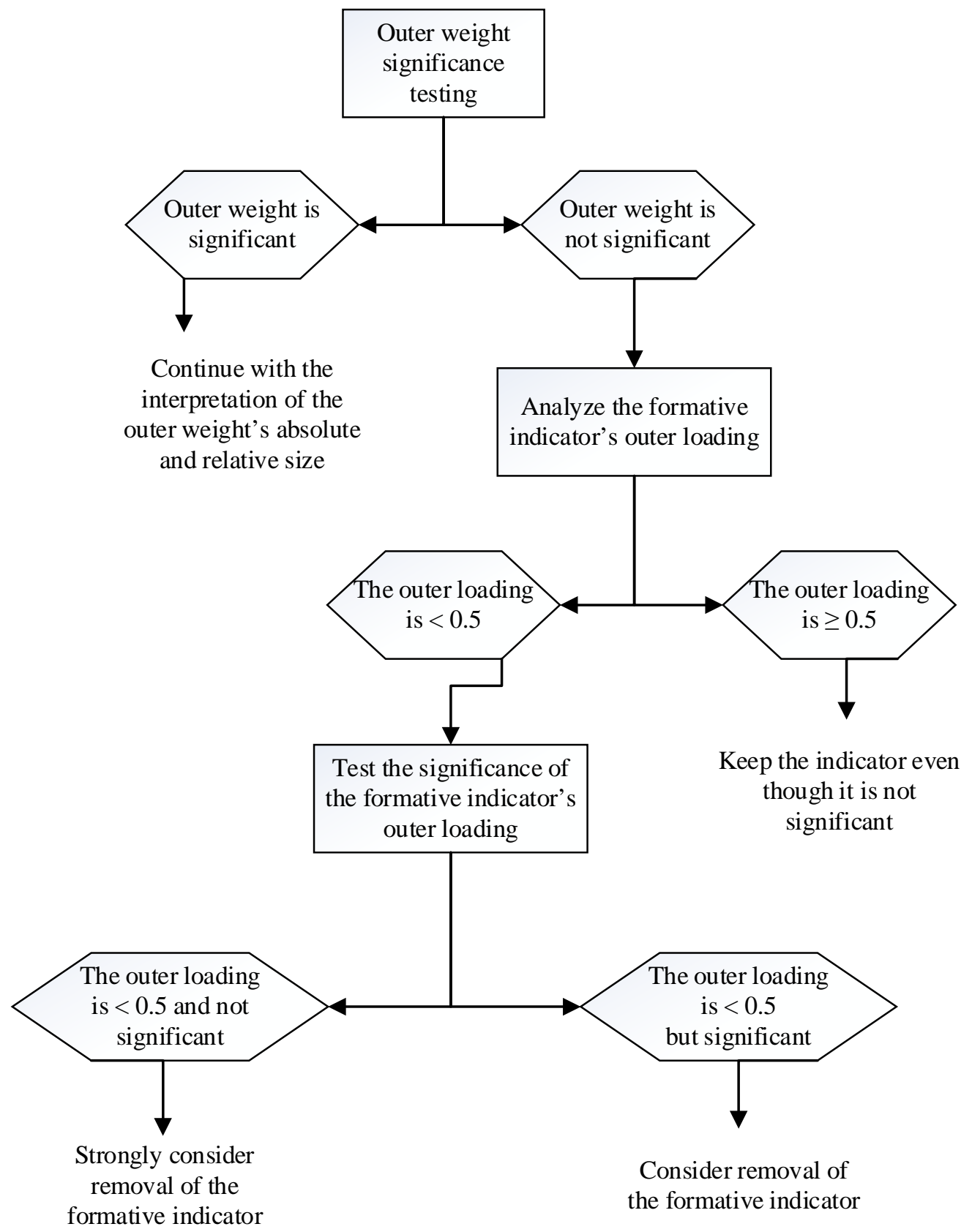

Figure 22 The steps to eliminate or keep the formative indicators (Source: Hair et al. (2017))

\subsubsection{Evaluation of the structural model}

After confirming that the indicators are reliable and valid during the procedures mentioned above, the next stage is to evaluate the results of the structural model. This consists of evaluating the predictive capabilities of the model and the relationships between the constructs. To do so, figure below shows a systematic approach to evaluate the results of the structural model. 


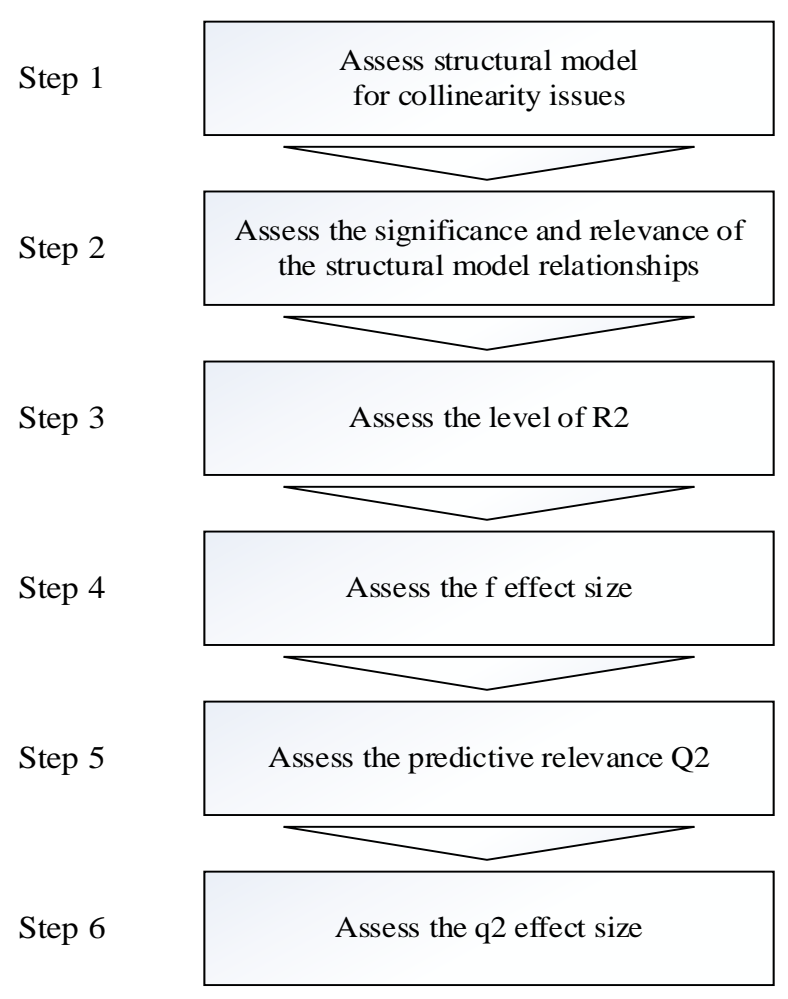

Figure 23 The systematic approach to evaluate the structural model (Source: Hair et al. (2017))

The first step to do before carrying out the analysis of the structural model is the evaluation of collinearity (Step 1). To evaluate collinearity, the same tool of evaluation of formative indicators should be used (i.e., tolerance and variance inflation factor (VIF) -the critical level of collinearity occurs for tolerance when it is less than or equal to 0.2 and for VIF value when it is equal to or greater than five and VIF values). The reason for carrying out this analysis is to understand the coefficients ( $\beta$ ) of the relations between the constructs, which are based on ordinary least squares regressions. Multicollinearity analysis happens when in the structural model, two or more constructs act as predictors of another indicator of another construct.

The next step, which is the key criterion for evaluating the structural model in PLS-SEM, is Path Coefficients (Step 2). Once it has been verified that there are no collinearity problems, the structural model would be evaluated in terms of its predictive capacity. The key criteria are to analyze the magnitude of the relations between constructs - path coefficients - and their statistical significance. This analysis shows that to what extent a construct can predict other sub-constructs. In addition, it shows the relationship between variables. In fact, the path coefficients would confirm if there is a relationship between variables and thereby would support the hypothesis mentioned in the theoretical model (Hair et al., 2017). According to Cepeda Carrión and Salgueiro (2004), the desirable values of the path coefficients should be above 0.3 in order to show the strong relationship between variables. In addition, values between 0.1 and 0.2 are considered a moderate influence. In order to obtain this coefficient path, the researcher uses SPSS 21.00 IBM, since Smart PLS does not provide this analysis. 


$$
Y_{i}=\beta_{1} x_{i 1}+\beta_{2} x_{i 2}+\cdots+\beta_{j} x_{i j}+\varepsilon_{i}
$$

In addition to understanding the magnitude of the path coefficients, statistical significance should be measured. To obtain the statistical significance of the values of the path coefficients, due to the nature of PLS, since it cannot be obtained directly, it is necessary to resort to nonparametric techniques of resampling such as bootstrap. This statistical technique offers both the standard errors and the t-values of the last-mile logistics and consists of performing a resampling $n$ sets of $m$ subsamples. Each sample is obtained by replacing the original data set until the number of cases is identical to the original sample set (Chin, 1998). From the bootstrap result, we obtain the t-values with n-1 degrees of freedom, where $\mathrm{n}$ is the number of subsamples. Traditionally bootstrap's sample was a minimum of 500 and with a number of cases equal to that of observations of the original sample (Chin, 1998); however, Hair et al. (2017) recommended the number of resampling to 5000.

Table 34 The critical values of t student last-mile logistics for 5000 samples, for one and two tails

\begin{tabular}{|c|c|c|}
\hline P-values & Two tail & One tail \\
\hline 0,1 & 1,65 & 1,28 \\
\hline 0,05 & 1,96 & 1,65 \\
\hline 0,01 & 2,57 & 2,33 \\
\hline
\end{tabular}

The next step is to measure the level of the $\mathrm{R}^{2}$ values (Step 3). This value represents the predictive power of the dependent variables of the model and it is obtained via squared correlation between a specific endogenous latent variable and latent variable predictors. According to Falk \& Miller (1992), the coefficient value should be greater than 0.1 and the value lower than this amount shows weak relationships between constructs and the predictive level would be very low. As a general rule by (Hair et al., 2017), $\mathrm{R}^{2}$ values of $0.75,0.50$, and 0.25 can be interpreted as strong, moderate, and weak.

The $\mathrm{f}^{2}$ effect size is another step in the evaluation of the structural model (Step 4), which determines if the influence of an independent construct on a dependent construct is significant or not. The previous tests are insufficient in practical situations. This test allows us to know if a predictor variable has a substantial impact on the dependent variable (Chin, 1998). To obtain this effect, the following equation is used. According to J. E. Cohe (1988), the values obtained from this equation can be interpreted. 0.02, 0.15 , and 0.35 correspond to a small, medium, and large effect of the predictor variable on the dependent variable.

$$
f^{2}=\frac{R_{\text {included }}^{2}-R_{\text {excluded }}^{2}}{1-R_{\text {included }}^{2}}
$$


In order to evaluate the predictive relevance of relations (Step 5) between constructs the Stone-Geisser Test $\left(\mathrm{Q}^{2}\right)$ is used. This test determines the influence of predictor variables on other dependent variables. To obtain $\mathrm{Q}^{2}$, the blindfolding technique is carried out. This method basically consists of omitting part of a determined construct and estimating the parameters with the remaining data (Cohen, 1988; Tenenhaus et al., 2005; Henseler et al., 2009). Then, the conducted results are used to predict the omitted data. The difference between the real data and the estimated data is used as an input for the value of $\mathrm{Q}^{2}$. Generally, if $\mathrm{Q}^{2}$ is greater than zero, it means that the relationship between two constructs has predictive relevance.

The final step is to measure the $\mathrm{q}^{2}$ effect size (Step 6). Similar to the $f^{2}$ effect size method for evaluating $\mathrm{R}^{2}$, it is also possible to know the change in the predictive relevance via measuring the $\mathrm{q}^{2}$ effect size, formally defined as follows:

$$
q^{2}=\frac{Q_{\text {included }}^{2}-Q_{\text {excluded }}^{2}}{1-Q_{\text {included }}^{2}}
$$

Similarly, according to J. E. Cohe (1988), the values obtained from this equation can be interpreted accordingly. $0.02,0.15$, and 0.35 correspond to a small, medium, and large effect of the predictor variable on the dependent variable.

\subsubsection{Evaluation of the Moderator in the model}

Sometimes, cause-effect relationships between exogenous constructs and endogenous constructs are influenced by other variables. These variables, which are known as mediation and moderating variables, can easily change the nature of the relationship in the model (Hair et al., 2017). In other words, the relationship between dependent variables and independent variables can be differed by the values of the third variables. The two most prominent variables are mediation and moderation. Each of these variables can be divided into the categorical moderator/mediation variable and continuous moderator/mediation variables. However, in this particular research, due to the importance, categorical moderating variable will only be explained in the following.

Categorical moderating variables are known as the third variables in the relationship between two constructs, which can change the strength or even the direction of a relationship. Moreover, these variables can be understood as a way to explain the heterogeneity of the sample's data and are usually dummy coded. The figure shows how moderating effects are modeled. 


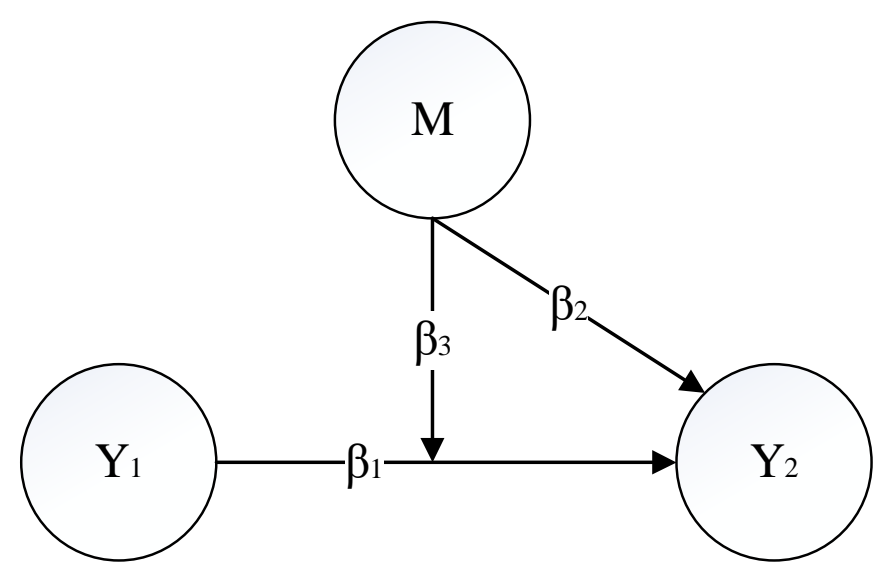

Figure 24 Moderating effects in the model (Source: Hair et al. (2017))

$$
Y_{2}=\beta_{1} \cdot Y_{1}+\beta_{2} \cdot \mathrm{M}+\beta_{3} \cdot\left(Y_{1} \cdot \mathrm{M}\right)
$$

According to Hair et al. (2017), there are three approaches to calculate the moderator effect between variables:(1) the product indicator approach, (2) the orthogonal approach, and (3) the two-stage approach. Concerning the first approach, it could be said that this approach is not applicable when there are formative indicators, since formative indicators do not have to correspond to a predefined theoretical concept, which in this case, produces a set of indicators, leading to the distortion of the interaction term. The second approach, which is the orthogonal approach, like the previous one, can only be used when the exogenous constructs and moderating variables are reflective, and the moderating variables are continuous variables.

However, the last approach, which is the two-stage approach, is a suitable approach for this study. It allows analyzing the moderator effect in models where the exogenous variable and/or the moderating variable are formative. As its names imply, this approach consists of two stages, which are:

Stage 1: The main analyses of PLS-SEM model are carried out without considering the interaction term (the moderate effect) to obtain the scores for constructs of the model.

Stage 2: The main analyses of PLS-SEM model are carried out this time with the interaction term (the moderate effect) to calculate the scores for constructs of the model.

\subsubsection{Summary of the PLS-SEM method}

Table 35 The summary of formative indicators in PLS-SEM model

\begin{tabular}{|c|c|}
\hline \multicolumn{2}{|c|}{ The summary of reflective indicators in PLS-SEM model } \\
\hline Factorial loads $(\lambda)$ & - $\quad$ Minimum load $>0.707$ \\
\hline Reliability of the indicators & $\begin{array}{l}\text { - Cronbach's alpha: values between } 0.6 \text { and } \\
0.7 \\
\text { - } \quad \text { Composite reliability varies between } 0 \\
\text { and } 1\end{array}$ \\
\hline
\end{tabular}




\begin{tabular}{|c|c|}
\hline & $\begin{array}{ll}- & \text { AVE }>0.5 \\
\text { - } & \text { Discriminant validity }\end{array}$ \\
\hline \multicolumn{2}{|c|}{ The summary of formative indicators in PLS-SEM model } \\
\hline Multi-collinearity & $\begin{array}{ll}\text { - } & \text { Tolerance }(\mathrm{TOL}>0.2) \\
\text { - } & \text { Variance inflation factor }(\mathrm{VIF}<5)\end{array}$ \\
\hline $\begin{array}{l}\text { Level of relevance and } \\
\text { significance }\end{array}$ & $\begin{array}{l}\text { - If outer weight is significant and load is }> \\
=0.5 \text { then keep the indicator } \\
\text { - If outer weight is not significant and load } \\
\text { is }>=0.5 \text { then keep the indicator } \\
\text { - If outer weight is not significant and load } \\
\text { is }<0.5 \text { and the theory supports it, then } \\
\text { keep the indicator } \\
\text { - If outer weight is not significant, and load } \\
\text { is }<0.5 \text { and theory does not support it, } \\
\text { then it is strongly recommended to omit } \\
\text { the indicator }\end{array}$ \\
\hline
\end{tabular}

Table 36 The summary of the structural model PLS-SEM

\begin{tabular}{|c|c|}
\hline \multicolumn{2}{|c|}{ The summary of the structural model PLS-SEM } \\
\hline Multi-collinearity & $\begin{array}{ll}\text { - } & \text { Tolerance }(\mathrm{TOL}>0.2) \\
\text { - } & \text { Variance inflation factor }(\mathrm{VIF}<5)\end{array}$ \\
\hline Coefficient path & $\begin{array}{ll}- & \text { Moderate relationship if } \beta \text { is between } 0.1 \\
\text { and } 0.2 \\
\text { - }\end{array}$ \\
\hline $\mathrm{R}^{2}$ & $\begin{array}{l}\text { - } \quad \text { Maximum prediction level: } 1 \\
\text { - } \quad \text { Strong prediction level: } 0.75 \\
\text { - } \quad \text { Moderate prediction level: } 0.5 \\
\text { - } \quad \text { Weak prediction level: } 0.25\end{array}$ \\
\hline $\mathrm{f}^{2}$ effect size & $\begin{array}{ll}\text { - } & \text { Small: } 0.02 \\
\text { - } & \text { Medium: } 0.15 \\
\text { - } & \text { Large: } 0.35\end{array}$ \\
\hline $\mathrm{Q}^{2}$ & - $\quad$ Predictive relevance $\left(\mathrm{Q}^{2>} 0\right)$ \\
\hline $\mathrm{q}^{2}$ effect size & $\begin{array}{ll}- & \text { Small: } 0.02 \\
- & \text { Medium: } 0.15 \\
\text { - } & \text { Large: } 0.35\end{array}$ \\
\hline
\end{tabular}


Chapter 6: Data analysis and results 


\subsection{Description of the sample}

A national sample on individuals aged 18 and above was conducted. Of 32,760 questionnaires e-mailed, 2,430 participants tended to participate in the survey. However, of this number of participants, 475 responses were obtained. After consistency controls and checks for completeness, 434 usable questionnaires were available for further analysis. In order to check if the obtained data were representative of the mean and variance of Spain's national population (2018), one-sample Z test and Chi-square test were run. The results from one-sample $Z$ test and Chi-square with $\alpha=0.05$ respectively were $Z(\mu=41.02, \sigma=12.056)=0.0375$ and Chi-square $=1.005$, which demonstrated the mean and variance of samples were representative of the mean of Spain's national population. Moreover, by comparing the demographic characteristics of the sample with Spain's national demographic characteristics, it can be noted that the samples were fairly representative of Spain's national population. The following shows the characteristics of the sample.

\subsubsection{Gender}

The sample shows that about $46.1 \%$ of the respondents were male, which showed that data were almost gender-balanced. The chart below shows the last-mile logistics of respondents by gender:

\begin{tabular}{|c|c|c|}
\hline Variables & $\begin{array}{c}\text { Frequency } \\
(\mathrm{N}=434)\end{array}$ & $\begin{array}{c}\text { PERCENT } \\
(\%)\end{array}$ \\
\hline Male & 200 & $46.1 \%$ \\
\hline Female & 234 & $53.9 \%$ \\
\hline
\end{tabular}

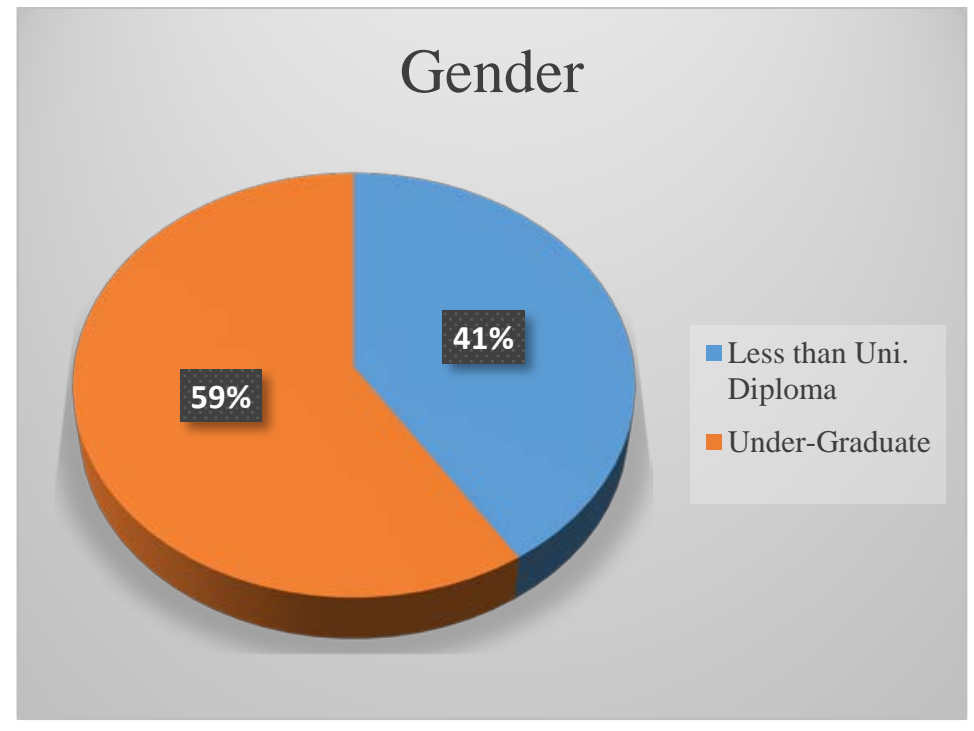

Figure 25 The last-mile logistics of respondents by gender (Source: Author)

The pie chart of gender shows a similar situation in both groups, offline commerce (ONTSI, 2019), and online commerce (ONTSI, 2019).

\subsubsection{Age}

The age pie chart shows that the majority are between 38 and 47 years old, with 120 people (27.7\%). Graphically, the age in last-mile logistics is represented as follows: 


\begin{tabular}{|c|c|c|}
\hline Variables & $\begin{array}{c}\text { Frequency } \\
(\mathrm{N}=434)\end{array}$ & $\begin{array}{c}\text { PERCENT } \\
(\%)\end{array}$ \\
\hline $18-27$ & 79 & $18.3 \%$ \\
\hline $28-37$ & 94 & $21.8 \%$ \\
\hline $38-47$ & 120 & $27.7 \%$ \\
\hline $48-57$ & 102 & $23.6 \%$ \\
\hline Over 57 & 38 & $8.6 \%$ \\
\hline
\end{tabular}

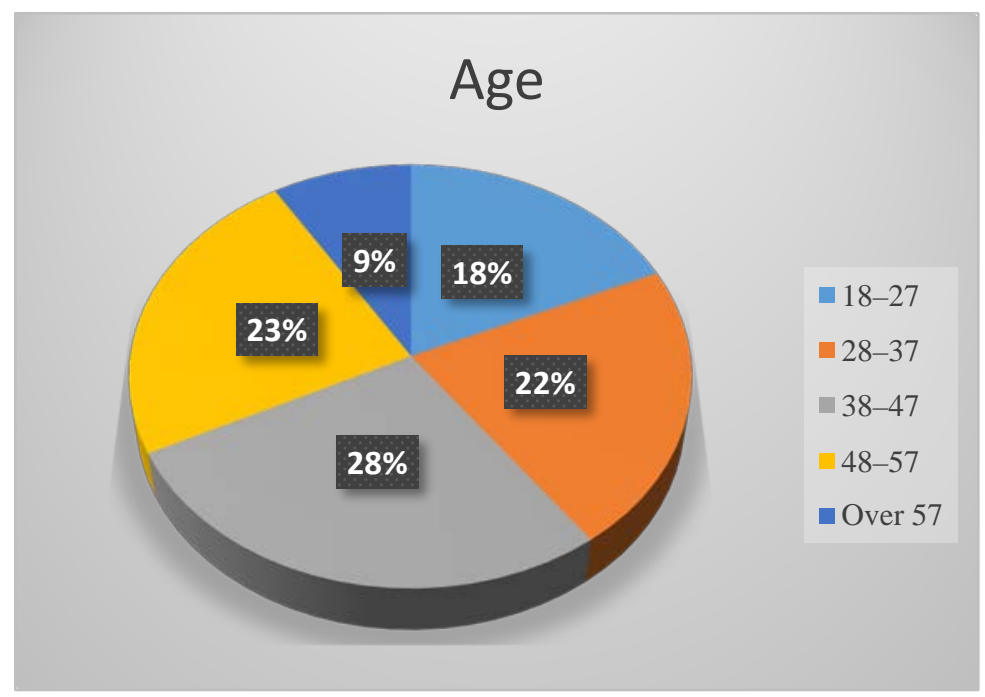

Figure 26 The last-mile logistics of respondents by age (Source: Author)

The last-mile logistics of the sample has a high representation of all groups under the age of 48 . It is worth mentioning that the survey has been distributed among groups of different ages. However, the results lack greater representation of elderly people, which can be due to the fact that this group of people has lower access to the Internet and the purchase through the online channel. Compared with the data about the behavior of purchase via Internet in Spain, the majority belong to individuals between 25 and 50 years old (ONTSI, 2019). According to the data mentioned in Chapter 4, 17.1\% of people under 27 years old, $46 \%$ of people from 26 to 45 years old, and $13.3 \%$ of people over 47 years old buy online. Hence, the sample is representative of Spain's national population.

\subsubsection{Income}

The pie chart of income shows that $55.7 \%$ of the samples are having a monthly household income of over $€ 1,500$. The results show a uniform last-mile logistics of the sample, with very similar group sizes. Graphically, the income of last-mile logistics is represented as follows: 


\begin{tabular}{|l|c|c|}
\hline \multicolumn{1}{|c|}{ Variables } & $\begin{array}{c}\text { Frequency } \\
(\mathrm{N}=434)\end{array}$ & $\begin{array}{c}\text { Percent } \\
(\%)\end{array}$ \\
\hline $\begin{array}{l}\text { Less than } \\
€ 500\end{array}$ & 33 & $7.6 \%$ \\
\hline $\begin{array}{l}€ 500- \\
€ 999\end{array}$ & 65 & $15 \%$ \\
\hline $\begin{array}{l}€ 1,000- \\
€ 1,499\end{array}$ & 94 & $21.7 \%$ \\
\hline $\begin{array}{l}€ 1,500- \\
€ 1,999\end{array}$ & 87 & $20 \%$ \\
\hline $\begin{array}{l}€ 2,000- \\
€ 2,499\end{array}$ & 61 & $14.4 \%$ \\
\hline $\begin{array}{l}€ 2,500- \\
€ 2,999\end{array}$ & 45 & $11.3 \%$ \\
\hline $\begin{array}{l}€ 3,000 \text { or } \\
\text { more }\end{array}$ & $49 \%$ \\
\hline
\end{tabular}

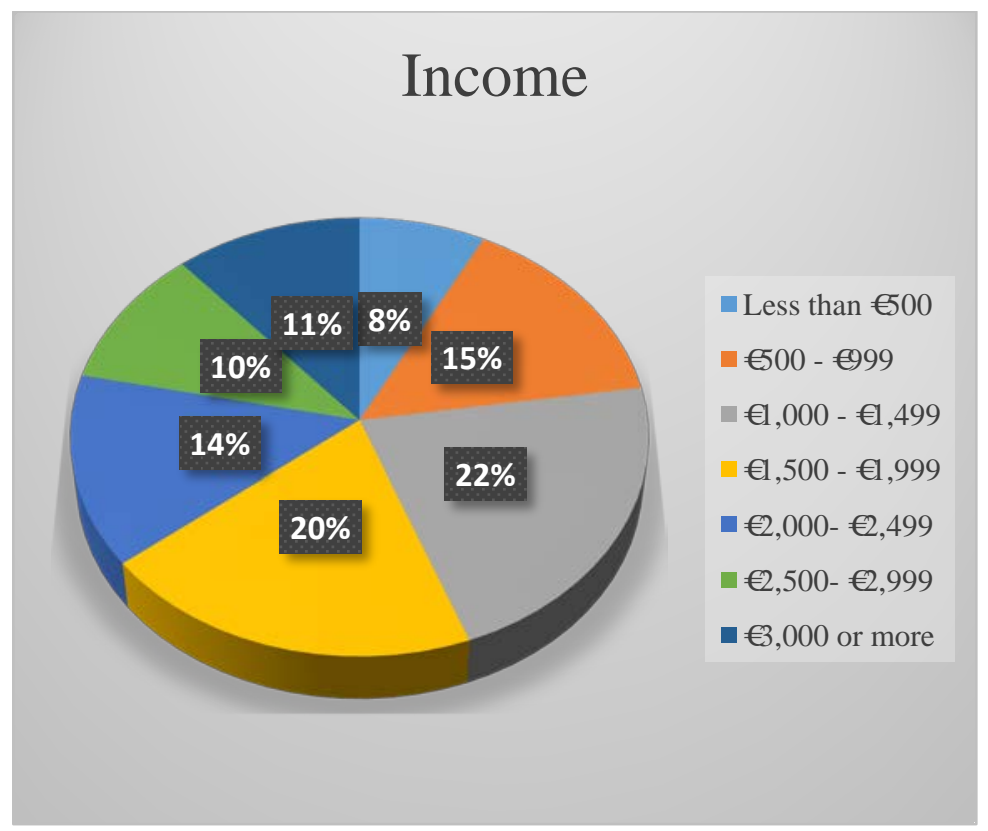

Figure 27 The last-mile logistics of respondents by Income (Source: Author)

The analysis of the behavior of Spanish society shows that participation in the online channel is much more common in middle and high social classes than in the lower classes of the population (ONTSI, 2019). The samples also show that the majority are above the middle class who actively buy online or offline.

\subsubsection{The education level}

The education level of last-mile logistics of the sample shows that roughly $87.5 \%$ of the respondents had the education at the university level or beyond (Degree (13.4\%), Master (50.5\%), and Ph.D. (23.6\%)). The pie chart below represents the last-mile logistics of respondents by the education level:

\begin{tabular}{|l|c|c|}
\hline Variables & $\begin{array}{c}\text { Frequency } \\
(\mathrm{N}=434)\end{array}$ & $\begin{array}{c}\text { Percent } \\
(\%)\end{array}$ \\
\hline $\begin{array}{l}\text { Less than } \\
\text { Uni. } \\
\text { Diploma }\end{array}$ & 40 & 9.3 \\
\hline $\begin{array}{l}\text { Under- } \\
\text { Graduate }\end{array}$ & 58 & 13.4 \\
\hline Master & 219 & 50.5 \\
\hline PhD & 103 & 23.6 \\
\hline $\begin{array}{l}\text { Profession } \\
\text { al degree }\end{array}$ & 14 & 3.2 \\
\hline
\end{tabular}

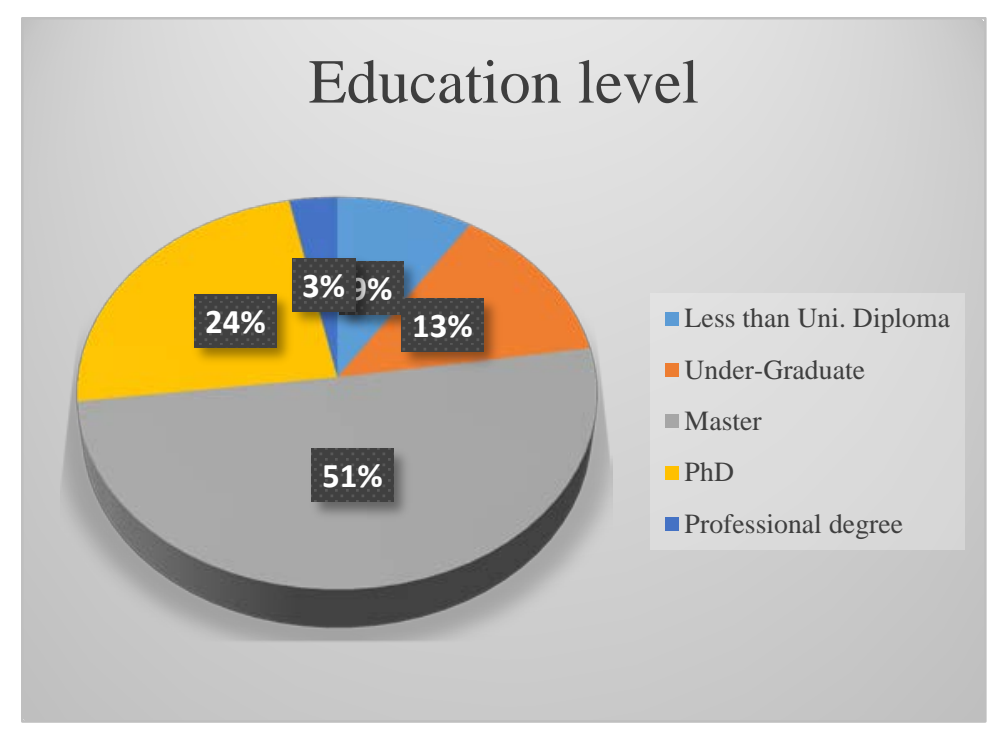

Figure 28 The last-mile logistics of respondents by education level (Source: Author) 
The education level of the Spanish population shows that in 2018, $52.7 \%$ and $43.6 \%$ of the population respectively are without academic background and with academic background. By comparing with the data obtained, it could be concluded that in the case of education level, there is discrimination for the population without academic education.

\subsection{Analysis of the collected data}

In accordance with the research model and hypotheses proposed in Chapter 4 and Chapter 5, in the present section, we will analyze the results of the data, which were described in the previous section.

The objective of this preliminary analysis is to analyze the validity of the research model with respect to the fundamental variables. Although this analysis is not necessary when applying the SEM-PLS technique, Hair et al., (2017) recommend proceeding this analysis in order to ensure that the sample does not depart excessively from the normal last-mile logistics. The data obtained from the survey were analyzed using SmartPLS V3.0. Some analyses were executed.

\subsubsection{Analysis of the indicators}

\subsubsection{Dimensions for home delivery}

The tables below show the values of the means and the standard deviations of the indicators and also mean and standard deviation of the constructs have been measured.

It is worth highlighting that clearly, the important factor among other factors in home delivery option, such as monetary which states the fact that consumers pay attention to cost of home delivery when they are selecting an option.

Table 37 Means and the standard deviations of the indicators for home delivery

\begin{tabular}{|c|c|c|c|c|}
\hline \multicolumn{5}{|c|}{ Home delivery } \\
\hline Indicator & Mean & Standard deviation & Mean of construct & Standard deviation of construct \\
\hline \multicolumn{5}{|l|}{ Monetary } \\
\hline Tc1 & 0,870 & 0,249 & \multirow{2}{*}{0,648} & \multirow{2}{*}{0,255} \\
\hline Tc2 & 0,426 & 0,336 & & \\
\hline \multicolumn{5}{|c|}{ Convenience } \\
\hline Co1 & $-0,828$ & 0,149 & \multirow{3}{*}{0,124} & \multirow{3}{*}{0,108} \\
\hline Co2 & 0,749 & 0,124 & & \\
\hline $\mathrm{Co} 3$ & 0,452 & 0,095 & & \\
\hline \multicolumn{5}{|c|}{ Perceived risk } \\
\hline Pr1 & $-0,967$ & 0,022 & \multirow{4}{*}{$-0,056$} & \multirow{4}{*}{0,101} \\
\hline Pr2 & 0,285 & 0,107 & & \\
\hline Pr3 & 0,206 & 0,106 & & \\
\hline Pr4 & 0,251 & 0,106 & & \\
\hline \multicolumn{5}{|c|}{ Normative beliefs } \\
\hline Nq1 & 0,896 & 0,012 & \multirow{2}{*}{0,888} & \multirow{2}{*}{0,014} \\
\hline Nq2 & 0,880 & 0,016 & & \\
\hline \multicolumn{5}{|c|}{ Self-efficacy } \\
\hline Se1 & 0,874 & 0,019 & \multirow{2}{*}{0,884} & \multirow{2}{*}{0,016} \\
\hline Se2 & 0,894 & 0,013 & & \\
\hline \multicolumn{5}{|c|}{ Facilitating conditions } \\
\hline Fc1 & 0,751 & 0,048 & \multirow{2}{*}{0,841} & \multirow{2}{*}{0,028} \\
\hline Fc2 & 0,931 & 0,012 & & \\
\hline
\end{tabular}




\begin{tabular}{|c|c|c|c|c|}
\hline \multicolumn{5}{|c|}{ Attitude toward a behavior } \\
\hline AQ1 & 0,939 & 0,009 & \multirow{2}{*}{0,938} & \multirow{2}{*}{0,010} \\
\hline AQ2 & 0,938 & 0,010 & & \\
\hline \multicolumn{5}{|c|}{ Subjective norms } \\
\hline SN1 & 0,896 & 0,012 & \multirow{2}{*}{0,888} & \multirow[b]{2}{*}{0,014} \\
\hline SN2 & 0,880 & 0,016 & & \\
\hline \multicolumn{5}{|c|}{ Control perceived behavior } \\
\hline PBC1 & 0,899 & 0,012 & \multirow{2}{*}{0,869} & \multirow{2}{*}{0.020} \\
\hline PBC2 & 0,840 & 0,027 & & \\
\hline \multicolumn{5}{|c|}{ Intention } \\
\hline IQ1 & 0,937 & 0,008 & \multirow{2}{*}{0,932} & \multirow{2}{*}{0.009} \\
\hline IQ2 & 0,928 & 0,011 & & \\
\hline
\end{tabular}

Regarding the collinearity between formative indicators, the values corresponding to the inflation factor of variance (VIF) are lower than 2.4 in all cases, which allows us to affirm that there is no evidence of collinearity between indicators.

On the other hand, after measuring the weight and loading factor of indicators in home delivery, it can be seen that in all cases the indicators were suitable for the model except in some cases such as the privacy risk, the loading is lower than 0.5 . However, the analysis shows that the loading factor of those indicators are significant. When the loading is less than 0.5 and significant, based on the steps, it will be up to the researcher to maintain the indicator in the model or not.

Table 38 Factor loads and indicator weights for Home delivery

\begin{tabular}{|c|c|c|c|c|}
\hline \multicolumn{5}{|c|}{ Home delivery } \\
\hline Indicator & $\begin{array}{c}\text { Factor load (P- } \\
\text { value) }\end{array}$ & Weight & T Statistical & P-value \\
\hline \multicolumn{5}{|l|}{ Monetary } \\
\hline Tc1 & 0,959 & & 5,947 & 0,000 \\
\hline Tc2 & 0,756 & & 3,590 & 0,000 \\
\hline \multicolumn{5}{|l|}{ Convenience } \\
\hline Co1 & $-0,843$ & $-0,691$ & 4,472 & 0,000 \\
\hline $\mathrm{Co} 2$ & 0,764 & 0,607 & 4,963 & 0.000 \\
\hline Co3 & $0,460(0,000)$ & $-0,100$ & 1,253 & 0,210 \\
\hline \multicolumn{5}{|l|}{ Perceived risk } \\
\hline Pr1 & 0,984 & 1,036 & 24,252 & 0,000 \\
\hline Pr2 & $0,292(0,000)$ & $-0,061$ & 0,475 & 0,635 \\
\hline Pr3 & $0,214(0,046)$ & $-0,155$ & 1,394 & 0,163 \\
\hline Pr4 & $0,254(0,021)$ & 0,127 & 1,166 & 0,244 \\
\hline \multicolumn{5}{|l|}{ Normative belief } \\
\hline Nq1 & 0,896 & & 73,425 & 0,000 \\
\hline $\mathrm{Nq} 2$ & 0,880 & & 53,877 & 0,000 \\
\hline \multicolumn{5}{|l|}{ Self-efficacy } \\
\hline Se1 & 0,876 & & 45,837 & 0,000 \\
\hline Se2 & 0,894 & & 67,284 & 0,000 \\
\hline \multicolumn{5}{|c|}{ Facilitating conditions } \\
\hline Fc1 & 0,752 & & 15,512 & 0,000 \\
\hline Fc2 & 0,931 & & 74,866 & 0,000 \\
\hline \multicolumn{5}{|c|}{ Attitude toward a behavior } \\
\hline AQ1 & 0,940 & 0,535 & 99,956 & 0,000 \\
\hline AQ2 & 0,938 & 0,530 & 95,053 & 0,000 \\
\hline
\end{tabular}




\begin{tabular}{|l|c|c|c|c|}
\hline SN1 & 0,896 & 0,514 & 73,425 & 0,000 \\
\hline SN2 & 0,880 & 0,829 & 53,877 & 0,000 \\
\hline Control perceived behavior & 0,899 & 0,633 & 72,778 & 0,000 \\
\hline PBC1 & 0,841 & 0,513 & 30,820 & 0,000 \\
\hline PBC2 & 0,938 & 0,554 & 118,035 & 0,000 \\
\hline Intention & 0,928 & 0,518 & 87,118 & 0,000 \\
\hline IQ1 &
\end{tabular}

Moreover, the Cronbach's alpha and composite reliability's indicators for home delivery are far exceed the value set of 0.7 except for Subjective norms, however, all the AVEs are well above the value set of 0.5 .

Table 39 Convergent validity indicators for home delivery

\begin{tabular}{|l|c|c|c|}
\hline \multicolumn{1}{|c|}{ Constructs } & $\begin{array}{c}\text { Composite } \\
\text { Reliability }\end{array}$ & $\begin{array}{c}\text { Cronbach's } \\
\text { Alpha }\end{array}$ & AVE \\
\hline Attitude toward & 0,937 & 0,866 & 0,882 \\
\hline Control perceived behavior & 0,862 & $\mathbf{0 , 6 8 4}$ & 0,758 \\
\hline Convenience & & & \\
\hline Facilitating condition & 0,833 & $\mathbf{0 , 6 3 1}$ & 0,717 \\
\hline Intention & 0,931 & 0,851 & 0,871 \\
\hline Monetary & 0,853 & 0,701 & 0,746 \\
\hline Perceived risk & & & \\
\hline Reference groups & 0,882 & 0,732 & 0,789 \\
\hline Self-efficacy & 0,878 & 0,723 & 0,783 \\
\hline Subjective norms & $\mathbf{0 , 1 1 7}$ & $\mathbf{- 0 , 5 1 4}$ & 0,588 \\
\hline
\end{tabular}

Applying the Fornell-Larcker criterion, the values of the main diagonal, square root of the AVE, must be greater than the values corresponding to their respective rows and columns. This criterion is met in all cases. Moreover, the discriminant validity is established to make sure the analysis is enough, the result shows that the difference between the correlations is minimal.

Table 40 Discriminant validity using the Fornell-Larcker criterion for Home delivery

\begin{tabular}{|c|c|c|c|c|c|c|c|c|c|c|}
\hline Constructs & 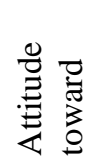 & $\stackrel{u}{n}$ & 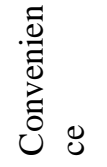 & 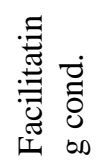 & 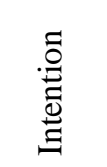 & 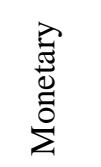 & 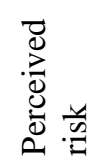 & 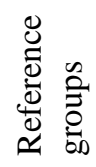 & 岕 & 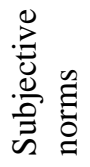 \\
\hline Attitude toward & 0,939 & & & & & & & & & \\
\hline PBC & 0,695 & 0,871 & & & & & & & & \\
\hline Convenience & $-0,640$ & $-0,536$ & N/A & & & & & & & \\
\hline Facilitating cond. & 0,531 & 0,617 & $-0,478$ & 0,846 & & & & & & \\
\hline Intention & 0,862 & 0,695 & $-0,617$ & 0,566 & 0,933 & & & & & \\
\hline Monetary & 0,102 & 0,088 & 0,032 & $-0,074$ & 0,105 & 0,863 & & & & \\
\hline Perceived risk & $-0,421$ & $-0,300$ & 0,507 & $-0,420$ & $-0,446$ & 0,141 & N/A & & & \\
\hline Reference groups & 0,453 & 0,369 & $-0,267$ & 0,220 & 0,462 & 0,244 & $-0,140$ & 0,888 & & \\
\hline
\end{tabular}




\begin{tabular}{|l|l|l|l|l|l|l|l|l|l|l|} 
Self-efficacy & 0,809 & 0,779 & $-0,606$ & 0,651 & 0,783 & 0,109 & $-0,379$ & 0,400 & $\mathbf{0 , 8 8 5}$ & \\
\hline Subjective norms & 0,559 & 0,488 & $-0,542$ & 0,403 & 0,563 & 0,088 & $-0,382$ & 0,768 & 0,517 & $\mathbf{0 , 7 6 7}$ \\
\hline
\end{tabular}

\subsubsection{Dimensions for In-store delivery}

The tables below show the values of the means and the standard deviations of the indicators and also mean and standard deviation of the constructs have been measured.

After reviewing the data, it can be seen that the important factor in In-store delivery option is selfefficacy which can be interpret that consumers have more confidence while selecting in-store delivery.

Table 41 Means and the standard deviations of the indicators for In-store delivery

\begin{tabular}{|c|c|c|c|c|}
\hline \multicolumn{5}{|c|}{ In-store delivery } \\
\hline Indicator & Mean & Standard deviation & Mean of construct & Standard deviation of construct \\
\hline \multicolumn{5}{|l|}{ Monetary } \\
\hline Tc1 & 0,452 & 0,311 & \multirow{2}{*}{0,652} & \multirow[b]{2}{*}{0,307} \\
\hline Tc2 & 0,856 & 0,302 & & \\
\hline \multicolumn{5}{|c|}{ Convenience } \\
\hline Co1 & 0,928 & 0,204 & \multirow{3}{*}{0,232} & \multirow{3}{*}{0,134} \\
\hline Co2 & $-0,151$ & 0,103 & & \\
\hline Co3 & $-0,079$ & 0,104 & & \\
\hline \multicolumn{5}{|c|}{ Perceived risk } \\
\hline Pr1 & 0,855 & 0,073 & \multirow{4}{*}{$-0,310$} & \multirow{4}{*}{0,139} \\
\hline Pr2 & $-0,151$ & 0,151 & & \\
\hline Pr3 & 0,049 & 0,145 & & \\
\hline Pr4 & 0,490 & 0,127 & & \\
\hline \multicolumn{5}{|c|}{ Normative beliefs } \\
\hline $\mathrm{Nq} 1$ & 0,645 & 0,527 & \multirow{2}{*}{0,648} & \multirow{2}{*}{0,548} \\
\hline $\mathrm{Nq} 2$ & 0,651 & 0,569 & & \\
\hline \multicolumn{5}{|c|}{ Self-efficacy } \\
\hline Se1 & 0,761 & 0,045 & \multirow{2}{*}{0,800} & \multirow{2}{*}{0,035} \\
\hline Se2 & 0,839 & 0,025 & & \\
\hline \multicolumn{5}{|c|}{ Facilitating conditions } \\
\hline Fc1 & 0,731 & 0,056 & \multirow[b]{2}{*}{0,827} & \multirow{2}{*}{0,036} \\
\hline Fc2 & 0,924 & 0,020 & & \\
\hline \multicolumn{5}{|c|}{ Attitude toward a behavior } \\
\hline AQ1 & 0,903 & 0,013 & \multirow{2}{*}{0,906} & \multirow{2}{*}{0,012} \\
\hline AQ2 & 0,910 & 0,012 & & \\
\hline \multicolumn{5}{|c|}{ Subjective norms } \\
\hline SN1 & 0,693 & 0,457 & \multirow{2}{*}{0,222} & \multirow{2}{*}{0,468} \\
\hline SN2 & $-0,248$ & 0,486 & & \\
\hline \multicolumn{5}{|c|}{ Control perceived behavior } \\
\hline PBC1 & 0,895 & 0,014 & \multirow{2}{*}{0,866} & \multirow{2}{*}{0.027} \\
\hline PBC2 & 0,838 & 0,031 & & \\
\hline \multicolumn{5}{|l|}{ Intention } \\
\hline IQ1 & 0,930 & 0,008 & כ2רי & 000 \\
\hline IQ2 & 0,914 & 0,012 & & \\
\hline
\end{tabular}

Regarding the collinearity between formative indicators, the values corresponding to the inflation factor of variance (VIF) are lower than 1.7 in all cases, which allows us to affirm that there is no evidence of collinearity between indicators. 
On the other hand, after measuring the weight and loading factor of indicators in in-store delivery, it can be seen that in all cases the indicators were suitable for the model except in some cases such as the financial risk, the loading is lower than 0.5. Moreover, the analysis shows that the loading factor of those indicators are not significant. Thus, in the next analysis they will be removed.

Table 42 Factor loads and indicator weights for In-store delivery

\begin{tabular}{|c|c|c|c|c|}
\hline \multicolumn{5}{|c|}{ In-store delivery } \\
\hline Indicator & $\begin{array}{c}\text { Factor load (P- } \\
\text { value) }\end{array}$ & Weight & T Statistical & P-value \\
\hline \multicolumn{5}{|l|}{ Monetary } \\
\hline Tc1 & 0,463 & & 1,486 & 0,137 \\
\hline Tc2 & 0,996 & & 3,303 & 0,001 \\
\hline \multicolumn{5}{|l|}{ Convenience } \\
\hline Co1 & $-0,976$ & 0,956 & 4,697 & 0,000 \\
\hline Co2 & $-0,292(0,023)$ & $-0,158$ & 1,529 & 0.126 \\
\hline Co3 & $-0,237(0,062)$ & $-0,085$ & 0,815 & 0,415 \\
\hline \multicolumn{5}{|l|}{ Perceived risk } \\
\hline Pr1 & 0,879 & 0,879 & 24,252 & 0,000 \\
\hline Pr2 & $0,202(0,137)$ & $-0,158$ & 0,475 & 0,294 \\
\hline Pr3 & $0,201(0,158)$ & 0,053 & 1,394 & 0,716 \\
\hline Pr4 & 0,494 & 0,503 & 1,166 & 0,000 \\
\hline \multicolumn{5}{|l|}{ Normative belief } \\
\hline Nq1 & 0,980 & & 1,859 & 0,063 \\
\hline $\mathrm{Nq} 2$ & 0,771 & & 1,354 & 0,176 \\
\hline \multicolumn{5}{|l|}{ Self-efficacy } \\
\hline Se1 & 0,837 & & 33,756 & 0,000 \\
\hline Se2 & 0,765 & & 16,825 & 0,000 \\
\hline \multicolumn{5}{|c|}{ Facilitating conditions } \\
\hline Fc1 & 0,924 & & 47,347 & 0,000 \\
\hline Fc2 & 0,734 & & 13,032 & 0,000 \\
\hline \multicolumn{5}{|c|}{ Attitude toward a behavior } \\
\hline AQ1 & 0,904 & 0,541 & 68,606 & 0,000 \\
\hline AQ2 & 0,911 & 0,562 & 76,411 & 0,000 \\
\hline \multicolumn{5}{|l|}{ Subjective norms } \\
\hline SN1 & 0,894 & 0,863 & 1,859 & 0,063 \\
\hline SN2 & $-0,505$ & $-0,528$ & 1,039 & 0,299 \\
\hline \multicolumn{5}{|c|}{ Control perceived behavior } \\
\hline PBC1 & 0,899 & 0,629 & 72,778 & 0,000 \\
\hline PBC2 & 0,841 & 0,519 & 30,820 & 0,000 \\
\hline \multicolumn{5}{|l|}{ Intention } \\
\hline IQ1 & 0,930 & 0,567 & 111,602 & 0,000 \\
\hline IQ2 & 0,915 & 0,517 & 76,476 & 0,000 \\
\hline
\end{tabular}

Moreover, the Cronbach's alpha and composite reliability's indicators for in-store delivery far exceed the value set of 0.7 except for Subjective norms, however, all the AVEs are well above the value set of 0.5 . 
Table 43 Convergent validity indicators for home delivery

\begin{tabular}{|l|c|c|c|}
\hline \multicolumn{1}{|c|}{ Constructs } & $\begin{array}{c}\text { Composite } \\
\text { Reliability }\end{array}$ & $\begin{array}{c}\text { Cronbach's } \\
\text { Alpha }\end{array}$ & AVE \\
\hline Attitude toward & 0,903 & 0,785 & 0,823 \\
\hline Control perceived behavior & 0,860 & $\mathbf{0 , 6 7 6}$ & 0,754 \\
\hline Convenience & & & \\
\hline Facilitating condition & 0,819 & $\mathbf{0 , 5 9 0}$ & 0,696 \\
\hline Intention & 0,919 & 0,825 & 0,851 \\
\hline Monetary & 0,728 & 0,701 & 0,603 \\
\hline Perceived risk & & & \\
\hline Reference groups & 0,873 & 0,773 & 0,778 \\
\hline Self-efficacy & 0,783 & $\mathbf{0 , 5 4 9}$ & 0,643 \\
\hline Subjective norms & $\mathbf{0 , 1 0 4}$ & $\mathbf{0 , 0 5 1}$ & 0,588 \\
\hline
\end{tabular}

Applying the Fornell-Larcker criterion, the values of the main diagonal, square root of the AVE, must be greater than the values corresponding to their respective rows and columns. This criterion is met in all cases. Moreover, the discriminant validity is established to make sure the analysis is enough, the result shows that the difference between the correlations is minimal.

Table 44 Discriminant validity using the Fornell-Larcker criterion for In-store deivery

\begin{tabular}{|c|c|c|c|c|c|c|c|c|c|c|}
\hline Constructs & 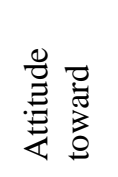 & $\begin{array}{c}u \\
\stackrel{D}{0}\end{array}$ & 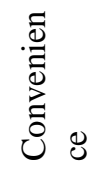 & 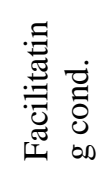 & 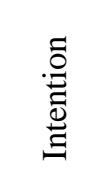 & 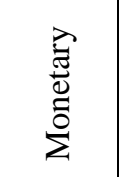 & 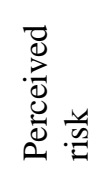 & 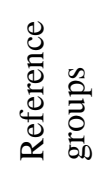 & 志兽 & 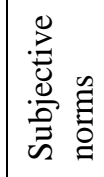 \\
\hline Attitude toward & $\mathbf{0 , 9 0 7}$ & & & & & & & & & \\
\hline PBC & 0,484 & 0,868 & & & & & & & & \\
\hline Convenience & 0,522 & 0,384 & $\mathrm{~N} / \mathrm{A}$ & & & & & & & \\
\hline Facilitating cond. & 0,277 & 0,554 & 0,223 & 0,834 & & & & & & \\
\hline Intention & 0,765 & 0,453 & 0,505 & 0,258 & 0,922 & & & & & \\
\hline Monetary & $-0,140$ & $-0,254$ & $-0,067$ & $-0,370$ & $-0,125$ & $\mathbf{0 , 7 7 7}$ & & & & \\
\hline Perceived risk & $-0,320$ & $-0,177$ & $-0,242$ & $-0,234$ & $-0,345$ & 0,333 & N/A & & & \\
\hline Reference groups & 0,428 & 0,240 & 0,237 & 0,115 & 0,465 & 0,037 & $-0,017$ & 0,882 & & \\
\hline Self-efficacy & 0,640 & 0,597 & 0,451 & 0,499 & 0,598 & $-0,170$ & $-0,265$ & 0,342 & 0,802 & \\
\hline Subjective norms & $-0,214$ & $-0,064$ & $-0,418$ & $-0,097$ & $-0,253$ & 0,122 & 0,375 & 0,043 & $-0,163$ & 0,699 \\
\hline
\end{tabular}

\subsubsection{Dimensions for CDPs}

The tables below show the values of the means and the standard deviations of the indicators and also mean and standard deviation of the constructs have been measured. The values of the means and the standard deviations for CDPs show that consumers prefer to go to these places, because it is cheaper than other options.

After reviewing the data, it can be seen that the important factor in CDPs option is: monetary which states the fact that consumers pay attention to the cost of CDPs when they are selecting an option. 
Table 45 Means and the standard deviations of the indicators for CDPs

\begin{tabular}{|c|c|c|c|c|}
\hline \multicolumn{5}{|c|}{ CDPs } \\
\hline Indicator & Mean & Standard deviation & Mean of construct & Standard deviation of construct \\
\hline \multicolumn{5}{|l|}{ Monetary } \\
\hline Tc1 & 0,644 & 0,315 & \multirow{2}{*}{0,738} & \multirow{2}{*}{0,290} \\
\hline Tc2 & 0,833 & 0,265 & & \\
\hline \multicolumn{5}{|c|}{ Convenience } \\
\hline Co1 & $-0,619$ & 0,497 & \multirow{3}{*}{$-0,064$} & \multirow{3}{*}{0,266} \\
\hline $\mathrm{Co} 2$ & 0,239 & 0,167 & & \\
\hline $\mathrm{Co3}$ & 0,187 & 0,135 & & \\
\hline \multicolumn{5}{|c|}{ Perceived risk } \\
\hline Pr1 & 1,003 & 0,040 & \multirow{4}{*}{0,225} & \multirow{4}{*}{0,103} \\
\hline Pr2 & 0,080 & 0,128 & & \\
\hline Pr3 & $-0,303$ & 0,126 & & \\
\hline Pr4 & 0,122 & 0,118 & & \\
\hline \multicolumn{5}{|c|}{ Normative beliefs } \\
\hline $\mathrm{Nq1}$ & 0,876 & 0,013 & \multirow{2}{*}{0,866} & \multirow{2}{*}{0,015} \\
\hline $\mathrm{Nq} 2$ & 0,856 & 0,018 & & \\
\hline \multicolumn{5}{|c|}{ Self-efficacy } \\
\hline Se1 & 0,778 & 0,027 & \multirow{2}{*}{0,821} & \multirow{2}{*}{0,019} \\
\hline Se2 & 0,865 & 0,012 & & \\
\hline \multicolumn{5}{|c|}{ Facilitating conditions } \\
\hline Fc1 & 0,779 & 0,036 & \multirow{2}{*}{0,846} & \multirow{2}{*}{0,025} \\
\hline Fc2 & 0,914 & 0,013 & & \\
\hline \multicolumn{5}{|c|}{ Attitude toward a behavior } \\
\hline AQ1 & 0,914 & 0,009 & \multirow{2}{*}{0,915} & \multirow{2}{*}{0,009} \\
\hline AQ2 & 0,916 & 0,009 & & \\
\hline \multicolumn{5}{|c|}{ Subjective norms } \\
\hline SN1 & $-0,471$ & 0,084 & \multirow{2}{*}{0,238} & \multirow{2}{*}{0,049} \\
\hline SN2 & 0,947 & 0,014 & & \\
\hline \multicolumn{5}{|c|}{ Control perceived behavior } \\
\hline PBC1 & 0,900 & 0,011 & \multirow{2}{*}{0,890} & \multirow{2}{*}{0.013} \\
\hline PBC2 & 0,881 & 0,014 & & \\
\hline \multicolumn{5}{|l|}{ Intention } \\
\hline IQ1 & 0,930 & 0,008 & & \\
\hline IQ2 & 0,914 & 0,012 & 0,922 & 0.010 \\
\hline
\end{tabular}

Regarding the collinearity between formative indicators, the values corresponding to the inflation factor of variance (VIF) are lower than 2.1 in all cases, which allows us to affirm that there is no evidence of collinearity between indicators.

On the other hand, after measuring the weight and loading factor of indicators in CDPs, it can be seen that in all cases the indicators were suitable for the model except in some cases such as the effort saving, the loading is lower than 0.5. Moreover, the analysis shows that the loading factor of those indicators are not significant. Thus, in the next analysis they will be removed.

Table 46 Factor loads and indicator weights for CDPs

\begin{tabular}{|l|c|c|c|c|}
\hline \multicolumn{1}{|c|}{ CDPs } \\
\hline \multicolumn{1}{|c|}{ Indicator } & $\begin{array}{c}\text { Factor load (P- } \\
\text { value) }\end{array}$ & Weight & T Statistical & P-value \\
\hline Monetary & 0,703 & 2,231 & 0,026 \\
\hline Tc1 & & & \multicolumn{3}{l|}{} \\
\hline
\end{tabular}




\begin{tabular}{|c|c|c|c|c|}
\hline Tc2 & 0,963 & & 3,630 & 0,000 \\
\hline \multicolumn{5}{|c|}{ Convenience } \\
\hline Co1 & $-0,907(0,099)$ & $-0,796$ & 1,602 & 0,109 \\
\hline Co2 & $-0,587(0,070)$ & 0,283 & 1,695 & 0,090 \\
\hline Co3 & $0,502(0,048)$ & 0,218 & 1,616 & 0,106 \\
\hline \multicolumn{5}{|c|}{ Perceived risk } \\
\hline Pr1 & 0,955 & 1,020 & 25,391 & 0,000 \\
\hline Pr2 & $0,228(0,045)$ & 0,080 & 0,620 & 0,536 \\
\hline Pr3 & 0,109 & $-0,306$ & 2,435 & 0,015 \\
\hline Pr4 & $0,240(0,028)$ & 0,127 & 1,076 & 0,282 \\
\hline \multicolumn{5}{|c|}{ Normative belief } \\
\hline Nq1 & 0,876 & & 69,024 & 0,000 \\
\hline $\mathrm{Nq} 2$ & 0,856 & & 47,671 & 0,000 \\
\hline \multicolumn{5}{|c|}{ Self-efficacy } \\
\hline Se1 & 0,885 & & 71,006 & 0,000 \\
\hline Se2 & 0,779 & & 28,409 & 0,000 \\
\hline \multicolumn{5}{|c|}{ Facilitating conditions } \\
\hline Fc1 & 0,914 & & 71,562 & 0,000 \\
\hline Fc2 & 0,780 & & 21,534 & 0,000 \\
\hline \multicolumn{5}{|c|}{ Attitude toward a behavior } \\
\hline AQ1 & 0,915 & 0,544 & 106,009 & 0,000 \\
\hline AQ2 & 0,916 & 0,548 & 100,898 & 0,000 \\
\hline \multicolumn{5}{|c|}{ Subjective norms } \\
\hline SN1 & 0,946 & 0,891 & 69,228 & 0,000 \\
\hline SN2 & $-0,479$ & $-0,329$ & 5,725 & 0,000 \\
\hline \multicolumn{5}{|c|}{ Control perceived behavior } \\
\hline PBC1 & 0,900 & 0,584 & 78,444 & 0,000 \\
\hline PBC2 & 0,881 & 0,538 & 63,019 & 0,000 \\
\hline \multicolumn{5}{|c|}{ Intention } \\
\hline IQ1 & 0,929 & 0,547 & 119,379 & 0,000 \\
\hline IQ2 & 0,925 & 0,533 & 114,444 & 0,000 \\
\hline
\end{tabular}

Moreover, the Cronbach's alpha and composite reliability's indicators for CDPs far exceed the value set of 0.7 except for Subjective norms, however, all the AVEs are well above the value set of 0.5.

Table 47 Convergent validity indicators for CDPs

\begin{tabular}{|l|c|c|c|}
\hline \multicolumn{1}{|c|}{ Constructs } & $\begin{array}{c}\text { Composite } \\
\text { Reliability }\end{array}$ & $\begin{array}{c}\text { Cronbach's } \\
\text { Alpha }\end{array}$ & AVE \\
\hline Attitude toward & 0,912 & 0,806 & 0,838 \\
\hline Control perceived behavior & 0,885 & 0,740 & 0,794 \\
\hline Convenience & & & 0,722 \\
\hline Facilitating condition & 0,838 & $\mathbf{0 , 6 3 0}$ & 0,859 \\
\hline Intention & 0,924 & 0,835 & 0,711 \\
\hline Monetary & 0,828 & $\mathbf{0 , 6 5 3}$ & \\
\hline Perceived risk & & & 0,750 \\
\hline Reference groups & 0,857 & $\mathbf{0 , 6 6 7}$ & 0,677 \\
\hline Self-efficacy & 0,807 & $\mathbf{0 , 5 2 8}$ & 0,562 \\
\hline Subjective norms & $\mathbf{0 , 2 0 0}$ & $\mathbf{- 0 , 4 0 6}$ & \\
\hline
\end{tabular}


Applying the Fornell-Larcker criterion, the values of the main diagonal, square root of the AVE, must be greater than the values corresponding to their respective rows and columns. This criterion is met in all cases. Moreover, the discriminant validity is established to make sure the analysis is enough, the result shows that the difference between the correlations is minimal.

Table 48 Discriminant validity using the Fornell-Larcker criterion for CDPs

\begin{tabular}{|c|c|c|c|c|c|c|c|c|c|c|}
\hline Constructs & 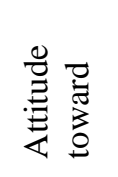 & 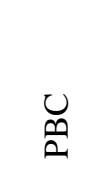 & 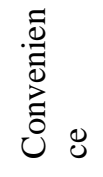 & 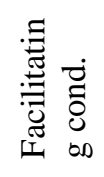 & 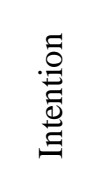 & 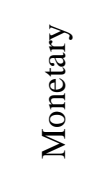 & 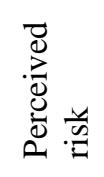 & 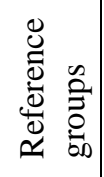 & 岂: & 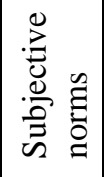 \\
\hline Attitude toward & 0,915 & & & & & & & & & \\
\hline PBC & 0,443 & 0,891 & & & & & & & & \\
\hline Convenience & $\begin{array}{l}-0,588 \\
\end{array}$ & $-0,433$ & N/A & & & & & & & \\
\hline Facilitating cond. & 0,307 & 0,596 & $-0,318$ & 0,850 & & & & & & \\
\hline Intention & 0,807 & 0,477 & $-0,619$ & 0,345 & 0,927 & & & & & \\
\hline Monetary & $-0,024$ & $-0,205$ & 0,176 & $-0,296$ & $-0,077$ & 0,843 & & & & \\
\hline Perceived risk & $\begin{array}{l}-0,377 \\
\end{array}$ & $-0,222$ & 0,398 & $-0,196$ & $-0,464$ & 0,205 & N/A & & & \\
\hline Reference groups & 0,388 & 0,257 & $-0,221$ & 0,214 & 0,407 & 0,081 & $-0,162$ & 0,866 & & \\
\hline Self-efficacy & 0,727 & 0,676 & $-0,550$ & 0,519 & 0,718 & $-0,130$ & $-0,335$ & 0,341 & 0,823 & \\
\hline Subjective norms & 0,455 & 0,314 & $-0,434$ & 0,262 & 0,485 & 0,004 & $-0,300$ & 0,702 & 0,394 & 750 \\
\hline
\end{tabular}

\subsubsection{Dimensions for Home return}

The tables below show the values of the means and the standard deviations of the indicators and also mean and standard deviation of the constructs have been measured. The results show that the value corresponding to some indicators are high such as: convenience. However, the perceived risk is low, this means that consumers perceive more convenience and less perceived risk in home return.

Table 49 Means and the standard deviations of the indicators for Home return

\begin{tabular}{|c|c|c|c|c|}
\hline \multicolumn{5}{|c|}{ Home return } \\
\hline Indicator & Mean & Standard deviation & Mean of construct & Standard deviation of construct \\
\hline \multicolumn{5}{|l|}{ Monetary } \\
\hline Tc1 & 0,765 & 0,303 & \multirow{2}{*}{0,738} & \multirow{2}{*}{0,290} \\
\hline Tc2 & 0,724 & 0,312 & & \\
\hline \multicolumn{5}{|c|}{ Convenience } \\
\hline Co1 & $-0,548$ & 0,079 & \multirow{3}{*}{0,039} & \multirow{3}{*}{0,076} \\
\hline $\mathrm{Co} 2$ & 0,649 & 0,072 & & \\
\hline Co3 & 0,016 & 0,078 & & \\
\hline \multicolumn{5}{|c|}{ Perceived risk } \\
\hline Pr1 & 0,976 & 0,040 & \multirow{4}{*}{0,242} & \multirow{4}{*}{0,081} \\
\hline Pr2 & 0,002 & 0,105 & & \\
\hline Pr3 & 0,047 & 0,089 & & \\
\hline Pr4 & $-0,054$ & 0,091 & & \\
\hline \multicolumn{5}{|c|}{ Normative beliefs } \\
\hline Nq1 & 0,876 & 0,013 & \multirow{2}{*}{0,866} & \multirow{2}{*}{0,015} \\
\hline $\mathrm{Nq} 2$ & 0,856 & 0,018 & & \\
\hline \multicolumn{5}{|c|}{ Self-efficacy } \\
\hline Se1 & 0,856 & 0,019 & \multirow{2}{*}{0,873} & \multirow{2}{*}{0,015} \\
\hline Se2 & 0,890 & 0,012 & & \\
\hline
\end{tabular}




\begin{tabular}{|c|c|c|c|c|}
\hline \multicolumn{5}{|c|}{ Facilitating conditions } \\
\hline Fc1 & 0,776 & 0,042 & \multirow{2}{*}{0,855} & \multirow{2}{*}{0,026} \\
\hline Fc2 & 0,935 & 0,010 & & \\
\hline \multicolumn{5}{|c|}{ Attitude toward a behavior } \\
\hline AQ1 & 0,934 & 0,008 & \multirow{2}{*}{ 0,932 } & \multirow{2}{*}{0,009} \\
\hline AQ2 & 0,931 & 0,010 & & \\
\hline \multicolumn{5}{|c|}{ Subjective norms } \\
\hline SN1 & $-0,527$ & 0,092 & \multirow{2}{*}{0,202} & \multirow{2}{*}{0,057} \\
\hline SN2 & 0,931 & 0,022 & & \\
\hline \multicolumn{5}{|c|}{ Control perceived behavior } \\
\hline PBC1 & 0,888 & 0,014 & \multirow{2}{*}{0,874} & \multirow{2}{*}{0.017} \\
\hline PBC2 & 0,860 & 0,020 & & \\
\hline \multicolumn{5}{|c|}{ Intention } \\
\hline IQ1 & 0,927 & 0,009 & \multirow{2}{*}{0,927} & \multirow{2}{*}{0.09} \\
\hline IQ2 & 0,928 & 0,008 & & \\
\hline
\end{tabular}

Regarding the collinearity between formative indicators, the values corresponding to the inflation factor of variance (VIF) are lower than 2.1 in all cases, which allows us to affirm that there is no evidence of collinearity between indicators.

After measuring the weight and loading factor of indicators in Home return, it can be seen that in all cases the indicators were suitable for the model except in one case: the privacy risk, the loading is lower than 0.5. Moreover, the analysis shows that the loading factor of this indicator is not significant. Thus, in the next analysis it will be removed.

Table 50 Factor loads and indicator weights for Home return

\begin{tabular}{|c|c|c|c|c|}
\hline \multicolumn{5}{|c|}{ Home return } \\
\hline Indicator & $\begin{array}{l}\text { Factor load (P- } \\
\text { value) }\end{array}$ & Weight & T Statistical & P-value \\
\hline \multicolumn{5}{|l|}{ Monetary } \\
\hline Tc1 & 0,496 & & 1,268 & 0,205 \\
\hline Tc2 & 0,983 & & 3,245 & 0,001 \\
\hline \multicolumn{5}{|l|}{ Convenience } \\
\hline Co1 & 0,787 & $-0,551$ & 6,973 & 0,000 \\
\hline Co2 & 0,855 & 0,650 & 9,051 & 0,000 \\
\hline $\mathrm{Co} 3$ & $0,572(0,000)$ & 0,018 & 0,228 & 0,819 \\
\hline \multicolumn{5}{|l|}{ Perceived risk } \\
\hline Pr1 & 0,998 & 0,986 & 25,391 & 0,000 \\
\hline Pr2 & $0,323(0,000)$ & 0,004 & 0,620 & 0,536 \\
\hline Pr3 & 0,371 & 0,048 & 2,435 & 0,015 \\
\hline Pr4 & $0,058(0,565)$ & $-0,055$ & 1,076 & 0,282 \\
\hline \multicolumn{5}{|l|}{ Normative belief } \\
\hline Nq1 & 0,905 & & 84,572 & 0,000 \\
\hline $\mathrm{Nq} 2$ & 0,877 & & 49,428 & 0,000 \\
\hline \multicolumn{5}{|l|}{ Self-efficacy } \\
\hline Se1 & 0,858 & & 44,036 & 0,000 \\
\hline Se2 & 0,890 & & 77,249 & 0,000 \\
\hline \multicolumn{5}{|c|}{ Facilitating conditions } \\
\hline Fc1 & 0,778 & & 18,660 & 0,000 \\
\hline Fc2 & 0,934 & & 90,976 & 0,000 \\
\hline \multicolumn{5}{|c|}{ Attitude toward a behavior } \\
\hline AQ1 & 0,934 & 0,544 & 112,977 & 0,000 \\
\hline
\end{tabular}




\begin{tabular}{|l|c|c|c|c|}
\hline AQ2 & 0,932 & 0,548 & 93,575 & 0,000 \\
\hline Subjective norms & $\mathbf{0 , 5 1 3}$ & 0,891 & 5,606 & 0,000 \\
\hline SN1 & 0,937 & $-0,329$ & 43,444 & 0,000 \\
\hline SN2 & 0,887 & 0,584 & 65,608 & 0,000 \\
\hline Control perceived behavior & 0,538 & 42,357 & 0,000 \\
\hline PBC1 & 0,860 & 0,547 & 99,983 & 0,000 \\
\hline PBC2 & 0,927 & 0,533 & 110,440 & 0,000 \\
\hline Intention
\end{tabular}

Moreover, the Cronbach's alpha and composite reliability's indicators for home delivery far exceed the value set of 0.7 except for Subjective norms, however, all the AVEs are well above the value set of 0.5.

Table 51 Convergent validity indicators for Home return

\begin{tabular}{|l|c|c|c|}
\hline \multicolumn{1}{|c|}{ Constructs } & $\begin{array}{c}\text { Composite } \\
\text { Reliability }\end{array}$ & $\begin{array}{c}\text { Cronbach's } \\
\text { Alpha }\end{array}$ & AVE \\
\hline Attitude toward & 0,931 & 0,851 & 0,871 \\
\hline Control perceived behavior & 0,866 & $\mathbf{0 , 6 9 1}$ & 0,763 \\
\hline Convenience & & & \\
\hline Facilitating condition & 0,849 & 0,669 & 0,739 \\
\hline Intention & 0,925 & 0,837 & 0,860 \\
\hline Monetary & $\mathbf{0 , 6 8 4}$ & 0,717 & 0,561 \\
\hline Perceived risk & & & \\
\hline Reference groups & 0,885 & 0,742 & 0,794 \\
\hline Self-efficacy & 0,866 & $\mathbf{0 , 6 9 1}$ & 0,764 \\
\hline Subjective norms & $\mathbf{0 , 1 7 3}$ & $\mathbf{- 0 , 4 4 0}$ & 0,570 \\
\hline
\end{tabular}

Applying the Fornell-Larcker criterion, the values of the main diagonal, square root of the AVE, must be greater than the values corresponding to their respective rows and columns. This criterion is met in all cases. Moreover, the discriminant validity is established to make sure the analysis is enough, the result shows that the difference between the correlations is minimal.

Table 52 Discriminant validity using the Fornell-Larcker criterion for Home return

\begin{tabular}{|c|c|c|c|c|c|c|c|c|c|c|}
\hline Constructs & 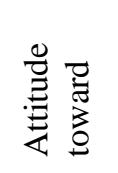 & $\stackrel{u}{D}$ & 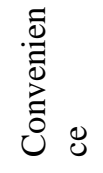 & 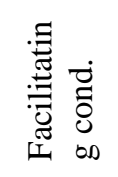 & 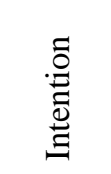 & 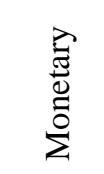 & 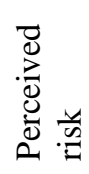 & 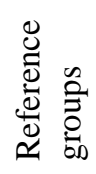 & 岕遏 & 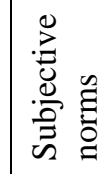 \\
\hline Attitude toward & 0,933 & & & & & & & & & \\
\hline PBC & 0,562 & 0,874 & & & & & & & & \\
\hline Convenience & $-0,636$ & $-0,447$ & N/A & & & & & & & \\
\hline Facilitating cond. & 0,450 & 0,588 & $-0,415$ & 0,860 & & & & & & \\
\hline Intention & 0,843 & 0,546 & $-0,636$ & 0,422 & 0,927 & & & & & \\
\hline Monetary & 0,026 & 0,057 & 0,079 & $-0,056$ & 0,035 & 0,749 & & & & \\
\hline Perceived risk & $-0,475$ & $-0,250$ & 0,576 & $-0,344$ & $-0,511$ & 0,038 & N/A & & & \\
\hline
\end{tabular}




\begin{tabular}{|l|l|l|l|l|l|l|l|l|l|l|} 
Reference groups & 0,463 & 0,275 & $-0,269$ & 0,166 & 0,472 & 0,132 & $-0,142$ & $\mathbf{0 , 8 9 1}$ & & \\
\hline Self-efficacy & 0,737 & 0,672 & $-0,578$ & 0,575 & 0,725 & 0,052 & $-0,394$ & 0,393 & $\mathbf{0 , 8 7 4}$ & \\
\hline Subjective norms & 0,564 & 0,377 & $-0,478$ & 0,297 & 0,567 & 0,086 & $-0,307$ & 0,656 & 0,506 & $\mathbf{0 , 7 5 5}$ \\
\hline
\end{tabular}

\subsubsection{Dimensions for In-store return}

The tables below show the values of the means and the standard deviations of the indicators and also mean and standard deviation of the constructs have been measured. In in-store return, the highest values belong to the perceived risk and monetary. This implies that consumers perceive risk and monetary at the same time in this option more than convenience.

Table 53 Means and the standard deviations of the indicators for In-store return

\begin{tabular}{|c|c|c|c|c|}
\hline \multicolumn{5}{|c|}{ In-store return } \\
\hline Indicator & Mean & Standard deviation & Mean of construct & Standard deviation of construct \\
\hline \multicolumn{5}{|l|}{ Monetary } \\
\hline Tc1 & 0,713 & 0,241 & \multirow{2}{*}{0,797} & \multirow{2}{*}{0,234} \\
\hline Tc2 & 0,881 & 0,227 & & \\
\hline \multicolumn{5}{|c|}{ Convenience } \\
\hline Co1 & 0,891 & 0,291 & \multirow{3}{*}{0,221} & \multirow{3}{*}{0,172} \\
\hline Co2 & $-0,226$ & 0,126 & & \\
\hline Co3 & $-0,025$ & 0,097 & & \\
\hline \multicolumn{5}{|c|}{ Perceived risk } \\
\hline Pr1 & 0,812 & 0,077 & \multirow{4}{*}{$-0,321$} & \multirow{4}{*}{0,121} \\
\hline Pr2 & $-0,134$ & 0,152 & & \\
\hline Pr3 & 0,056 & 0,140 & & \\
\hline Pr4 & 0,552 & 0,116 & & \\
\hline \multicolumn{5}{|c|}{ Normative beliefs } \\
\hline $\mathrm{Nq1}$ & 0,892 & 0,014 & \multirow{2}{*}{0,890} & \multirow{2}{*}{0,014} \\
\hline $\mathrm{Nq} 2$ & 0,888 & 0,014 & & \\
\hline \multicolumn{5}{|c|}{ Self-efficacy } \\
\hline Se1 & 0,069 & 0,140 & \multirow{2}{*}{0,533} & \multirow{2}{*}{0,072} \\
\hline Se2 & 0,997 & 0,004 & & \\
\hline \multicolumn{5}{|c|}{ Facilitating conditions } \\
\hline Fc1 & 0,747 & 0,056 & \multirow{2}{*}{0,831} & \multirow{2}{*}{0,038} \\
\hline Fc2 & 0,916 & 0,022 & & \\
\hline \multicolumn{5}{|c|}{ Attitude toward a behavior } \\
\hline AQ1 & 0,902 & 0,013 & \multirow{2}{*}{0,905} & \multirow{2}{*}{0,013} \\
\hline AQ2 & 0,908 & 0,013 & & \\
\hline \multicolumn{5}{|c|}{ Subjective norms } \\
\hline SN1 & 0,693 & 0,457 & \multirow{2}{*}{0,445} & \multirow{2}{*}{0,471} \\
\hline SN2 & $-0,248$ & 0,486 & & \\
\hline \multicolumn{5}{|c|}{ Control perceived behavior } \\
\hline PBC1 & 0,876 & 0,020 & \multirow{2}{*}{0,868} & \multirow{2}{*}{0.022} \\
\hline PBC2 & 0,860 & 0,023 & & \\
\hline \multicolumn{5}{|l|}{ Intention } \\
\hline IQ1 & 0,929 & 0,007 & ברם 0 & $0 \cap \cap 9$ \\
\hline IQ2 & 0,915 & 0,011 & $0,9 \angle 2$ & 0.009 \\
\hline
\end{tabular}

Regarding the collinearity between formative indicators, the values corresponding to the inflation factor of variance (VIF) are lower than 2.0 in all cases, which allows us to affirm that there is no evidence of collinearity between indicators. 
After assessing the weight and loading factor of indicators in in-store return, it can be seen that in all cases the indicators were suitable for the model except in some cases such as the financial risk, the loading is lower than 0.5. Moreover, the analysis shows that the loading factor of those indicators are not significant. Thus, in the next analysis they will be removed.

Table 54 Factor loads and indicator weights for In-store return

\begin{tabular}{|c|c|c|c|c|}
\hline \multicolumn{5}{|c|}{ In-store return } \\
\hline Indicator & $\begin{array}{l}\text { Factor load (P- } \\
\text { value) }\end{array}$ & Weight & T Statistical & P-value \\
\hline \multicolumn{5}{|l|}{ Monetary } \\
\hline Tc1 & 0,739 & & 3,060 & 0,002 \\
\hline Tc2 & 0,979 & & 4,318 & 0,000 \\
\hline \multicolumn{5}{|l|}{ Convenience } \\
\hline Co1 & 0,965 & 0,945 & 4,697 & 0,001 \\
\hline Co2 & $-0,330(0,050)$ & $-0,245$ & 1,938 & 0,053 \\
\hline Co3 & $-0,207(0,159)$ & $-0,034$ & 0,345 & 0,730 \\
\hline \multicolumn{5}{|l|}{ Perceived risk } \\
\hline Pr1 & 0,843 & 0,833 & 24,252 & 0,000 \\
\hline Pr2 & $0,246(0,058)$ & $-0,142$ & 0,935 & 0,350 \\
\hline Pr3 & $0,205(0,126)$ & 0,054 & 0,383 & 0,702 \\
\hline Pr4 & 0,568 & 0,567 & 4,891 & 0,000 \\
\hline \multicolumn{5}{|l|}{ Normative belief } \\
\hline Nq1 & 0,893 & & 65,179 & 0,000 \\
\hline $\mathrm{Nq} 2$ & 0,889 & & 61,973 & 0,000 \\
\hline \multicolumn{5}{|l|}{ Self-efficacy } \\
\hline Se1 & 0,861 & & 14,908 & 0,000 \\
\hline Se2 & 0,752 & & 36,226 & 0,000 \\
\hline \multicolumn{5}{|c|}{ Facilitating conditions } \\
\hline Fc1 & 0,917 & & 13,244 & 0,000 \\
\hline Fc2 & 0,747 & & 42,226 & 0,000 \\
\hline \multicolumn{5}{|c|}{ Attitude toward a behavior } \\
\hline AQ1 & 0,902 & 0,544 & 68,671 & 0,000 \\
\hline AQ2 & 0,908 & 0,561 & 69,117 & 0,000 \\
\hline \multicolumn{5}{|l|}{ Subjective norms } \\
\hline SN1 & 1,000 & 1,001 & 252,065 & 0,000 \\
\hline SN2 & 0,072 & $-0,007$ & 0,515 & 0,607 \\
\hline \multicolumn{5}{|c|}{ Control perceived behavior } \\
\hline PBC1 & 0,877 & 0,592 & 44,902 & 0,000 \\
\hline PBC2 & 0,861 & 0,559 & 37,457 & 0,000 \\
\hline \multicolumn{5}{|l|}{ Intention } \\
\hline IQ1 & 0,929 & 0,566 & 124,974 & 0,000 \\
\hline IQ2 & 0,915 & 0,518 & 83,621 & 0,000 \\
\hline
\end{tabular}

Moreover, the Cronbach's alpha and composite reliability's indicators for in-store delivery far exceed the value set of 0.7 except for Subjective norms, however, all the AVEs are well above the value set of 0.5 . 
Table 55 Convergent validity indicators for In-store return

\begin{tabular}{|l|c|c|c|}
\hline \multicolumn{1}{|c|}{ Constructs } & $\begin{array}{c}\text { Composite } \\
\text { Reliability }\end{array}$ & $\begin{array}{c}\text { Cronbach's } \\
\text { Alpha }\end{array}$ & AVE \\
\hline Attitude toward & 0,901 & 0,779 & 0,819 \\
\hline Control perceived behavior & 0,860 & $\mathbf{0 , 6 7 5}$ & 0,755 \\
\hline Convenience & & & \\
\hline Facilitating condition & 0,822 & $\mathbf{0 , 5 9 3}$ & 0,700 \\
\hline Intention & 0,919 & 0,825 & 0,851 \\
\hline Monetary & 0,856 & 0,739 & 0,752 \\
\hline Perceived risk & & & 0,793 \\
\hline Reference groups & 0,885 & 0,739 & 0,653 \\
\hline Self-efficacy & 0,789 & $\mathbf{0 , 4 7 5}$ & 0,503 \\
\hline Subjective norms & $\mathbf{0 , 5 3 6}$ & $\mathbf{0 , 1 4 6}$ & \\
\hline
\end{tabular}

Applying the Fornell-Larcker criterion, the values of the main diagonal, square root of the AVE, must be greater than the values corresponding to their respective rows and columns. This criterion is met in all cases. Moreover, the discriminant validity is established to make sure the analysis is enough, the result shows that the difference between the correlations is minimal.

Table 56 Discriminant validity using the Fornell-Larcker criterion for In-store return

\begin{tabular}{|c|c|c|c|c|c|c|c|c|c|c|}
\hline Constructs & 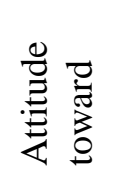 & U & 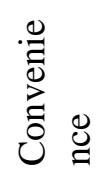 & 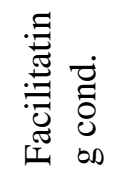 & 韋 & 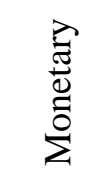 & 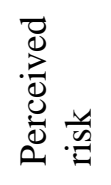 & 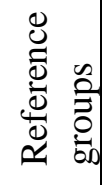 & 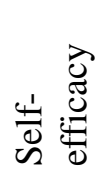 & 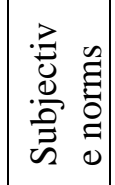 \\
\hline Attitude toward & 0,905 & & & & & & & & & \\
\hline PBC & 0,456 & 0,869 & & & & & & & & \\
\hline Convenience & 0,519 & 0,442 & N/A & & & & & & & \\
\hline Facilitating cond. & 0,299 & 0,527 & 0,248 & 0,837 & & & & & & \\
\hline Intention & 0,767 & 0,453 & 0,516 & 0,252 & 0,922 & & & & & \\
\hline Monetary & $-0,059$ & $-0,257$ & $-0,071$ & $-0,413$ & $-0,100$ & $\mathbf{0 , 8 6 7}$ & & & & \\
\hline Perceived risk & $-0,316$ & $-0,181$ & $-0,235$ & $-0,232$ & $-0,367$ & 0,366 & N/A & & & \\
\hline Reference groups & 0,439 & 0,238 & 0,201 & 0,091 & 0,452 & 0,150 & $-0,004$ & 0,891 & & \\
\hline Self-efficacy & 0,662 & 0,601 & 0,476 & 0,492 & 0,607 & $-0,177$ & $-0,250$ & 0,378 & 0,808 & \\
\hline Subjective norms & 0,459 & 0,255 & 0,215 & 0,119 & 0,442 & 0,112 & $-0,037$ & 0,600 & 0,390 & 0,70 \\
\hline
\end{tabular}

\subsubsection{Dimensions for CRPs}

The tables below show the values of the means and the standard deviations of the indicators and also mean and standard deviation of the constructs have been measured. The values of the means and the standard deviations for CRPs show that consumers prefer to go to these places, because it is more convenient, though it is also with some perceived risk. 
Table 57 Means and the standard deviations of the indicators for CRPs

\begin{tabular}{|c|c|c|c|c|}
\hline \multicolumn{5}{|c|}{ CRPs } \\
\hline Indicator & Mean & Standard deviation & Mean of construct & $\begin{array}{c}\text { Standard } \\
\text { deviation of } \\
\text { construct } \\
\end{array}$ \\
\hline \multicolumn{5}{|l|}{ Monetary } \\
\hline Tc1 & 0,554 & 0,361 & \multirow{2}{*}{0,677} & \multirow{2}{*}{0,344} \\
\hline Tc2 & 0,801 & 0,327 & & \\
\hline \multicolumn{5}{|l|}{ Convenience } \\
\hline Co1 & $-0,398$ & 0,726 & \multirow{3}{*}{$-0,041$} & \multirow{3}{*}{0,366} \\
\hline $\mathrm{Co} 2$ & 0,155 & 0,212 & & \\
\hline Co3 & 0,118 & 0,162 & & \\
\hline \multicolumn{5}{|l|}{ Perceived risk } \\
\hline Pr1 & 0,921 & 0,062 & \multirow{4}{*}{0,236} & \multirow{4}{*}{0,104} \\
\hline Pr2 & $-0,005$ & 0,122 & & \\
\hline Pr3 & $-0,365$ & 0,116 & & \\
\hline Pr4 & 0,394 & 0,117 & & \\
\hline \multicolumn{5}{|l|}{ Normative beliefs } \\
\hline Nq1 & 0,860 & 0,016 & \multirow{2}{*}{0,857} & \multirow{2}{*}{0,017} \\
\hline $\mathrm{Nq} 2$ & 0,854 & 0,018 & & \\
\hline \multicolumn{5}{|l|}{ Self-efficacy } \\
\hline Se1 & 0,806 & 0,024 & \multirow{2}{*}{0,821} & \multirow{2}{*}{0,019} \\
\hline Se2 & 0,863 & 0,014 & & \\
\hline \multicolumn{5}{|c|}{ Facilitating conditions } \\
\hline Fc1 & 0,781 & 0,036 & \multirow{2}{*}{0,834} & \multirow{2}{*}{0,024} \\
\hline Fc2 & 0,918 & 0,012 & & \\
\hline \multicolumn{5}{|c|}{ Attitude toward a behavior } \\
\hline AQ1 & 0,914 & 0,009 & \multirow{2}{*}{0,916} & \multirow{2}{*}{0,009} \\
\hline AQ2 & 0,918 & 0,009 & & \\
\hline \multicolumn{5}{|l|}{ Subjective norms } \\
\hline SN1 & 0,082 & 0,105 & \multirow{2}{*}{0,539} & \multirow{2}{*}{0,054} \\
\hline SN2 & 0,997 & 0,004 & & \\
\hline \multicolumn{5}{|c|}{ Control perceived behavior } \\
\hline PBC1 & 0,887 & 0,013 & \multirow{2}{*}{0,876} & \multirow{2}{*}{0.015} \\
\hline PBC2 & 0,866 & 0,016 & & \\
\hline \multicolumn{5}{|l|}{ Intention } \\
\hline IQ1 & 0,926 & 0,008 & 0975 & \\
\hline IQ2 & 0,925 & 0,008 & $0,9<5$ & 0.008 \\
\hline
\end{tabular}

Regarding the collinearity between formative indicators, the values corresponding to the inflation factor of variance (VIF) are lower than 1.9 in all cases, which allows us to affirm that there is no evidence of collinearity between indicators.

On the other hand, after measuring the weight and loading factor of indicators in CRPs, it can be seen that in all cases the indicators were suitable for the model except in some cases such as the flexibility, the loading is lower than 0.5. Moreover, the analysis shows that the loading factor of those indicators are not significant. Thus, in the next analysis they will be removed.

Table 58 Factor loads and indicator weights for CDPs

\begin{tabular}{|c|c|c|c|c|}
\hline \multicolumn{4}{|c|}{ CRPs } \\
\hline Indicator & $\begin{array}{c}\text { Factor load (P- } \\
\text { value) }\end{array}$ & Weight & T Statistical & P-value \\
\hline
\end{tabular}




\begin{tabular}{|c|c|c|c|c|}
\hline \multicolumn{5}{|c|}{ Monetary } \\
\hline Tc1 & 0,517 & & 1,433 & 0,152 \\
\hline Tc2 & 0,999 & & 3,059 & 0,002 \\
\hline \multicolumn{5}{|c|}{ Convenience } \\
\hline Co1 & $\begin{array}{l}-0,929(0,245) \\
\end{array}$ & $-0,931$ & 1,145 & 0,392 \\
\hline Co2 & $-0,548(0,015)$ & 0,250 & 1,181 & 0,238 \\
\hline Co3 & $0,492(0,017)$ & 0,184 & 1,137 & 0,256 \\
\hline \multicolumn{5}{|c|}{ Perceived risk } \\
\hline Pr1 & 0,888 & 0,935 & 14,996 & 0,000 \\
\hline Pr2 & $0,210(0,063)$ & $-0,007$ & 0,058 & 0,954 \\
\hline Pr3 & 0,035 & $-0,370$ & 3,202 & 0,001 \\
\hline Pr4 & $0,456(0,028)$ & 0,405 & 3,472 & 0,001 \\
\hline \multicolumn{5}{|c|}{ Normative belief } \\
\hline Nq1 & 0,861 & & 52,728 & 0,000 \\
\hline $\mathrm{Nq} 2$ & 0,854 & & 47,033 & 0,000 \\
\hline \multicolumn{5}{|c|}{ Self-efficacy } \\
\hline Se1 & 0,863 & & 34,264 & 0,000 \\
\hline Se2 & 0,807 & & 62,128 & 0,000 \\
\hline \multicolumn{5}{|c|}{ Facilitating conditions } \\
\hline Fc1 & 0,917 & & 21,541 & 0,000 \\
\hline Fc2 & 0,782 & & 77,211 & 0,000 \\
\hline \multicolumn{5}{|c|}{ Attitude toward a behavior } \\
\hline AQ1 & 0,915 & 0,540 & 101,046 & 0,000 \\
\hline AQ2 & 0,918 & 0,551 & 101,456 & 0,000 \\
\hline \multicolumn{5}{|c|}{ Subjective norms } \\
\hline SN1 & 0,999 & 0,997 & 284,126 & 0,000 \\
\hline SN2 & 0,086 & 0,053 & 0,819 & 0,413 \\
\hline \multicolumn{5}{|c|}{ Control perceived behavior } \\
\hline PBC1 & 0,888 & 0,593 & 68,231 & 0,000 \\
\hline PBC2 & 0,866 & 0,547 & 54,589 & 0,000 \\
\hline \multicolumn{5}{|c|}{ Intention } \\
\hline IQ1 & 0,926 & 0,543 & 110,221 & 0,000 \\
\hline IQ2 & 0,925 & 0,538 & 119,051 & 0,000 \\
\hline
\end{tabular}

Moreover, the Cronbach's alpha and composite reliability's indicators for CRPs far exceed the value set of 0.7 except for Subjective norms, however, all the AVEs are well above the value set of 0.5.

Table 59 Convergent validity indicators for CRPs

\begin{tabular}{|l|c|c|c|}
\hline \multicolumn{1}{|c|}{ Constructs } & $\begin{array}{c}\text { Composite } \\
\text { Reliability }\end{array}$ & $\begin{array}{c}\text { Cronbach's } \\
\text { Alpha }\end{array}$ & AVE \\
\hline Attitude toward & 0,913 & 0,809 & 0,839 \\
\hline Control perceived behavior & 0,869 & 0,700 & 0,769 \\
\hline Convenience & & & \\
\hline Facilitating condition & 0,841 & $\mathbf{0 , 6 3 9}$ & 0,727 \\
\hline Intention & 0,923 & 0,833 & 0,857 \\
\hline Monetary & 0,758 & $\mathbf{0 , 6 5 6}$ & 0,633 \\
\hline Perceived risk & & & \\
\hline Reference groups & 0,848 & $\mathbf{0 , 6 4 0}$ & 0,735 \\
\hline Self-efficacy & 0,822 & $\mathbf{0 , 5 6 8}$ & 0,697 \\
\hline Subjective norms & $\mathbf{0 , 5 4 2}$ & $\mathbf{0 , 0 6 3}$ & 0,502 \\
\hline
\end{tabular}


Applying the Fornell-Larcker criterion, the values of the main diagonal, square root of the AVE, must be greater than the values corresponding to their respective rows and columns. This criterion is met in all cases. Moreover, the discriminant validity is established to make sure the analysis is enough, the result shows that the difference between the correlations is minimal.

Table 60 Discriminant validity using the Fornell-Larcker criterion for CRPs

\begin{tabular}{|c|c|c|c|c|c|c|c|c|c|c|}
\hline Constructs & 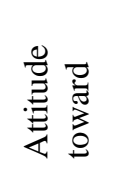 & $\stackrel{D}{a}$ & 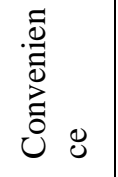 & 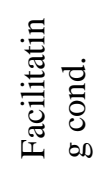 & 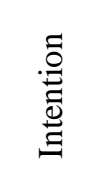 & 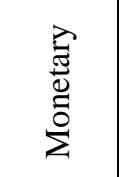 & 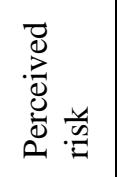 & 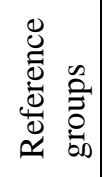 & 岂: & 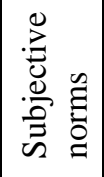 \\
\hline Attitude toward & 0,916 & & & & & & & & & \\
\hline PBC & 0,462 & $\mathbf{0 , 8 7 7}$ & & & & & & & & \\
\hline Convenience & $-0,552$ & $-0,436$ & N/A & & & & & & & \\
\hline Facilitating cond. & 0,352 & 0,612 & $-0,313$ & 0,853 & & & & & & \\
\hline Intention & 0,804 & 0,464 & -0,590 & 0,349 & 0,926 & & & & & \\
\hline Monetary & $-0,013$ & $-0,216$ & 0,215 & $-0,249$ & $-0,089$ & 0,796 & & & & \\
\hline Perceived risk & $-0,380$ & $-0,213$ & 0,354 & $-0,205$ & $-0,457$ & 0,187 & N/A & & & \\
\hline Reference groups & 0,390 & 0,276 & $-0,242$ & 0,208 & 0,481 & 0,040 & $-0,180$ & 0,858 & & \\
\hline Self-efficacy & 0,714 & 0,698 & $-0,545$ & 0,538 & 0,713 & $-0,135$ & $-0,318$ & 0,393 & 0,835 & \\
\hline Subjective norms & 0,347 & 0,245 & $-0,221$ & 0,175 & 0,447 & 0,047 & $-0,193$ & 0,647 & 0,343 & 0,709 \\
\hline
\end{tabular}

\subsubsection{Analysis of the structural model}

In this section, after removing some indicators based on the previous results, the analysis of the structural model is carried out in order to respond to the hypotheses established in the previous sections. The evaluation of the results of the structural model allows us to determine to what extent the empirical data support the hypotheses and the final model. The following analysis is presented.

\subsubsection{Structural model for home delivery}

The first assessment is to evaluate the collinearity of the constructs. To do so, the inflation factor of variance (VIF) is evaluated. Generally, if VIF is greater than 5, we will have signs of collinearity.

Table 61 Multicollinearity evaluation using VIF for Home delivery

\begin{tabular}{|c|c|c|c|c|c|c|c|c|c|c|}
\hline Constructs & $\begin{array}{l}\text { 营焉 } \\
\text { 焉 }\end{array}$ & 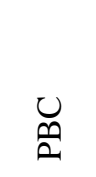 & 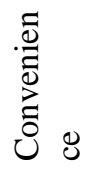 & 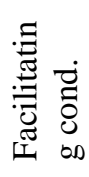 & 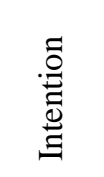 & 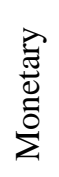 & 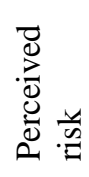 & 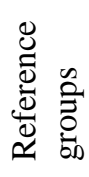 & 岂 & 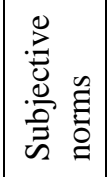 \\
\hline Attitude toward & & & & & 2,845 & & & & & \\
\hline PBC & & & & & 2,133 & & & & & \\
\hline Convenience & 1,504 & & & & 2,198 & & & & & \\
\hline Facilitating cond. & & 1,494 & & & 1,760 & & & & & \\
\hline \multicolumn{11}{|l|}{ Intention } \\
\hline Monetary & 1,006 & & & & 1,047 & & & & & \\
\hline Perceived risk & 1,497 & & & & 1,594 & & & & & \\
\hline
\end{tabular}




\begin{tabular}{|l|l|l|l|l|l|l|l|l|l|l|} 
Reference groups & & & & & & & & & & 1,000 \\
\hline Self-efficacy & & 1,494 & & & 3,067 & & & & & \\
\hline Subjective norms & & & & & 1,562 & & & & & \\
\hline
\end{tabular}

The values are well below the established limit (5), therefore, it can be stated that there is no multicollinearity in the structural model for Home delivery.

According to the statistical steps for analyzing the structure of the model, the next step is to measure the path coefficients or standardized regression coefficients. The results that come from this part show the basis for assessing the hypotheses and their statistical significance.

Table 62 shows the coefficients for each path for the Home delivery.

Table 62 Path coefficients for Home delivery

\begin{tabular}{|c|c|c|c|c|c|c|c|c|c|c|}
\hline Constructs & 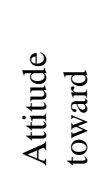 & 足 & 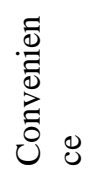 & 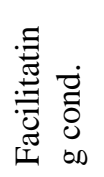 & 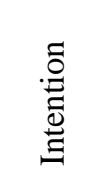 & $\begin{array}{l}\vec{\Xi} \\
\stackrel{\Xi}{\Xi} \\
\dot{0}\end{array}$ & 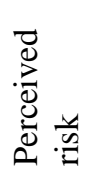 & 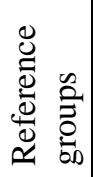 & 岂: & 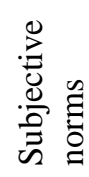 \\
\hline Attitude toward & & & & & 0,583 & & & & & \\
\hline PBC & & & & & 0,086 & & & & & \\
\hline Convenience & $-0,566$ & & & & $-0,023$ & & & & & \\
\hline Facilitating cond. & & 0,192 & & & 0,052 & & & & & \\
\hline \multicolumn{11}{|l|}{ Intention } \\
\hline Monetary & 0,142 & & & & 0,032 & & & & & \\
\hline Perceived risk & $-0,154$ & & & & $-0,070$ & & & & & \\
\hline Reference groups & & & & & & & & & & 0,768 \\
\hline Self-efficacy & & 0,654 & & & 0,134 & & & & & \\
\hline Subjective norms & & & & & 0,062 & & & & & \\
\hline
\end{tabular}

In order to evaluate if the constructs are significant or not, One-tailed T-Student is considered- since the direction of the relationship was specified. The relationships marked in bold are significant at least 95\%. Statistical significance values have been obtained using the bootstrapping technique with subsampling of 5000 samples.

Table 63 Levels of statistical significance for Path coefficients for Home delivery

\begin{tabular}{|l|c|c|}
\hline \multicolumn{1}{|c|}{ Path coefficients } & T Statistical & P-value \\
& & \\
\hline Attitude toward selecting HD -> Intention to select HD & 9,802 & 0,000 \\
\hline Control perceived behavior to select HD -> Intention to select HD & 1,618 & 0,106 \\
\hline Convenience -> Attitude toward selecting HD & 5,094 & 0,000 \\
\hline Convenience -> Intention to select HD & 0,597 & 0,551 \\
\hline
\end{tabular}




\begin{tabular}{|l|c|c|} 
Facilitating condition -> Control perceived behavior to select HD & 3,367 & 0,001 \\
\hline Facilitating condition -> Intention to select HD & 1,108 & 0,268 \\
\hline Monetary -> Attitude toward selecting HD & 3,244 & 0,001 \\
\hline Monetary -> Intention to select HD & 1,382 & 0,167 \\
\hline Perceived risk -> Attitude toward selecting HD & 3,575 & 0,000 \\
\hline Perceived risk -> Intention to select HD & 1,869 & 0,062 \\
\hline Reference groups -> Subjective norms to select HD & 39,060 & 0,000 \\
\hline Self-efficacy -> Control perceived behavior to select HD & 12,610 & 0,000 \\
\hline Self-efficacy -> Intention to select HD & 2,029 & 0,043 \\
\hline Subjective norms to select HD -> Intention to select HD & 2,298 & 0,022 \\
\hline
\end{tabular}

The discussion of the results will be carried out in the evaluation section.

Based on the PLS-SEM steps, the next steps are to evaluate $\mathrm{R}^{2}$ - variance values (coefficient of determination), $\mathrm{f}^{2}$ values, effect size. This coefficient indicates to what extent the predictor variables are capable of explaining the corresponding constructs. In addition, the following also shows the values of $\mathrm{f}^{2}$, size of the effect, which indicates to what extent it is relevant to the presence or absence of a construct in the model. The values obtained indicate that the model explains a large part of the variance -> 50\% for the intention of selecting options in delivery. However, in one case such as Attitude toward selecting HD the variance values are around $45 \%$, which makes us think that there are other additional factors that can help explain them.

Table 64 The values of the variance $\left(R^{2}\right)$ for Home delivery

\begin{tabular}{|l|c|c|}
\hline \multicolumn{1}{|c|}{ Constructs } & R Square & $\begin{array}{c}\text { R Square } \\
\text { Adjusted }\end{array}$ \\
\hline Attitude toward selecting HD & $\mathbf{0 , 4 4 2}$ & 0,438 \\
\hline Control perceived behavior to select HD & 0,627 & 0,626 \\
\hline Intention to select HD & 0,781 & 0,777 \\
\hline Subjective norms to select HD & 0,590 & 0,589 \\
\hline
\end{tabular}

The table below shows the values corresponding to the size of the effect $\mathrm{f}^{2}$ for each construct with respect to its predictor variables. It should take into account the reference values, $0.02,0.15$, and 0.35 (small, medium, and large effect respectively). This high value shows that the contribution of subconstruct to the construct is important.

Table 65 The size of the effect $\left(f^{2}\right)$ with respect to its predictor variables for Home delivery

\begin{tabular}{|c|c|c|c|c|c|c|c|c|c|c|}
\hline Constructs & 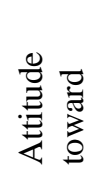 & 品 & 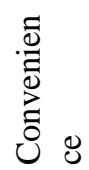 & 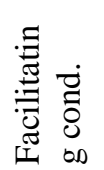 & 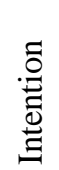 & 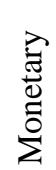 & 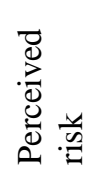 & 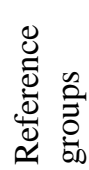 & 恶总 & 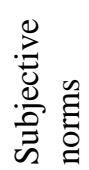 \\
\hline
\end{tabular}




\begin{tabular}{|l|l|l|l|l|l|l|l|l|l|l|} 
Attitude toward & & & & & 0,447 & & & & & \\
\hline PBC & & & & & $\mathbf{0 , 0 1 2}$ & & & & & \\
\hline Convenience & 0,426 & & & & $\mathbf{0 , 0 0 1}$ & & & & & \\
\hline Facilitating cond. & & 0,057 & & & $\mathbf{0 , 0 0 6}$ & & & & & \\
\hline Intention & & & & & & & & & & \\
\hline Monetary & $\mathbf{0 , 0 3 5}$ & & & & $\mathbf{0 , 0 0 4}$ & & & & & \\
\hline Perceived risk & $\mathbf{0 , 0 3 1}$ & & & & $\mathbf{0 , 0 1 5}$ & & & & & \\
\hline Reference groups & & & & & & & & & & 1,441 \\
\hline Self-efficacy & & 0,661 & & & $\mathbf{0 , 0 1 8}$ & & & & & \\
\hline Subjective norms & & & & & $\mathbf{0 , 0 1 1}$ & & & & & \\
\hline
\end{tabular}

The next step is to determine the predictive relevance of the proposed theoretical model. For this, the value of $\mathrm{Q}^{2}$ will be calculated. Generally, it is considered that the relationship between two constructs has predictive relevance if $\mathrm{Q}^{2>} 0$.

The table below shows the result of the calculation of the predictive relevance index for Home delivery. The value of all constructs was greater than zero, therefore, it can be stated that the model for Home delivery has predictive relevance.

Table 66 The predictive relevance index $\left(Q^{2}\right)$ for Home delivery

\begin{tabular}{|l|c|}
\hline \multicolumn{1}{|c|}{ Constructs } & Q Square \\
& \\
\hline Attitude toward selecting HD & 0,380 \\
\hline Control perceived behavior to select HD & 0,467 \\
\hline Intention to select HD & 0,671 \\
\hline Subjective norms to select HD & 0,321 \\
\hline
\end{tabular}

The effect size $\left(\mathrm{q}^{2}\right)$ is available to measure the capacity of influence of each independent variable that predicts the construct. The reference values, $0.02,0.15$, and 0.35 correspond to small, medium, and large effects respectively. The table below shows the calculation of $\mathrm{q}^{2}$ for each independent variable that predicts the construct.

Table 67 The effect size $\left(q^{2}\right)$ of independent variable that predicts the construct for Home delivery

\begin{tabular}{|c|c|}
\hline Indicators & Effect size $q^{2}$ \\
\hline AQ1 & 0,527 \\
\hline AQ2 & 0,530 \\
\hline PBC1 & 0,267 \\
\hline PBC2 & 0,268 \\
\hline Tc1 & 0,234 \\
\hline Tc2 & 0,287 \\
\hline Fc1 & 0,199 \\
\hline
\end{tabular}




\begin{tabular}{|c|c|}
\hline Fc2 & 0,209 \\
\hline Pr2 & 0,123 \\
\hline IQ1 & 0,498 \\
\hline IQ2 & 0,511 \\
\hline Nq1 & 0,331 \\
\hline Nq2 & 0,333 \\
\hline Pr3 & 0,103 \\
\hline Pr4 & 0,010 \\
\hline Co2 & 0,016 \\
\hline Se1 & 0,322 \\
\hline Se2 & 0,319 \\
\hline SN1 & $-0,048$ \\
\hline SN2 & 0,004 \\
\hline Pr1 & $-0,065$ \\
\hline Co3 & 0,276 \\
\hline Co1 & 0,044 \\
\hline &
\end{tabular}

\subsubsection{Structural model for In-store delivery}

The first assessment is to evaluate the collinearity of the constructs. To do so, the inflation factor of variance (VIF) is evaluated. Generally, if VIF is greater than 5, we will have signs of collinearity.

Table 68 Multicollinearity evaluation using VIF for In-store delivery

\begin{tabular}{|c|c|c|c|c|c|c|c|c|c|c|}
\hline Constructs & $\begin{array}{l}\text { 营营 } \\
\text { 至 }\end{array}$ & 足 & 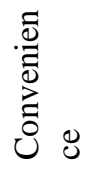 & 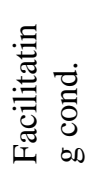 & 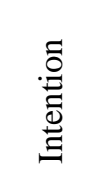 & 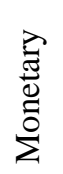 & 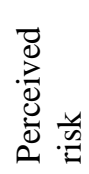 & 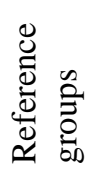 & 岕荛 & 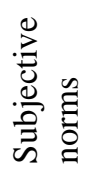 \\
\hline Attitude toward & & & & & 2,040 & & & & & \\
\hline PBC & & & & & 1,953 & & & & & \\
\hline Convenience & 1,064 & & & & 1,483 & & & & & \\
\hline Facilitating cond. & & 1,331 & & & 1,737 & & & & & \\
\hline \multicolumn{11}{|l|}{ Intention } \\
\hline Monetary & 1,151 & & & & 1,297 & & & & & \\
\hline Perceived risk & 1,218 & & & & 1,293 & & & & & \\
\hline Reference groups & & & & & & & & & & 1,000 \\
\hline Self-efficacy & & 1,331 & & & 2,305 & & & & & \\
\hline Subjective norms & & & & & 1,047 & & & & & \\
\hline
\end{tabular}

The values are well below the established limit (5), therefore, it can be stated that there is no multicollinearity in the structural model for Home delivery.

According to the statistical steps for analyzing the structure of the model, the next step is to measure the path coefficients or standardized regression coefficients. The results that come from this part show the basis for assessing the hypotheses and their statistical significance. 
Table 69 shows the coefficients for each path for the In-store delivery.

Table 69 Path coefficients for In-store delivery

\begin{tabular}{|c|c|c|c|c|c|c|c|c|c|c|}
\hline Constructs & 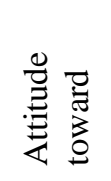 & $\begin{array}{l}\text { O } \\
\text { L }\end{array}$ & 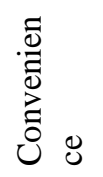 & 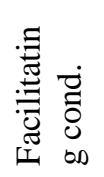 & 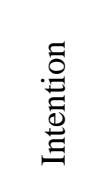 & 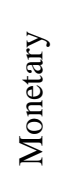 & 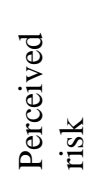 & 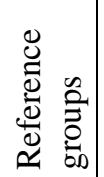 & 岕 & 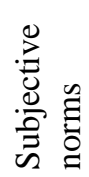 \\
\hline Attitude toward & & & & & 0,564 & & & & & \\
\hline PBC & & & & & 0,069 & & & & & \\
\hline Convenience & 0,474 & & & & 0,091 & & & & & \\
\hline Facilitating cond. & & 0,341 & & & $-0,047$ & & & & & \\
\hline \multicolumn{11}{|l|}{ Intention } \\
\hline Monetary & $-0,044$ & & & & 0,020 & & & & & \\
\hline Perceived risk & $-0,184$ & & & & $-0,109$ & & & & & \\
\hline Reference groups & & & & & & & & & & 0,093 \\
\hline Self-efficacy & & 0,427 & & & 0,148 & & & & & \\
\hline Subjective norms & & & & & 0,060 & & & & & \\
\hline
\end{tabular}

In order to evaluate if the constructs are significant or not, One-tailed T-Student is considered- since the direction of the relationship was specified. The relationships marked in bold are significant at least 95\%. Statistical significance values have been obtained using the bootstrapping technique with subsampling of 5000 samples.

Table 70 Levels of statistical significance for Path coefficients for Home delivery

\begin{tabular}{|l|c|c|}
\hline \multicolumn{1}{|c|}{ Path coefficients } & T Statistical & P-value \\
& & \\
\hline Attitude toward selecting SD -> Intention to select SD & 10,770 & 0,000 \\
\hline Control perceived behavior to select SD -> Intention to select SD & 1,401 & 0,161 \\
\hline Convenience -> Attitude toward selecting SD & 8,861 & 0,000 \\
\hline Convenience -> Intention to select SD & 2,135 & 0,033 \\
\hline Facilitating condition -> Control perceived behavior to select SD & 6,780 & 0,000 \\
\hline Facilitating condition -> Intention to select SD & 0,911 & 0,363 \\
\hline Monetary -> Attitude toward selecting SD & 0,628 & 0,530 \\
\hline Monetary -> Intention to select SD & 0,507 & 0,612 \\
\hline Perceived risk -> Attitude toward selecting SD & 3,831 & 0,000 \\
\hline Perceived risk -> Intention to select SD & 2,746 & 0,006 \\
\hline Reference groups -> Subjective norms to select SD & 1,331 & 0,183 \\
\hline Self-efficacy -> Control perceived behavior to select SD & 8,307 & 0,000 \\
\hline Self-efficacy -> Intention to select SD & 2,958 & 0,003 \\
\hline Subjective norms to select SD -> Intention to select SD & 2,171 & 0,030 \\
\hline
\end{tabular}

The discussion of the results will be carried out in the evaluation section. 
Based on the PLS-SEM steps, the next steps are to evaluate $\mathrm{R}^{2}$ - variance values (coefficient of determination), $\mathrm{f}^{2}$ values, effect size. This coefficient indicates to what extent the predictor variables are capable of explaining the corresponding constructs. In addition, the following also shows the values of $\mathrm{f}^{2}$, size of the effect, which indicates to what extent it is relevant to the presence or absence of a construct in the model. The values obtained indicate that the model explains a large part of the variance -> 50\% for the intention of selecting options in delivery. However, in two cases such as Attitude toward selecting SD and Control perceived behavior to select SD the variance values are around $45 \%$, which makes us think that there are other additional factors that can help explain them.

Table 71 The values of the variance $\left(R^{2}\right)$ for In-store delivery

\begin{tabular}{|l|c|c|}
\hline \multicolumn{1}{|c|}{ Constructs } & R Square & $\begin{array}{c}\text { R Square } \\
\text { Adjusted }\end{array}$ \\
\hline Attitude toward selecting SD & $\mathbf{0 , 3 1 2}$ & 0,307 \\
\hline Control perceived behavior to select SD & $\mathbf{0 , 4 4 4}$ & 0,442 \\
\hline Intention to select SD & 0,629 & 0,622 \\
\hline Subjective norms to select SD & 0,009 & 0,006 \\
\hline
\end{tabular}

The table below shows the values corresponding to the size of the effect $\mathrm{f}^{2}$ for each construct with respect to its predictor variables. It should take into account the reference values, $0.02,0.15$, and 0.35 (small, medium, and large effect respectively). This high value shows that the contribution of subconstruct to the construct is important.

Table 72 The size of the effect $\left(f^{2}\right)$ respect to its predictor variables for In-store delivery

\begin{tabular}{|c|c|c|c|c|c|c|c|c|c|c|}
\hline Constructs & 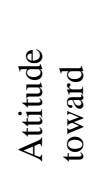 & 品 & 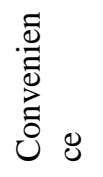 & 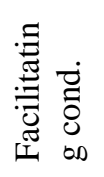 & 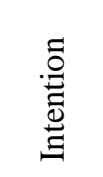 & 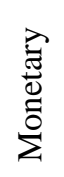 & 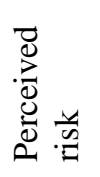 & 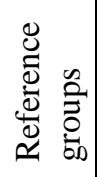 & 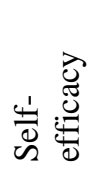 & 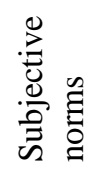 \\
\hline Attitude toward & & & & & 0,421 & & & & & \\
\hline PBC & & & & & 0,007 & & & & & \\
\hline Convenience & 0,307 & & & & 0,015 & & & & & \\
\hline Facilitating cond. & & 0,157 & & & 0,003 & & & & & \\
\hline \multicolumn{11}{|l|}{ Intention } \\
\hline Monetary & 0,002 & & & & 0,001 & & & & & \\
\hline Perceived risk & 0,041 & & & & 0,025 & & & & & \\
\hline Reference groups & & & & & & & & & & 0,009 \\
\hline Self-efficacy & & 0,247 & & & 0,026 & & & & & \\
\hline Subjective norms & & & & & 0,009 & & & & & \\
\hline
\end{tabular}


The next step is to determine the predictive relevance of the proposed theoretical model. For this, the value of $\mathrm{Q}^{2}$ will be calculated. Generally, it is considered that the relationship between two constructs has predictive relevance if $\mathrm{Q}^{2}>0$.

The table below shows the result of the calculation of the predictive relevance index for delivery options. The value of all constructs was greater than zero, therefore, it can be stated that the model for In-store delivery has predictive relevance.

Table 73 The predictive relevance index $\left(Q^{2}\right)$ for In-store delivery

\begin{tabular}{|l|c|}
\hline \multicolumn{1}{|c|}{ Constructs } & Q Square \\
& \\
\hline Attitude toward selecting SD & 0,247 \\
\hline Control perceived behavior to select SD & 0,329 \\
\hline Intention to select SD & 0,521 \\
\hline Subjective norms to select SD & 0,001 \\
\hline
\end{tabular}

The effect size $\left(\mathrm{q}^{2}\right)$ is available to measure the capacity of influence of each independent variable that predicts the construct. The reference values, $0.02,0.15$, and 0.35 correspond to small, medium, and large effects respectively. The table below shows the calculation of $\mathrm{q}^{2}$ for each independent variable that predicts the construct.

Table 74 The effect size $\left(q^{2}\right)$ of independent variable that predict the construct for In-store delivery

\begin{tabular}{|c|c|}
\hline Indicators & Effect size $\mathbf{~ q}^{\mathbf{2}}$ \\
\hline AQ1 & 0,405 \\
\hline AQ2 & 0,401 \\
\hline PBC1 & 0,262 \\
\hline PBC2 & 0,260 \\
\hline Tc1 & 0,283 \\
\hline Tc2 & $-0,136$ \\
\hline Fc1 & 0,154 \\
\hline Fc2 & 0,174 \\
\hline Pr2 & $-0,006$ \\
\hline IQ1 & 0,455 \\
\hline IQ2 & 0,468 \\
\hline Nq1 & 0,393 \\
\hline Nq2 & 0,069 \\
\hline Pr3 & $-0,170$ \\
\hline Pr4 & $-0,040$ \\
\hline Co2 & 0,020 \\
\hline Se1 & 0,037 \\
\hline Se2 & 1,000 \\
\hline &
\end{tabular}




\begin{tabular}{|c|c|}
\hline SN1 & $-0,139$ \\
\hline SN2 & 0,405 \\
\hline Pr1 & 0,401 \\
\hline Co3 & 0,262 \\
\hline Co1 & 0,260 \\
\hline
\end{tabular}

\subsubsection{Structural model for CDPs}

The first assessment is to evaluate the collinearity of the constructs. To do so, the inflation factor of variance (VIF) is evaluated. Generally, if VIF is greater than 5, we will have signs of collinearity.

Table 75 Multicollinearity evaluation using VIF for CDPs

\begin{tabular}{|c|c|c|c|c|c|c|c|c|c|c|}
\hline Constructs & 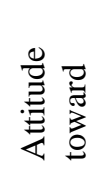 & $U_{\mathfrak{Q}}$ & 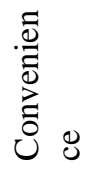 & 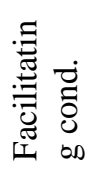 & 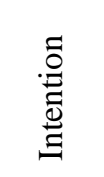 & 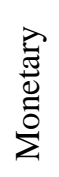 & 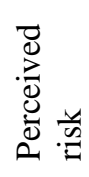 & 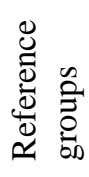 & 莺 & 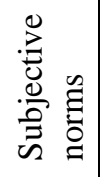 \\
\hline Attitude toward & & & & & 2,398 & & & & & \\
\hline PBC & & & & & 2,202 & & & & & \\
\hline Convenience & 1,357 & & & & 1,383 & & & & & \\
\hline Facilitating cond. & & 1,370 & & & 1,723 & & & & & \\
\hline \multicolumn{11}{|l|}{ Intention } \\
\hline Monetary & 1,062 & & & & 1,189 & & & & & \\
\hline Perceived risk & 1,352 & & & & 1,517 & & & & & \\
\hline Reference groups & & & & & & & & & & 1,000 \\
\hline Self-efficacy & & 1,370 & & & 3,350 & & & & & \\
\hline Subjective norms & & & & & 1,182 & & & & & \\
\hline
\end{tabular}

The values are well below the established limit (5), therefore, it can be stated that there is no multicollinearity in the structural model for CDPs.

According to the statistical steps for analyzing the structure of the model, the next step is to measure the path coefficients or standardized regression coefficients. The results that come from this part show the basis for assessing the hypotheses and their statistical significance.

Table 76 shows the coefficients for each path for the CDPs. 
Table 76 Path coefficients for CDPs

\begin{tabular}{|c|c|c|c|c|c|c|c|c|c|c|}
\hline Constructs & 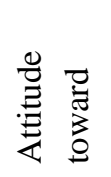 & $\begin{array}{l}U_{0} \\
\text { a }\end{array}$ & 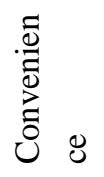 & 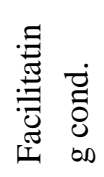 & 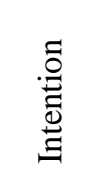 & 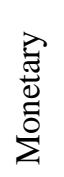 & 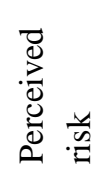 & 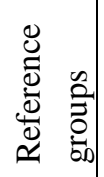 & 峁莺 & 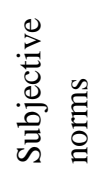 \\
\hline Attitude toward & & & & & 0,518 & & & & & \\
\hline PBC & & & & & 0,022 & & & & & \\
\hline Convenience & $-0,089$ & & & & $-0,139$ & & & & & \\
\hline Facilitating cond. & & 0,336 & & & $-0,010$ & & & & & \\
\hline \multicolumn{11}{|l|}{ Intention } \\
\hline Monetary & 0,066 & & & & 0,013 & & & & & \\
\hline Perceived risk & $-0,346$ & & & & $-0,102$ & & & & & \\
\hline Reference groups & & & & & & & & & & 0,951 \\
\hline Self-efficacy & & 0,502 & & & 0,249 & & & & & \\
\hline Subjective norms & & & & & 0,084 & & & & & \\
\hline
\end{tabular}

In order to evaluate if the constructs are significant or not, One-tailed T-Student is considered- since the direction of the relationship was specified. The relationships marked in bold are significant at least 95\%. Statistical significance values have been obtained using the bootstrapping technique with subsampling of 5000 samples.

Table 77 Levels of statistical significance for Path coefficients for CDPs

\begin{tabular}{|l|c|c|}
\hline \multicolumn{1}{|c|}{ Path coefficients } & T Statistical & P-value \\
& & \\
\hline Attitude toward selecting CDPs -> Intention to select CDPs & 11,575 & 0,000 \\
\hline Control perceived behavior to select CDPs -> Intention to select CDPs & 0,515 & 0,606 \\
\hline Convenience -> Attitude toward selecting CDPs & 1,530 & 0,126 \\
\hline Convenience -> Intention to select CDPs & 4,500 & 0,000 \\
\hline Facilitating condition -> Control perceived behavior to select CDPs & 7,453 & 0,000 \\
\hline Facilitating condition -> Intention to select CDPs & 0,279 & 0,780 \\
\hline Monetary -> Attitude toward selecting CDPs & 1,123 & 0,261 \\
\hline Monetary -> Intention to select CDPs & 0,335 & 0,738 \\
\hline Perceived risk -> Attitude toward selecting CDPs & 6,154 & 0,000 \\
\hline Perceived risk -> Intention to select CDPs & 3,035 & 0,002 \\
\hline Reference groups -> Subjective norms to select CDPs & 158,025 & 0,000 \\
\hline Self-efficacy -> Control perceived behavior to select CDPs & 11,886 & 0,000 \\
\hline Self-efficacy -> Intention to select CDPs & 4,816 & 0,000 \\
\hline Subjective norms to select CDPs -> Intention to select CDPs & 2,578 & 0,010 \\
\hline
\end{tabular}

The discussion of the results will be carried out in the evaluation section. 
Based on the PLS-SEM steps, the next steps are to evaluate $\mathrm{R}^{2}$ - variance values (coefficient of determination), $\mathrm{f}^{2}$ values, effect size. This coefficient indicates to what extent the predictor variables are capable of explaining the corresponding constructs. In addition, the following also shows the values of $\mathrm{f}^{2}$, size of the effect, which indicates to what extent it is relevant to the presence or absence of a construct in the model. The values obtained indicate that the model explains a large part of the variance -> 50\% for the intention of selecting options in delivery. However, in a case such as Attitude toward selecting CDPs the variance values is around 15\%, which makes us think that there are other additional factors that can help explain them.

Table 78 The values of the variance $\left(R^{2}\right)$ for $C D P s$

\begin{tabular}{|l|c|c|}
\hline \multicolumn{1}{|c|}{ Constructs } & R Square & $\begin{array}{c}\text { R Square } \\
\text { Adjusted }\end{array}$ \\
\hline Attitude toward selecting CDPs & $\mathbf{0 , 1 5 1}$ & 0,145 \\
\hline Control perceived behavior to select CDPs & 0,540 & 0,538 \\
\hline Intention to select CDPs & 0,732 & 0,727 \\
\hline Subjective norms to select CDPs & 0,905 & 0,905 \\
\hline
\end{tabular}

The table below shows the values corresponding to the size of the effect $\mathrm{f}^{2}$ for each construct with respect to its predictor variables. It should take into account the reference values, $0.02,0.15$, and 0.35 (small, medium, and large effect respectively). This high value shows that the contribution of subconstruct to the construct is important.

Table 79 The size of the effect $\left(f^{2}\right)$ with respect to its predictor variables for CDPs

\begin{tabular}{|c|c|c|c|c|c|c|c|c|c|c|}
\hline Constructs & 总总 & 品 & 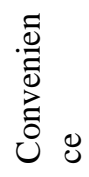 & 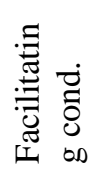 & 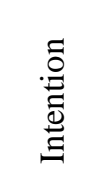 & 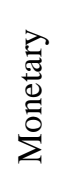 & 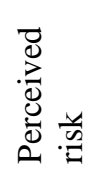 & 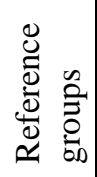 & 峞莺 & 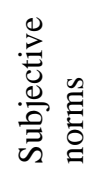 \\
\hline Attitude toward & & & & & 0,417 & & & & & \\
\hline PBC & & & & & 0,001 & & & & & \\
\hline Convenience & 0,007 & & & & 0,052 & & & & & \\
\hline Facilitating cond. & & 0,179 & & & 0,000 & & & & & \\
\hline \multicolumn{11}{|l|}{ Intention } \\
\hline Monetary & 0,005 & & & & 0,001 & & & & & \\
\hline Perceived risk & 0,104 & & & & 0,026 & & & & & \\
\hline Reference groups & & & & & & & & & & 9,553 \\
\hline Self-efficacy & & 0,400 & & & 0,069 & & & & & \\
\hline Subjective norms & & & & & 0,022 & & & & & \\
\hline
\end{tabular}

The next step is to determine the predictive relevance of the proposed theoretical model. For this, the value of $\mathrm{Q}^{2}$ will be calculated. Generally, it is considered that the relationship between two constructs has predictive relevance if $\mathrm{Q}^{2}>0$. 
The table below shows the result of the calculation of the predictive relevance index for CDPs. The value of all constructs was greater than zero, therefore, it can be stated that the model for In-store delivery has predictive relevance.

Table 80 The predictive relevance index $\left(Q^{2}\right)$ for $C D P s$

\begin{tabular}{|l|c|}
\hline \multicolumn{1}{|c|}{ Constructs } & Q Square \\
\hline Attitude toward selecting CDPs & \\
\hline Control perceived behavior to select CDPs & 0,247 \\
\hline Intention to select CDPs & 0,329 \\
\hline Subjective norms to select CDPs & 0,521 \\
\hline
\end{tabular}

The effect size $\left(\mathrm{q}^{2}\right)$ is available to measure the capacity of influence of each independent variable that predicts the construct. The reference values, $0.02,0.15$, and 0.35 correspond to small, medium, and large effects respectively. The table below shows the calculation of $\mathrm{q}^{2}$ for each independent variable that predicts the construct.

Table 81 The effect size $\left(q^{2}\right)$ of independent variable that predicts the construct for CDPs

\begin{tabular}{|c|c|}
\hline Indicators & Effect size $q^{2}$ \\
\hline AQ1 & 0,436 \\
\hline AQ2 & 0,432 \\
\hline PBC1 & 0,339 \\
\hline PBC2 & 0,343 \\
\hline Tc1 & 0,228 \\
\hline Tc2 & 0,192 \\
\hline Fc1 & 0,199 \\
\hline Fc2 & 0,211 \\
\hline Pr2 & 0,025 \\
\hline IQ1 & 0,477 \\
\hline IQ2 & 0,478 \\
\hline $\mathrm{Nq1}$ & 0,251 \\
\hline $\mathrm{Nq} 2$ & 0,249 \\
\hline Pr3 & 0,055 \\
\hline Pr4 & $-0,008$ \\
\hline Co2 & 0,093 \\
\hline Se1 & 0,111 \\
\hline Se2 & 1,000 \\
\hline SN1 & $-0,108$ \\
\hline SN2 & 1,000 \\
\hline Pr1 & 0,436 \\
\hline Co3 & 0,432 \\
\hline Co1 & 0,339 \\
\hline
\end{tabular}




\subsubsection{Structural model for Home return}

The first assessment is to evaluate the collinearity of the constructs. To do so, the inflation factor of variance (VIF) is evaluated. Generally, if VIF is greater than 5, we will have signs of collinearity.

Table 82 Multicollinearity evaluation using VIF for Home return

\begin{tabular}{|c|c|c|c|c|c|c|c|c|c|c|}
\hline Constructs & 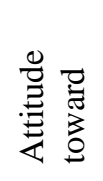 & 崩 & 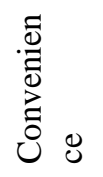 & 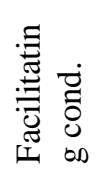 & 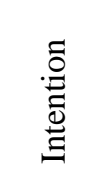 & $\begin{array}{l}\vec{\Xi} \\
\stackrel{\Xi}{\Xi} \\
\stackrel{0}{\Sigma}\end{array}$ & 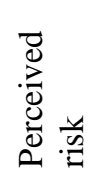 & 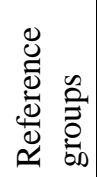 & 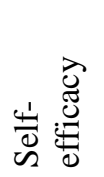 & 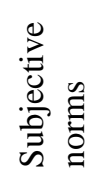 \\
\hline Attitude toward & & & & & 2,871 & & & & & \\
\hline $\mathrm{PBC}$ & & & & & 2,132 & & & & & \\
\hline Convenience & 1,504 & & & & 2,136 & & & & & \\
\hline Facilitating cond. & & 1,494 & & & 1,759 & & & & & \\
\hline \multicolumn{11}{|l|}{ Intention } \\
\hline Monetary & 1,006 & & & & 1,050 & & & & & \\
\hline Perceived risk & 1,497 & & & & 1,604 & & & & & \\
\hline Reference groups & & & & & & & & & & 1,000 \\
\hline Self-efficacy & & 1,494 & & & 3,057 & & & & & \\
\hline Subjective norms & & & & & 1,318 & & & & & \\
\hline
\end{tabular}

The values are well below the established limit (5), therefore, it can be stated that there is no multicollinearity in the structural model for Home return.

According to the statistical steps for analyzing the structure of the model, the next step is to measure the path coefficients or standardized regression coefficients. The results that come from this part show the basis for assessing the hypotheses and their statistical significance.

Table 83 shows the coefficients for each path for the Home return.

Table 83 Path coefficients for Home return

\begin{tabular}{|c|c|c|c|c|c|c|c|c|c|c|}
\hline Constructs & 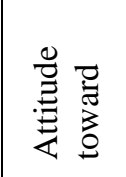 & U & 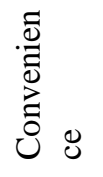 & 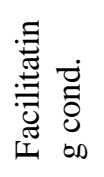 & 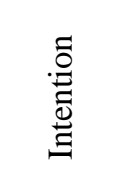 & 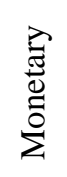 & 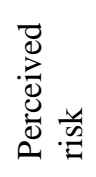 & 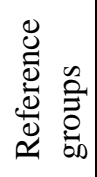 & 声莺 & 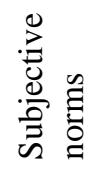 \\
\hline Attitude toward & & & & & 0,554 & & & & & \\
\hline PBC & & & & & 0,048 & & & & & \\
\hline Convenience & $-0,549$ & & & & $-0,089$ & & & & & \\
\hline Facilitating cond. & & 0,301 & & & $-0,057$ & & & & & \\
\hline \multicolumn{11}{|l|}{ Intention } \\
\hline Monetary & 0,076 & & & & 0,006 & & & & & \\
\hline Perceived risk & $-0,162$ & & & & $-0,117$ & & & & & \\
\hline Reference groups & & & & & & & & & & 0,905 \\
\hline
\end{tabular}




\begin{tabular}{|l|l|l|l|l|l|l|l|l|l|l|} 
Self-efficacy & & 0,499 & & & 0,185 & & & & & \\
\hline Subjective norms & & & & & $\mathbf{0 , 0 8 3}$ & & & & & \\
\hline
\end{tabular}

In order to evaluate if the constructs are significant or not, One-tailed T-Student is considered- since the direction of the relationship was specified. The relationships marked in bold are significant at least $95 \%$. Statistical significance values have been obtained using the bootstrapping technique with subsampling of 5000 samples.

Table 84 Levels of statistical significance for Path coefficients for Home return

\begin{tabular}{|l|c|c|}
\hline \multicolumn{1}{|c|}{ Path coefficients } & T Statistical & P-value \\
& & \\
\hline Attitude toward selecting HR -> Intention to select HR & 10,060 & 0,000 \\
\hline Control perceived behavior to select HR -> Intention to select HR & 1,065 & 0,287 \\
\hline Convenience -> Attitude toward selecting HR & 11,665 & 0,000 \\
\hline Convenience -> Intention to select HR & 2,044 & 0,041 \\
\hline Facilitating condition -> Control perceived behavior to select HR & 5,106 & 0,000 \\
\hline Facilitating condition -> Intention to select HR & 1,681 & 0,093 \\
\hline Monetary -> Attitude toward selecting HR & 1,620 & 0,105 \\
\hline Monetary -> Intention to select HR & 0,227 & 0,820 \\
\hline Perceived risk -> Attitude toward selecting HR & 3,426 & 0,001 \\
\hline Perceived risk -> Intention to select HR & 2,966 & 0,003 \\
\hline Reference groups -> Subjective norms to select HR & 111,727 & 0,000 \\
\hline Self-efficacy -> Control perceived behavior to select HR & 8,212 & 0,000 \\
\hline Self-efficacy -> Intention to select HR & 3,533 & 0,000 \\
\hline Subjective norms to select HR -> Intention to select HR & 2,991 & 0,003 \\
\hline
\end{tabular}

The discussion of the results will be carried out in the evaluation section.

Based on the PLS-SEM steps, the next steps are to evaluate $\mathrm{R}^{2}$ - variance values (coefficient of determination), $\mathrm{f}^{2}$ values, effect size. This coefficient indicates to what extent the predictor variables are capable of explaining the corresponding constructs. In addition, the following also shows the values of $\mathrm{f}^{2}$, size of the effect, which indicates to what extent it is relevant to the presence or absence of a construct in the model. The values obtained indicate that the model explains a large part of the variance -> 50\% for the intention of selecting options in delivery. However, in a case such as Attitude toward selecting HR the variance values is around $45 \%$, which makes us think that there are other additional factors that can help explain them. 


\begin{tabular}{|l|c|c|}
\hline \multicolumn{1}{|c|}{ Constructs } & R Square & $\begin{array}{c}\text { R Square } \\
\text { Adjusted }\end{array}$ \\
\hline Attitude toward selecting HR & $\mathbf{0 , 4 2 8}$ & 0,424 \\
\hline Control perceived behavior to select HR & 0,512 & 0,509 \\
\hline Intention to select HR & 0,758 & 0,753 \\
\hline Subjective norms to select HR & 0,820 & 0,820 \\
\hline
\end{tabular}

The table below shows the values corresponding to the size of the effect $f^{2}$ for each construct with respect to its predictor variables. It should take into account the reference values, $0.02,0.15$, and 0.35 (small, medium, and large effect respectively). This high value shows that the contribution of subconstruct to the construct is important.

Table 86 The size of the effect $\left(f^{2}\right)$ with respect to its predictor variables for Home return

\begin{tabular}{|c|c|c|c|c|c|c|c|c|c|c|}
\hline Constructs & 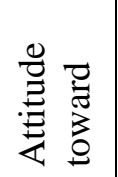 & $\stackrel{u}{0}$ & 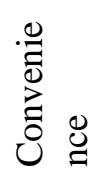 & 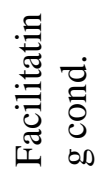 & 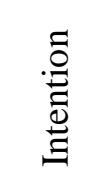 & $\begin{array}{l}\overrightarrow{0} \\
\stackrel{0}{0} \\
\tilde{\Xi}^{0}\end{array}$ & 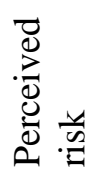 & 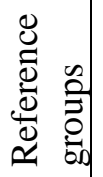 & 岂 & 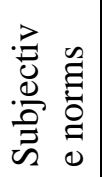 \\
\hline Attitude toward & & & & & 0,442 & & & & & \\
\hline PBC & & & & & 0,004 & & & & & \\
\hline Convenience & 0,350 & & & & 0,015 & & & & & \\
\hline Facilitating cond. & & 0,124 & & & 0,008 & & & & & \\
\hline \multicolumn{11}{|l|}{ Intention } \\
\hline Monetary & 0,010 & & & & 0,000 & & & & & \\
\hline Perceived risk & 0,031 & & & & 0,035 & & & & & \\
\hline Reference groups & & & & & & & & & & 4,553 \\
\hline Self-efficacy & & 0,341 & & & 0,046 & & & & & \\
\hline Subjective norms & & & & & 0,021 & & & & & \\
\hline
\end{tabular}

The next step is to determine the predictive relevance of the proposed theoretical model. For this, the value of $\mathrm{Q}^{2}$ will be calculated. Generally, it is considered that the relationship between two constructs has predictive relevance if $\mathrm{Q}^{2>} 0$.

The table below shows the result of the calculation of the predictive relevance index for Home return. The value of all constructs was greater than zero, therefore, it can be stated that the model for In-store delivery has predictive relevance. 
Table 87 The predictive relevance index $\left(Q^{2}\right)$ for Home return

\begin{tabular}{|l|c|}
\hline \multicolumn{1}{|c|}{ Constructs } & Q Square \\
& \\
\hline Attitude toward selecting HR & 0,362 \\
\hline Control perceived behavior to select HR & 0,385 \\
\hline Intention to select HR & 0,643 \\
\hline Subjective norms to select HR & 0,816 \\
\hline
\end{tabular}

The effect size $\left(\mathrm{q}^{2}\right)$ is available to measure the capacity of influence of each independent variable that predicts the construct. The reference values, $0.02,0.15$, and 0.35 correspond to small, medium, and large effects respectively. The table below shows the calculation of $\mathrm{q}^{2}$ for each independent variable that predicts the construct.

Table 88 The effect size $\left(q^{2}\right)$ of independent variable that predicts the construct for Home return

\begin{tabular}{|c|c|}
\hline Indicators & Effect size $q^{2}$ \\
\hline AQ1 & 0,502 \\
\hline AQ2 & 0,506 \\
\hline PBC1 & 0,278 \\
\hline PBC2 & 0,282 \\
\hline Tc1 & $-0,014$ \\
\hline Tc2 & $-0,004$ \\
\hline Fc1 & 0,245 \\
\hline Fc2 & 0,247 \\
\hline Pr2 & 0,118 \\
\hline IQ1 & 0,108 \\
\hline IQ2 & 0,482 \\
\hline Nq1 & 0,480 \\
\hline $\mathrm{Nq} 2$ & 0,342 \\
\hline Pr3 & 0,345 \\
\hline Pr4 & 0,114 \\
\hline Co2 & 0,160 \\
\hline Se1 & 0,279 \\
\hline Se2 & 0,278 \\
\hline SN1 & 1,000 \\
\hline SN2 & 0,054 \\
\hline Pr1 & 0,307 \\
\hline Co3 & 0,502 \\
\hline Co1 & 0,506 \\
\hline
\end{tabular}




\subsubsection{Structural model for In-store return}

The first assessment is to evaluate the collinearity of the constructs. To do so, the inflation factor of variance (VIF) is evaluated. Generally, if VIF is greater than 5, we will have signs of collinearity.

Table 89 Multicollinearity evaluation using VIF for In-store return

\begin{tabular}{|c|c|c|c|c|c|c|c|c|c|c|}
\hline Constructs & 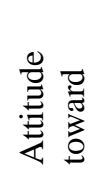 & 品 & 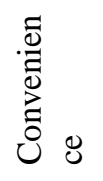 & 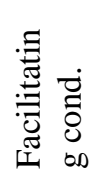 & 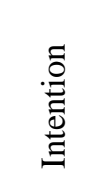 & $\begin{array}{l}\vec{\Xi} \\
\stackrel{\Xi}{\Xi} \\
\dot{0}\end{array}$ & 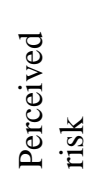 & 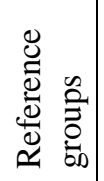 & 岕 & 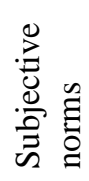 \\
\hline Attitude toward & & & & & 2,263 & & & & & \\
\hline PBC & & & & & 1,899 & & & & & \\
\hline Convenience & 1,062 & & & & 1,520 & & & & & \\
\hline Facilitating cond. & & 1,319 & & & 1,689 & & & & & \\
\hline \multicolumn{11}{|l|}{ Intention } \\
\hline Monetary & 1,182 & & & & 1,438 & & & & & \\
\hline Perceived risk & 1,249 & & & & 1,335 & & & & & \\
\hline Reference groups & & & & & & & & & & 1,000 \\
\hline Self-efficacy & & 1,319 & & & 2,466 & & & & & \\
\hline Subjective norms & & & & & 1,347 & & & & & \\
\hline
\end{tabular}

The values are well below the established limit (5), therefore, it can be stated that there is no multicollinearity in the structural model for In-store return.

According to the statistical steps for analyzing the structure of the model, the next step is to measure the path coefficients or standardized regression coefficients. The results that come from this part show the basis for assessing the hypotheses and their statistical significance. Table 90 shows the coefficients for each path for the In-store return.

Table 90 Path coefficients for In-store return

\begin{tabular}{|c|c|c|c|c|c|c|c|c|c|c|}
\hline Constructs & 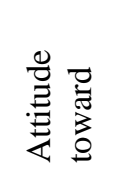 & 品 & 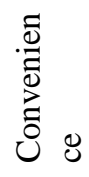 & 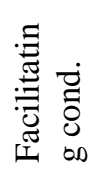 & 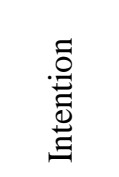 & 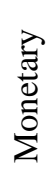 & 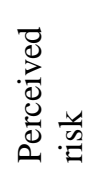 & 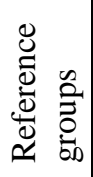 & 岂 & 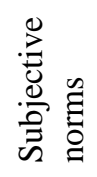 \\
\hline Attitude toward & & & & & 0,520 & & & & & \\
\hline PBC & & & & & 0,080 & & & & & \\
\hline Convenience & 0,470 & & & & 0,114 & & & & & \\
\hline Facilitating cond. & & 0,305 & & & $-0,089$ & & & & & \\
\hline \multicolumn{11}{|l|}{ Intention } \\
\hline Monetary & 0,060 & & & & $-0,013$ & & & & & \\
\hline Perceived risk & $-0,221$ & & & & $-0,146$ & & & & & \\
\hline Reference groups & & & & & & & & & & 0,901 \\
\hline Self-efficacy & & 0,451 & & & 0,118 & & & & & \\
\hline Subjective norms & & & & & 0,118 & & & & & \\
\hline
\end{tabular}


In order to evaluate if the constructs are significant or not, One-tailed T-Student is considered- since the direction of the relationship was specified. The relationships marked in bold are significant at least 95\%. Statistical significance values have been obtained using the bootstrapping technique with subsampling of 5000 samples.

Table 91 Levels of statistical significance for Path coefficients for In-store return

\begin{tabular}{|l|c|c|}
\hline \multicolumn{1}{|c|}{ Path coefficients } & T Statistical & P-value \\
& & \\
\hline Attitude toward selecting SR -> Intention to select SR & 9,237 & 0,000 \\
\hline Control perceived behavior to select SR -> Intention to select SR & 1,736 & 0,083 \\
\hline Convenience -> Attitude toward selecting SR & 8,350 & 0,000 \\
\hline Convenience -> Intention to select SR & 2,729 & 0,006 \\
\hline Facilitating condition -> Control perceived behavior to select SR & 5,601 & 0,000 \\
\hline Facilitating condition -> Intention to select SR & 1,675 & 0,094 \\
\hline Monetary -> Attitude toward selecting SR & 1,276 & 0,202 \\
\hline Monetary -> Intention to select SR & 0,280 & 0,779 \\
\hline Perceived risk -> Attitude toward selecting SR & 3,988 & 0,000 \\
\hline Perceived risk -> Intention to select SR & 3,577 & 0,000 \\
\hline Reference groups -> Subjective norms to select SR & 95,159 & 0,000 \\
\hline Self-efficacy -> Control perceived behavior to select SR & 8,155 & 0,000 \\
\hline Self-efficacy -> Intention to select SR & 2,408 & 0,016 \\
\hline Subjective norms to select SR -> Intention to select SR & 3,711 & 0,000 \\
\hline
\end{tabular}

The discussion of the results will be carried out in the evaluation section.

Based on the PLS-SEM steps, the next steps are to evaluate $\mathrm{R}^{2}$ - variance values (coefficient of determination), $\mathrm{f}^{2}$ values, effect size. This coefficient indicates to what extent the predictor variables are capable of explaining the corresponding constructs. In addition, the following also shows the values of $\mathrm{f}^{2}$, size of the effect, which indicates to what extent it is relevant to the presence or absence of a construct in the model. The values obtained indicate that the model explains a large part of the variance -> 50\% for the intention of selecting options in delivery. However, in two cases such as Attitude toward selecting SR and Control perceived behavior to select SR the variance values are around $40 \%$, which makes us think that there are other additional factors that can help explain them. 


\begin{tabular}{|l|c|c|}
\hline \multicolumn{1}{|c|}{ Constructs } & R Square & $\begin{array}{c}\text { R Square } \\
\text { Adjusted }\end{array}$ \\
\hline Attitude toward selecting SR & $\mathbf{0 , 3 0 9}$ & 0,304 \\
\hline Control perceived behavior to select SR & $\mathbf{0 , 4 3 2}$ & 0,429 \\
\hline Intention to select SR & 0,650 & 0,644 \\
\hline Subjective norms to select SR & 0,811 & 0,811 \\
\hline
\end{tabular}

The table below shows the values corresponding to the size of the effect $\mathrm{f}^{2}$ for each construct with respect to its predictor variables. It should take into account the reference values, $0.02,0.15$, and 0.35 (small, medium, and large effect respectively). This high value shows that the contribution of subconstruct to the construct is important.

Table 93 The size of the effect $\left(f^{2}\right)$ with respect to its predictor variables for In-store return

\begin{tabular}{|c|c|c|c|c|c|c|c|c|c|c|}
\hline Constructs & 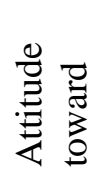 & $\stackrel{u}{n}$ & 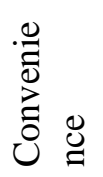 & 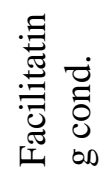 & 总 & 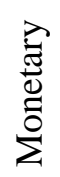 & 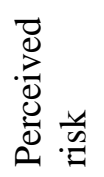 & 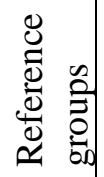 & 至莺 & 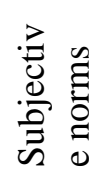 \\
\hline Attitude toward & & & & & 0,342 & & & & & \\
\hline PBC & & & & & 0,010 & & & & & \\
\hline Convenience & 0,301 & & & & 0,025 & & & & & \\
\hline Facilitating cond. & & 0,124 & & & 0,013 & & & & & \\
\hline \multicolumn{11}{|l|}{ Intention } \\
\hline Monetary & 0,004 & & & & 0,000 & & & & & \\
\hline Perceived risk & 0,056 & & & & 0,046 & & & & & \\
\hline Reference groups & & & & & & & & & & 4,297 \\
\hline Self-efficacy & & 0,272 & & & 0,016 & & & & & \\
\hline Subjective norms & & & & & 0,029 & & & & & \\
\hline
\end{tabular}

The next step is to determine the predictive relevance of the proposed theoretical model. For this, the value of $\mathrm{Q}^{2}$ will be calculated. Generally, it is considered that the relationship between two constructs has predictive relevance if $\mathrm{Q}^{2>} 0$.

The table below shows the result of the calculation of the predictive relevance index for Home return. The value of all constructs was greater than zero, therefore, it can be stated that the model for In-store delivery has predictive relevance. 
Table 94 The predictive relevance index $\left(Q^{2}\right)$ for In-store return

\begin{tabular}{|l|c|}
\hline \multicolumn{1}{|c|}{ Constructs } & Q Square \\
& \\
\hline Attitude toward selecting SR & 9,237 \\
\hline Control perceived behavior to select SR & 1,736 \\
\hline Intention to select SR & 0,540 \\
\hline Subjective norms to select SR & 0,807 \\
\hline
\end{tabular}

The effect size $\left(\mathrm{q}^{2}\right)$ is available to measure the capacity of influence of each independent variable that predicts the construct. The reference values, $0.02,0.15$, and 0.35 correspond to small, medium, and large effects respectively. The table below shows the calculation of $\mathrm{q}^{2}$ for each independent variable that predicts the construct.

Table 95 The effect size $\left(q^{2}\right)$ of independent variable that predicts the construct for In-store return

\begin{tabular}{|c|c|}
\hline Indicators & Effect size $q^{2}$ \\
\hline AQ1 & 0,397 \\
\hline AQ2 & 0,393 \\
\hline PBC1 & 0,260 \\
\hline PBC2 & 0,260 \\
\hline Tc1 & 0,341 \\
\hline Tc2 & 0,237 \\
\hline Fc1 & 0,155 \\
\hline Fc2 & 0,175 \\
\hline Pr2 & $-0,034$ \\
\hline IQ1 & 0,455 \\
\hline IQ2 & 0,468 \\
\hline Nq1 & 0,341 \\
\hline $\mathrm{Nq} 2$ & 0,342 \\
\hline Pr3 & $-0,195$ \\
\hline Pr4 & $-0,064$ \\
\hline $\mathrm{Co} 2$ & 0,041 \\
\hline Se1 & 0,067 \\
\hline Se2 & 1,000 \\
\hline SN1 & $-0,167$ \\
\hline SN2 & 0,397 \\
\hline Pr1 & 0,393 \\
\hline Co3 & 0,260 \\
\hline Co1 & 0,260 \\
\hline
\end{tabular}




\subsubsection{Structural model for CRPs}

The first assessment is to evaluate the collinearity of the constructs. To do so, the inflation factor of variance (VIF) is evaluated. Generally, if VIF is greater than 5, we will have signs of collinearity.

Table 96 Multicollinearity evaluation using VIF for CRPs

\begin{tabular}{|c|c|c|c|c|c|c|c|c|c|c|}
\hline Constructs & 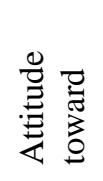 & 品 & 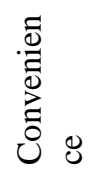 & 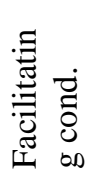 & 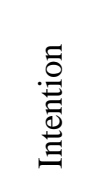 & 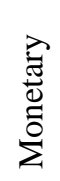 & 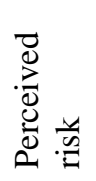 & 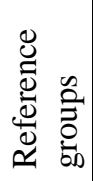 & 岂 & 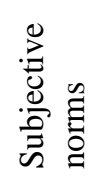 \\
\hline Attitude toward & & & & & 2,271 & & & & & \\
\hline \multicolumn{11}{|l|}{ PBC } \\
\hline Convenience & 1,409 & & & & & & & & & \\
\hline Facilitating cond. & & 1,407 & & & 1,708 & & & & & \\
\hline \multicolumn{11}{|l|}{ Intention } \\
\hline Monetary & 1,117 & & & & 1,222 & & & & & \\
\hline Perceived risk & 1,310 & & & & 1,444 & & & & & \\
\hline Reference groups & & & & & & & & & & 1,000 \\
\hline Self-efficacy & & 1,407 & & & 3,292 & & & & & \\
\hline Subjective norms & & & & & 1,177 & & & & & \\
\hline
\end{tabular}

The values are well below the established limit (5), therefore, it can be stated that there is no multicollinearity in the structural model for CRPs.

According to the statistical steps for analyzing the structure of the model, the next step is to measure the path coefficients or standardized regression coefficients. The results that come from this part show the basis for assessing the hypotheses and their statistical significance. Table 97 shows the coefficients for each path for the CRPs.

Table 97 Path coefficients for CRPs

\begin{tabular}{|c|c|c|c|c|c|c|c|c|c|c|}
\hline Constructs & 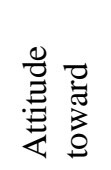 & U & 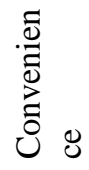 & 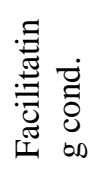 & 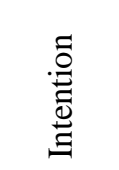 & 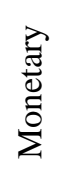 & 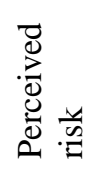 & 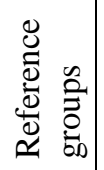 & 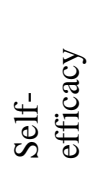 & 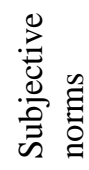 \\
\hline Attitude toward & & & & & 0,513 & & & & & \\
\hline PBC & & & & & $-0,021$ & & & & & \\
\hline Convenience & $-0,161$ & & & & $-0,125$ & & & & & \\
\hline Facilitating cond. & & 0,333 & & & $-0,035$ & & & & & \\
\hline \multicolumn{11}{|l|}{ Intention } \\
\hline Monetary & 0,100 & & & & $-0,007$ & & & & & \\
\hline Perceived risk & $-0,321$ & & & & $-0,100$ & & & & & \\
\hline Reference groups & & & & & & & & & & 0,949 \\
\hline Self-efficacy & & 0,519 & & & 0,261 & & & & & \\
\hline Subjective norms & & & & & 0,157 & & & & & \\
\hline
\end{tabular}


In order to evaluate if the constructs are significant or not, One-tailed T-Student is considered- since the direction of the relationship was specified. The relationships marked in bold are significant at least 95\%. Statistical significance values have been obtained using the bootstrapping technique with subsampling of 5000 samples.

Table 98 Levels of statistical significance for Path coefficients for CRPs

\begin{tabular}{|l|c|c|}
\hline \multicolumn{1}{|c|}{ Path coefficients } & T Statistical & P-value \\
& & \\
\hline Attitude toward selecting CRPs -> Intention to select CRPs & 11,079 & 0,000 \\
\hline Control perceived behavior to select CRPs -> Intention to select CRPs & 0,533 & 0,594 \\
\hline Convenience -> Attitude toward selecting CRPs & 2,643 & 0,008 \\
\hline Convenience -> Intention to select CRPs & 3,828 & 0,000 \\
\hline Facilitating condition -> Control perceived behavior to select CRPs & 7,483 & 0,000 \\
\hline Facilitating condition -> Intention to select CRPs & 0,964 & 0,335 \\
\hline Monetary -> Attitude toward selecting CRPs & 1,557 & 0,119 \\
\hline Monetary -> Intention to select CRPs & 0,145 & 0,885 \\
\hline Perceived risk -> Attitude toward selecting CRPs & 5,994 & 0,000 \\
\hline Perceived risk -> Intention to select CRPs & 3,030 & 0,002 \\
\hline Reference groups -> Subjective norms to select CDRPs & 154,153 & 0,000 \\
\hline Self-efficacy -> Control perceived behavior to select CRPs & 12,349 & 0,000 \\
\hline Self-efficacy -> Intention to select CRPs & 4,959 & 0,000 \\
\hline Subjective norms to select CDRPs -> Intention to select CRPs & 4,784 & 0,000 \\
\hline
\end{tabular}

The discussion of the results will be carried out in the evaluation section.

Based on the PLS-SEM steps, the next steps are to evaluate $\mathrm{R}^{2}$ - variance values (coefficient of determination), $\mathrm{f}^{2}$ values, effect size. This coefficient indicates to what extent the predictor variables are capable of explaining the corresponding constructs. In addition, the following also shows the values of $\mathrm{f}^{2}$, size of the effect, which indicates to what extent it is relevant to the presence or absence of a construct in the model. The values obtained indicate that the model explains a large part of the variance -> 50\% for the intention of selecting options in delivery. However, in a case such as Attitude toward selecting CRPs the variance value is around 15\%, which makes us think that there are other additional factors that can help explain them. 


\begin{tabular}{|l|c|c|}
\hline \multicolumn{1}{|c|}{ Constructs } & R Square & $\begin{array}{c}\text { R Square } \\
\text { Adjusted }\end{array}$ \\
\hline Attitude toward selecting CRPs & $\mathbf{0 , 1 6 7}$ & 0,161 \\
\hline Control perceived behavior to select CRPs & 0,566 & 0,564 \\
\hline Intention to select CRPs & 0,741 & 0,736 \\
\hline Subjective norms to select CRPs & 0,901 & 0,901 \\
\hline
\end{tabular}

The table below shows the values corresponding to the size of the effect $\mathrm{f}^{2}$ for each construct with respect to its predictor variables. It should take into account the reference values, $0.02,0.15$, and 0.35 (small, medium, and large effect respectively). This high value shows that the contribution of subconstruct to the construct is important.

Table 100 The size of the effect $\left(f^{2}\right)$ with respect to its predictor variables for CRPs

\begin{tabular}{|c|c|c|c|c|c|c|c|c|c|c|}
\hline Constructs & 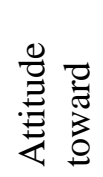 & $\stackrel{u}{0}$ & 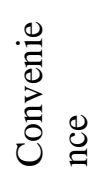 & 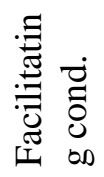 & 兽 & $\begin{array}{l}\overrightarrow{0} \\
\stackrel{0}{0} \\
\sum_{0}^{0}\end{array}$ & 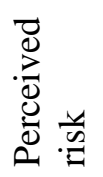 & 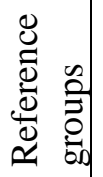 & 岕 & 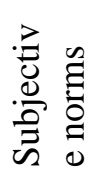 \\
\hline Attitude toward & & & & & 0,446 & & & & & \\
\hline PBC & & & & & 0,001 & & & & & \\
\hline Convenience & 0,022 & & & & 0,042 & & & & & \\
\hline Facilitating cond. & & 0,182 & & & 0,003 & & & & & \\
\hline \multicolumn{11}{|l|}{ Intention } \\
\hline Monetary & 0,011 & & & & 0,000 & & & & & \\
\hline Perceived risk & 0,094 & & & & 0,027 & & & & & \\
\hline Reference groups & & & & & & & & & & 9,138 \\
\hline Self-efficacy & & 0,441 & & & 0,080 & & & & & \\
\hline Subjective norms & & & & & 0,081 & & & & & \\
\hline
\end{tabular}

The next step is to determine the predictive relevance of the proposed theoretical model. For this, the value of $\mathrm{Q}^{2}$ will be calculated. Generally, it is considered that the relationship between two constructs has predictive relevance if $\mathrm{Q}^{2>} 0$.

The table below shows the result of the calculation of the predictive relevance index for Home return. The value of all constructs was greater than zero, therefore, it can be stated that the model for In-store delivery has predictive relevance. 
Table 101 The predictive relevance index $\left(Q^{2}\right)$ for $C R P S$

\begin{tabular}{|l|c|}
\hline \multicolumn{1}{|c|}{ Constructs } & Q Square \\
\hline Attitude toward selecting CRPs & 0,130 \\
\hline Control perceived behavior to select CRPs & 0,430 \\
\hline Intention to select CRPs & 0,625 \\
\hline Subjective norms to select CRPs & 0,808 \\
\hline
\end{tabular}

The effect size $\left(\mathrm{q}^{2}\right)$ is available to measure the capacity of influence of each independent variable that predicts the construct. The reference values, $0.02,0.15$, and 0.35 correspond to small, medium, and large effects respectively. The table below shows the calculation of $\mathrm{q}^{2}$ for each independent variable that predicts the construct.

Table 102 The effect size $\left(q^{2}\right)$ of independent variable that predicts the construct for CRPs

\begin{tabular}{|c|c|}
\hline Indicators & Effect size $q^{2}$ \\
\hline AQ1 & 0,440 \\
\hline AQ2 & 0,436 \\
\hline PBC1 & 0,289 \\
\hline PBC2 & 0,290 \\
\hline Tc1 & 0,205 \\
\hline Tc2 & $-0,010$ \\
\hline Fc1 & 0,209 \\
\hline Fc2 & 0,219 \\
\hline Pr2 & 0,473 \\
\hline IQ1 & 0,475 \\
\hline IQ2 & 0,220 \\
\hline Nq1 & 0,220 \\
\hline $\mathrm{Nq2}$ & 0,005 \\
\hline Pr3 & $-0,119$ \\
\hline Pr4 & 0,265 \\
\hline Co2 & 0,136 \\
\hline Se1 & 0,147 \\
\hline Se2 & 1,000 \\
\hline SN1 & $-0,213$ \\
\hline SN2 & 0,285 \\
\hline Pr1 & 0,440 \\
\hline Co3 & 0,436 \\
\hline Co1 & 0,289 \\
\hline
\end{tabular}




\subsubsection{Analyzing the moderating indicators}

To examine the moderating effects of situational factors (i.e. time availability, channel spillover effect, distance to store) in consumer's attitudes to intention, this study uses the two-steps process manually. This is due to the fact that this research did not conduct data from situational factors alone in the study due to the length of the survey and this research was carried out only by asking different scenarios on attitude toward that behavior. Hence, in order to see the influence of situational factors, we analyze 6 (all last-mile logistics) * 8 (all scenarios carrying out all situations). The difference of scores in indicators of the exogenous constructs can be shown by comparing the path coefficients value. In order to see the significance, the research conduct the P-value. After that, to obtain the path coefficients of each situational factor, the dummy variable regression is conducted. In this case, it shows that the moderating variables to what extent influence the relationships between exogenous constructs and endogenous constructs.

Table 103 All scenarios apply in this study

\begin{tabular}{|c|c|c|c|c|c|c|}
\hline \multirow{2}{*}{ Scenarios } & \multicolumn{2}{|c|}{ Spill Over effect } & \multicolumn{2}{c|}{ Time } & \multicolumn{2}{c|}{ Distance } \\
\cline { 2 - 7 } & Store & Internet & Limited & Unlimited & Far & Near \\
\hline 1 & 1 & 0 & 1 & 0 & 1 & 0 \\
\hline 2 & 1 & 0 & 1 & 0 & 0 & 1 \\
\hline 3 & 1 & 0 & 0 & 1 & 1 & 0 \\
\hline 4 & 1 & 0 & 0 & 1 & 0 & 1 \\
\hline 5 & 0 & 1 & 1 & 0 & 1 & 0 \\
\hline 6 & 0 & 1 & 1 & 0 & 0 & 1 \\
\hline 7 & 0 & 1 & 0 & 1 & 1 & 0 \\
\hline 8 & 0 & 1 & 0 & 1 & 0 & 1 \\
\hline
\end{tabular}

Table 104 Comparing the path coefficients and P-value for Home delivery

\begin{tabular}{|c|c|c|c|c|c|c|c|c|}
\hline Scenarios & 011 & 010 & 001 & 000 & 111 & 110 & 101 & 100 \\
\hline 011 & & $\mathbf{3 , 5 9 E - 8 2}$ & $\mathbf{1 , 0 6 E - 2 2}$ & $\mathbf{1 , 3 8 E - 7 5}$ & $\mathbf{0}$ & $\mathbf{1 , 6 E}-292$ & $3,1 E-265$ & $\mathbf{6 E - 1 6 4}$ \\
\hline 010 & $-0,067$ & & $\mathbf{8 , 7 4 E - 2 2}$ & $\mathbf{0 , 3 1 4 8 7 1}$ & $\mathbf{0}$ & $\mathbf{0}$ & $\mathbf{0}$ & $\mathbf{0}$ \\
\hline 001 & $-0,034$ & 0,032 & & $\mathbf{3 , 4 9 E}-19$ & $\mathbf{0}$ & $\mathbf{0}$ & $\mathbf{0}$ & $\mathbf{5 , 1 E}-220$ \\
\hline 000 & $-0,065$ & 0,001 & $-0,031$ & & $\mathbf{0}$ & $\mathbf{0}$ & $\mathbf{0}$ & $\mathbf{0}$ \\
\hline 111 & 0,200 & 0,267 & 0,234 & 0,265 & & $3,5 E-108$ & $\mathbf{9 , 8 E - 1 2 6}$ & $5,3 E-271$ \\
\hline 110 & 0,150 & 0,217 & 0,185 & 0,216 & $-0,049$ & & $\mathbf{7 , 2 9 E - 0 6}$ & $\mathbf{9 , 3 E - 1 8 9}$ \\
\hline 101 & 0,142 & 0,209 & 0,176 & 0,207 & $-0,058$ & $-0,009$ & & $\mathbf{4 , 0 5 E - 8 9}$ \\
\hline 100 & 0,094 & 0,161 & 0,128 & 0,322 & $-0,106$ & $-0,057$ & $-0,048$ & \\
\hline
\end{tabular}

Hint: P-value is bold

Table 105 Comparing the path coefficients and P-value for In-store delivery

\begin{tabular}{|c|c|c|c|c|c|c|c|c|}
\hline Scenarios & 011 & 010 & 001 & 000 & 111 & 110 & 101 & 100 \\
\hline 011 & & $\mathbf{6 E - 2 2 6}$ & $\mathbf{7 , 6 E - 3 9}$ & $\mathbf{0}$ & $\mathbf{0 , 0 1 0 1 6 1}$ & $\mathbf{5 , 4 8 E - 3 1}$ & $\mathbf{2 , 0 6 E - 2 1}$ & $\mathbf{8 , 7 6 E - 6 6}$ \\
\hline 010 & $-0,140$ & & $\mathbf{1 , 1 E}-157$ & $\mathbf{5 , 4 E - 1 2 4}$ & $\mathbf{1 , 9 E}-235$ & $\mathbf{1 , 3 E}-146$ & $\mathbf{7 E - 2 7 0}$ & 4,54E-97 \\
\hline
\end{tabular}




\begin{tabular}{|l|c|c|c|c|c|c|c|c|}
\cline { 6 - 8 } 001 & $-0,108$ & 0,029 & & $\mathbf{0}$ & $\mathbf{3 , 6 E}-\mathbf{5 0}$ & $\mathbf{0 , 2 9 4 1 6 3}$ & $\mathbf{0}$ & $\mathbf{5 , 8 5 E - 1 2}$ \\
\hline 000 & $-0,139$ & $-0,002$ & $-0,103$ & & $\mathbf{0}$ & $\mathbf{0}$ & $\mathbf{0}$ & $\mathbf{0}$ \\
\hline 111 & 0,126 & 0,263 & 0,163 & 0,354 & & $\mathbf{9 , 5 E}-\mathbf{4 1}$ & $\mathbf{3 , 3 4 E - 1 3}$ & $\mathbf{5 , 3 3 E - 7 7}$ \\
\hline 110 & 0,077 & 0,214 & 0,113 & 0,305 & 0,071 & & $\mathbf{9 , 3 9 E - 7 9}$ & $\mathbf{3 , 5 3 E - 2 0}$ \\
\hline 101 & 0,068 & 0,205 & 0,105 & 0,296 & 0,062 & 0,103 & & $\mathbf{4 , 2 E - 1 1 7}$ \\
\hline 100 & 0,021 & 0,157 & 0,057 & 0,411 & 0,014 & 0,055 & $-0,006$ & \\
\hline
\end{tabular}

Hint: P-value is bold

Table 106 Comparing the path coefficients and P-value for CDPs

\begin{tabular}{|c|c|c|c|c|c|c|c|c|}
\hline Scenarios & 011 & 010 & 001 & 000 & 111 & 110 & 101 & 100 \\
\hline 011 & & $\mathbf{4 , 6 9 E - 0 9}$ & $\mathbf{2 , 7 7 E - 6 2}$ & $\mathbf{9 , 7 9 E - 0 8}$ & $\mathbf{3 , 5 E - 2 2 9}$ & $\mathbf{9 , 5 E - 2 4 2}$ & $\mathbf{1 , 5 E - 1 0 9}$ & $\mathbf{1 , 4 E - 1 4 8}$ \\
\hline 010 & $-0,066$ & & $\mathbf{1 , 0 5 E - 9 2}$ & $\mathbf{2 , 8 7 E - 2 5}$ & $\mathbf{5 , 6 E - 2 5 2}$ & $\mathbf{2 , 7 E - 2 6 3}$ & $\mathbf{1 , 4 E - 1 4 0}$ & $\mathbf{2 , 8 E - 1 7 7}$ \\
\hline 001 & $-0,033$ & $-0,019$ & & $\mathbf{1 , 4 4 E - 3 1}$ & $\mathbf{7 E - 1 1 6}$ & $\mathbf{4 , 3 E - 1 3 3}$ & $\mathbf{2 , 2 5 E - 7 5}$ & $\mathbf{1 , 6 E - 3 8}$ \\
\hline 000 & $-0,064$ & $-0,050$ & $-0,107$ & & $\mathbf{1 , 7 E - 1 8 6}$ & $\mathbf{9 , 5 E - 2 0 1}$ & $\mathbf{0}$ & $\mathbf{0}$ \\
\hline 111 & 0,201 & 0,215 & 0,158 & 0,188 & & $\mathbf{0 , 0 0 0 2 1 6}$ & $\mathbf{1 , 2 E - 7 6}$ & $\mathbf{3 , 8 5 E - 3 8}$ \\
\hline 110 & 0,152 & 0,166 & 0,109 & 0,139 & 0,048 & & $\mathbf{9 , 0 5 E}-\mathbf{9 5}$ & $\mathbf{8 , 1 E}-100$ \\
\hline 101 & 0,143 & 0,157 & 0,100 & 0,130 & 0,039 & 0,031 & & $\mathbf{1 , 1 4 E - 1 1}$ \\
\hline 100 & 0,095 & 0,110 & 0,053 & 0,245 & $-0,009$ & $-0,017$ & 0,036 & \\
\hline
\end{tabular}

Hint: P-value is bold

Table 107 Comparing the path coefficients and P-value for Home return

\begin{tabular}{|c|c|c|c|c|c|c|c|c|}
\hline Scenarios & 011 & 010 & 001 & 000 & 111 & 110 & 101 & 100 \\
\hline 011 & & $\mathbf{5 , 9 2 E - 2 3}$ & $\mathbf{3 , 4 3 E - 4 1}$ & $\mathbf{3 E - 1 4 4}$ & $\mathbf{2 , 6 E - 1 9 7}$ & $\mathbf{5 , 2 E - 1 2 9}$ & $\mathbf{0 , 4 1 6 5 6 1}$ & $\mathbf{3 , 7 1 E - 0 5}$ \\
\hline 010 & $-0,061$ & & $\mathbf{3 , 7 8 E - 9 2}$ & $\mathbf{2 , 1 E - 1 9 9}$ & $\mathbf{4 , 2 E - 1 2 5}$ & $\mathbf{1 , 1 5 E - 6 1}$ & $\mathbf{1 , 5 6 E - 2 1}$ & $\mathbf{4 , 3 6 E - 1 0}$ \\
\hline 001 & $-0,028$ & $-0,054$ & & $\mathbf{8 , 0 7 E - 4 7}$ & $\mathbf{6 , 1 E}-260$ & $\mathbf{8 , 8 E - 2 0 2}$ & $\mathbf{4 , 4 E - 1 2 6}$ & $\mathbf{1 , 2 9 E - 6 0}$ \\
\hline 000 & $-0,059$ & $-0,085$ & $-0,020$ & & $\mathbf{0}$ & $\mathbf{5 , 9 E - 3 0 4}$ & $\mathbf{0}$ & $\mathbf{0}$ \\
\hline 111 & 0,206 & 0,180 & 0,245 & 0,289 & & $\mathbf{8 , 2 3 E - 2 4}$ & $\mathbf{2 , 4 E - 1 8 3}$ & $\mathbf{6 , 2 E - 1 7 2}$ \\
\hline 110 & 0,157 & 0,131 & 0,196 & 0,240 & 0,060 & & $\mathbf{2 , 7 E - 1 1 9}$ & $\mathbf{1 , 1 E - 1 6 7}$ \\
\hline 101 & 0,148 & 0,122 & 0,187 & 0,231 & 0,051 & 0,076 & & $\mathbf{4 , 1 3 E - 0 5}$ \\
\hline 100 & 0,100 & 0,074 & 0,139 & 0,346 & 0,003 & 0,028 & 0,101 & \\
\hline
\end{tabular}

Hint: P-value is bold

Table 108 Comparing the path coefficients and P-value for In-store return

\begin{tabular}{|c|c|c|c|c|c|c|c|c|}
\hline Scenarios & 011 & 010 & 001 & 000 & 111 & 110 & 101 & 100 \\
\hline 011 & & $\mathbf{5 , 8 E - 1 7 1}$ & $\mathbf{1 , 5 E - 1 8 5}$ & $\mathbf{8 , 1 E - 1 2 6}$ & $\mathbf{6 , 6 E - 1 5 3}$ & $\mathbf{1 , 4 E - 1 0 1}$ & $\mathbf{5 , 4 E - 1 3 3}$ & $\mathbf{4 , 3 2 E - 9 5}$ \\
\hline 010 & $-0,107$ & & $\mathbf{0}$ & $\mathbf{2 , 5 3 E - 1 0}$ & $\mathbf{0}$ & $\mathbf{1 , 0 8 E - 2 0}$ & $\mathbf{0}$ & $\mathbf{1 , 5 1 E - 2 4}$ \\
\hline 001 & $-0,074$ & 0,026 & & $\mathbf{0}$ & $\mathbf{3 , 8 6 E - 0 7}$ & $\mathbf{0}$ & $\mathbf{0}$ & $\mathbf{1 , 2 E}-304$ \\
\hline 000 & $-0,105$ & $-0,005$ & $-0,200$ & & $\mathbf{2 , 1 E - 3 0 7}$ & $\mathbf{0 , 0 0 0 6 2 6}$ & $\mathbf{0}$ & $\mathbf{0}$ \\
\hline 111 & 0,160 & 0,260 & 0,065 & 0,241 & & $\mathbf{1 , 1 E}-284$ & $\mathbf{0 , 0 0 8 5 7 9}$ & $\mathbf{5 , 8 E - 2 7 9}$ \\
\hline 110 & 0,111 & 0,211 & 0,016 & 0,192 & 0,028 & & $\mathbf{4 , 1 E - 2 6 7}$ & $\mathbf{0 , 0 8 7 3 0 5}$ \\
\hline 101 & 0,102 & 0,202 & 0,007 & 0,183 & 0,019 & 0,173 & & $\mathbf{2 , 5 E}-261$ \\
\hline 100 & 0,054 & 0,154 & $-0,041$ & 0,298 & $-0,029$ & 0,125 & $-0,023$ & \\
\hline
\end{tabular}

Hint: P-value is bold 
Table 109 Comparing the path coefficients and P-value for CRPs

\begin{tabular}{|c|c|c|c|c|c|c|c|c|}
\hline Scenarios & 011 & 010 & 001 & 000 & 111 & 110 & 101 & 100 \\
\hline 011 & & $\mathbf{1 , 2 E - 2 6 5}$ & $\mathbf{1 , 8 1 E - 9 2}$ & $\mathbf{2 , 6 9 E - 6 4}$ & $\mathbf{3 , 7 7 E - 6 4}$ & $\mathbf{3 , 4 E - 2 2 7}$ & $\mathbf{1 , 7 E - 1 3 7}$ & $\mathbf{6 , 3 E - 1 6 6}$ \\
\hline 010 & $-0,143$ & & $\mathbf{0}$ & $\mathbf{3 E - 1 4 3}$ & $\mathbf{0}$ & $\mathbf{7 , 5 1 E - 0 9}$ & $\mathbf{0}$ & $\mathbf{1 , 0 1 E - 4 7}$ \\
\hline 001 & $-0,110$ & 0,001 & & $\mathbf{1 , 8 E - 1 9 8}$ & $\mathbf{2 , 3 9 E - 0 6}$ & $\mathbf{0}$ & $\mathbf{1 , 4 E - 2 5 1}$ & $\mathbf{3 , 5 E - 2 8 9}$ \\
\hline 000 & $-0,141$ & $-0,030$ & $-0,190$ & & $\mathbf{8 , 6 E}-171$ & $\mathbf{1 , 9 E - 1 0 4}$ & $\mathbf{0}$ & $\mathbf{0}$ \\
\hline 111 & 0,124 & 0,235 & 0,075 & 0,164 & & $\mathbf{0}$ & $\mathbf{4 , 0 3 E - 2 5}$ & $\mathbf{4 , 2 E - 2 6 5}$ \\
\hline 110 & 0,075 & 0,186 & 0,026 & 0,115 & 0,036 & & $\mathbf{0}$ & $\mathbf{4 , 9 1 E - 3 8}$ \\
\hline 101 & 0,066 & 0,177 & 0,017 & 0,106 & 0,027 & 0,164 & & $\mathbf{0}$ \\
\hline 100 & 0,018 & 0,129 & $-0,031$ & 0,221 & $-0,021$ & 0,116 & $-0,043$ & \\
\hline
\end{tabular}

\section{Hint: P-value is bold}

The result, given in Table 110, indicates strong relationships between home delivery and return option and situations. Results show that time availability is positively related to all available options and negatively related to the in-store return and CRPs options. The negative relationship indicates that those who have limited time prefer to return their items to store or collection points where the return process is faster than other options like home returns.

In addition, the result shows that the spillover effect in all the available last-mile logistics options has a negative impact and also has a significant impact on all delivery and return options except in-store return and CRPs. This analysis indicates that consumers who have in-store return and CRPs preferences, feel almost the same way to purchase the items through either internet or store.

Lastly, the distance to store situation has a positive impact in all the available last-mile logistics options and significant - except for the home delivery option and CDPs. This suggests that, consumers who have lived far away to the store, preference to select home delivery. Those who live next to the store or collection points prefers to select in-store return or CRP more often than for those who live far away.

Table 110 The dummy variable regression analysis for situational factors

Spillover effect Time availability Distance to store

Attitude to Intention (Beta weights) (Beta weights) (Beta weights)

$\mathbf{R}^{2} \quad$ F-value

\begin{tabular}{lccccc}
\hline Home delivery & $-0,18^{*}$ & $0,03^{* *}$ & $-0,04^{* *}$ & 0,98 & 65,14 \\
In-store delivery & $-0,09^{* *}$ & $0,01 \mathrm{Ns}$ & $0,09^{* *}$ & 0,85 & 5,82 \\
CDPs & $-0,06^{* *}$ & $0,01 \mathrm{Ns}$ & $0,01 \mathrm{Ns}$ & 0,75 & 3,04 \\
Home return & $-0,05^{* *}$ & $0,08^{* *}$ & 0,01 & 0,96 & 25,04 \\
In-store return & $-0,01 \mathrm{Ns}$ & $-0,01 \mathrm{Ns}$ & $0,16^{* *}$ & 0,98 & 81,26 \\
CRPs & $0,01 \mathrm{Ns}$ & $-0,03^{* *}$ & $0,12 * *$ & 0,96 & 27,05
\end{tabular}

Notes: Offline (+) vs. Online (-); Plenty of time (+) vs. limited time (-); Nearby (+) vs. Far away (-) $\mathrm{P}<0.1 \quad \mathrm{P}^{*}<0.05 \quad \mathrm{P}^{* *}<0.01 \quad$ Ns: Not significant 


\subsection{The final model of investigation}

This section summarizes the corresponding values conducted in the previous sections. The analysis will be carried out for each last-mile logistics options.

\subsubsection{Final model for Home delivery}

In the first model, Home delivery, the results show that there is a positive and significant relationship between attitude towards the selecting home delivery and its intention, supporting $H 1_{a}$. However, descriptive statistics indicate that the Control perceived behavior clearly has a weak path coefficient to the intention (also not being significant at 95\%), with moderate predication level and small effective size. Thus, rejecting the $H 3_{a}$ hypothesis (though it is significant). This result contradicts the result obtained by Pookulangara et al., (2011a), although in that study the sample was more concentrated in channel selection. Moreover, the results obtained indicate that Subjective norms are not a good predictor of consumers intention of selecting home delivery, rejecting the $H 2_{a}$ hypothesis. This result also contradicts with other previous studies on consumer 'shopping behavior (e.g., Priebe \& Spink, 2011). The results confirm that consumers do not consider presence of the social environment while selecting home delivery.

As the results showed, Convenience, Monetary and Perceived risk have a weak path coefficient to the intention. Moreover, the data obtained indicates that in case of the convenience, there is not significant impact to the final model, rejecting $H 5_{a}, H 7_{a}$ and $H 9_{a}$. Furthermore, a direct, significant and negative influence can be observed between the Convenience and Perceived risk toward the attitude toward. In case of the convenience the hypothesis is rejected $H 6_{a}$ due to the fact that the path is negative; however, for Perceived risk, the hypothesis is supported $H 8_{a}$. In case of monetary the coefficient path is negative, and it supports its hypothesis, $H 4_{a}$. The result means that they have an indirectly influence toward consumer's intention and the attitude towards selecting home delivery only is a good predictor of the intention. In accordance the previous works, consumers by considering these factors (Convenience, Monetary and Perceived risk) would have a favorable attitude towards the home delivery option, and then that attitude would have a significant influence on the intention to the home delivery option (e.g., Childers et al., 2001; Hofacker, 2001; Schröder \& Zaharia, 2008; Ganesh et al., 2010).

Given to the analysis, the possibility that the self-efficacy is a more appropriate predictors of the intention to selecting home delivery is considered, and the results show that the relationship is verified, $H 14_{a}$ a direct influence, and a path coefficient is obtained moderate. Although in case of facilitating condition the results show that there is a weak path coefficient which is not significant toward intention, rejecting $H 12_{a}$. The results confirm that in the case of the home delivery sample, the self-efficacy is a better predictor of the intention than control perceived behavior and facilitating condition. This is clearly consistent with previous research (Juaneda-Ayensa, Mosquera, \& Sierra Murillo, 2016; Pookulangara et al., 2011). A possible explanation for these results may be 
related to ages of offering home delivery to consumers, hence consumers nowadays have a confident in ability to select a specific last-mile logistics.

Figure below and the equation show the final model for Home delivery.

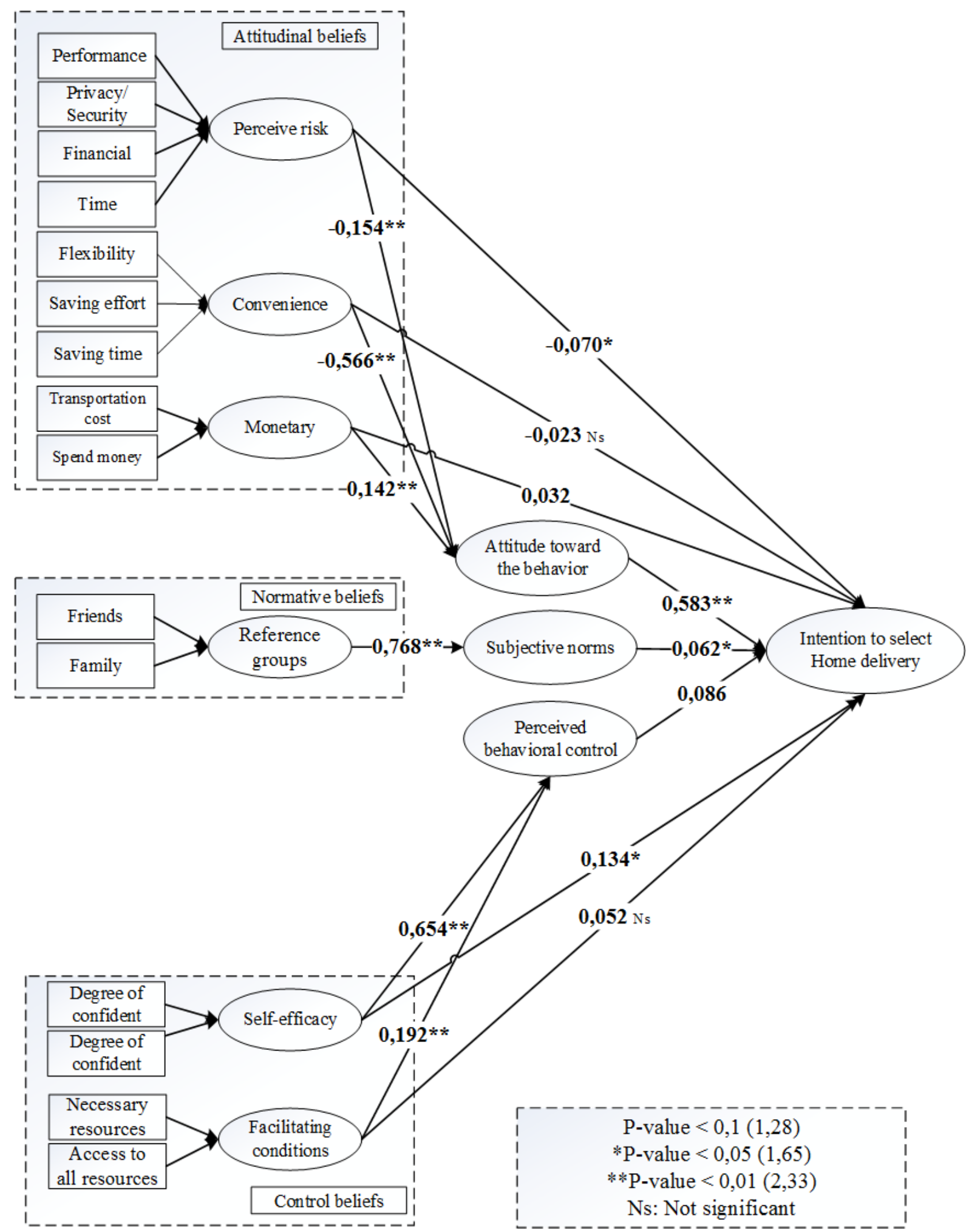

Figure 29 The model for Home delivery (Source: Author) 


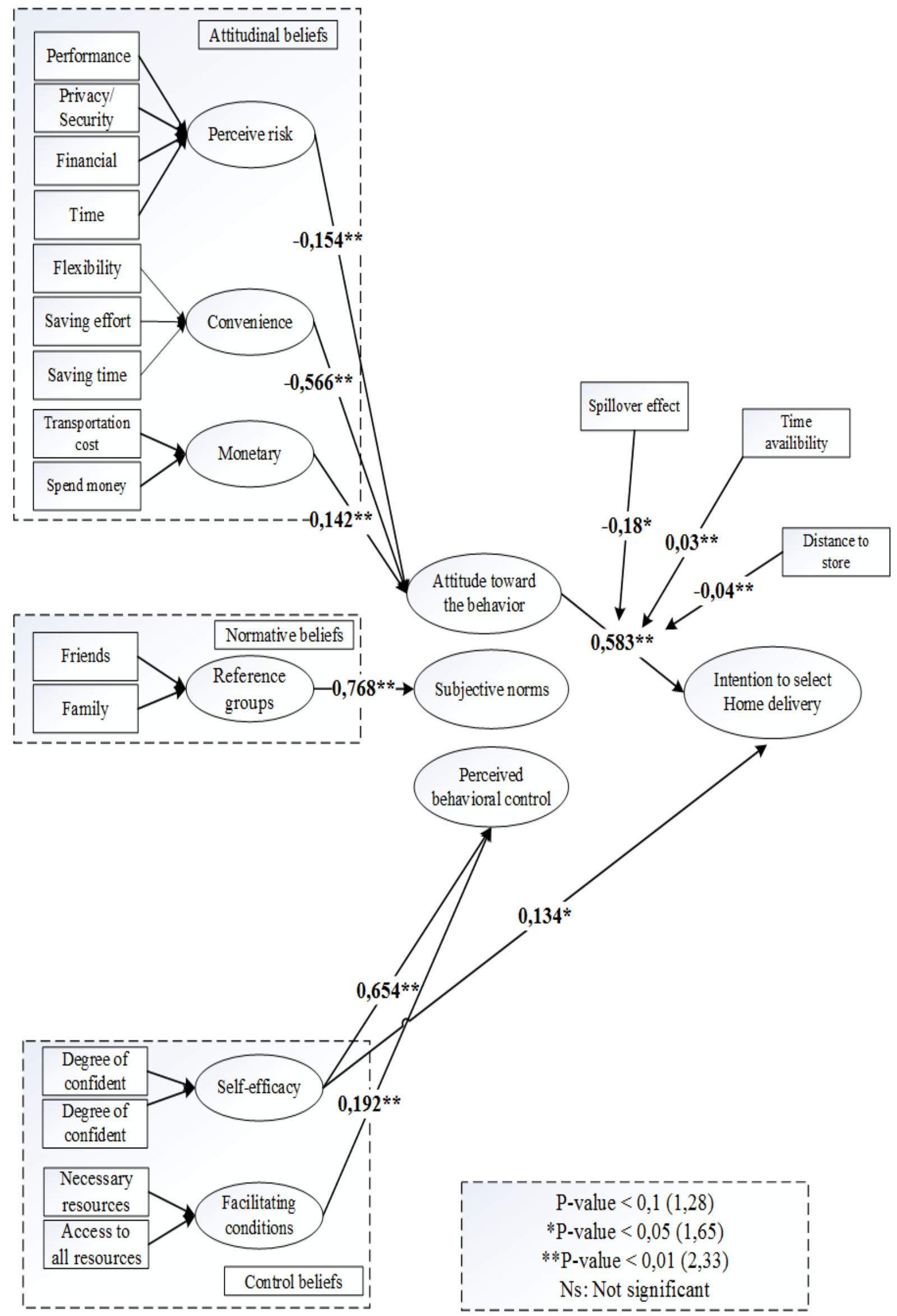

Figure 30 The final model for Home delivery (Source: Author) 


\subsubsection{Final model for In-store delivery}

Likewise, from the home delivery, the results corresponding to the sample of in-store delivery show that there is a positive and significant relationship between attitude towards the selecting in-store delivery and its intention, supporting therefore supporting $H 1_{b}$. This finding is consistent with Chou, et al. (2016). However, the final results indicate that the Control perceived behavior clearly has a weak path coefficient to the intention (also not being significant at 95\%), with moderate predication level and small effective size. Thus, rejecting the $H 3_{b}$ hypothesis (though it is significant). This result contradicts the result obtained by Pookulangara et al., (2011a), although in that study the sample was more concentrated in channel selection. Furthermore, according to results obtained, the Subjective norms are not a good predictor of consumers intention of selecting in-store delivery, rejecting the $H 2_{b}$ hypothesis. This result also contradicts with other previous studies on consumer 'shopping behavior (e.g., Priebe \& Spink, 2011). The results confirm that consumers do not consider presence of the social environment while selecting in-store delivery.

With regards to the final results for Convenience, Monetary and Perceived risk, it can be said that the Convenience has a weak path coefficient to the intention, however it is significant at $95 \%$ in the final model, rejecting $H 7_{b}$. However, the Convenience has a moderate path coefficient to the attitude, and it is significant in the final model, supporting $H 6_{b}$. Moreover, the data obtained indicates, in case of Perceived risk, it has a moderate negative path coefficient to the intention (weak) and to the attitude (moderate). Also, the analysis shows that it has a significant impact on the attitude, rejecting $H 9_{b}$ and supporting $H 8_{b}$. For the Monetary, it does not have a significant and positive influence either to intention or to attitude, hence rejecting $H 4_{b}$ and $H 5_{b}$. This result contradict with the previous works, consumers by considering these factors (Convenience, Monetary and Perceived risk) would have a favorable attitude towards the home delivery option, and then that attitude would have a significant influence on the intention to the home delivery option (e.g., Childers et al., 2001; Hofacker, 2001; Schröder \& Zaharia, 2008; Ganesh et al., 2010).

Given to the analysis, the possibility that the self-efficacy is a more appropriate predictors of the intention to selecting in-store delivery is considered, and the results show that the relationship is verified, $H 14_{b}$ a direct influence, and a path coefficient is obtained moderate. Although in case of facilitating condition the results show that there is a weak and negative path coefficient which is not significant toward intention, rejecting $H 12_{b}$. The results confirm that in the case of the in-store delivery sample, the self-efficacy is a better predictor of the intention than control perceived behavior and facilitating condition. This result is consistent with the study by Chiu et al. (2011). A possible explanation for these results may be related to ages of offering in-store delivery to consumers, hence consumers nowadays have a confident in ability to select a specific last-mile logistics.

Figure below and the equation show the final model for In-store delivery. 


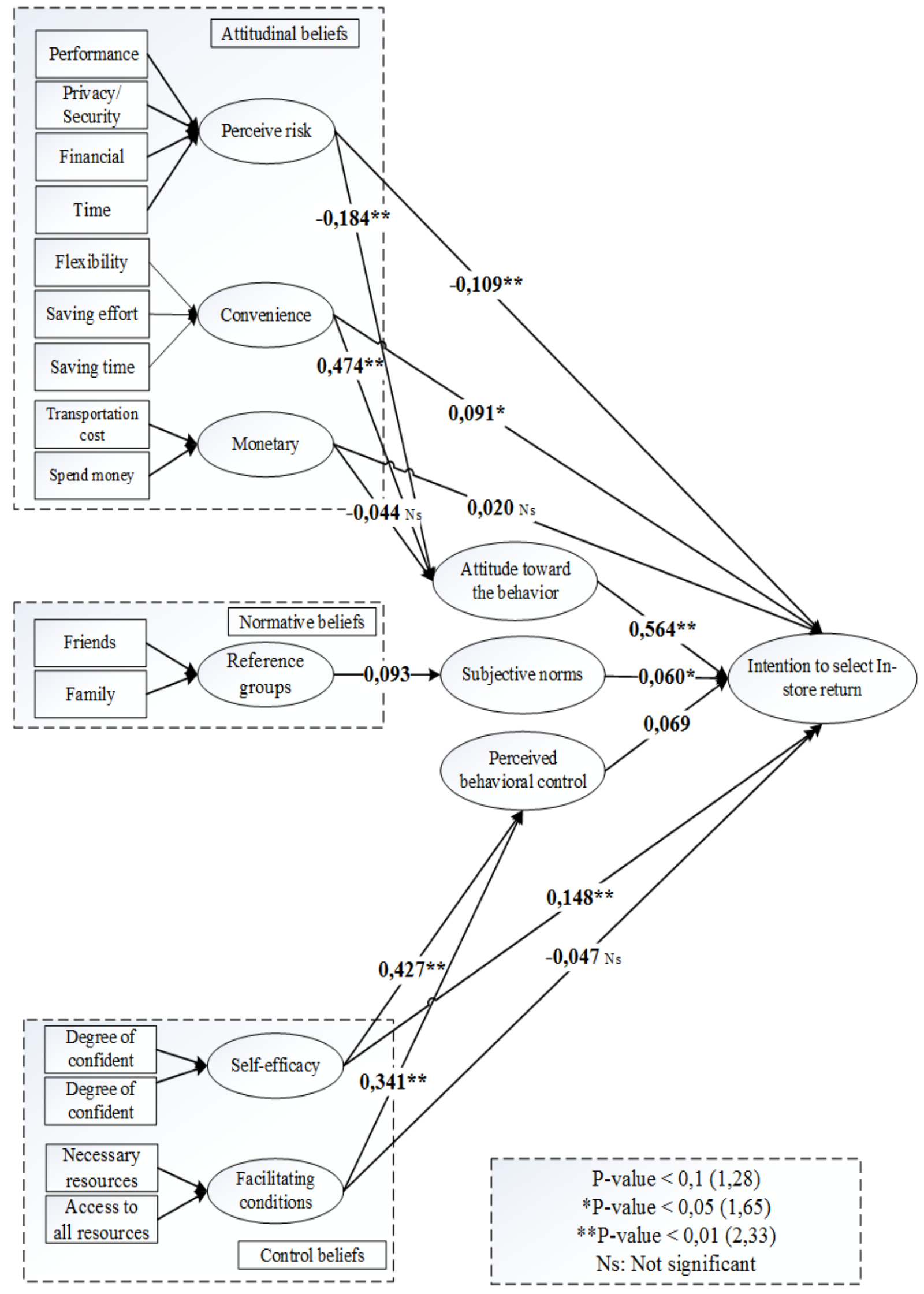

Figure 31 The model for In-store delivery (Source: Author) 


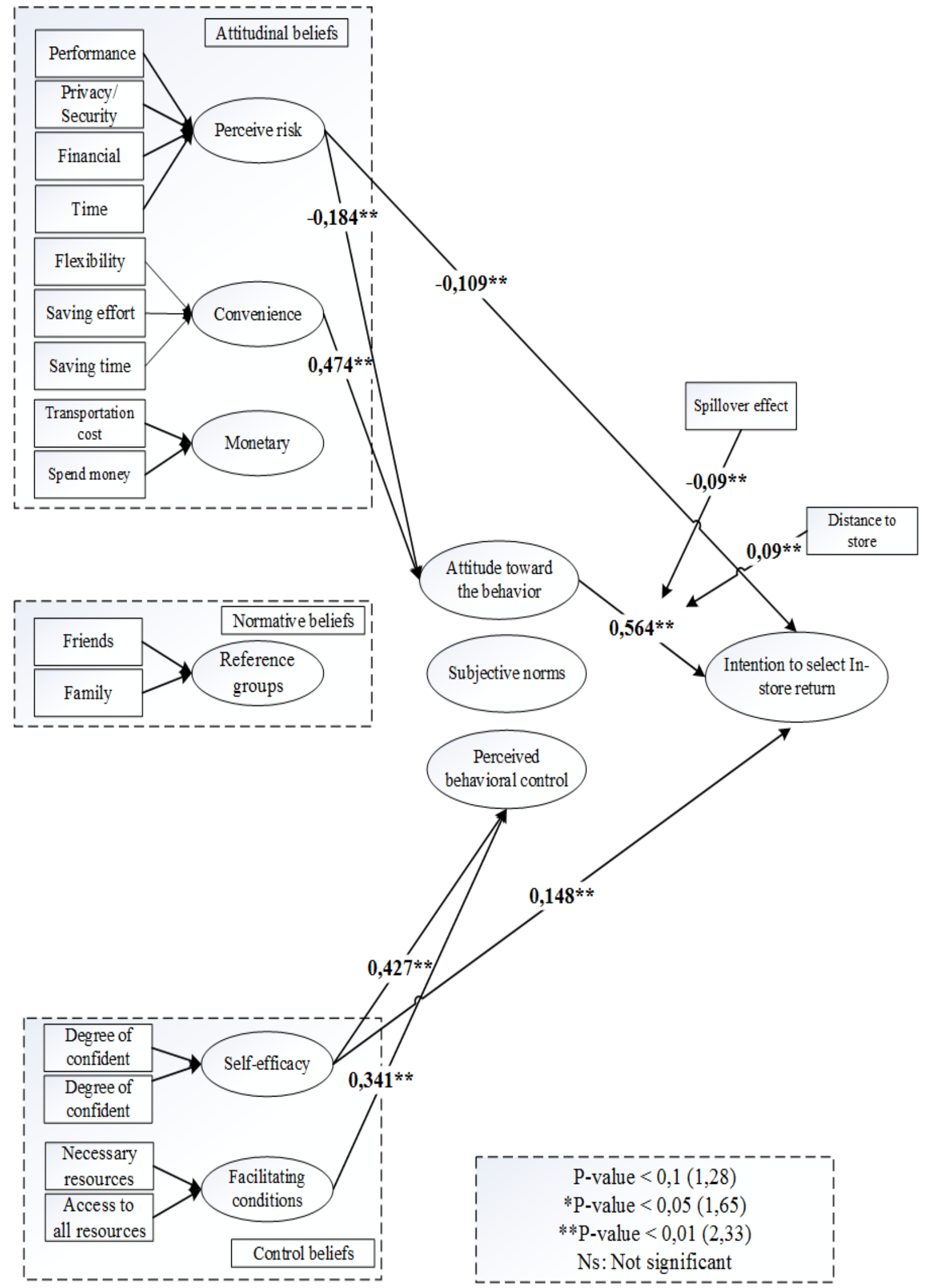

Figure 32 The final model for In-store delivery (Source: Author) 


\subsubsection{Final model for CDPs}

In the CDPs, the results show that there is a positive and significant relationship between attitude towards the selecting CDPs and its intention, supporting $H 1_{c}$. However, descriptive statistics indicate that the Control perceived behavior clearly has a weak path coefficient to the intention (also not being significant at 95\%), with moderate predication level and small effective size. Thus, rejecting the $H 3_{C}$ hypothesis (though it is significant). This result contradicts the result obtained by Pookulangara et al., (2011a), although in that study the sample was more concentrated in channel selection. Moreover, the results obtained indicate that Subjective norms are not a good predictor of consumers intention of selecting CDPs, rejecting the $H 2_{c}$ hypothesis. This result also contradicts with other previous studies on consumer 'shopping behavior (e.g., Priebe \& Spink, 2011). The results confirm that consumers do not consider presence of the social environment while selecting CDPs.

With regards to the final results for Convenience, Monetary and Perceived risk, it can be said that the Convenience has a weak negative path coefficient to the attitude, and it has significant impact toward attitude (being significant at 95\%), rejecting $\mathrm{H6}_{c}$. However, the result shows that Convenience has a negative and moderate impact on the intention of selecting CDPs, rejecting $H 7_{c}$. The data obtained also indicates, in case of Perceived risk, it has a moderate negative path coefficient to the intention and to the attitude. Furthermore, the analysis shows that are significant in the final model, supporting $H 9_{c}$ and $H 8_{c}$. However, for the Monetary, the data show that there is a weak path coefficient to either intention or attitude and also not significant, rejecting $H 4_{c}$ and $H 5_{c}$. This result contradict with the previous works, consumers by considering these factors (Convenience, Monetary and Perceived risk) would have a favorable attitude towards the CDPs option, and then that attitude would have a significant influence on the intention to the home delivery option (e.g., Childers et al., 2001; Hofacker, 2001; Schröder \& Zaharia, 2008; Ganesh et al., 2010).

Given to the analysis, the possibility that the self-efficacy is a more appropriate predictors of the intention to selecting CDPs is considered, and the results show that the relationship is verified, $H 14_{c}$ a direct influence, and a path coefficient is obtained moderate. Although in case of facilitating condition the results show that there is a weak path coefficient which is not significant toward intention, rejecting $H 12_{c}$. The results confirm that in the case of the CDPs sample, the self-efficacy is a better predictor of the intention than control perceived behavior and facilitating condition. This result is consistent with the study by Chiu et al. (2011). A possible explanation for these results may be related to ages of offering CDPs to consumers, hence consumers nowadays have a confident in ability to select a specific last-mile logistics.

Figure below and the equation show the final model for CDPs. 


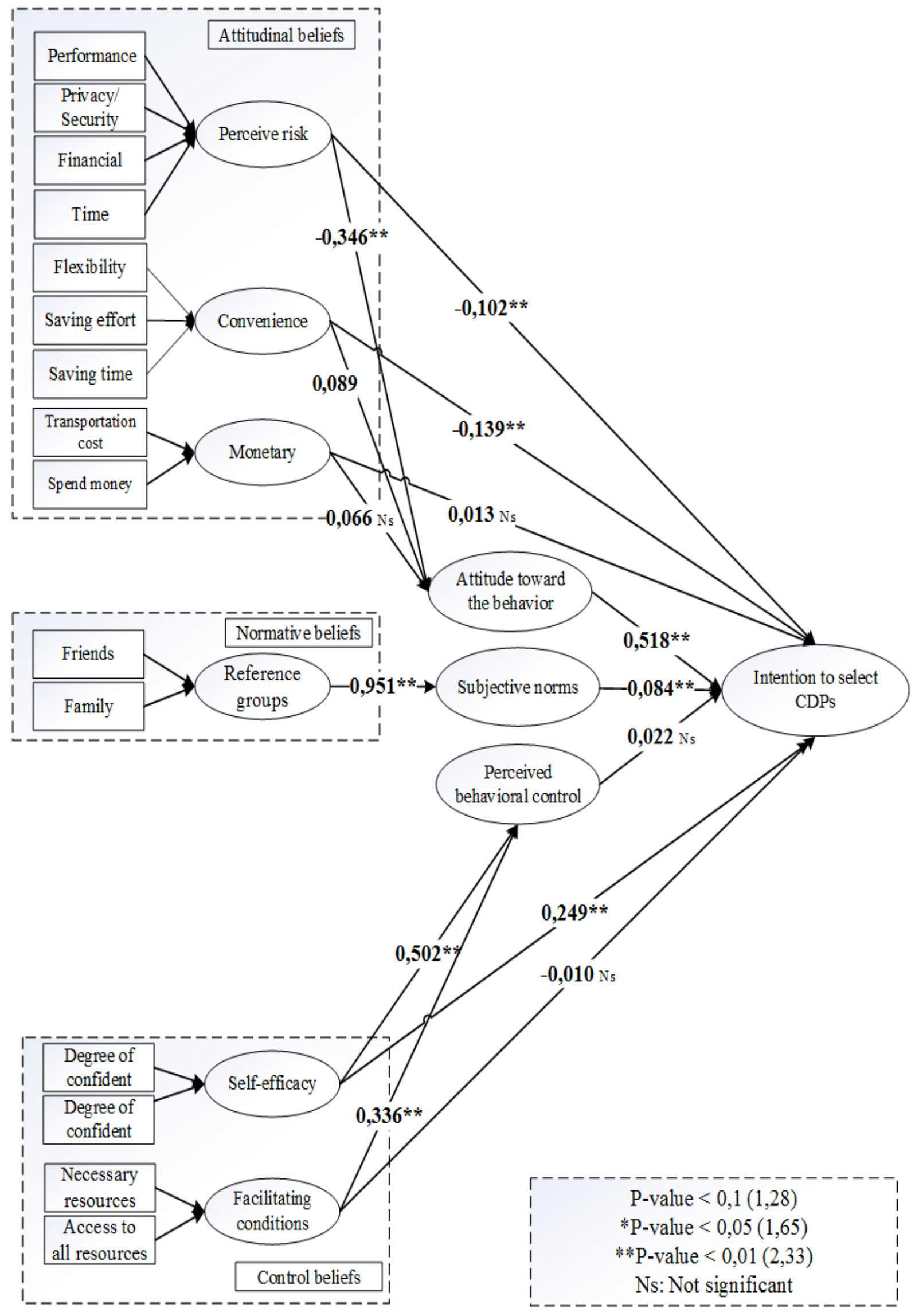

Figure 33 The model for CDPs (Source: Author) 


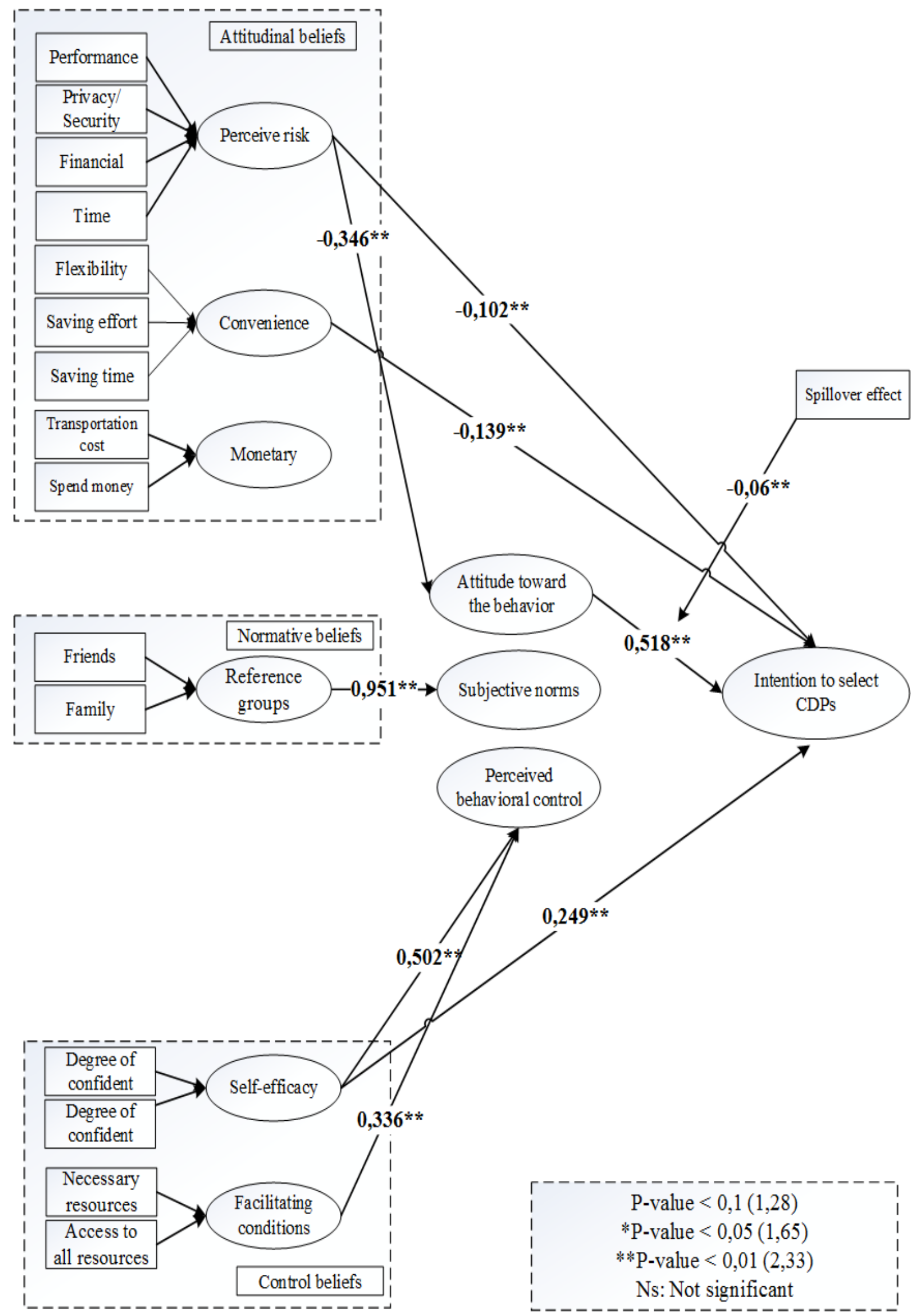

Figure 34 The final model for CDPs (Source: Author) 


\subsubsection{Final model for Home return}

In the Home return, the results show that there is a positive and significant relationship between attitude towards the selecting Home return and its intention, supporting $H 1_{d}$. However, descriptive statistics indicate that the Control perceived behavior clearly has a weak path coefficient to the intention (also not being significant at 90\%), with moderate predication level and small effective size. Thus, rejecting the $H 3_{d}$ hypothesis. This result contradicts the result obtained by Pookulangara et al., (2011a), although in that study the sample was more concentrated in channel selection. Moreover, the results obtained indicate that Subjective norms are not a good predictor of consumers intention of selecting Home return, rejecting the $H 2_{d}$ hypothesis. This result also contradicts with other previous studies on consumer 'shopping behavior (e.g., Priebe \& Spink, 2011). The results confirm that consumers do not consider presence of the social environment while selecting home return.

With regards to the final results for Convenience, Monetary and Perceived risk, it can be said that the Convenience has a weak path coefficient to the intention of selecting home return, However, it does have a significant impact in the final model, rejecting $H 6_{d}$. However, the result shows that Convenience has a negative and moderate impact on the attitude, rejecting $H 7_{d}$. The data obtained also indicates, in case of Perceived risk, it has a moderate negative path coefficient to the intention and to the attitude. Furthermore, the analysis shows that are significant in the final model, supporting $H 9_{d}$ and $H 8_{d}$. However, for the Monetary, the data show that there is a weak positive path coefficient to either to intention or to attitude, and also partially significant, rejecting $H 4_{d}$ and $H 5_{d}$. This result contradict with the previous works, consumers by considering these factors (Convenience, Monetary and Perceived risk) would have a favorable attitude towards the home return option, and then that attitude would have a significant influence on the intention to the home return option (e.g., Childers et al., 2001; Hofacker, 2001; Schröder \& Zaharia, 2008; Ganesh et al., 2010).

Given to the analysis, the possibility that the self-efficacy is a more appropriate predictors of the intention to selecting home return is considered, and the results show that the relationship is verified, $H 14_{d}$ a direct influence, and a path coefficient is obtained moderate. Although in case of facilitating condition the results show that there is a weak path coefficient which is not significant toward intention, rejecting $H 12_{d}$. The results confirm that in the case of the home return sample, the self-efficacy is a better predictor of the intention than control perceived behavior and facilitating condition. This result is consistent with the study by Chiu et al. (2011). A possible explanation for these results may be related to ages of offering home return to consumers, hence consumers nowadays have a confident in ability to select a specific last-mile logistics.

Figure below and the equation show the final model for Home return. 


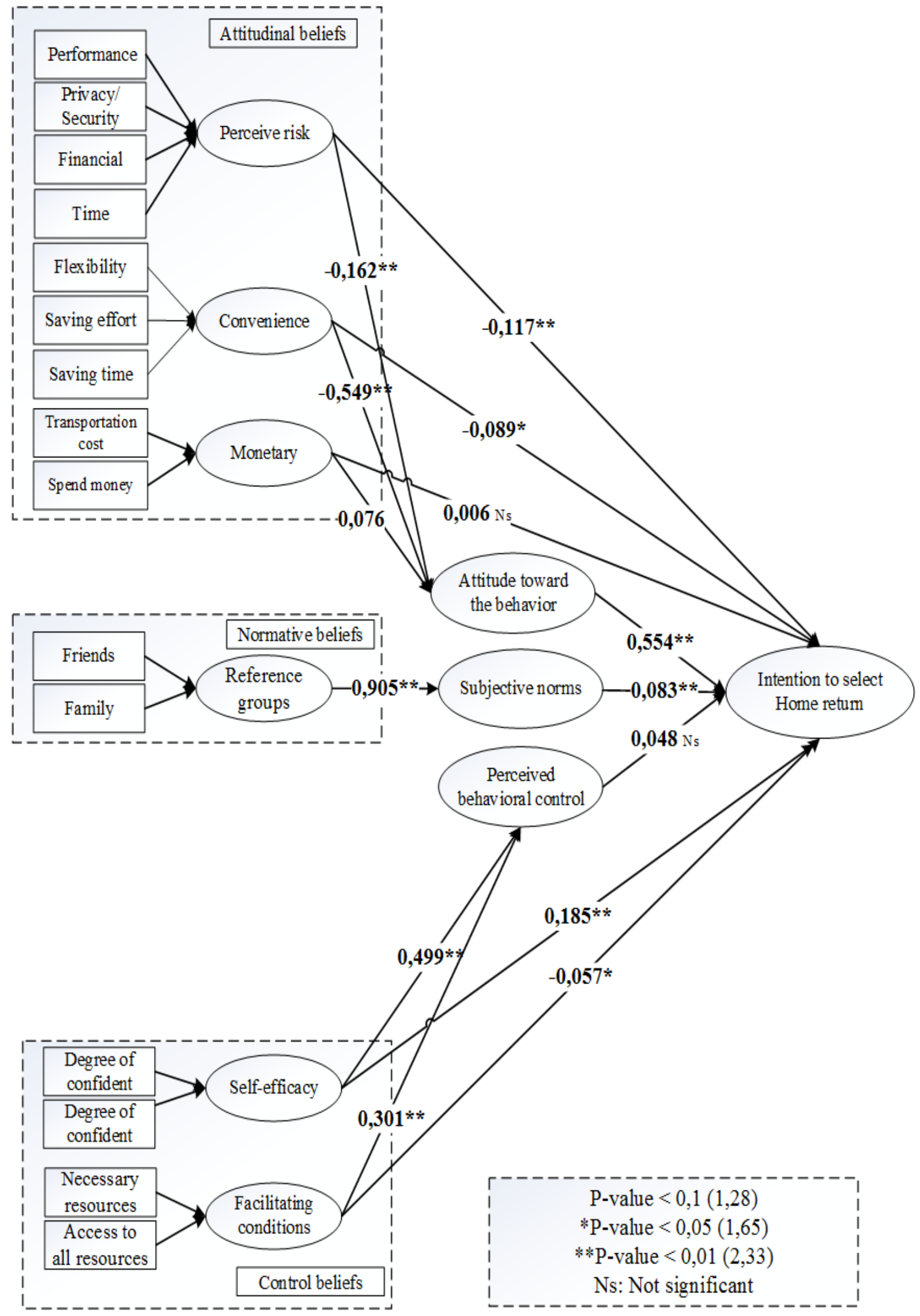

Figure 35 The model for Home return (Source: Author) 


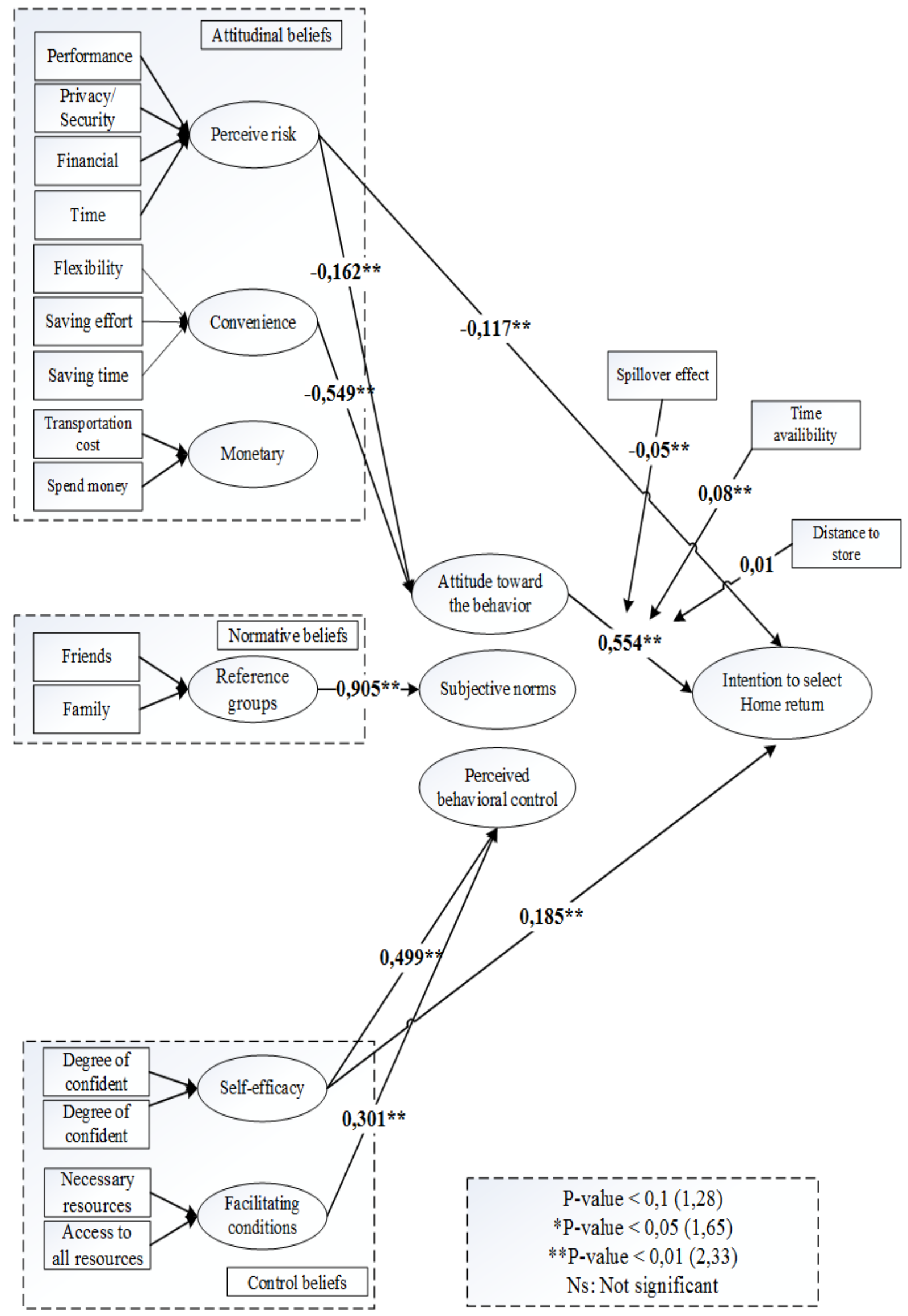

Figure 36 The final model for Home return (Source: Author) 


\subsubsection{Final model for In-store return}

Likewise from the In-store return, the results corresponding to the sample of In-store return show that there is a positive and significant relationship between attitude towards the selecting in-store delivery and its intention, supporting therefore supporting $H 1_{e}$. The final results also indicate that the Control perceived behavior clearly has a moderate path coefficient to the intention (being significant at 95\%), with moderate predication level and small effective size. Thus, supporting the $H 3_{e}$ hypothesis. This result consistent with the result obtained by Pookulangara et al., (2011a), although in that study the sample was more concentrated in channel selection. Furthermore, according to results obtained, the Subjective norms are a moderate predictor of consumers intention of selecting In-store return, supporting the $H 2_{e}$ hypothesis. This result also consistent with other previous studies on consumer 'shopping behavior (e.g., Priebe \& Spink, 2011). The results confirm that consumers do not consider presence of the social environment while selecting in-store return.

With regards to the final results for Convenience, Monetary and Perceived risk, it can be said that the Convenience has a moderate path coefficient to the intention and to the attitude, and they have a significant level in the final model, supporting $H 6_{e}$ and $H 7_{e}$. Moreover, the data obtained indicates, in case of Perceived risk, it has a moderate negative path coefficient to the intention and to the attitude. Also, the analysis shows that are significant in the final model, supporting $H 9_{e}$ and $H 8_{e}$. However, for the Monetary, it does not have a significant level of influence either to intention or to attitude, hence rejecting $H 4_{e}$ and $H 5_{e}$. This result partially contradict with the previous works, consumers by considering these factors (Convenience, Monetary and Perceived risk) would have a favorable attitude towards the In-store return option, and then that attitude would have a significant influence on the intention to the In-store return option (e.g., Childers et al., 2001; Hofacker, 2001; Schröder \& Zaharia, 2008; Ganesh et al., 2010).

Given to the analysis, the possibility that the self-efficacy is a more appropriate predictors of the intention to selecting In-store return is considered, and the results show that the relationship is verified, $H 14_{b}$ a direct influence, and a path coefficient is obtained moderate. Although in case of facilitating condition the results show that there is a weak and negative path coefficient which is not significant toward intention, rejecting $H 12_{b}$. The results confirm that in the case of the In-store return sample, the self-efficacy is a better predictor of the intention than control perceived behavior and facilitating condition. This result is consistent with the study by Chiu et al. (2011). A possible explanation for these results may be related to ages of offering In-store return to consumers, hence consumers nowadays have a confident in ability to select a specific last-mile logistics.

Figure below and the equation show the final model for In-store return. 


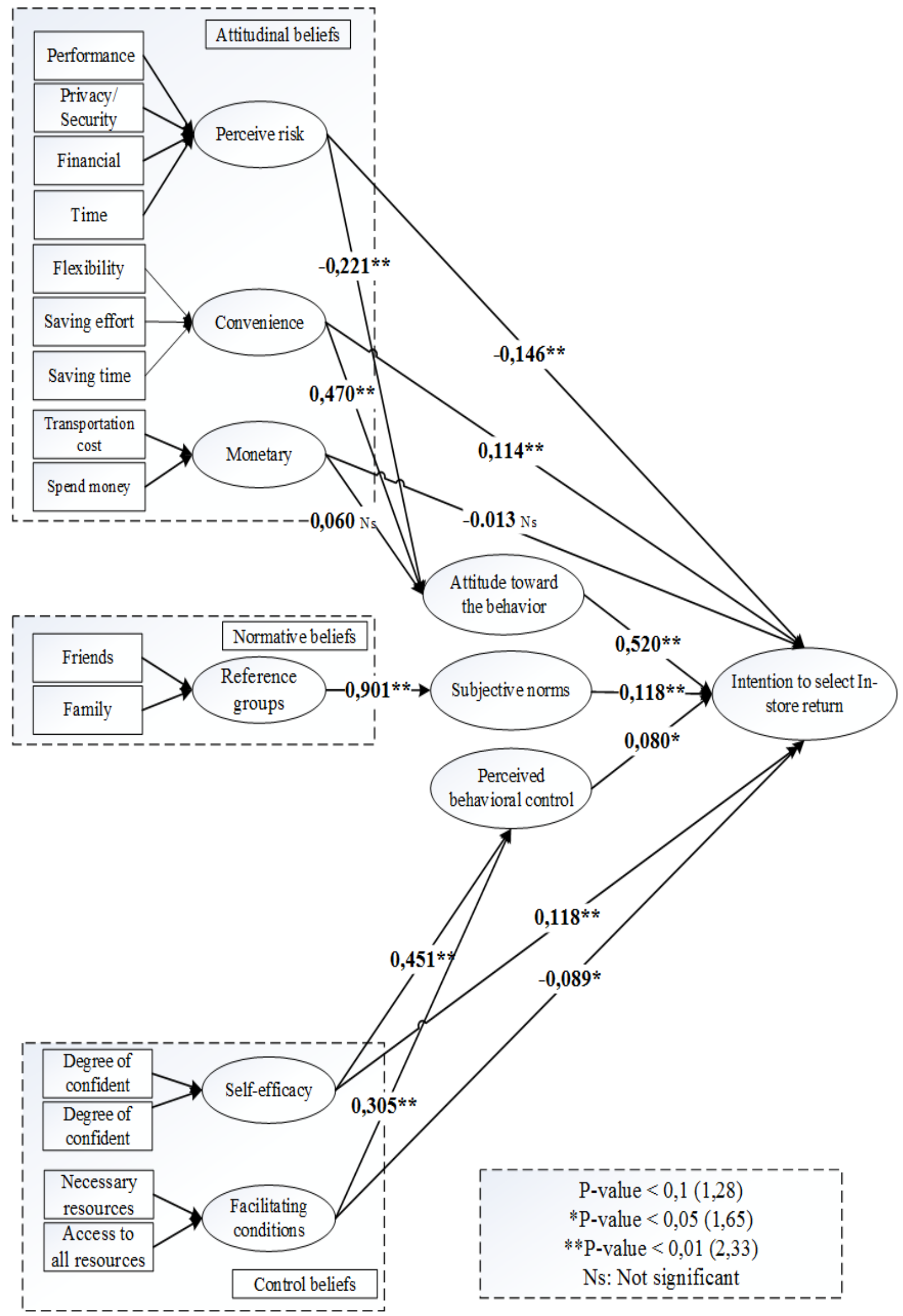

Figure 37 The model for In-store return (Source: Author) 


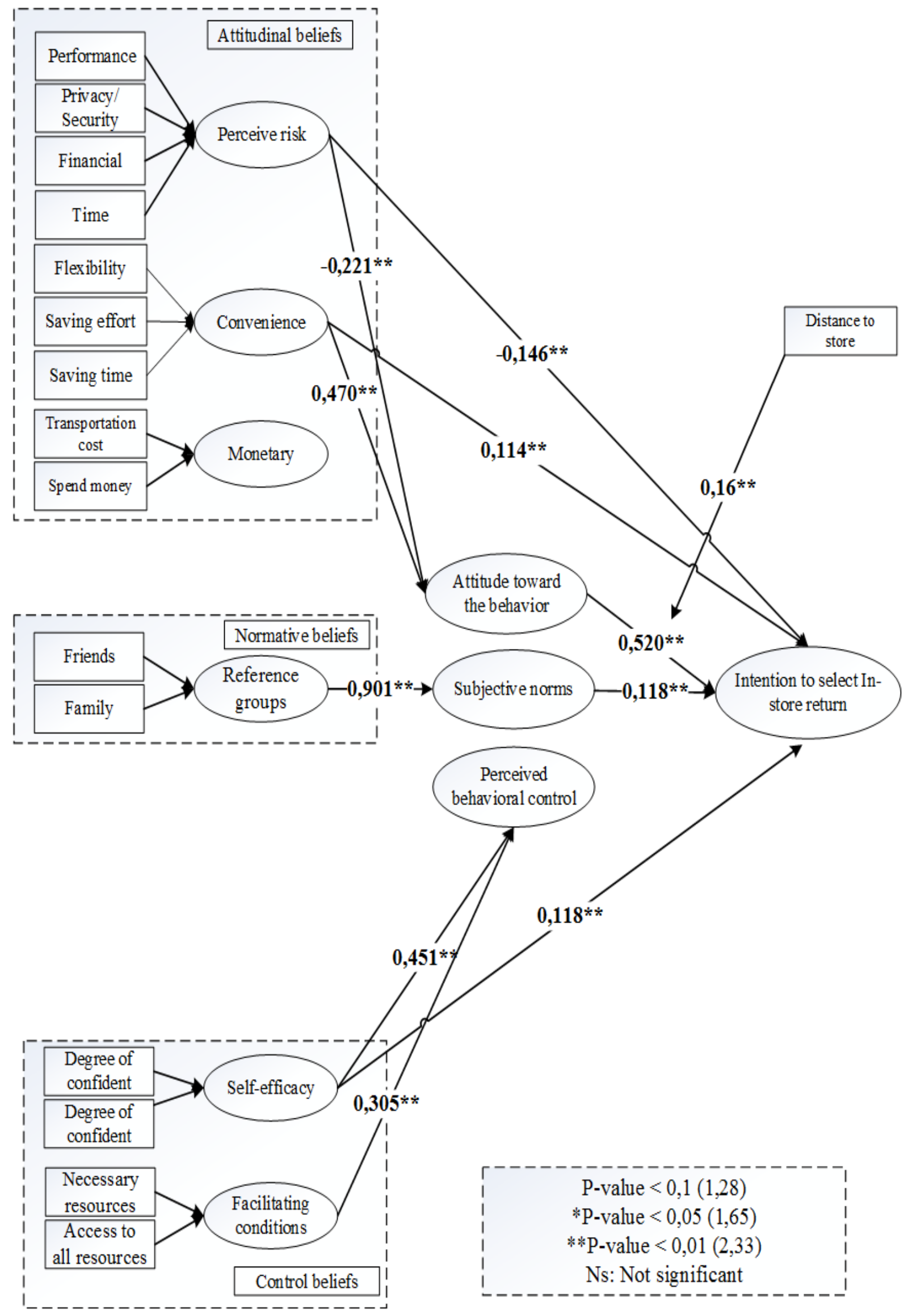

Figure 38 The final model for In-store return (Source: Author) 


\subsubsection{Final model for CRPs}

In the CRPs, the results show that there is a positive and significant relationship between attitude towards the selecting CRPs and its intention, supporting $H 1_{f}$. However, descriptive statistics indicate that the Control perceived behavior clearly has a weak path coefficient to the intention (also not being significant at 95\%), with moderate predication level and small effective size. Thus, rejecting the $H 3_{f}$ hypothesis (though it is significant). This result contradicts the result obtained by Pookulangara et al., (2011a), although in that study the sample was more concentrated in channel selection. Moreover, in case of CRPs, the results obtained indicate that Subjective norms are a good predictor of consumers intention of selecting CRPs, supporting the $H 2_{f}$ hypothesis. This result also consist with other previous studies on consumer 'shopping behavior (e.g., Priebe \& Spink, 2011). The results confirm that consumers do not consider presence of the social environment while selecting CRPs.

With regards to the final results for Convenience, Monetary and Perceived risk, it can be said that the Convenience has a moderate negative path coefficient to the attitude and to the intention of selecting CRPs, and significant in the final model, rejecting $H 6_{f}$ and $H 7_{f}$. The data obtained also indicates, in case of the Perceived risk, it has a moderate negative path coefficient to the intention and to the attitude. Furthermore, the analysis shows that they are significant in the final model, supporting $H 9_{f}$ and $H 8_{f}$. However, for the Monetary, the data shows that there is a weak path coefficient and not significant. Although, the data shows that there is a moderate path coefficient to attitude, it shows that it has have significant impact in the model, supporting $H 4_{f}$ and rejecting $H 5_{f}$. This result contradict with the previous works, consumers by considering these factors (Convenience, Monetary and Perceived risk) would have a favorable attitude towards the CRPs option, and then that attitude would have a significant influence on the intention to the home delivery option (e.g., Childers et al., 2001; Hofacker, 2001; Schröder \& Zaharia, 2008; Ganesh et al., 2010).

Given to the analysis, the possibility that the self-efficacy is a more appropriate predictors of the intention to selecting CRPs is considered, and the results show that the relationship is verified, $H 14_{f}$ a direct influence, and a path coefficient is obtained moderate. Although in case of facilitating condition the results show that there is a weak path coefficient which is not significant toward intention, rejecting $H 12_{f}$. The results confirm that in the case of the CRPs sample, the self-efficacy is a better predictor of the intention than control perceived behavior and facilitating condition. This result is consistent with the study by Chiu et al. (2011). A possible explanation for these results may be related to ages of offering CDPs to consumers, hence consumers nowadays have a confident in ability to select a specific last-mile logistics.

Figure below and the equation show the final model for CRPs. 


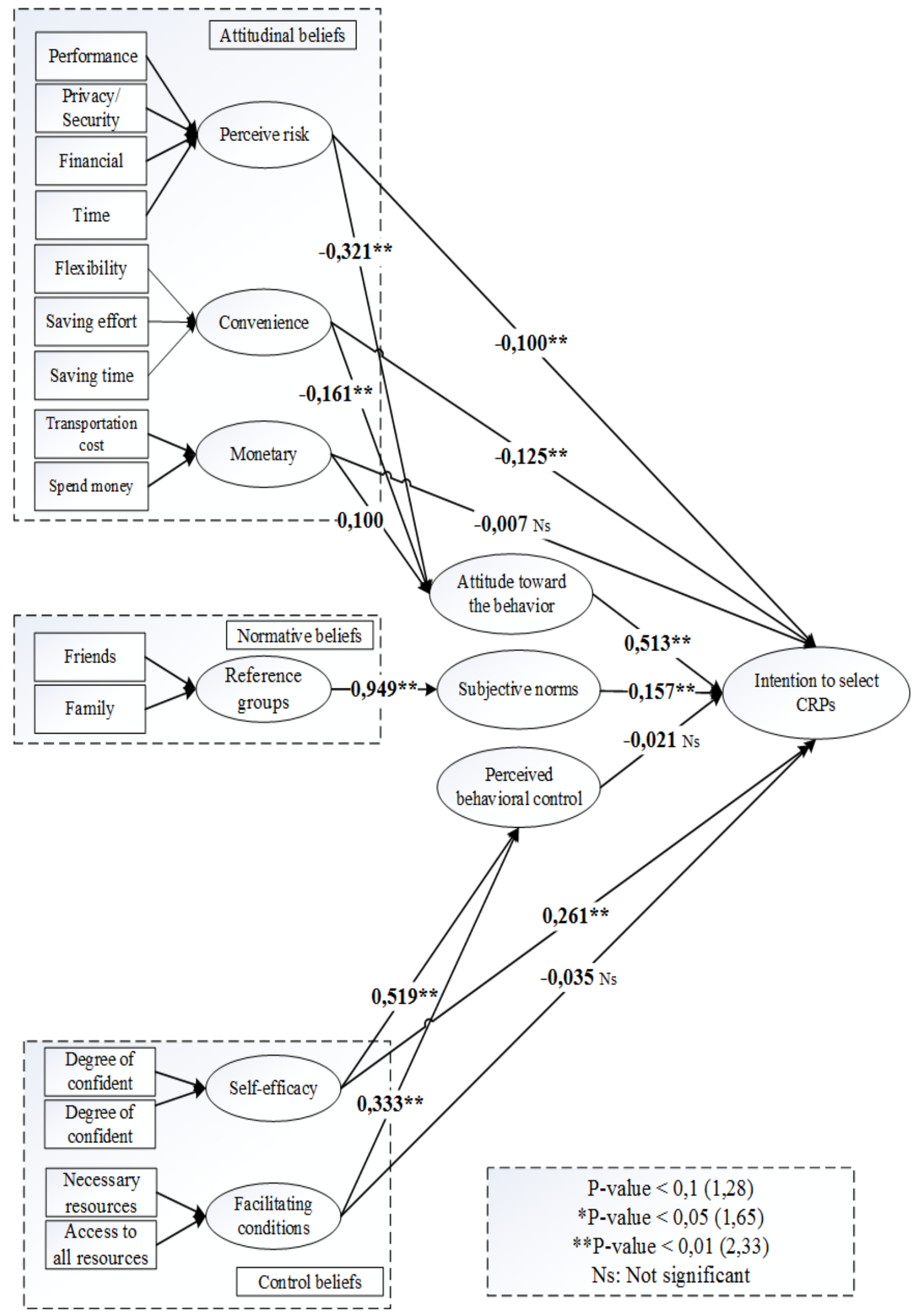

Figure 39 The model for CRPs (Source: Author) 


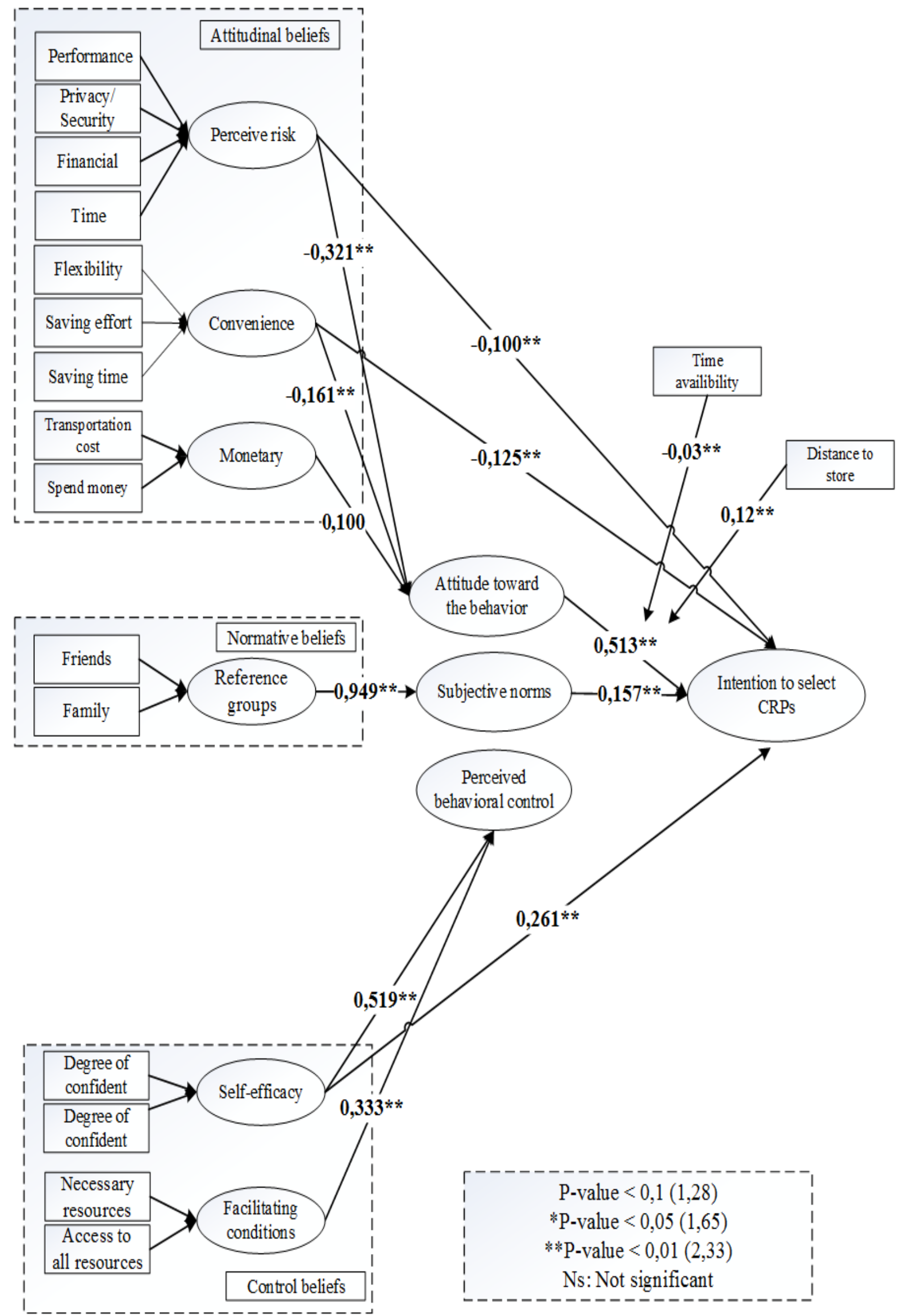

Figure 40 The final model for CRPs (Source: Author) 


\subsection{Summary of the evaluation of the hypotheses}

Table below shows a summary of the evaluation of the hypotheses after the empirical analysis.

(a: home delivery, b: store delivery, c: CDPs, d: home return, e: store return, f: CRPs)

Table 111 Summary of the evaluation of the hypotheses

\begin{tabular}{|c|c|c|}
\hline$H 1_{a}$ & \multirow{6}{*}{$\begin{array}{l}\text { Attitude has a positive influence with respect to option } \\
\text { a,b,c,d,e,f } \\
\text { intention }\end{array}$} & $\checkmark$ \\
\hline$H 1_{b}$ & & $\checkmark$ \\
\hline$H 1_{c}$ & & $\checkmark$ \\
\hline$H 1_{d}$ & & $\checkmark$ \\
\hline$H 1_{e}$ & & $\checkmark$ \\
\hline$H 1_{f}$ & & $\checkmark$ \\
\hline$H 2_{a}$ & \multirow{6}{*}{$\begin{array}{l}\text { Subjective norm has a positive influence with respect to option }{ }_{\mathrm{a}, \mathrm{b}, \mathrm{c}, \mathrm{d}, \mathrm{e}, \mathrm{f}} \text { selection } \\
\text { behavior intention. }\end{array}$} & $x$ \\
\hline$H 2_{b}$ & & $x$ \\
\hline$H 2_{c}$ & & $x$ \\
\hline$H 2_{d}$ & & $x$ \\
\hline$H 2_{e}$ & & $\checkmark$ \\
\hline$H 2_{f}$ & & $\checkmark$ \\
\hline$H 3_{a}$ & \multirow{6}{*}{$\begin{array}{l}\text { Perceived behavioral control has a positive influence with respect to option } \mathrm{a,b,c,d,e,f} \\
\text { selection behavior intention. }\end{array}$} & $x$ \\
\hline$H 3_{b}$ & & $x$ \\
\hline$H 3_{c}$ & & $x$ \\
\hline$H 3_{d}$ & & $x$ \\
\hline$H 3_{e}$ & & $x$ \\
\hline$H 3_{f}$ & & $x$ \\
\hline$H 4_{a}$ & \multirow{3}{*}{$\begin{array}{l}\text { Monetary costs have a negative influence with respect to attitude toward } \\
\qquad \text { option }_{\mathrm{a}, \mathrm{b}, \mathrm{c}, \mathrm{d}, \mathrm{e}, \mathrm{f}} \text { selection. }\end{array}$} & $x$ \\
\hline$H 4_{b}$ & & $x$ \\
\hline$H 4_{c}$ & & $x$ \\
\hline
\end{tabular}




\begin{tabular}{|c|c|c|}
\hline$H 4_{d}$ & & $x$ \\
\hline$H 4_{e}$ & & $x$ \\
\hline$H 4_{f}$ & & $\checkmark$ \\
\hline$H 5_{a}$ & \multirow{6}{*}{$\begin{array}{l}\text { Monetary costs have a negative influence with respect to option }{ }_{\mathrm{a}, \mathrm{b}, \mathrm{c}, \mathrm{d}, \mathrm{e}, \mathrm{f}} \text { selection } \\
\text { behavior intention. }\end{array}$} & $x$ \\
\hline$H 5_{b}$ & & $x$ \\
\hline$H 5_{c}$ & & $x$ \\
\hline$H 5_{d}$ & & $x$ \\
\hline$H 5_{e}$ & & $\checkmark$ \\
\hline$H 5_{f}$ & & $x$ \\
\hline$H 6_{a}$ & \multirow{6}{*}{$\begin{array}{l}\text { Convenience has a positive influence with respect to attitude toward option }{ }_{\mathrm{a}, \mathrm{b}, \mathrm{c}, \mathrm{d}, \mathrm{e}, \mathrm{f}} \\
\text { selection }\end{array}$} & $x$ \\
\hline$H 6_{b}$ & & $\checkmark$ \\
\hline$H 6_{c}$ & & $x$ \\
\hline$H 6_{d}$ & & $x$ \\
\hline$H 6_{e}$ & & $\checkmark$ \\
\hline$H 6_{f}$ & & $x$ \\
\hline$H 7_{a}$ & \multirow{6}{*}{$\begin{array}{l}\text { Convenience has a positive influence with respect to option }{ }_{\mathrm{a}, \mathrm{b}, \mathrm{c}, \mathrm{d}, \mathrm{e}, \mathrm{f}} \text { selection } \\
\text { behavior intention. }\end{array}$} & $x$ \\
\hline$H 7_{b}$ & & $x$ \\
\hline$H 7_{c}$ & & $x$ \\
\hline$H 7_{d}$ & & $x$ \\
\hline$H 7_{e}$ & & $\checkmark$ \\
\hline$H 7_{f}$ & & $x$ \\
\hline$H 8_{a}$ & \multirow{3}{*}{$\begin{array}{l}\text { Perceived risk has a negative influence with respect to attitude toward option } \mathrm{a,b}, \mathrm{c}, \mathrm{d}, \mathrm{e}, \mathrm{f} \\
\text { selection. }\end{array}$} & $\checkmark$ \\
\hline$H 8_{b}$ & & $\checkmark$ \\
\hline$H 8_{c}$ & & $\checkmark$ \\
\hline
\end{tabular}




\begin{tabular}{|c|c|c|}
\hline$H 8_{d}$ & & $\checkmark$ \\
\hline$H 8_{e}$ & & $\checkmark$ \\
\hline$H 8_{f}$ & & $\checkmark$ \\
\hline$H 9_{a}$ & \multirow{6}{*}{$\begin{array}{l}\text { Perceived risk has a negative influence with respect to option } \mathrm{a}, \mathrm{b}, \mathrm{c}, \mathrm{d}, \mathrm{e}, \mathrm{f} \\
\text { behavior intention. }\end{array}$} & $x$ \\
\hline$H 9_{b}$ & & $\checkmark$ \\
\hline$H 9_{c}$ & & $\checkmark$ \\
\hline$H 9_{d}$ & & $\checkmark$ \\
\hline$H 9_{e}$ & & $\checkmark$ \\
\hline$H 9_{f}$ & & $\checkmark$ \\
\hline$H 10_{a}$ & \multirow{6}{*}{$\begin{array}{l}\text { Normative beliefs (friends and family) have a positive influence with respect to } \\
\text { subjective norms in option } a, b, c, d, e, f \text { selection. }\end{array}$} & $\checkmark$ \\
\hline$H 10_{b}$ & & $x$ \\
\hline$H 10_{c}$ & & $\checkmark$ \\
\hline$H 10_{d}$ & & $\checkmark$ \\
\hline$H 10_{e}$ & & $\checkmark$ \\
\hline$H 10_{f}$ & & $\checkmark$ \\
\hline$H 11_{a}$ & \multirow{6}{*}{$\begin{array}{l}\text { Facilitating conditions have a positive influence with respect to perceived behavioral } \\
\text { control in option }{ }_{a, b, c, d, e, f} \text { selection. }\end{array}$} & $\checkmark$ \\
\hline$H 11_{b}$ & & $\checkmark$ \\
\hline$H 11_{c}$ & & $\checkmark$ \\
\hline$H 11_{d}$ & & $\checkmark$ \\
\hline$H 11_{e}$ & & $\checkmark$ \\
\hline$H 11_{f}$ & & $\checkmark$ \\
\hline$H 12_{a}$ & \multirow{3}{*}{$\begin{array}{l}\text { Facilitating conditions have a positive influence with respect to option }{ }_{a, b, c, d, e, f} \\
\text { selection behavior intention. }\end{array}$} & $x$ \\
\hline$H 12_{b}$ & & $x$ \\
\hline$H 12_{c}$ & & $x$ \\
\hline
\end{tabular}




\begin{tabular}{|c|c|c|}
\hline$H 12_{d}$ & & $x$ \\
\hline$H 12_{e}$ & & $x$ \\
\hline$H 12_{f}$ & & $x$ \\
\hline$H 13_{a}$ & \multirow{6}{*}{$\begin{array}{l}\text { Self-efficacy has a positive influence with respect to perceived behavioral control in } \\
\text { option }_{\mathrm{a}, \mathrm{b}, \mathrm{c}, \mathrm{d}, \mathrm{e}, \mathrm{f}} \text { selection }\end{array}$} & $\checkmark$ \\
\hline$H 13_{b}$ & & $\checkmark$ \\
\hline$H 13_{c}$ & & $\checkmark$ \\
\hline$H 13_{d}$ & & $\checkmark$ \\
\hline$H 13_{e}$ & & $\checkmark$ \\
\hline$H 13_{f}$ & & $\checkmark$ \\
\hline$H 14_{a}$ & \multirow{6}{*}{$\begin{array}{l}\text { Self-efficacy has a positive influence with respect to option }{ }_{\mathrm{a}, \mathrm{b}, \mathrm{c}, \mathrm{d}, \mathrm{e}, \mathrm{f}} \text { selection behavior } \\
\text { intention. }\end{array}$} & $\checkmark$ \\
\hline$H 14_{b}$ & & $\checkmark$ \\
\hline$H 14_{c}$ & & $\checkmark$ \\
\hline$H 14_{d}$ & & $\checkmark$ \\
\hline$H 14_{e}$ & & $\checkmark$ \\
\hline$H 14_{f}$ & & $\checkmark$ \\
\hline
\end{tabular}

Hint: a: Home delivery, b: In-store delivery, c: Collection delivery points (CDPs), d: Home return, e: In-store return, f: Collection return points (CRPs) 
Table 112 Summary of hypotheses in moderation effect in delivery options

\begin{tabular}{|c|c|c|}
\hline$H 15_{a}$ & \multirow{6}{*}{$\begin{array}{l}\text { With greater time pressure, the positive relationship between attitudes toward the } \\
\text { intention will be strengthened in option } a, b, c, d, e, f \text { selection. }\end{array}$} & $x$ \\
\hline$H 15_{b}$ & & $x$ \\
\hline$H 15_{c}$ & & $x$ \\
\hline$H 15_{d}$ & & $x$ \\
\hline$H 15_{e}$ & & $\checkmark$ \\
\hline$H 15_{f}$ & & $\checkmark$ \\
\hline$H 16_{a}$ & \multirow{6}{*}{$\begin{array}{l}\text { With greater distance to store, the positive relationship between attitudes toward the } \\
\text { intention will be strengthened in option }{ }_{a, b, c, d, e, f} \text { selection. }\end{array}$} & $\checkmark$ \\
\hline$H 16_{b}$ & & $x$ \\
\hline$H 16_{c}$ & & $x$ \\
\hline$H 16_{d}$ & & $x$ \\
\hline$H 16_{e}$ & & $x$ \\
\hline$H 16_{f}$ & & $x$ \\
\hline$H 17_{a}$ & \multirow{6}{*}{$\begin{array}{l}\text { With greater spillover effect, the positive relationship between attitudes toward the } \\
\text { intention will be strengthened in option } \mathrm{a}_{\mathrm{a}, \mathrm{b}, \mathrm{c}, \mathrm{d}, \mathrm{e}, \mathrm{f}} \text { selection. }\end{array}$} & $x$ \\
\hline$H 17_{b}$ & & $\checkmark$ \\
\hline$H 17_{c}$ & & $\checkmark$ \\
\hline$H 1_{d}$ & & $x$ \\
\hline$H 17_{e}$ & & $x$ \\
\hline$H 17_{f}$ & & $x$ \\
\hline
\end{tabular}

Hint: a: Home delivery, b: In-store delivery, c: Collection delivery points (CDPs), d: Home return, e: In-store return, f: Collection return points (CRPs) 
Chapter 7: Conclusions 


\subsection{Evaluation of compliance with the proposed objectives}

The main objective of the research was to understand why consumers select different last-mile logistics options and which factors influence consumer's option selections. The plan was to do this by identifying the factors influencing the intention of selecting the actual behavior of option selection in delivery and return by the Spanish final consumers in Omnichannel environments, using apparel as the case in question.

To achieve this objective, we established a set of secondary objective that play an important role in the process of achieving the main objective. The level of compliance of both the main objective and the secondary objective can be considered satisfactory, as will be justified below.

First secondary objective: Establish a conceptual framework by reviewing articles to identify the factors that affect consumer's delivery and return option selection in a multi-channel context, in order to cover the shortcomings of previous research in delivery and return in the Omnichannel environment. Also, we conducted an empirical study due to the fact that, the research may detect new beliefs in new retailing environment that may not be found in the existing literature. Apart from being new in the research line, some beliefs may remain over time, others may be forgotten, and new beliefs may be formed by both positive and negative experiences (Ajzen \& Fishbein, 1980). If this test is not conducted, the research may not be accurate, which in the short and long term, this may actually be quite effective and the determinants may not really capture the consumer's behavior (Ajzen, 1985). The results obtained were then compared with previous research in different contexts. The empirical analysis helped reduce the variables identified through the literature review, identify the important factors, and introduce new factors. In addition, all the factors introduced have been tried to be solid in the theoreticalconceptual model. From this conceptual analysis, the influential factors have been identified: eight factors related to attitude toward the behavior, there were two control factors and two factors related to the socio-normative context. Therefore, the second secondary objective of the investigation can be considered fulfilled (Zarei et al., 2020).

Through a literature review, the different models of technology adoption have been studied, specifically, the one that applied to the case of this study, in order to able to connect and organize all the factors presented by the previous studies. Therefore, this objective is considered to be fulfilled.

Moreover, in order to overcome the limitation from a chosen technology adoption model, we considered an exploratory study to explore the influence of the situational factors in consumers' delivery and return option decisions. The results obtained in this analysis offer in-depth information about the behavior, which no one has used to explore the impact of these situational factors in the context of consumers' delivery and return option selection. Therefore, the analysis covered the shortcomings of previous research of situational factors on consumers' delivery and return option selection decisions. It also identified the most influential situational factors in order to reduce the length of the questionnaire, and 
thereby the complexity of the analysis, and to avoid errors in the results. Therefore, the third secondary objective of the investigation can be considered fulfilled (Zarei et al., 2019).

With respect to the main objective of the research, this study has developed a general model for lastmile logistics. This model has been presented as the action of a series of factors grouped into three main categories on the intention to select last-mile logistics (attitude toward the behavior, subjective norms, and perceived control behavior), analyzing the nature and influence of these relationships and keeping in mind the situational factors that are capable of changing consumer's attitude toward the intentions as the main predictor of real behavior of the individual in the last-mile logistics. Moreover, in line with the main objective of the research, this study has established a valid measurement that makes it possible to contrast the hypotheses. The methodology used in this study is directly applicable to the majority of studies with the objective of studying consumer shopping behavior, although for some studies it should be particularized, and the samples should be correctly defined. By these means, the main objective of the investigation can be considered fulfilled.

\subsection{Contribution of the investigation}

This study explains not only the causal relationships between factors within three last-mile logistics options - home/office, in-store, and CDPs/CRPs - but also the main contributions of the research from theoretical, methodological, and practical points of view.

\subsubsection{Theoretical contribution}

From the theoretical point of view, the main contribution of this research is the presentation of a unified theoretical model applicable to the consumer's behavior in selecting a last-mile logistics option based on existing models in the field of human behavior sciences, and adding specific factors for the case of this study. The chosen factors are supported in most cases in last-mile logistics options, which provide solid theoretical-conceptual support.

From the main contribution, different specific contributions can be extracted:

- After reviewing the previous studies, no work has been identified that shows the consumer's behavior in last-mile logistics. The present study addresses the shortcomings of previous research, building a conceptual framework for only the last part of the shopping journey and giving a comprehensive explanation that previous studies have ignored.

- Regarding the factors considered in the research, previous studies have focused mostly on the shopping stage and attempted to predict shopping behavior by limiting factors such as perceived ease of use, perceived usefulness, performance and hedonic motivation. Although the present study explains new factors, it shows the relationships among these factors. As the first theoretical contribution of the study, it can be said that hedonic factors do not impact consumer last-mile logistics options. 
- This study presents environmental elements such as the moderation effect (such as time availability, spill-over effect, and geographical distance) on attitudes toward the behavior, a topic that lacks sufficient academic research despite having been recommended strongly by previous researchers. Researchers can use the comprehensive framework of this study and benefit in their research by following the structure of the study and incorporating it into other research designs. However, it should be noted that considering more environmental factors (more than three) can increase the complexity of the model and thereby increase the error of the final result. Hence, it is not recommended.

\subsubsection{Methodological contribution}

The following explains some contributions from a methodological point of view.

- The final factors were not identified solely from the literature review. Since no studies have been identified, either in multi-channel or in Omnichannel retailing - hence, during the research process - an experimental study has been carried out using the basis of the TBP approach. The aim of this experimental study was to check the adequacy of the factors found in the literature, omitting unnecessary factors, and eliciting new factors (Zarei et al., 2020).

- The most influential situational factors were identified in order to decrease the complexity of the research by using an exploratory method without developing specific hypotheses to show the positive or negative influence of these situational factors. However, usual methods could be used instead in order to clearly demonstrate the influence trend of these situational factors (Zarei et al., 2019).

- We prepared a measuring instrument such as sample size and the statistical technique in order to analyze parameters of the structural equation model.

- We added and analyzed the moderating effects of certain variables - the most influential situational factors - in the model that previous studies have generally ignored. The methodology carried out in this research provides weights of effect for each moderation factor in the model.

\subsubsection{Practical contribution}

These results offer managers some interesting contributions, which are explained below.

Using attitude toward the behavior factors: As the study results indicate, the high value of attitude shows that consumers tend to complete their shopping task more efficiently (that is, conveniently). This enables consumers to receive, and return goods more conveniently, and less riskily, enabling companies to be rewarded with increased consumer loyalty, revenue growth, differentiation, and profitability. Hence, investing more in a delivery and return policy could not only result in happier consumers, but also increase companies' revenue. In addition to the findings, consumers feel that at pick-up points, 
both in-store and CDPs, either for collecting or returning items, are more convenient than home delivery or return. This could depend on the specific product, since consumers often feel the need to assess apparel products at the store and be able to easily return the product - despite the inconvenience caused by the extra effort of going to these points.

Moreover, the results show that, in most of the last-mile options except for home delivery or return option, consumers do not consider the monetary charges. This shows that consumers are aware of the charges while purchasing the items. Hence, companies by playing the transportation charges can manipulate consumer's last-mile logistics option behavior. However, a lenient last-mile logistics strategy can produce problems for the companies such as could lead to higher return rates through home return and thereby increase the transportation cost for the companies.

Using perceived behavioral control factors: Another contribution for managers is to facilitate the conditions for the consumers, such as access to facilities. Access to facilities has been shown to be not important for consumers while choosing different delivery and return options. Facilitating the conditions is sometimes not feasible or does not have economic justification. In such cases, managers need to employ a specific delivery and return strategy and explain to consumers the implicit benefits of delivery and return charges only being nominal in the shopping process. For example, retailers can show the difficulty of carrying heavy items on a rainy day and emphasize the ease of having heavy items delivered to the house.

Moreover, the results show that the level of confidence or perceived capability to perform tasks is an important self-efficacy trigger. More importantly, when the results show that the self-efficacy is linked directly to the intention of selecting the last-mile logistics option. Hence, it may be more important for practitioners to emphasize the compatibility of all available last-mile logistics options to their consumers with their communications. To do so, a continuous effort may be implemented by retailers to highlight confidence in a customer's ability to select different last-mile logistics options. The role of advertising cannot be underestimated and might be usefully applied for some product categories.

Using situational factors: Logistics designers can take situational factors into consideration when designing delivery and return options for apparel. Logistics designers' efforts may be geared up to create or alter particular delivery or return options; for example, to orient a specific shopper to select particular delivery or return option in a specific situation, such as Christmas or bad weather. By doing this, consumers are positively encouraged to select a specific delivery and return options. In this case, managers may have the upper hand to design properly and optimize their delivery and return options.

Managers - particularly those from Spain - can benefit from this study in several ways. In general way, it helps retailers to have an effective mechanism for predicting option-selection intention and behavior for delivery and return. They can use these findings to design a proper logistics strategy by targeting 
these factors and overcoming the current challenges. For instance, managers are encouraged to emphasize the advantages of choosing different last-mile logistics options (such as adding more pickup points), as well as developing strategies for assisting consumers to overcome their perceived obstacles (such as accessibility to facilities, cost of time and money). Hence, retailers have to expand their horizons and be more creative in their offerings if they want to keep their consumers throughout the shopping process. As an outcome of this study, such information helps companies formulate their marketing strategy (Kotler, 2009) and retailing planning (Levy \& Weitz, 2012) to improve their resource allocation and productivity.

\subsection{Conclusion and discussion}

This section discusses the general conclusion derived from the results, then offers some specific conclusions derived from each factor presented in this research, which provides some action lines for retailers in Spain.

\subsubsection{General conclusion}

The first objective of this study was to shed some light on last-mile logistics consumer's preferences in the Omnichannel environment, a topic that lacks sufficient academic research despite being the basic business model under the Omnichannel strategy. The model developed in this research is based on TPB, and the characteristics of the model are: attitudinal beliefs (flexibility, saving effort, saving time, monetary, risk factors, etc.), normative beliefs (such as family and friends), and perceived behavioral control beliefs (e.g., self-efficacy and facilitating conditions). The empirical analysis of the proposed model shows that attitudes toward the behavior and one factor from perceived control behavior influence the intention of last-mile logistics option selection in all cases, and that socionormative factors are not a good predictor of this intention. Only in the case of in-store return and CRPs options does the model show that socio-normative factors influence the consumer's intention. The findings also suggest that there are similarities and differences in the manner in which the independent factors in each last-mile logistics option predict the dependent factors. Overall, it can be stated that convenience and perceived risk are more relevant in predicting attitudes toward last-mile option selection for all delivery and return options. In fact, utilitarian motivations are functional and incorporate more cognitive aspects of attitude and are means to an end (Noble et al., 2005; Pookulangara et al., 2011a). Hence, it can be concluded to be an important factor in consumer's behavior, which is significantly influenced.

The second objective of this study is to determine potential situational influences on consumers' lastmile logistics option preferences: time pressure (a temporal setting); distance to store (a physical setting); and channel spillover effect (a spillover effect). According to Monsuwé et al. (2004), three situational factors are employed in attitude-consumers intention. The final results support this hypothesis, which is important given that, to our knowledge, this is the first study to examine situational factors in last-mile logistics. The result shows that consumers' attitudes can be influenced by these three 
factors, which are consistent with other studies with different contexts (e.g., Gehrt \& Yan, 2004; Kim et al., 2017) and situation-related research (Russell Belk, 1974). Moreover, it shows that consumers' attitudes can easily change due to spillover effects and distance to the store. This information tells us that in order to design last-mile logistics, it is necessary to take environmental factors into consideration.

\subsubsection{Specific conclusions}

This section provides a specific conclusion for each factor analyzed and offers action guidelines for retailers where possible.

\subsubsection{Attitude toward the behavior factors}

The results show that, in some cases of last-mile logistics options, either for delivery or return, consumers' attitudes are significantly predicted by convenience, perceived risk, and in some cases by monetary. However, the coefficient path for convenience values is much higher and, in some cases, negative. This indicates that consumers' behavioral beliefs for selecting a last-mile logistics option are anticipated to be influenced mostly by efficiency and convenience (less effort, less time-consuming, and less inflexibility). This supports the growth of home delivery and return and consistent with previous researchers' conclusions in the multi-channel environment ( e.g., Gensler et al., 2012; Keeney, 1999; Kleinman, 2012; Swaid \& Wigand, 2012). However, physical stores' delivery and return play an important role for consumers (Kim et al., 2017), due to the fact that consumers want some of the touchand-feel aspect and more of the convenience in receiving in the physical stores. Generally, it can be stated that the convenience factor is more relevant for predicting attitudes toward the selection of lastmile logistics options. Moreover, offering different options of last-mile logistics allows consumers to complete their shopping task more efficiently (that is, conveniently), so it can be inferred that attitudes towards the last-mile logistics option will be significantly influenced by convenience factors.

Regarding the perceived risk, the results show that the coefficient path is negative. This negative coefficient path also connected respectfully with studies by Schröder and Zaharia (2008) and Xu et al. (2011) who have shown that perceiving risks are those factors that affect consumers' shopping behavior. Moreover, the results show that coefficient path for collection points or returning points are much higher than other options. This can be due to the fact that consumers may perceive performance and financial risk in delivery or return. This means that, consumers fear more in these options because they the purchased order may be lost or damaged. Hence, a study by DHL Consumer Solutions and Innovation (2015) pointed out that enabling consumers to receive and return less risky way make companies to be rewarded with the increased consumer loyalty, revenue growth, differentiation, and profitability.

Moreover, the result shows that attitude was the predictor of the last-mile logistics option selection intention, as proposed by Ajzen (1991). Past studies on consumers' behavioral intentions have supported this relationship between a favorable attitude and intention, and have considered attitude as the most important predictor of a person's behavioral intention (e.g., Altawallbeh et al., 2015; 
Pookulangara et al., 2011a; Potwarka, 2015). The higher coefficient values in this study for attitude indicate that the influence is greater with respect to consumer's intention in the last-mile logistics. Therefore, this finding shows that, for consumers, attitude is an important factor when selecting a lastmile logistics option from among other factors.

\subsubsection{Subjective norms factors}

The results show that the normative beliefs for each of the last-mile logistics option are the predictors of subjective norms and are significant except in in-store delivery. The results also show that the relationship is positively consistent with studies in different contexts, such as Lim and Dubinsky's (2005) study on online purchase intention. The results show that, the influence of normative beliefs in subjective norms of last-mile logistics are big. However, the same results demonstrate that the subjective norms have the small coefficient path values and in some cases are not significant. In other words, it can be inferred that subjective norms hardly reflect consumer intention and can therefore be omitted from the final model. This finding is important given that in the previous shopping stage, "peerinfluence” was considered as an important factor (Pookulangara et al., 2011a), and its absence can sometimes have a great effect on retail strategy.

However, the results show that subjective norms for in-store return and CRPs have the significant and moderate coefficient path values after attitude. This finding is consistent with Chou et al.'s (2016) findings, which indicated that not only attitude influence intentions, but even the subjective norm component play an important role in consumers' shopping decisions, due to the nature of the shopping itself (that is, shoppers attempt to fit in with perceived opinions of important others in each stage of the shopping journey). Thus, it can be inferred that consumers' intention to in these last-mile logistics options might not occur until an individual (family or friends) confirms their return option.

\subsubsection{Perceived behavior control factors}

Self-efficacy and facilitating conditions significantly predicte PBC, with positive coefficient path values. Moreover, the results show that the largest value belongs to self-efficacy. Self-efficacy measures a feeling of self-competence (Pookulangara et al., 2011a); hence, it can be inferred that consumers prefer to feel of self-competence while selecting a last-mile logistics option. The higher coefficient value for self-efficacy indicates that a greater degree of consumer confidence is needed to select a single delivery and return option. Facilitating conditions also significantly predictes last-mile logistics option. This is clearly consistent with previous research (Juaneda-Ayensa et al., 2016; Pookulangara et al., 2011a). In fact, it shows that the perception of facilitating conditions for a task influences the shopping outcome and is one of the important beliefs that determine consumers shopping behavior (Pookulangara et al., 2011a). Thus, it can be inferred that some consumers segment the criteria in the last-mile logistics format based on the availability of resources. 
Regarding the perceived behavioral control itself, the results show that it does have a weak coefficient path with not being significantly predictive for all last-mile logistics options. This result is contradict with previous studies showing consumers may feel that perceived control is actually a real control factor and can impact the evaluation of their shopping decision (Pookulangara et al., 2011a). The findings of this study indicate that when a consumer selects an option in the last mile logistics, she or he is not influenced by the level of perceived control, and thereby with more control leading select a last-mile logistics option. However, the results show that self-efficacy has a direct influence toward consumer's intention of selecting last-mile logistics. This result is similar to what earlier studies in channel switching have indicated (Heitz-Spahn, 2013; Pookulangara et al., 2011a). Thus, it can be inferred that when consumers have higher self-efficacy over an option, they are more capable of selecting that lastmile logistics option than other available last-mile logistics options.

\subsubsection{Situational factors}

The results show a significant relationship between home delivery/return, CDPs, and in-store delivery with a spillover situation. This indicates that home delivery and return options perform better for online orders. This would be consistent with Hübner et al.'s (2016) study, which clearly shows that retailers need to expand their home delivery and return options because consumers have begun to embrace the idea of online shopping, and are ordering to receive at home or return from home. Moreover, the spillover effect situation does not have a significant on in-store returns and CRPs, indicating that consumers who have returning points preferences feel almost the same way about purchasing items through either the Internet or at a store. This statement suggests that retailers have to offer in-store returns or CRPs with a set of return or refund policies that can minimize the risks felt by consumers about online shopping (Kim et al., 2017).

The results show that, for time-pressed consumers, stores and collection points perform well for returned products, while home returns perform poorly. This indicates that, in terms of time-pressure, consumers suffer from a lag time between returning the product and handing it over to the courier, and/or only during waiting time sending back to the retailer. This would be consistent with the recommendation of Rein (2015) that consumers have to invest time and sometimes money (returning cost) to return the product from home. The fact that availability of time is significantly related to lastmile logistics option may be good news for retailers who provide more fast delivery and return options in order to overcome the time disadvantage caused by the lag in the delivery or return cycle.

Last but not least, home delivery and return are favored for consumers who live far away from the store. Consumers perceive that they must spend a large amount of time and effort to get the purchased item and send it back (Chintagunta et al., 2012), so they tend to receive or return their purchased items as close as possible. Also, the results of the present study are consistent with the DHL (2015) report stating that consumers who purchase a product from distance first prefer to select delivery to home, then delivery to a nearby retail store, and finally other nearby collection points. Offering nearby collection 
points seems to be a great choice for non-store retailers. Some studies have suggested tactics that online appeal retailers could utilize, such as prompt and consistent delivery and lenient return options (Lantz \& Hjort, 2013; Rein, 2015).

\subsection{Study limitations and suggestions for future studies}

Although the research follows a systematic methodology in order to achieve the objectives and offer interesting results from a practical point of view, it should be noted that this study has certain limitations that should be taken into account when interpreting the conclusions properly. The main limitations of the investigation detected are as follows:

- The most important limitation of this research is that the sample conducted in the study may not be generalizable to universal behavior since the sample extracted was only restricted to Spain. Future studies should be expanded to ethnic groups. Moreover, the sample size must be representative in terms of the educational level.

- This study only investigated one product (clothing). Other products such as computerrelated items or books, which have less of a touch-and-feel aspect, should be considered. Although arguments have been provided to justify this choice, there is not enough empirical evidence to determine the influence of the different types of products on last-mile logistics option selection. This gives rise to a future line of research and it is necessary to define the consider moderation effect of the product type in the lastmile logistics options.

- We did not consider other variables to the model that can help predict the intention of selecting last-mile logistics, especially where the results showed weak confident path or low R square. Also, we decided not to include hedonic motivation, in this model, for the reasons explained in the Chapter 3. This decision was made to reduce the length of the questionnaire and thereby the complexity of the analysis and to avoid the error in the results (Wang \& Li, 2002; Zarei et al., 2020).

- This study only considers three situational factors and three delivery and three return options. Moreover, it only explores the direct effects of situational factors in intentionbehavior link. Existing literature on the direct effects of situational factors in the retail context has argued that the emotion arising from situational factors can mediate shopping evaluation (Machleit \& Eroglu, 2000). Hence, it is suggested that future studies should examine more situational factors and their effect in the final model.

\subsection{Research lines for future studies}

During the investigation for this study to fulfill the objectives, a series of questions have arisen that can be considered as future lines of research: 
- Need to be studied more: Since no theoretical framework has been developed in consumer's behavior in the post-purchase area, and despite the fact that this research opens a new avenue of research in this area with the limited number of hypotheses, it needs to be studied more in order to gain comprehensive knowledge in this particular stage of the shopping process.

- Performing cross-cultural: As stated in the previous section, one of the limitations of this research comes from the sample selection: the data was obtained solely from Spain. Future analyses should consider different cultures that make it possible to compare different cultures and conduct vital recommendations for practitioners. Hence, it is recommended to carry out a new empirical experiment in order to compare it with the Spanish geographical scope.

- Deepening the predictive variables: We suggest adding other variables to the model that can help predict better the intention of selecting last-mile logistics, such as price values of the product, habit, demographic characteristics, perceived compatibility, retailer image, etc.

- Consideration of different situational factors: This study used the three most influential situational factors. It is possible to consider new situational factors that were not included in the model.

- Using a different type of product: Taken from the limitations of the present investigation, it was decided not to consider the influence of the type of product in the mode; hence, there is an open investigation by considering a different type of product in the study.

- Automation of the process: Finally, to be more practical, once a series of behavioral patterns have been identified, it could be possible to deepen the knowledge of users regarding the way of selecting delivery or return options and thus adapt better to their tastes or needs. In this sense, a simple and intelligent mechanism needs to be developed that allows the investigation in other similar profiles.

With this information, future studies may enrich the understanding of consumers' logistics selection by considering the direct effects of situational factors on the intention to select and use one of the last-mile logistics. 
Chapter 8: References 
Ajzen, I. (1985) From intentions to actions: A theory of planned behavior, Organizational Behavior and Human Decision Processes. Springer Berlin Heidelberg.

Ajzen, I. (1988) Attitudes, personality, and behavior. McGraw-Hill Education (UK).

Ajzen, I. (1991) 'The theory of planned behavior', Organizational behavior and human decision processes. Elsevier, 50(2), pp. 179-211.

Ajzen, I. (2005) Attitudes, personality, and behavior. McGraw-Hill Education (UK).

Ajzen, I. (2015) 'The theory of planned behaviour is alive and well, and not ready to retire: a commentary on Sniehotta, Presseau, and Araújo-Soares’, Health Psychology Review. Taylor \& Francis, 9(2), pp. 131-137.

Ajzen, I. and Driver, B. L. (1991) 'Prediction of leisure participation from behavioral, normative, and control beliefs: An application of the theory of planned behavior', Leisure Sciences, 13(3), pp. 185204.

Ajzen, I. and Fishbein, M. (1980) Understanding attitudes and predicting social behaviour. United States of America: Prentice-Hall.

Ajzen, I. and Fishbein, M. (2000) 'Attitudes and the attitude-behavior relation: Reasoned and automatic processes’, European review of social psychology. Taylor \& Francis, 11(1), pp. 1-33.

Ajzen, I. and Madden, T. J. (1986) 'Prediction of goal-directed behavior: Attitudes, intentions, and perceived behavioral control', Journal of experimental social psychology. Elsevier, 22(5), pp. 453-474.

Altawallbeh, M. et al. (2015) 'Mediating role of attitude, subjective norm and perceived behavioural control in the relationships between their respective salient beliefs and behavioural intention to adopt e-learning among instructors in Jordanian universities.', Journal of Education and Practice, 6(11), pp. $152-160$.

Arvind, R. and Bruggen, G. H. Van (2005) 'Opportunities and challenges in multichannel marketing: An introduction to the special issue', Journal of Interactive Marketing, 19(2), p. 5.

Arora, S., Singha, K., \& Sahney, S. (2017). Understanding consumer's showrooming behaviour. Asia Pacific Journal of Marketing and Logistics, 29(2), 409-431.

ATKearney (2020) 'Online retail is front and center in the quest for growth', The 2013 Global Retail E-Commerce Index, p. 7. Available at: http://de.slideshare.net/alexbaar/global-retail-e-commerceindex-2013.

Aubrey, C. and Judge, D. (2012) 'Re-imagine retail: Why store innovation is key to a brand's growth in the "new normal", digitally-connected and transparent world', Journal of brand strategy. Henry Stewart Publications, 1(1), pp. 31-39. 
Ayoade, A. and Eneh, S. (2015) Showroom, the Future of Online Fashion Retailing Enhancing the online shopping experience. Swedish School of Textiles Sweden.

Azhari, J. El and Bennett, D. (2015) 'Omni-channel customer experience: An investigation into the use of digital technology in physical stores and its impact on the consumer's decision-making process', in XXIV AEDEM International Conference, pp. 1-2.

Ba, S., Stallaert, J. and Whinston, A. B. (2005) 'Choice of Transaction Channels: The Effects of Product Characteristics on Market Evolution', Journal of Management Information Systems, 21(4), pp. 173197.

Babin, B. J., Darden, W. R. and Griffin, M. (1994) 'Work and/or fun: measuring hedonic and utilitarian shopping value', Journal of consumer research. The Oxford University Press, 20(4), pp. 644-656.

Bala, H. and Venkatesh, V. (2008) 'Technology acceptance model 3 and a research agenda on interventions', Decision Sciences, 39(2), pp. 273-315.

Balabanis, G., \& Reynolds, N. L. (2001). Consumer attitudes towards multi-channel retailers' Web sites: The role of involvement, brand attitude, Internet knowledge and visit duration. Journal of Business strategies, 18(2), 105.

Balasubramanian, S., Raghunathan, R. and Mahajan, V. (2005) 'Consumers in a multichannel environment: Product utility, process utility, and channel choice', Journal of Interactive Marketing, 19(2), pp. 12-30.

Bandura, A. (1986) 'Self-Efficacy Mechanism in Human Agency’, Brain Research, 37(2), pp. 395398.

Banker, S. and Cooke, J. A. (2013) Stores: the weak link in omnichannel distribution - DC Velocity. Available at: http://www.dcvelocity.com/articles/20130805-stores-the-weak-link-in-omnichanneldistribution/.

Barclay, D.; Higgins, C.; Thompson, R.L. (1995). The partial least squares (PLS) approach to causal modeling: personal computer adoption and uses an illustration. Technology Studies, Special Issue on Research Methodology, 2(2), 285-309.

Baron, R. M. and Kenny, D. A. (1986) 'The Moderator-Mediator Variable Distinction in Social Psychological Research: Conceptual, Strategic, and Statistical Considerations', Journal of Personality and Social Psychology, 51(6), pp. 1173-1182.

Beamonte, E., Bermúdez, J. D. and Casino, A. (2007) 'A statistical study of the quality of surface water intended for human consumption near Valencia (Spain)', Journal of Environmental Management, 83(3), pp. 307-314. 
Belk, R. W. (1974) 'An exploratory assessment of situational effects in buyer behavior', Journal of marketing research. JSTOR, 11(2), pp. 156-163.

Belk, R. W. (1975) 'Situation variables and consumer behavior', Journal of Consumer Research, 2(3), pp. 157-164.

Bell, D. R., Gallino, S. and Moreno, A. (2014) 'How to win in an Omnichanel wolrd', MITSloan Management Review, pp. 1-13.

Beltrami, M., Kim, D. and Rolkens, F. (2019) 'The State of Fashion 2020', pp. 1-107. Available at: https://www.mckinsey.com/ /media/McKinsey/Industries/Retail/Our Insights/The State of Fashion 2019 A year of awakening/The-State-of-Fashion-2019-final.ashx.

Belu, M. G. and Marinoiu, A. (2014) 'A new distribution strategy: the omnichannel strategy', The Romanian Economic Journal, (52), pp. 117-134.

Ben-Shabat, H. et al. (2015) The Global Retail E-Commerce Index 2015. Available at: http://www.atkearney.com/documents/10192/5691153/Global+Retail+E-

Commerce+Keeps+On+Clicking.pdf/abe38776-2669-47ba-9387-5d1653e40409.

Bentler, P. M. and Speckart, G. (1979) 'Models of attitude-behavior relations.', Psychological Review. US: American Psychological Association, 86(5), pp. 452-464.

Berman, B. and Thelen, S. (2004) 'A guide to developing and managing a well-integrated multi-channel retail strategy', International Journal of Retail \& Distribution Management, 32(3), pp. 147-156.

Bezes, C. (2016) ‘Comparing online and in-store risks in multichannel shopping’, International Journal of Retail \& Distribution Management, 44(3), pp. 284-300.

Bhattacherjee, A. (2000) 'Acceptance of e-commerce services: The case of electronic brokerages', IEEE Transactions on Systems, Man, and Cybernetics Part A:Systems and Humans., 30(4), pp. 411420.

Black, N. J. et al. (2002) 'Modelling consumer choice of distribution channels: an illustration from financial services’, International Journal of Bank Marketing, 20(4), pp. 161-173.

Blackwell, R. D., Miniard, P. W. and Engel, J. F. (2006) Consumer Behavior. 10th edn. Thomson/South-Western.

Blázquez, M. (2014) 'Fashion Shopping in Multichannel Retail: The Role of Technology in Enhancing the Customer Experience', International Journal of Electronic Commerce, 18(4), pp. 97-116.

Bosnjak, M., Galesic, M. and Tuten, T. (2007) 'Personality determinants of online shopping: Explaining online purchase intentions using a hierarchical approach', Journal of Business Research, 60(6), pp. 597-605. 
Breuer, P. et al. (2012) Retailing \& Retail Formats, Rai Technology University. Department of Higher Education.

Brock, D. (2009) Aftersales management: creating a successful aftersales strategy to reduce costs, improve customer service and increase sales. Kogan Page.

Bromage, N. (2001) 'Keep the customer satisfied', Supply Management. Proquest ABI/INFORM, 6(10), pp. 34-36.

BRP consulting (2019) 2019 Special Report - Real-time Retail. Available at: https://brpconsulting.com/download/2019-special-report-real-time-retail/

Buldeo Rai, H., Verlinde, S. and Macharis, C. (2019) 'Logistics outsourcing in omnichannel retail', International Journal of Physical Distribution \& Logistics Management, Apr 16.

Burt, S. and Sparks, L. (2003) 'E-commerce and the retail process : a review', Journal of Retailing and Consumer Services, 10, pp. 275-286.

Burton-Jones, A. and Hubona, G. S. (2006) 'The mediation of external variables in the technology acceptance model', Information and Management, 43(6), pp. 706-717.

Cammiss, S. (2015) ‘Omni-Channel Retail’. Singapore: NUS-ISS Paper.

Cao, L. and Li, L. (2015) 'The Impact of Cross-Channel Integration on Retailers' Sales Growth', Journal of Retailing, 91(2), pp. 198-216.

Capper, T. (2014) “Are Delivery Options Part of Your E-Commerce Strategy?”, onlineownership. Available at: http://onlineownership.com/delivery-options-part-e-commerce-strategy/.

Cavalieri, S., Gaiardelli, P. and Ierace, S. (2007) 'Aligning strategic profiles with operational metrics in after-sales service', International Journal of Productivity and Performance Management, 56(5/6), pp. 436-455.

Cepeda Carrión, G. and Salgueiro, J. L. R. (2004) Aplicando en la práctica la técnica PLS en la administración de empresas. Universidad de Sevilla.

Chatterjee, P. (2006) 'Cross-Channel Product Ordering and Payment Policies in Multichannel Retailing: Implications for Shopping Behavior and Retailer Profitability.', Journal of Shopping Center Research, 13(2), pp. 31-56.

Chatterjee, P. (2010) 'Causes and consequences of “order online pick up in-store” shopping behavior', The International Review of Retail, Distribution and Consumer Research, 20(4), pp. 431-448.

Chen, C.-W. and Cheng, C.-Y. (2012) 'How online and offline behavior processes affect each other: customer behavior in a cyber-enhanced bookstore’, Quality \& Quantity, 47(5), pp. 2539-2555. 
Chetsumon, S. (2005) Attitudes of extension agents towards expert systems as decision support tools in Thailand. Lincoln University.

Childers, T. L. et al. (2001) 'Hedonic and utilitarian motivations for online retail shopping behavior', Journal of Retailing, 77(3), pp. 511-535.

Chin, W. W. (1998) Modern Methods for Business Research, Modern Methods for Business Research. Califiornia State Universtiy.

Chintagunta, P. K., Chu, J. and Cebollada, J. (2012) 'Quantifying Transaction Costs in Online/Off-line Grocery Channel Choice', Marketing Science, 31(1), pp. 96-114.

Chipidza, W., Green, G. and Riemenschneider, C. (2015) 'Salient Beliefs in Majoring in Management Information Systems : An Elicitation Study', in Proceedings of the EDSIG Conference. Wilmington, North Carolina USA, pp. 1-10.

Chiu, C. M. et al. (2014) ‘Understanding customers’ repeat purchase intentions in B2C e-commerce: The roles of utilitarian value, hedonic value and perceived risk', Information Systems Journal, 24(1), pp. 85-114.

Chiu, H. C., Hsieh, Y. C. and Roan, J. (2011) 'The challenge for multichannel services: Cross-channel free-riding behavior', Electronic Commerce Research and Applications. Elsevier B.V., 10(2), pp. 268277.

Chocarro, R., Cortiñas, M. and Villanueva, M. L. (2013) 'Situational variables in online versus offline channel choice', Electronic Commerce Research and Applications, 12(5), pp. 347-361.

Chopra, S. (2015) 'How omni-channel can be the future of retailing', in 2015, I. I. of M. C. (ed.) Decision. Indian Institute of Management Calcutta 2015: Springer India.

Chou, S. Y. et al. (2016) 'Multichannel service providers' strategy: Understanding customers' switching and free-riding behavior', Journal of Business Research. Elsevier Inc., 69(6), pp. 2226-2232. Cohen, J. E. (1988) Statistical power analysis for the behavioral sciences. 2th edn, Routledge. 2th edn. Cohen, M. A., Agrawal, N. and Agrawal, V. (2006) 'Winning in the Aftermarket', Harvard Business Review, 84(5), p. 129.

Combs, C. (2015) Omnichannel Fashion Term, Apparel Search. Available at: http://www.apparelsearch.com/terms/o/omnichannel-fashion.html (Accessed: 18 November 2015).

Commission, E. (2018) Europe’s Digital Progress Report.

Conner, M. and Armitage, C. J. (1998) 'Extending the Theory of Planned Behavior: A Review and Avenues for Further Research', Journal of Applied Social Psychology, 28(2), pp. 1429-1464. 
Constantinides, E. (2004) 'Influencing the online consumer's behavior: the Web experience', Internet Research, 14(2), pp. 111-126.

Cox, N. C. and Dannehl, K. (2007) Perceptions of retailing in early modern England. Ashgate Publishing, Ltd.

Crawford, J. (2005) 'Are You Really Measuring Your Multi-Channel Customer Experience?’, International Business Machines Corporation, 47(4), pp. S1-S8.

Cummins, S., Peltier, J. W. and Dixon, A. (2016) 'Omni-channel research framework in the context of personal selling and sales management: A review and research extensions', Journal of Research in Interactive Marketing, pp. 2-16.

Cunningham, L. F., Gerlach, J. H. and Harper, M. D. (2005) 'Perceived risk and the consumer buying process: internet airline reservations', International Journal of Service Industry Management. Emerald Group Publishing Limited, 16(4), pp. 357-372.

Cyr, D. et al. (2007) 'The role of social presence in establishing loyalty in e-Service environments', Interacting with Computers, 19(1), pp. 43-56.

Dabholkar, P. A. and Bagozzi, R. P. (2002) 'An Attitudinal Model of Technology - Based Self - Service: Moderating Effects of Consumer Traits and Situational Factors', Journal of the Academy of Marketing Science, 30(3), pp. 184-201.

Dange, U. and Kumar, V. (2012) 'A Study of Factors Affecting Online Buying Behavior: A Conceptual Model', Journal of the Academy of Marketing Science, 31(4), pp. 1-11.

Davies, M. A., Waite, K., Pookulangara, S., Hawley, J., \& Xiao, G. (2011). Explaining multi-channel consumer's channel-migration intention using theory of reasoned action. International Journal of Retail \& Distribution Management.

Davis, F. D. (1986) 'Perceived usefulness, perceived ease of use, and user acceptance of information technology', MIS quarterly. JSTOR, pp. 319-340.

Davis, F. D. (1989) 'Perceived Usefulness, Perceived Ease of Use, and User Acceptance of Information Technology', MIS Quarterly, 13(3), p. 319.

Davis, F. D. (1993) 'User acceptance of information technology: system characteristics, user perceptions and behavioral impacts', International journal of man-machine studies, 38(3), pp. 475-487.

Davis, F. D., Bagozzi, R. P. and Warshaw, P. R. (1989) 'User Acceptance of Computer Technology: A Comparison of Two Theoretical Models', Management Science, 35(8), pp. 982-1003.

Delafrooz, N., Paim, L. H., Haron, S. A., Sidin, S. M., \& Khatibi, A. (2009). Factors affecting students' attitude toward online shopping. African Journal of Business Management, 3(5), 200. 
Deloitte (2018) Global Powers of Retailing 2018. Available at: https://www2.deloitte.com/content/dam/Deloitte/at/Documents/about-deloitte/global-powers-ofretailing-2018.pdf

DHL (2015) Shop the World! Consumer Attitudes Towards Global Distance Selling. Available at: http://www.dhl.com/content/dam/Campaigns/Mail_Campaigns/GMStudy2014/pdf/shop_the_worlden.pdf.

DHL Customer Solutions \& Innovation (2015) 'Omni-channel logistics: A DHL perspective on implications and use cases for the logistics industry', pp. 1-38.

Doherty, N. F. and Ellis-chadwick, F. (2010) 'Internet retailing : the past , the present and the future', 38(11), pp. 943-965.

Doong, H.-S., Wang, H.-C. and Law, R. (2012) ‘An Examination of the Determinants of In-Flight DutyFree Shopping: Hedonic and Utilitarian Motivations', International Journal of Tourism Research, 14, pp. 303-306.

Dorman, A. J. (2013) Omni-Channel Retail and the New Age Consumer: An Empirical Analysis of Direct-to-Consumer Channel Interaction in the Retail Industry, CMC Senior Theses.

Eaglen, M. (2013) 'Omni-channel retail: joining up the consumer experience| Media Network| The Guardian’.

eMarketer (2019) Global Ecommerce 2019 Ecommerce Continues Strong Gains Amid Global Economic Uncertainty | eMarketer. Available at: https://www.emarketer.com/content/globalecommerce-2019

eMarketer (2020) Internet Users - Reports, Statistics; Marketing Trends | eMarketer. Available at: https://www.emarketer.com/topics/topic/internet-users.

Engel, J. F., Blackwell, R. D. and Miniard, P. W. (1995) 'Consumer Behaviour. Int. ed', Florida: Dryden.

Esper, T. L., Jensen, T. D. and Turnipseed, F. L. (2003) 'The last mile: an examination of effects of online retail delivery strategies on consumers', Journal of Business Logistics, 24(2), pp. 177-203.

Falk, R. F. and Miller, N. B. (1992) A primer for soft modeling. University of Akron Press.

Fernie, J. and Grant, D. B. (2015) Fashion Logistics: Insights into the Fashion Retail Supply Chain. Kogan Page Publishers.

Ferrand, B. et al. (2008) 'The last mile of e-commerce - Unattended delivery from the consumers and eTailers ' perspectives', International Journal of Electronic Marketing and Retailing, 2(1), pp. 20-38. 
Fishbein, M. and Ajzen, A. (1975) 'Belief, Attitude, Intention, and Behavior: An Introduction to Theory and Research.' Addison-Wesley.

Fishbein, M. E. (1967) 'Readings in attitude theory and measurement.’ Wiley.

Forman, C., Ghose, A. and Goldfarb, A. (2009) 'Competition Between Local and Electronic Markets: How the Benefit of Buying Online Depends on Where You Live', Management Science, 55(1), pp. 4757.

Fornell, C.; Larcker, D. (1981). Evaluating structural equation models with unobservable variables and measurement error. Journal of Marketing Research, 18, 39-50.

Forrester (2016) Forrester Data Web-Influenced Retail Sales Forecast, 2016 To 2021 (EU-7) Available at:

https://www.forrester.com/report/Forrester+Data+WebInfluenced+Retail+Sales+Forecast+2016+To+ 2021+EU7/-/E-RES133600.

Frasquet, M., Mollá, A. and Ruiz, E. (2015) 'Identifying patterns in channel usage across the search, purchase and post-sales stages of shopping', Electronic Commerce Research and Applications, 14(6), pp. 654-665.

Gallino, S. and Moreno, A. (2014) 'Integration of Online and Offline Channels in Retail: The Impact of Sharing Reliable Inventory', Management Science, 60(6), pp. 1434-1451.

Ganesh, J. (2004) ‘Managing customer preferences in a environment using Web services’, International Journal of Retail \& Distribution Management, 32(3), pp. 140-146.

Ganesh, J., Reynolds, K. E. and Luckett, M. (2010) 'Online Shopper Motivations, and e-Store Attributes: An Examination of Online Patronage Behavior and Shopper Typologies', Journal of Retailing. New York University, 86(1), pp. 106-115.

Garbarino, E. and Strahilevitz, M. (2004) 'Gender differences in the perceived risk of buying online and the effects of receiving a site recommendation', Journal of Business Research, 57(7), pp. 768-775.

Gefen, D., Karahanna, E. and Straub, D. W. (2003) 'Trust and TAM in Online Shopping: An Integrated Model', MIS Quarterly, 12(1), pp. 51-90.

Gehrt, K. C. and Shim, S. (2002) 'Situational Influcence in the Internationa Marketplace: An Examination of Japanese Gift-Giving', Journal of Marketing Theory and Practice, 10(1), pp. 11-22.

Gehrt, K. C. and Yan, R.-N. (2004) 'Situational, consumer, and retailer factors affecting Internet, catalog, and store shopping', International Journal of Retail \& Distribution Management, 32(1), pp. 518.

Gensler, S., Dekimpe, M. G. and Skiera, B. (2007) 'Evaluating channel performance in multi-channel 
environments', Journal of Retailing and Consumer Services, 14(1), pp. 17-23.

Gensler, S., Verhoef, P. C. and Böhm, M. (2012) 'Understanding consumers’ multichannel choices across the different stages of the buying process’, Marketing Letters, 23(4), pp. 987-1003.

Gevaers, R., Vanelslander, T. and Van de Voorde, E. (2011) 'Characteristics and Typology of LastMile Logistics from an Innovation Perspective in an Urban Context', City Distribution and Urban Freight Transport: Multiple Perspectives, pp. 56-71.

Golombek, J. (2013) Omni-channel: The Future of Retailing. Available at: http://www.personal.psu.edu/users/j/l/jlg5690/images/White Paper.pdf.

Goodwin, N. C. (1987) 'Functionality and usability', Communications of the ACM. Association for Computing Machinery, Inc., 30(3), pp. 229-234.

Graham Charlton (2014) Multichannel retailers need to work on their returns policies | Econsultancy. Available at: https://econsultancy.com/blog/64801-multichannel-retailers-need-to-work-on-theirreturns-policies/.

Gupta, A., South, A. and Su, B. (2004) 'Risk Profile and Consumer Shopping Behavior in Electronic and Traditional Channels Risk Profile and Consumer Shopping Behavior in Electronic and Traditional Channels’, Decision Support Systems, 38(3), pp. 347--367.

Hahn, K. H., \& Kim, J. (2009). The effect of offline brand trust and perceived internet confidence on online shopping intention in the integrated multi-channel context. International Journal of Retail \& Distribution Management 30(3), pp. 229-234.

Hair, J. F. et al. (2017) Multivariate Data Analysis. 7th edn, Pearson Education Limited. 7th edn.

Halaweh, M. and Fidler, C. (2008) 'Security perception in e-commerce: Conflict between customer and organizational perspectives', 2008 International Multiconference on Computer Science and Information Technology, pp. 443-449.

Hand, C., Dall'Olmo Riley, F. and Harris, P. (2009) 'Online grocery shopping: the influence of situational factors’, European Journal of Marketing, 43(9/10), pp. 1205-1219.

Hayduk, L. A., \& Littvay, L. (2012). Should researchers use single indicators, best indicators, or multiple indicators in structural equation models?. BMC medical research methodology, 12(1), 159.

Henseler, J. rg, Ringle, C. M. and Sinkovics, R. R. (2009) 'Advances in international marketing', International Journal of Research in Marketing, 9(4), pp. 291-318.

Herath, C. S. (2010) 'Eliciting salient beliefs are critical to predict behavioural change in theory of planned behaviour', E-psychologie, 4(3), pp. 24-36. 
Herhausen, D., Binder, J. and Schoegel, M. (2015) 'Integrating Bricks with Clicks: Retailer-Level and Channel-Level Outcomes of Online-Offline Channel Integration', Journal of Retailing. New York University, 91(2), pp. 309-325.

Hofacker, C. F. (2001) Internet marketing. 3rd, illustr edn. Wiley New York.

Hoffman, K. D. and Bateson, J. E. G. (2010) Services marketing: concepts, strategies, \& cases. 4th edn. Cengage learning.

Hofstede, G. (1980) 'Motivation, leadership, and organization: do American theories apply abroad?', Organizational dynamics, 9(1), pp. 42-63.

Holloway, B. B. and Beatty, S. E. (2003) 'Service Failure in Online Retailing: A Recovery Opportunity', Journal of Service Research, 6(1), pp. 92-105.

Hoyer, wayne D., Maclnnis, deborah J. and Pieters, R. (2012) Consumer behavior. Sixth Edit. Mason: South-Western, Cengage Learning ALL.

Hsiao, M.-H. H. (2009) 'Shopping mode choice: Physical store shopping versus e-shopping', Transportation Research Part E: Logistics and Transportation Review. Elsevier Ltd, 45(1), pp. 86-95.

Hsu, M. H. and Chiu, C. M. (2004) 'Internet self-efficacy and electronic service acceptance’, Decision Support Systems, 38(3), pp. 369-381.

Hu, K. and Chang, T. (2009) 'An Innovative Logistics Model for Multi-Channel Retailing', Journal of the Chinese Institute of Industrial Engineers, 26(5), pp. 327-336.

Huang, S. (2006) 'Reading English for academic purposes--What situational factors may motivate learners to read?', System. Elsevier, 34(3), pp. 371-383.

Huang, Y. and Oppewal, H. (2006) 'Why consumers hesitate to shop online', International Journal of Retail \& Distribution Management, 34(4/5), pp. 334-353.

Hübner, A., Holzapfel, A. and Kuhn, H. (2016) 'Distribution systems in omni-channel retailing', Business Research, 9(2), pp. 255-296.

Hübner, A., Kuhn, H. and Wollenburg, J. (2016) ‘Last mile fulfilment and distribution in omni-channel grocery retailing: A strategic planning framework', International Journal of Retail \& Distribution Management, 44(3), p. 228-247.

Hübner, A., Wollenburg, J. and Holzapfel, A. (2016) 'Retail logistics in the transition from multichannel to omni-channel', International Journal of Physical Distribution \& Logistics Management, 46(6/7), pp. 562-583.

IABeCommerce (2019) Estudio anual eCommerce. Available at: https://iabspain.es/estudio/estudio- 
anual-de-ecommerce-2019/.

INE (2019) Population aged Internet in used. Available at: https://www.ine.es/en/prensa/tich_2017_en.pdf.

Ishfaq, R., Defee, C. C. and Gibson, B. J. (2016) 'Realignment of the physical distribution process in omni-channel fulfillment', International Journal of Physical Distribution \& Logistics Management, 46(6/7), pp. 543-561.

Janakiraman, R. and Niraj, R. (2011) 'The Impact of Geographic Proximity on What to Buy, How to Buy, and Where to Buy: Evidence from High-Tech Durable Goods Market*', Decision Sciences. Wiley Online Library, 42(4), pp. 889-919.

Jiang, L. (Alice), Yang, Z. and Jun, M. (2013) 'Measuring consumer perceptions of online shopping convenience', Journal of Service Management, 24(2), pp. 191-214.

Jiang, P. and Rosenbloom, B. (2005) 'Customer intention to return online: Price perception, attributelevel performance, and satisfaction unfolding over time', European Journal of Marketing, 39(1-2), pp. $150-174$.

Jones, J. M. and Vijayasarathy, L. R. (1998) 'Internet consumer catalog shopping: findings from an exploratory study and directions for future research', Internet Research. MCB UP Ltd, 8(4), pp. 322330.

Juaneda-Ayensa, E., Mosquera, A. and Sierra Murillo, Y. (2016) 'Omnichannel Customer Behavior: Key Drivers of Technology Acceptance and Use and Their Effects on Purchase Intention.', Frontiers in psychology, 7(July), p. 1117.

Kabadayi, S. (2011) 'Choosing the right multiple channel system to minimize transaction costs', Industrial Marketing Management. Elsevier Inc., 40(5), pp. 763-773.

Katros, V. (2000) 'A note on internet technologies and retail industry trends', Technology in Society, 22(1), pp. 75-81.

Keaveney, S. M. (1995) 'Customer switching behavior in service industries: An exploratory study’, The Journal of Marketing. JSTOR, pp. 71-82.

Keen, C., Wetzels, M. and de Ruyter, K. (2004) 'E-tailers versus retailers', Journal of Business Research, 57(7), pp. 685-695.

Kembro, J. H., Norrman, A. and Eriksson, E. (2018) 'Adapting warehouse operations and design to omni-channel logistics', International Journal of Physical Distribution \& Logistics Management, 48(9), pp. 890-912.

Kemperman, A., van Delft, L. and Borgers, A. (2015) ‘Omni Channel Fashion Shopping’, in Pantano, 
E. (ed.) Successful Technological Integration for Competitive Advantage in Retail Settings. IGI Global, pp. 144-167.

Kemperman, A., van Delft, Lieke and Borgers, A. (2015) Successful Technological Integration for Competitive Advantage in Retail Settings. Edited by E. Pantano. IGI Global.

Kim, E., Libaque-Saenz, C. F., \& Park, M. C. (2019). Understanding shopping routes of offline purchasers: selection of search-channels (online vs. offline) and search-platforms (mobile vs. PC) based on product types. Service Business, 13(2), 305-338.

Kim, J. and Park, J. (2005) 'A consumer shopping channel extension model: Attitude shift toward the online store', Journal of Fashion Marketing and Management, 9(1), pp. 106-121.

Kleinbaum, D. G., Kupper, L. L. and Muller, K. E. (1988) 'Variable reduction and factor analysis', Applied regression analysis and other multivariable methods. Kleinbaum, D., Kupper, L. \& Muller, K, 24, p. 605.

Kollmann, T., Kuckertz, A. and Kayser, I. (2012) 'Cannibalization or synergy? Consumers’ channel selection in online-offline multichannel systems', Journal of Retailing and Consumer Services, 19(2), pp. 186-194.

Konus, U., Verhoef, P. and Neslin, S. (2008) 'Multichannel Shopper Segments and Their Covariates 次', Journal of Retailing, 84(4), pp. 398-413.

Kumar, V. and Venkatesan, R. (2005) 'Who are the multichannel shoppers and how do they perform?: Correlates of multichannel shopping behavior', Journal of Interactive Marketing, 19(2), pp. 44-62.

Kurata, H. and Nam, S. H. (2010) 'After-sales service competition in a supply chain: Optimization of customer satisfaction level or profit or both?', International Journal of Production Economics. Elsevier, 127(1), pp. 136-146.

Lalwani, C. S., Disney, S. M. and Naim, M. M. (2006) 'On assessing the sensitivity to uncertainty in distribution network design', International Journal of Physical Distribution \& Logistics Management, 36(1), pp. 5-21.

Lazaris, C. and Vrechopoulos, A. (2013) 'From Multichannel to "Omnichannel " Retailing : Review of the Literature and Calls for Research', 2nd International Conference on Contemporary Marketing Issues,(ICCMI)., (JUNE 2014).

Lazaris, C., Vrechopoulos, A. and Katerina, F. (2014) 'Exploring the "Omnichannel” Shopper Behaviour', in AMA SERVSIG, International Service Research Conference, 13-15 June, pp. 1-5.

Lee, M. C. (2009) 'Factors influencing the adoption of internet banking: An integration of TAM and TPB with perceived risk and perceived benefit', Electronic Commerce Research and Applications. 
Elsevier B.V., 8(3), pp. 130-141.

Lemon, K. N. and Verhoef, P. C. (2016) Understanding Customer Experience and the Customer Journey, Journal of Marketing. University of Groningen.

Li, L. (2010) 'A critical review of technology acceptance literature', Southwest Decisino Sciences Institute, $\quad$ p. $22 . \quad$ Available at: http://www.swdsi.org/swdsi2010/SW2010_Preceedings/papers/PA104.pdf.

Lietz, C. a. and Zayas, L. E. (2010) 'Evaluating qualitative research for social work practitioners', Advances in Social Work, 11(2), pp. 188-202.

Lim, H. and Dubinsky, A. J. (2005) 'Determinants of consumers' purchase intention on the Internet: an application of theory of planned behavior’, Psychology \& Marketing, 22(10), pp. p833--855.

Lim, J., Grover, V. and Purvis, R. L. (2012) 'The consumer choice of E-channels as a purchasing avenue: An empirical investigation of the communicative aspects of information quality', IEEE Transactions on Engineering Management, 59(3), pp. 348-363.

Liska, A. E. (1984) 'A Critical Examination of the Causal Structure of the Fishbein/Ajzen AttitudeBehavior Model’, Social Psychology Quarterly, 47(1), pp. 61-74.

Littler, D. and Melanthiou, D. (2006) 'Consumer perceptions of risk and uncertainty and the implications for behaviour towards innovative retail services: The case of Internet Banking', Journal of Retailing and Consumer Services, 13(6), pp. 431-443.

Liu, X. and Wei, K. (2003) 'An empirical study of product differences in consumers' e-commerce adoption behavior', Electronic Commerce Research and Applications, 2(3), pp. 229-239.

Lu, Q., Pattnaik, C. and Xiao, J. (2018) 'Cross-national variation in consumers’ retail channel selection in a multichannel environment: Evidence from Asia-Pacific countries', Journal of Business Research. Elsevier, 86(October 2016), pp. 321-332.

Ma, W., Zhao, C. and Ke, H. (2020) 'Retailer's return policy in the presence of secondary market', Electronic Commerce Research and Applications. Elsevier, 39(October 2019), pp. 100-109.

MacCallum, R. C. and Browne, M. W. (1993) 'The use of causal indicators in covariance structure models: Some practical issues.', Psychological bulletin. American Psychological Association, 114(3), pp. 533-545.

MacKenzie, S. B., Podsakoff, P. M. and Jarvis, C. B. (2005) 'The problem of measurement model misspecification in behavioral and organizational research and some recommended solutions', Journal of Applied Psychology, 90(4), pp. 710-730.

Madahi, A. and Sukati, I. (2016) 'An empirical study of Malaysian consumers’ channel-switching 
intention: Using theory of planned behaviour', Global Business Review, 17(3), pp. 489-523.

Madlberger, M. (2005) 'The Last Mile in an Electronic Commerce Business Model - Service Expectations of Austrian Online Shoppers', in ECIS 2005 Proceedings. European Conference on Information Systems.

Manstead, A. S. R., Hewstone, M. E. and Fiske, S. T. (1995) The Blackwell encyclopedia of social psychology. illustrate. Edited by M. H. Tony Manstead. Blackwell Publishers.

Manuel Lamela Fernández (2019) Estructura de la Industria Alimentaria y las Tendencias del Consumo en la Comunidad de Madrid. Madrid.

MarketResearch (2018) Apparel Retail in Spain, MarketLine. Available at: https://www.marketresearch.com/MarketLine-v3883/Apparel-Retail-Spain-12077225/.

Martocchio, J. J. and Dulebohn, J. (1994) 'Performance Feedback Effects in Training: the Role of Perceived Controllability’, Personnel Psychology, 47(2), pp. 357-373.

Mathieson, K. (1991) 'Comparing The Technology Acceptance Model with The Theory of Planned Behaviour', Information Systems Research, 2(3), pp. 173-191.

McCormick, H., Cartwright, J. and Perry, P. (2014) 'Fashion retailing - past, present and future', Textile Progress, 46(3), pp. 227-321.

Mehra, A., Kumar, S. and Raju, J. S. (2013) ““ Showrooming ” and the Competition between Store and Online Retailers', Management Science, Forthcoming, 14(3), pp. 1-37.

Merrilees, B. and Fenech, T. (2007) 'From catalog to Web: B2B multi-channel marketing strategy', Industrial Marketing Management, 36(1), pp. 44-49.

Mikalef, P., Giannakos, M. and Pateli, A. (2013) 'Shopping and Word-of-Mouth Intentions on Social Media', Journal of Theoretical and Applied Electronic Commerce Research, 8(1), pp. 17-34.

Minguela-Rata, B. and de Leeuw, S. (2013) Managing the last mile of the supply chain for spare parts | Gestión de la última milla de la cadena de suministro para piezas de repuesto, Universia Business Review.

Modak, N. M. and Kelle, P. (2019) 'Managing a dual-channel supply chain under price and deliverytime dependent stochastic demand', European Journal of Operational Research. Elsevier B.V., 272(1), pp. 147-161. doi: 10.1016/j.ejor.2018.05.067.

Monsuwé, T. P. Y., Dellaert, B. G. C. and Ruyter, K. De (2004) 'What drives consumers to shop online? A literature review’, International Journal of Service Industry Management, 15(1), pp. 102-121.

Montano, D. E. and Kasprzyk, D. (2015) Theory of reasoned action, theory of planned behavior, and 
the integrated behavioral model, Health behavior: Theory, research and practice.

Montoya-Weiss, M. M., Voss, G. B. and Grewal, D. (2003) 'Determinants of Online Channel Use and Overall Satisfaction with a Relational, Multichannel Service Provider', Journal of the Academy of Marketing Science, 31(4), pp. 448-458.

Moon, J. W. and Kim, Y. G. (2001) 'Extending the TAM for a World-Wide-Web context’, Information and Management, 38(4), pp. 217-230.

Morganosky, M. A. and Cude, B. J. (2000) 'Consumer response to online grocery shopping', International Journal of Retail \& Distribution Management, 28(1), pp. 17-26.

Moshrefjavadi, M. H., Rezaie Dolatabadi, H. and Nourbakhsh, M. (2012) 'An Analysis of Factors Affecting on Online Shopping Behavior of Consumers', International Journal of Marketing Studies, 4(5), pp. 81-98.

Murphy, A. J. (2016) Grounding the virtual: The material effects of electronic grocery shopping Grounding the Virtual : the material effects of electronic grocery shopping. Massey University.

Neslin, S. a., Grewal, D. and Leghorn, R. (2006) 'Challenges and Opportunities in Multichannel Customer Management’, Journal of Service Research, 9(2), pp. 95-112.

Nguyen, D. H., de Leeuw, S. and Dullaert, W. (2019) 'What Is the Right Delivery Option for You? Consumer Preferences for Delivery Attributes in Online Retailing', Journal of Business Logistics, 40(4), pp. 299-321.

Nicholson, M., Clarke, I. and Blakemore, M. (2002) '’One brand, three ways to shop' : situational variables and multichannel consumer behaviour', The International Review of Retail, Distribution and Consumer Research, 12(2), pp. 131-148.

Nunnally, J. (1978). Psychometric theory. New York: McGraw-Hill.

Okholm, H. B., Thelle, M. H. and Möller, A. (2013) E-commerce and delivery: A study of the state of play of EU parcel markets with particular emphasis on e-commerce, European Commission, DG Internal Market and Services. Copenhagen.

ONTSI (2019) Estudio sobre Comercio Electrónico B2C (edición 2019) | ONTSI. Available at: https://www.ontsi.red.es/ontsi/es/content/estudio-sobre-comercio-electrónico-b2c-edición-2018 (Accessed: 12 February 2019).

Oomen, I. and Leenes, R. (2008) 'Privacy risk perceptions and privacy protection strategies', Policies and Research in Identity Management in The International Federation for Information Processing, 261, pp. 121-138.

Oppewal, H., Tojib, D. R. and Louvieris, P. (2013) 'Experimental analysis of consumer channel-mix 
use', Journal of Business Research, 66(11), pp. 2226-2233.

Ortis, I. (2010) Unified Retailing-Breaking Multichannel Barriers, IDC Retail Insights Report.

Palvia, P. (2013) 'The world IT project: A program on international research and call for participation', Journal of Global Information Technology Management. Taylor \& Francis, 16(2).

Pavlou, P. A. and Fygenson, M. (2006) 'Understanding and Predicting Electronic Commerce Adoption: An Extension of The Theory of Planned Behavior', MIS Quarterly, 30(1), pp. 115-143.

Payne, A. and Frow, P. (2004) 'The role of multichannel integration in customer relationship management’, Industrial Marketing Management, 33(6), pp. 527-538.

Pérez, R. (2020) El sueldo medio en el sector público es un 38\% mayor que en la empresa privada, ABC Ecomonia. Available at: https://www.abc.es/economia/abci-sueldo-medio-sector-publico-38-porciento-mayor-empresa-privada-201811190211_noticia.html.

Petersen, J. A. and Kumar, V. (2009) 'Are Product Returns a Necessary Evil? Antecedents and Consequences', Journal of Marketing, 73(3), pp. 35-51.

Piotrowicz, W. and Cuthbertson, R. (2014) 'Introduction to the Special Issue Information Technology in Retail: Toward Omnichannel Retailing', International Journal of Electronic Commerce, 18(4), pp. 5-16.

Piotrowicz, W. and Cuthbertson, R. (2019) Last Mile Framework for Omnichannel Retailing. Delivery from the Customer Perspective. Springer, Cham.

Pituch, K. A. and Lee, Y. kuei (2006) 'The influence of system characteristics on e-learning use', Computers and Education, 47(2), pp. 222-244.

Pookulangara, S., Hawley, J. and Xiao, G. (2011a) 'Explaining consumers’ channel-switching behavior using the theory of planned behavior', Journal of Retailing and Consumer Services. Elsevier, 18(4), pp. 311-321.

Pookulangara, S., Hawley, J. and Xiao, G. (2011b) 'Explaining multi-channel consumer’s channelmigration intention using theory of reasoned action', International Journal of Retail \& Distribution Management, 39(3), pp. 183-202.

Potwarka, L. R. (2015) 'Exploring physical activity intention as a response to the vancouver olympics: An application and extension of the theory of planned behavior', Event Management, 19(1), pp. 73-92.

Premkumar, G., Ramamurthy, K. and Liu, H. N. (2008) 'Internet messaging: An examination of the impact of attitudinal, normative, and control belief systems', Information and Management, 45(7), pp. 451-457. 
Priebe, C. S. and Spink, K. S. (2011) 'When in Rome: Descriptive norms and physical activity', Psychology of Sport and Exercise, 12(2), pp. 93-98.

Punakivi, M. and Saranen, J. (2001) 'Identifying the success factors in e-grocery home delivery', International Journal of Retail \& Distribution Management, 29(4), pp. 156-163.

Pyle, K. B. (1996) The making of modern Japan. illustrate. Harvard University Press.

Raes, M. (2019) Re-engineering the supply chain for the omni-channel of tomorrow. London, United Kingdom. Available at: http://www.ey.com/Publication/vwLUAssets/EY-re-engineering-the-supplychain-for-the-omni-channel-of-tomorrow/\%24FILE/EY-re-engineering-the-supply-chain-for-theomni-channel-of-tomorrow.pdf.

Rai, H. B., Verlinde, S. and Macharis, C. (2019) 'Logistics outsourcing in omnichannel retail', International Journal of Physical Distribution \& Logistics Management. Emerald Publishing Limited.

Reinartz, W., Haenlein, M. and Henseler, J. (2009) 'An empirical comparison of the efficacy of covariance-based and variance-based SEM', International Journal of Research in Marketing. Elsevier B.V., 26(4), pp. 332-344.

Rigby, D. (2011) ‘The Future of Shopping’, Harvard Business Review, 89(12), pp. 65-76.

Robinson, A. (2019) 7 Top Trends in Last Mile Logistics - The Revolution is Coming. Available at: https://www.supplychain247.com/article/7_top_trends_in_last_mile_logistics_the_revolution_is_com ing

Rogers, C. (1962) ‘The interpersonal relationship’, Harvard Educational Review, 32(4), pp. 416-429.

Rogers, E. M. and Shoemaker, F. F. (1971) Communication of Innovations; A Cross-Cultural Approach. 2nd, illustr edn. Free Press.

Rowell, J. (2015) 'Omni-Channel Retailing: the changing battleground', Romanian Distribution Committee Magazine, 6(4), pp. 10-17.

Sarmah, T. and Pawar, S. (2015) 'Omni - Channel Retailing: the Opulent Blend', Journal of Arts, Science \& Commerce, VI(3), pp. 1-10.

Sarstedt, M., Ringle, C. M. and Smith, D. (2014) 'Partial least squares structural equation modeling (PLS-SEM): A useful tool for family business researchers', Journal of Family Business Strategy. Elsevier Ltd, 5(1), pp. 105-115.

Sarver, V. T. (1983) 'Ajzen and Fishbein’s" theory of reasoned action": A critical assessment.', Journal for the Theory of Social Behaviour. Blackwell Publishing, 13(2).

Schifter, D. E. and Ajzen, I. (1985) 'Intention, Perceived Control, and Weight Loss. An Application of 
the Theory of Planned Behavior', Journal of Personality and Social Psychology, 49(3), pp. 843-851.

Schneider, G. P. and Perry, J. T. (2000) ‘Electronic commerce’, Course Technology, Cambridge, MA.

Schoenbachler, D. D. and Gordon, G. L. (2002) 'Multi-channel shopping: understanding what drives channel choice', Journal of Consumer Marketing, 19(1), pp. 42-53.

Schramm-Klein, H., Wagner, G. and Steinmann, S. (2011) 'Cross-channel integration - is it valued by customers?', The International Review of Retail, Distribution and Consumer Research, 21(5), pp. 501511.

Schröder, H. and Zaharia, S. (2008) 'Linking multi-channel customer behavior with shopping motives: An empirical investigation of a German retailer', Journal of Retailing and Consumer Services, 15(6), pp. 452-468.

Senn, J. A. (2000) ‘The emergence of m-commerce’, Computer, 33(12), pp. 148-150.

SHEN, L. (2003) Internet-based e-commerce Adoption for Supply Chain Management among U.S. Apparel Companies, Arbor Ciencia Pensamiento Y Cultura. University of Missouri-Columbia.

Sheppard, B. H. et al. (1988) 'The Theory of Reasoned Action : A Meta-Analysis of Past Research with Recommendations for Modifications', Journal of Consumer Research, 15(3), pp. 325-343.

Sherman, L. W. (1980) CAUSES OF POLICE BEHAVIOR: THE CURRENT STATE OF QUANTITATIVE RESEARCH, Journal of Research in Crime and Delinquency.

Shih, Y. and Fang, K. (2004) 'The use of a decomposed theory of planned behavior to study Internet banking in Taiwan', Internet Research, 14(3), pp. 213-223.

Shirdastian, H. and Laroch, M. (2017) 'Motivations for Shopping Channel Preferences and Purchase Intentions: The Moderating Role of Involvement', Creating Marketing Magic and Innovative Future Marketing, 17(3), pp. 1-36. doi: 10.1007/978-3-319-45596-9.

Shortridge-Baggett, L. M. (2002) 'The theory and measurement of the self-efficacy construct', Selfefficacy in nursing: Research and measurement perspectives. Springer Publishing Company, 15(3), pp. 189-207.

Simon, F. and Usunier, J. (2007) 'Cognitive , demographic , and situational determinants of service customer preference for personnel-in-contact over self-service technology', International Journal of Research in Marketing, 24(2), pp. 163-173.

Solomon, M. R. (2010) Consumer Behaviour: A European Perspective. Pearson Ed.

Srinivasan, S. S., Anderson, R. and Ponnavolu, K. (2002) 'Customer loyalty in e-commerce: An exploration of its antecedents and consequences', Journal of Retailing, 78(1), pp. 41-50. 
Statista (2019a) E-commerce delivery preferences in selected countries in Europe 2019. Available at: https://www.statista.com/statistics/980543/e-commerce-delivery-preferences-in-selected-countries-ineurope/.

Statista (2019b) Retail e-commerce sales worldwide from 2014 to 2023. Available at: https://www.statista.com/statistics/379046/worldwide-retail-e-commerce-sales/.

Statista (2020a) Number of internet users in global regions 2019. Available at: https://www.statista.com/statistics/379046/worldwide-retail-e-commerce-sales/.

Statista (2020b) Number of internet users in global regions 2019. Available at: https://es.statista.com/estadisticas/496554/habitos-de-busqueda-y-compra-online-y-offline-en-espana/ Steinfield, C., Bouwman, H. and Adelaar, T. (2002) 'The dynamics o click-and-mortar electronic commerce: opportunites and management strategies', International Journal of Electronic Commerce, 7(1), pp. 93-120.

Stone, M., Hobbs, M. and Khaleeli, M. (2002) 'Multichannel customer management: The benefits and challenges', Journal of Database Marketing \& Customer Strategy Management. Springer, 10(1), pp. $39-52$.

Suominen, J. (2005) 'One experience: optimizing customer experience channel planning process', in 3rd Interdisciplinary World Congress on Mass Customization and Personalization. Hong Kong, September, pp. 18-21.

Sutton, S., French, D. P. and Hennings, S. J. (2003) 'Eliciting Salient Beliefs in Research on the Theory of Planned Behaviour: The Effect of Question Wording', Current Psychology, 22(3), pp. 234-251.

Tang, W. and Mokhtarian, P. L. (2009) 'Accounting for taste heterogeneity in purchase channel intention modeling: An example from Northern California for book purchases', Journal of Choice Modelling, 2(2), pp. 148-172.

Tate, M. and Johnstone, D. (2011) 'ICT, Multi-channels and the changing line of visibility: An empirical study', e-Service Journal: A Journal of Electronic Services in the Public and Private Sectors. JSTOR, 7(2), pp. 66-98.

Tauber, E. M. (1972) ‘Why Do People Shop?’, Journal of Marketing, 36(4), pp. 46-50.

Taylor, S. and Todd, P. (1995) 'Decomposition and crossover effects in the theory of planned behavior: A study of consumer adoption intentions', International Journal of Research in Marketing, 12(2), pp. $137-155$.

Tenenhaus, M. et al. (2005) 'PLS path modeling', Computational Statistics and Data Analysis, 48(1), pp. 159-205. 
Teo, T. S. H. and Yu, Y. (2005) 'Online buying behavior: a transaction cost economics perspective', Omega. Elsevier, 33(5), pp. 451-465.

To, P., Liao, C. and Lin, T. (2007) 'Shopping motivations on Internet: A study based on utilitarian and hedonic value', Technovation Journal, 27(12), pp. 774-787.

Tobias, R. D. (1995) ‘An Introduction to Partial Least Squares Regression’, Analysis, 24(5), pp. 12501257.

Trenz, M. (2015) Multichannel Commerce. illustrate. Switzerland: Springer.

Triandis, H. C. (1977) Interpersonal behavior. illustrate. Brooks/Cole Pub. Co.

Tsai, M.-T. et al. (2012) 'The effects assessment of firm environmental strategy and customer environmental conscious on green product development.', Environmental monitoring and assessment, 184(7), pp. 4435-47.

Venkatesan, R., Kumar, V. and Ravishanker, N. (2007) 'Multichannel Shopping: Causes and Consequences', Journal of Marketing, 71(2), pp. 114-132.

Venkatesh, V. and Davis, F. (1994) 'Modeling the determinants of perceived ease of use', in ICIS 1994 Proceedings. Computer Science, p. 17.

Venkatesh, V. and Davis, F. D. (2000) 'A Theoretical Extension of the Technology Acceptance Model: Four Longitudinal Field Studies’, Management Science, 46(2), pp. 186-204.

Venkatesh, V., Morris, M. G. and Davis, G. B. (2003) 'User Acceptance of Information Technology: Toward a Unified View’, MIS Quarterly, 27(3), pp. 425-478.

Venkatesh, V., Thong, J. Y. L. and Xu, X. (2012) 'Consumer Acceptance and Use of Information Technology : Extending the Unified Theory', MIS Quarterly, 36(1), pp. 157-178.

Verhoef, P. C., Kannan, P. K. and Inman, J. J. (2015) 'From Multi-Channel Retailing to Omni-Channel Retailing', Journal of Retailing. New York University, 91(2), pp. 174-181.

Verhoef, P. C., Neslin, S. a. and Vroomen, B. (2007) 'Multichannel customer management: Understanding the research-shopper phenomenon', International Journal of Research in Marketing, 24(2), pp. 129-148.

Wakefield, K. L. and Inman, J. J. (2003) 'Situational price sensitivity: The role of consumption occasion, social context and income', Journal of Retailing, 79(4), pp. 199-212.

Wang, C., Harris, J. and Patterson, P. G. (2012) 'Customer choice of self-service technology: the roles of situational influences and past experience', Journal of Service Management, 23(1), pp. 54-78.

Wang, D. and Li, J. (2002) 'Handling Large Numbers of Attributes and/or Levels in Conjoint 
Experiments’, Geographical Analysis, 34(4), pp. 350-362.

Wang, S., Anitsal, M. M. and Anitsal, I. (2014) 'A Review of E-Commerce : The Influence of PostPurchase Factors on Relationships between Customer Loyalty and Perceived Risk', Journal of Retailing, 3(13).

Wang, X. et al. (2014) 'How to choose "last mile” delivery modes for E-fulfillment', in Mathematical Problems in Engineering. Hindawi Publishing Corporation.

Wang, Y. M., Lin, H. H. and Tai, W. C. (2016) 'Understanding multi-channel research shoppers: an analysis of Internet and physical channels', Information Systems and e-Business Management. Springer Berlin Heidelberg, 14(2), pp. 389-413.

Watson, M. Z. (2013) 'An Exploratory Study of the Decision Processes of Fast versus Slow Fashion Consumers', Journal of Fashion Marketing and Management, 17(2), pp. 1-25.

Webb, K. L. and Hogan, J. E. (2002) 'Hybrid channel conflict: causes and effects on channel performance’, Journal of Business \& Industrial Marketing, 17(5), pp. 338-356.

Weber, A. N. and Badenhorst-Weiss, A. J. (2018) 'The last-mile logistical challenges of an omnichannel grocery retailer: A South African perspective', Journal of Transport and Supply Chain Management, 12(0), pp. 1-13.

Weltevreden, J. W. J. (2008) 'B2c e-commerce logistics: the rise of collection-and-delivery points in The Netherlands', International Journal of Retail \& Distribution Management, 36(8), pp. 638-660.

Werts, C.E.; Linn, R.L.; Jöreskog, K.G. (1974). Interclass reliability estimates: testing structural assumptions. Educational and Psychological Measurement, 34, 25-33.

Westbrook, R. A. and Black, W. C. (1985) 'A motivation-based shopper typology.', Journal of retailing. Elsevier Science, 3(4), pp. 338-356.

Williams, T. and Williams, K. (2010) 'Self-efficacy and performance in mathematics: Reciprocal determinism in 33 nations.', Journal of educational Psychology. American Psychological Association, 102(2), p. 453.

Windham, L. and Orton, K. (2000) The soul of the new consumer: The attitudes, behaviors, and preferences of e-customers. illustrate. Edited by C. University. Windsor, 2000.

Wold, H. (1980) 'Model construction and evaluation when theoretical knowledge is scarce: Theory and application of partial least squares’, In Evaluation of econometric models, I, pp. 75-90.

Wold, H. (1985) 'Systems Analysis by Partial Least Squares’, in Measuring the Unmeasurable. IIASA Collaborative Paper, pp. 221-251. 
Wu, I. L. and Chen, J. L. (2005) 'An extension of Trust and TAM model with TPB in the initial adoption of on-line tax: An empirical study', International Journal of Human Computer Studies, 62(6), pp. 784808.

Xu, J., Hong, L. and Li, Y. (2011) 'Designing of collection and delivery point for E-commerce logistics', in Proceedings - 2011 International Conference of Information Technology, Computer Engineering and Management Sciences, ICM 2011, pp. 349-352.

$\mathrm{Xu}, \mathrm{X}$. and Jackson, J. E. (2019) 'Examining customer channel selection intention in the omni-channel retail environment', International Journal of Production Economics. Elsevier B.V., 208(Feb 1), pp. 434-445.

Xue, M. and Harker, P. T. (2002) 'Customer Efficiency: Concept and Its Impact on E-Business Management', Journal of Service Research, 4(4), pp. 253-267.

Yayla, A. and Hu, Q. (2007) 'User Acceptance of E-Commerce Technology: a Meta-Analytic Comparison of Competing Models', in European Conference on Information Systems. Association for Information Systems AIS Electronic Library (AISeL), pp. 179-190.

Ye, Y., Lau, K. H. and Teo, L. K. Y. (2018) 'Drivers and barriers of omni-channel retailing in China: A case study of the fashion and apparel industry', International Journal of Retail and Distribution Management, 2(17), pp. 15-47.

Yu, C. S. (2014). Consumer switching behavior from online banking to mobile banking. International Journal of Cyber Society and Education, 7(1), 1-28.

Yu, U. J., Niehm, L. S., \& Russell, D. W. (2011). Exploring perceived channel price, quality, and value as antecedents of channel choice and usage in multichannel shopping. Journal of Marketing Channels, 18(2), 79-102.

Zaharia, S. (2005) Consumer behaviour in multi-channel-retailing - how do consumers use the channels of a multi-channel-retailer during the buying process?, Les nouvelles tendances du marketing. University of Duisburg-Essen.

Zarei, M., Agudo-Peregrina, A. and Ponce-Cueto, E. (2019) 'Choosing the delivery and return method in purchases: the effect of situational factors in omni-channel contexts', Economic ResearchEkonomska Istraživanja, (April), pp. 1-18.

Zarei, M., Chaparro-Pelaez, J. and Agudo-Peregrina, A. (2020) 'Identifying Consumer's Last-mile Logistics Beliefs in Omni Channel environment', Economic Research-Ekonomska Istraživanja, 33(1).

Zebra (2019) Estudio de Perspectivas de Retail de Zebra. Available at: https://www.zebra.com/content/dam/zebra_new_ia/en-us/solutions-verticals/verticalsolutions/retail/vision-study/retail-vision-study-2019-es- 
es.pdf?tactic_type=PRB\&tactic_detail=RT_Smart+Shopping_Smart+Shopping_LATAM_MX.

Zhang, L., \& Oh, L. B. (2013, May). Determinants of Multichannel Consumer Switching Behavior: A Comparative Analysis of Search and Experience Products. In WHICEB (p. 30).

Zhou, T., Lu, Y. and Wang, B. (2010) 'Integrating TTF and UTAUT to explain mobile banking user adoption', Computers in Human Behavior. Elsevier Ltd, 26(4), pp. 760-767.

Zhou, M., Zhao, L., Kong, N., Campy, K. S., Xu, G., Zhu, G., ... \& Wang, S. (2020). Understanding consumers' behavior to adopt self-service parcel services for last-mile delivery. Journal of Retailing and Consumer Services, 52, 101911.

Zhuang, G. et al. (2006) 'Impacts of situational factors on buying decisions in shopping malls', European Journal of Marketing, 40(1/2), pp. 17-43.

Zubair, M. and Garforth, C. (2006) ‘Farm level tree planting in Pakistan: the role of farmers’ perceptions and attitudes', Agroforestry systems. Springer, 66(3), pp. 217-229. 